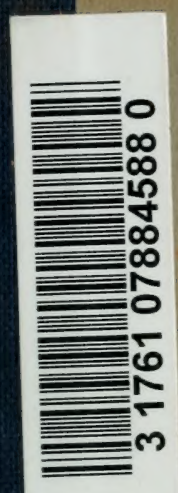

Ec.H

B9824ta

Busuiocescu, Dumitru

Das Tabakmonopol in Rumänien.

E c. H

B9824ta 


\title{
Das \\ Tabakmonopol in Rumänien.
}

\author{
Von
}

\section{Dr. Demetep Busuiocescu.}

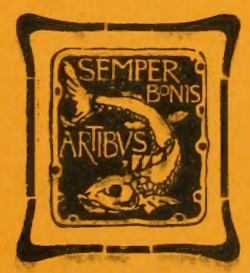

Verlag von Gustav Fischer in Jena.

1905.

Diese Abhandlung bildet zugleich das vierte Heft der Neuen Folge der Volkswirtschaftlichen und wirtschaftsgeschichtlichen Abhandlungen, herausgegeben von Dr. Wilhelm Stieda, Professor in Leipzig. Vgl, auch die Rückseite des Umschlags. 
Verlag von Jäh \& Schunke in Leipzig.

In unserm Verlage erschien:

\section{Volkswirtschaftliche und}

\section{wintschafftsgeschichtliche Abhandlungen}

Herausgegeben von

Wilhelm Stieda

o. ö. Professor der Nationalökonomie in Leipzig.

Heft 1: Der Haushalt der Stadt Hildesheim am Ende des 14. und in der ersten Hälfte des 15. Jahrhunderts. Von Dr. Paul Huber. M. 3.-.

Heft 2: Die Hollandsgänger in Hannover und Oldenburg. Ein Beitrag zur Geschichte der Arbeiterwanderung. Von Dr. Joh. Tack. M. 6.-.

Heft 3: Ein deutsches Reichs-Arbeitsamt. Geschichte und Organisation der Arbeiterstatistik im In- und Ausland. Von Dr. Rudolf Dreydorff. M. 4.-.

Heft 4: Samuel Selfisch, ein deutscher Buchhändler am Ausgange des 16. Jahrhunderts. Mit dem Bildnis Selfischs und 10 Faksimile-Beilagen. Von Dr. Hans Leonhard. M. 4.- .

Heft 5: Zur Wohnungsfrage im Königreich Sachsen. Von Dr. Walther Naumann. M. 3.-.

Heft 6: Der Teilbau in Theorie und Praxis. Ein Beitrag zur Lösung der ländlichen Arbeiterfrage. Von Dr. Theodor Spickermann. M. 2.- .

Heft 7: Die deutschen Arbeitersekretariate. Von Dr. Richard Soudek. M. 2.50.

Heft 8: Die Organisation und Bedeutung der freien öffentlichen Arbeitsnachweisämter in den Vereinigten Staaten von Nordamerika. Von Dr. Brainard H. Warner jr. M. 2.50 .

Heft 9: Die Verlegung der Büchermesse von Frankfurt a. M. nach Leipzig. Von Dr. Felix von Schroeder. M. 2.50 . 
Digitized by the Internet Archive in 2011 with funding from University of Toronto 


\title{
Volkswirtschaftliche und wirt- schaftsgeschichtliche Abhandlungen.
}

Herausgegeben

von

\section{Professor Dr. W. Stieda}

in Leipzig.

\author{
Neue Folge. - Viertes Heft.
}

Mit 2 Karten und 8 graph. Darstellungen.

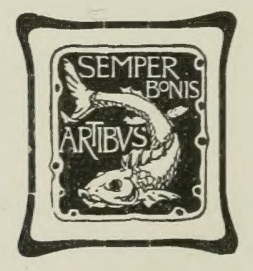

Verlag von Gustav Fischer in Jena. 1905. 
Ec.H

B9824ta

\section{Das \\ Tabakmonopol in Rumänien.}

Von

\section{Dr. Demeter Busuiocescu.}

(Rumäñínen).

Mit 2 Karten und 8 graph. Darstellungen.

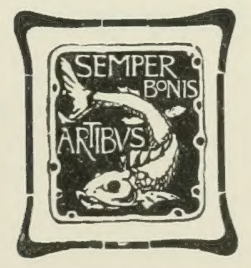

$\frac{523922}{20 \cdot 6 \cdot 51}$

Verlag von Gustav Fischer in Jenla.

1905. 
Alle Rechte vorbehalten. 


\section{Vorwort.}

In der vorliegenden Schrift, welche aus dem Seminar des Herrn Professor Dr. W. Stieda (Leipzig) hervorgegangen ist, versuchte ich ein übersichtliches Bild von dem Wesen, der Entwickelung, der finanziellen und volkswirtschaftlichen Bedeutung des rumänischen Tabakmonopols zu geben.

Die Antwort, ob mir das gelungen ist und ob ich damit zur Würdigung des rumänischen Tabakmonopols nach meinen Kräften beigesteuert habe, kann ich nicht geben, doch hoffe ich es getan zu haben.

Bevor ich nun diese Schrift der Öffentlichkeit übergebe, drängt es mich, an dieser Stelle meinen verbindlichsten Dank all den Herren zum Ausdruck zu bringen, welche mir ihre bereitwillige Hilfe jederzeit so freundlich zuteil werden ließen.

Insbesondere aber ist es mir ein Herzensbedürfnis, meinem hochverehrten Lehrer Herrn Professor Dr. W. Stieda meinen aufrichtigsten und tiefempfundensten Dank für die mir in bereitwilligster und liebenswürdigster Weise erteilten Ratschläge, für die mannigfachen, grundlegenden Anregungen und Unterweisungen, sowie für das stete Wohlwollen, womit er auch die vorliegende Arbeit begleitet hat, widmen zu dürfen.

Leipzig, im März 1905.

\section{Busuiocescu.}





\section{Inhaltsverzeichnis.}

Einleitung.

I. Entdeckung und Terbreitung des Tabaks . . . . . . . . I

II. Begründung und Erbebungsarten der Tabaksteuer . . . . . . .

III. Der Tabak und die Tabakbesteuerung in Rumänien bis zum Jabre $156 \pm$

IV. Die Einführung des Tabatwonopols, seine Dauer unil die bis zum Jahre 15.2 an seine Stelle tretende Tabakstecer . . . . . . . . . . . . .

T. Wiedereinführung des Tabakmonopols . . . . . . . . . . 11

VI. Die Regie in ihrer heutigen Crestaltung . . . . . . . . . . Srj

VII. Der Tabak unter dem Monopol:

1. Technisches . . . . . . . . . . 6 . . .

2. Wirtschaftliches und statistische Ergebnisse. . . . . . . 75

3. Bestrebungen der Regie zur Terbesserung des Tabakbautes . . S?

III. Die Tabakverarbeitung:

1. Anschaftung ron Rohmaterial ............ 91

2. Die Tabakfabrikation . . . . . . . . . . . 90

3. Die Arbeiter . . . . . . . . . . . I . Iits

IX. Der Verkaut:

1. Das Verschleilesstem . . . . . . . . . . . 121

2. Die Terkaufstarife und der honsum . . . . . . . 127

3. Die Ausfuhr der Regiefabrikate . . . . . . . . . . I33

4. Die finanziellen Ergebnisse. . . . . . . . . . . 131

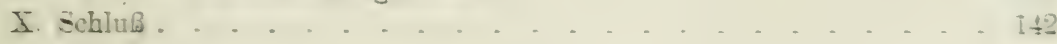





\section{Einleitung.}

\section{Entdeckung und Verbreitung des Tabaks.}

Über Ursprung und Alter des Tabakbaues bezw. die Verwendung des zwar entbehrlichen, aber doch in gewaltigen Mengen von der erwachsenen Bevölierung fast aller Lünder verbranchten Genufmittels "Tabak" ist nichts Sicheres bekannt. Wennschon nachgewiesen wurde, daf die Priester verschiedener Heilenvöllier, besonders im Orient, sich eines narkotischen Krautes bedienten, dessen durch Verbrennung entstandenen Rauch sie einatmeten, um sodann, in gelindere oder stärkere Narkose versetzt, den Willen der Gottheit durch Orakelsprüche zu verkünden, so fehlt doch jeder Beweis dafür, daß das zur Erzeugung der Dämpfe benutzte Kraut wirklich Tabak war ${ }^{1}$ ), um so mehr als gerade im Orient eine Anzahl anderer stark narkotischer Gewächse ihre ursprüngliche Heimat besitzt ${ }^{2}$ ).

Ebenso unbekannt ist es, ob man in China die Tabakpflanze schon vor der Entdeckung Amerikas kannte, kultivierte und deren Kraut zum Rauchen oder aber, wie später in Spanien, zu Heilzwecken verwandte. Aber auch die abendländischen Reisenden, wie z. B. Marco Polo, Portenau, Pegoletti, Vasco de Gama u. a. m., welche teilweise sehr scharfe Beobachtungen über Sitten und Gebräuche in den von ihmen besuchten Ländern anstellten ${ }^{3}$ ), berichten nichts über den Tabak und das Tabakrauchen, würden aber zweifellos einer so fremdartigen Sitte, wenn eine solche bestanden hätte, in ihren Reisebeschreibungen Erwähnung getan hahen. Tach den hentigen Forschungs-

1) Kloss, Heinrich, Der Tabak, sein Anbau und sein Handel, Dresden 1866 , S. 6 .

2) Kissling, Der Tabak im Lichte der neuesten naturwissenschaftlichen Forschungen, Berlin 1893, S. 1.

3) Tiedemann, Geschichte des Tabaks und anderer Genußmittel, Frankfurt a. M. 1854, S. 210.

Volkswirtschaftl. u, wirtschaftsgeschichtl. Abhandlungen. IL 4.

Busuiocescu, Das Tabakmonopol in Rumänien. 
ergebnissen müssen wir ohne weiteres Amerika als Ursprungsland des Takilis betrachten und Europa als denjenigen Erdteil, welcher zuerst von dieser Pflanze und deren Verwendung Kenntnis erhielt. Die allgemeine Regel, wonach Gewohnheiten aus kultivierten Ländern in weniger- oder unkultivierte Länder übergeführt zu werden pflegen, findet hier eine bedeutsame Ausnahme.

Übrigens dürfte das Tabakrauchen in Amerika seit urältester Zeit üblich gewesen sein; bei Entrleckung Virginiens durch Raleigh war dortselbst der Bau des Tabaks allgemein verbreitet. Es ist dies schon um deswillen erklärlich, als das Rauchen bei den Eingeborenen Amerikas für ein dem, großen Geist" (largebrachtes Opfer galt und einen Teil des Sonnenkultus darstellte.

Kolumbus war der erste Europäer, welcher 1492 von dem Dasein des Tabaks und seiner Verwertung Kenntnis erlangte; er sah dals die Eingeborenen ron Guanahani zylinderförmige Rollen rauchten. welche aus mit einem Maisblatt umwickelten Tabalisblättern bestanden. Die Art des Rauchens war der heutigen gleich, nur liebten die Eingeborenen die größere Menge des Rauches durch die Nasenöffnungen entweichen zn lassen ${ }^{1}$ ).

Genauere Mitteilungen über den Tabak und dessen Verwendung gelangten 4 Jahre später (1496) durch den spanischen Mönch Fra Romano $\mathrm{Pano}^{2}$ ) nach Europa. Kolumbus hatte letzteren auf seiner zweiten Expedition nach dem nenen liontinent mitgenommen und lief ihn auf der Insel Haiti behufs Beliehrung der dortigen heidnischen Eingeborenen zurück.

Eingehende Nachrichten über die Tabakpflanze als solche und ihre Kultur gelangten jedoch erst 1511 durch Petrus Martyr, einen spanischen Geschichtsschreiber, durch sein Werli: .De orbe novo“. Granata 1516, vorerst in Spanien. dann im übrigen Europa zur allgemeinen Kenntnis.

Im Jahre 1525 gab der Statthalter von St. Domingo, Gonzalo Hernandez de Oriedo y Valdes $^{3}$ ) ebenfalls eine genaue Beschreibung: der Pflanze, und 1571 hebt der spanische Naturforscher und Arzt Nicolas Menarles in seiner .. Beschreibung Westindiens" (erschienen zu Sevilla 1571) die Heilwirkung der Tabakpflanze besonders hervor.

Jean Nicot, französischer Gesandter in Portugal, sandte 1560 Tabaksamen von ihm selbst kulivierter Pflanzen nach Paris. Linné

1) Tiedemann a. a. O., S. 143.

2) Siehe seine Schrift: De insularium ritibus 1497 .

3) Seine Schrift: Historia general de las Indias 1535. 
bestimmte die Species derselben und benannte sie nach dem Tamen Übersender's „Nicotiana“ "1).

Konrad von Gesner, der bekannte Naturforscher und Polyhistor, wies 1562 in Deutschland zuerst auf den Tabak - welchen er durch Termittlung des Augsburger Stadtphysikus Occo² erhalten hatte - und dessen Heilkraft hin. Aus letzterer Eigenschaft erklärte sich wohl auch die immerhin rasche Verbreitung des Tabaks trotz der zur damaligen Zeit noch recht primitiven Verkehrsverhältnisse. Die Sitte des Tabakrauchens wurde um die Mitte des 16. Jahrhunterts durch spanische Matrosen aus Westindien nach Spanien verpflanzt, ebenso durch englische Kolonisten aus Virginien nach England ${ }^{3}$ ), so daß schon gegen Ende des 16. Jahrhunderts das Rauchen in England, Holland, Portugal, Spanien, wenige Jahre später auch in Ägypten, der Türkei und Indien ziemlich beliannt war. Durch die hollïndische und englische Soldateska gelangte die Sitte des Rauchens in die Gegenden des Rheins und Mains und der 30 jährige Krieg trug dann des weiteren dazu bei ${ }^{1}$ ), dasselbe bald in den übrigen Teilen Deutschlands zur allgemeinen Verbreitung zu bringen.

Aber nicht nur zum Rauchen, sondern auch zum Schnupfen diente der Tabak, und zwar hauptsächlich in Spanien, Frankreich und Italien. Die erste Schmupftahalifalurik entstand in Sevilla: und Venedig gab Herstellung und Verkauf von Schnupftabak in Pacht (1657). Der Konsum dieses Tabaks muß ein sehr bedeutender gewesen sein, fühlte sich doch Papst Urban VIII. veranlaft, um Mitte des 17. Jahrhunderts gegen diese Unsitte eine Bulle zu erlassen, welche erst 1724 wieder zurückgezogen wurde. Aber nicht nur das Oberhaupt der römischen Kirche erblickte im Gebrauch des Schnupftabaks eine Unsitte und im Rauchen eine Sünde, auch andersgläubige Kirchen ${ }^{5}$ ) und weltliche Fürsten bezw. Regierungen ${ }^{6}$ ) zogen gegen letzteres zı Felde. England, die Schweiz, Rußland und Türkei belegten den Verkauf des Rauchtabaks und dessen Verwendung mit schweren körperlichen Strafen und Verbannung, jedoch, wie die stets größere Verbreitung des Tabaks zeigte, ohme jerlen Erfolg. Ja, man dürfte

1) Kloss a. a. O., S. 7.

2) Prónay, Frh., von, Über Tabaksteuern, Leipzig 1880, S. 5 .

3) Léon Say et M. Josef Chailley, Nouvean Dictionnaire d'économie politique, Paris 1892, Tome II, p. 968.

4) Kissling a. a. O., S. 2.

5) Tiedemann a. a. O., S. $171 \mathrm{ff}$.

6) Misocapnus seu de abusu Tabaci Luxus regius, Londini 1603. 
wohl nicht fehlgehen in der Annahme, daß gerade das Verbot die treihende Kraft der Ausbreitung des Tabalikonsums war. Demzufolge hieh den geistlichen wie weltlichen Mächten. nachdem sie das Nutzlose ihrer Kampfesweise eingesehen hatten, nichts anderes übrig. als den Kampf einzustellen; sie änderten die Taktik ilıres Vorgehens insofern, als sie aus fiskalischem Interesse zur Besteuerung des Tabalis ühergingen. Das Verbot des Tahakhandels. Schnupfens und Rauchens wurde gänzlich aufgehohen. dafür trat die Tabakstener in Kraft. (ileichzeitig hestrel)ten sich die rerschiedenen Staaten, den Anbau, die Verarbeitung und den Handel des Tabaks zu schützen und auf diese Art der nationalen Industrie einen neuen Zweig anzureihen, denn es war bei der rapiden Ausdehnung des Tabakverbrauches von vornherein klar, daß dieses Produkt als Genußmittel ein finanziell sehr ergiebiges und geeignetes Nittel der Bestenerung werden würde ${ }^{1}$.

1) Milliet, S. 379 , a. a. u. S. 28. 


\section{Begründung und Erhebungsarten der Tabaksteuer.}

Unter allen Konsumtionssteuern nimmt die Tabakstener die richtigste und rationellste Stellung ein, denn sie trifft einen Gegenstand, der derjenigen Klasse von lionsumtionsartikehn angehört, die dem menschlischen Leben ohne Zweifel entbehrlich sind.

Es ist nun allerdings zuzugeben, daß der Tabakgenuß durch die Gewohnheit für manchen unentbehrlich geworden ist und gar viele lieber an einem anderen Lebensmittel sparen würden, als die Pfeife oder die Zigarre zu vermissen, aber ein unentbehrlicher Verbrauchsgegenstand ist der Tabak doch nicht. Man kann ein ganz menschenwürdiges Dasein führen, olne zu rauchen. Wenn unter Umständen bezüglich des Branntweins der Ansicht beigestimmt werden kann, daß eine gewisse Quantitüt desselben zu den notwendigen täglichen Lehensbedürfnissen eines Menschen gehöre, so vermag man das gleiche keineswegs vom Tabak zu behaupten.

Noch mehr, in gewisser Beziehung ist der Tabakgenuß geradezu gesundheitsschädlich. In Frankreich ${ }^{1}$ ), England 2 ; und Amerika wurlen aus diesem Grunde grohe Gesellschaften zur Bekïmpfung des Rianchens gelsildet ${ }^{3}$ ). Nach der allgemein geltenden Anschaumg ist der Tabali

1) La Société contre l'Abus du Tabac fondée par M. Decroix.

2) British antitabacco Society. Von Interesse sind hier zwei Antrïge, die in einer Sitzung in Edinburgh gestellt wurden und noch heute Geltung beanspruchen dürften: "Que les principes constituants que renferme le tabac étant fortement vénéneux, l'habitude de fumer et celle de prises tendent par des roies rliverses à altérer la constitution physique et les facultés intellectuelles." Und "Que l'usage du tabac ayant pour effet d'exciter à boire nonseulement en faisant nâitre une sensation de soif morbide, mais encore en raison de l'épuisement que determine cette substance par ses propriétés particulières ce qui conduit à pendre des boissons que l'on suppose à tort propres à réparer les forces, il y a lieu de regarder le tabac comme poussant au crime et à la dissipation dans les masses" (Jourual de Murat, 23. Mai 1861, nach Parieu, II, 480).

3) Lewinstein, G., Der Tabak als Objekt für Finanzmaßregeln und der jetzige Stand der 'abaksteuerfrage in Deutschland, Berlin 189\%, S. 36. 
ein Luxusartikel und infolgelessen ist es berechtigt, ihn zu besteuern, denn ein in diesem Sinne Luxus Treibender kann nicht als so arm bezeichnet werden, daß er steuerfrei zu lassen wäre.

Lag die Notwendigkeit vor, ein Genußmittel zu besteuern, so war es wohl die vorteilhafteste Idee, einen solchen Gegenstand zu treffen, welcher den menschlichen Beclürfnissen nicht nur enthehrlich erschien, sondern tatsächlich war und noch heute ist. Aber nicht nur in dieser Richtung fundet die Tabaksteuer ihre Berechtigung, sondern anch aus finanziellen und rolkswirtschaftlichen Grïnden, denn nach allgemeiner Überzeugung hat kein Verbrauchsgegenstand eine so große Stenerkraft wie der Tabak ${ }^{1}$ ). Den entsprechenden Beweis liefern nicht nur die bedentenden Erträge der Tabalistener in den verschiedenen Ländern, und zwar hauptsä̈chlich den Monoyolländern, sondern auch die Sicherheit dieser Erträge ${ }^{2}$. Kriegsfälle, finanzielle und wirtschaftliche Krisen wirken nur vorübergehend auf den Tabakverbrauch, und die Eimmahmen sind nur augenblicklich beeinflußt. Nach dem Kriege in Frankreich von 1870/71 wurde beinahe ebensoviel Tabak konsumiert als vor demselben. Auch in Osterreich hat die Krise von 1873 den Tabakkonsum nur unbedeutend vermindert ${ }^{3}$ ).

Ein anderer Vorzug des Tabaks als Besteuerungsobjekt besteht darin, daß die Franen und Kinder im grofen ganzen nicht getroffen werden, sonlern (ler erwachsene Mann allein steuerptlichtig ist *), demn in den meisten Kulturstaaten beschränkt sich der Tabakverbrauch ausschließlich auf die erwachsene, männliche Bevölkerung ${ }^{5}$ ). Ferner stellt die Tabaksteuer viel weniger eine Kopfsteuer dar, wie andere indirekte Steuern, z. B. die auf Salz, Zucker, Mehl usw. Diese (iegenstände dienen jedem einzelnen Familienglied zur Xahrung, und es wird das Haupt einer zahlreichen Familie infolgedessen in viel höherem Maße getroffen ${ }^{6}$ ) als durch eine Stener, welche lediglich durch den Tahakgenuf des männlichen Familienhauptes bedingt wird.

Noch ein Vorteil möge, erwähnt werden, nämlich der, daß der Tabakkonsum ziemlich gleichmäßjig unter allen Schichten des Volkes

1) Schall, Schönbergs Handbuch der politischen Ökonomie, Tübingen 1897, Bd. III, 1, II. Aufl. S. 398.

2) Schäffle, Grundsätze der Steuerpolitik, Tübingen 1880.

3) v. Prónay, Frh., a. a. O. S. 12.

4) Conrad, Finanzwissenschaft, Jena, S. 110.

5) Schall, Schönbergs Handwörterbuch etc., S. 398.

6) Mayr, G., Das Deutsche Reich und das Tabakmonopol, Stuttgart 1S78, S. 54 . 
verbreitet ist, daß also jeder in einem bestimmten Verhältnis zur Beitragsleistung herangezogen wird. Der Reiche wie der Arme wird im Verhältnis zu seinem Vermögen besteuert, denn keine andere Terbrauchssteuer läßt sich derart nach der Qualität abstufen, wie die Tabaksteuer.

Die Berechtigung der Tabakbestenerung ergibt sich noch aus der Tatsache, daß der Tabak keinen anderen Zwecken dient und in anderen Gewerben keine Verwendung findet. Kurzum, die Tabakbesteuerung ist berechtigt, weil sie einen Gegenstand der Komsumtion trifft, welcher einmal entbehrlich, zum anderen häufig sogar der Gesundheit nachteilig ist; sie ist beliebig, trifft jeden nach seinem Einkommen, bringt dem Staate sichere und große Erträge, und dient in Zeiten der Finanznot vielfach als Ultimum Refugium.

Die Besteuerung des Tabaks vollzieht sich in vierfacher Art, nåmlich als:
I. Urproduzentensteuer,
II. Fabrikatsteuer,
III. Eingangszoll und
IV. Monopol.

Die Urproduzentensteuer. Jiese ist entweder Pflanzenoder Flächen-oder Gewichtssteuer.

a) Die Pflanzensteuer bemißt die Steuer nach der Zahl der Tabakpflanzen. Sie ist in Belgien gebrätuchlich, woselbst für jerle TabalipHanze $1 \frac{1}{2}$ Centime bezahlt wird.

b) Bei der Flächensteuer wird die Steuerpflicht lediglich nach der Größe der mit Tabak bestellten Flächen bemessen, wobei auch noch Abstufungen nach der Ertragsfähigheit des Bodens stattfinden können ${ }^{1}$ ).

Tatsächlich ist diese Steuer nichts anderes als eine Extragrundstener. Sie bestand in Preußen seit 1828 und im Zollverein von 1868 bis 1879. Gegenwärtig hat man diese Besteuerungsart wanz aufgegeben. sie besteht nur in Kuba ${ }^{2}$ ).

Unter diesem System blieb die Fabrikation und der Verkauf des Tabaks steuerfrei, und der Steuerpflichtige war, wie dies auch bei der Pflanzensteuer der Fall ist, der Tabakbauer.

Die Steuer ist leicht zu erbeben, aber nur bei geringem Steuer-

1) Mayr, G., Tabak und Tabakbesteuerung im Handwörterbuch der Staatswissenschaften, Bd. VII.

2) Lewinstein, G., Die Belastung des Tabaks in den europäischen Staaten und in den staatlich geordneten Ländern der übrigen Erdteile, Berlin 1894, S. 43. 
fuß. Ist sie höher, dann wird sie zur großen Härte, weil die Tabakernte in verschiedenen Gegenden und Jahren ungleich ist und sogar eine Prämie für den Gebrauch von Surrogaten bildet ${ }^{1}$ ). Die Qualität wie auch die Quantität bleilen unberïicksichtigt, wodurch der Tabakbauer leicht geschädigt werden kann 2).

c) Bei der Gewichtstener wird die Steuer nach dem Gewicht der Erntemenge bemessen. Das zu erwartende Ergebnis wird an Ort und Stelle ror der Ernte amtlich eingeschätzt. Später finclet amtliche Nachzählung und Verwiegung des fermentierten Tabaks statt, worauf die Steuer beim Tabakpflanzer erhoben wird.

Die Gewichtsteuer bestand in Preußen von 1819-1829 und besteht gegenwärtig in Deutschland kombiniert mit einer Flächensteuer. d. h. der Tabakpflanzer bezahlt an Stener für $100 \mathrm{~kg}$ Tabak in fermentiertem oder getrocknetem Zustande 45 Mark. Die Tabakpflanzer zahlen für Gruntflächen von weniger als 4 a eine Flächensteuer, und zwar 4,5 Pfennig für jeden mit Tabak bepflanzten Quadratmeter.

Gegenüber der Flächensteuer stellt sie zwar eine Verbesserung dar, jedloch sie hat immerhin noch grofe Nachteile. Yor allem beengt sie den Tabakbau durch die häufige, sehr belästigende Kiontrolle gegenüber den Produzenten ${ }^{3}$ ). Ein solches Beispiel zeigt das deutsche Gesetz vom 16. Juli 1879, welches an lästiger und drückender Kontrolle dem strengsten Monopol nichts nachgibt ${ }^{4}$ )

Sie vereinigt sich sehr schwer mit dem Prinzip der Abstufung der Stener nach der Qualität des Tabaks, demn sie berüchsichtigt letztere gar nicht.

Alle diese Arten der Urproduzentensteuer haben die Schattenseite, daf sie den Tabakptlanzer zu Stenervorschüssen oft für mehrere Jahre nötigt und dadurch (len Grobibetrieb) durch finanziell gut fundierte Firmen begünstigt ${ }^{5}$ ).

Ein hoher Steuersatz zwingt ferner die Urproduzentensteuer zur Verwendung auch des verstenerten schlechten Materials sowie allerlei Surrogaten, sie reizt also zur Täuschung und Defraudation und macht dadurch denselben liostspieligen und umfangrcichen Kontrollapparat

1) Conrad a. a. O., S. 112.

2) Eheberg a. a. O., S. 290.

3) Eheberg a. a. O., S. 290.

4) Kürti, Desider, Betrachtungen über das Staatsmonopol im allgemeinen und das Tabakmonopol im speziellen, Budapest 1890, S. 17.

5) Schönbergs Handbuch etc., S. 573. 
notwendig wie das MIonopol ). Eine Rückrergütung der au:geführten Tabakerzeugnisse gestattet die Urproduzentensteuer nicht, weil die Ermittlung der Menge des hierzu verwendeten steuerpflichtigen Rohmaterials mit Schwierigkeiten verknüpft ist ${ }^{2}$ ).

$\mathrm{Zu}$ allen diesen Übelständen kommt noch der geringe Ertrag der Urproduzentensteuer, trotzdem der Tabak für eine ausgiehige Besteuerung wohl geeignet ist, welche z. B. in Deutschland einen jährlichen Durchschnittsertrag von 15 bis 30 Mill. Nark ergibt.

Diesen Nachteilen steht der einzige Vorteil gegenüber, daß die Tabakindustrie durch nichts gehemmt ist und sich infolgedessen blühend entwickeln kann ${ }^{3}$ ).

Der oft hervorgehobene Vorteil, daß die Urproduzentenstener den Tahakban günstig beeinflubt. insofern der Tabalibaner veranlabt sei, nur gute Tabaksorten zu bauen, fällt nicht schwer ins Gewicht. Zur Hebung der Tabakikultur kam die Lrproduzentenstener riel weniger beitragen als das Monopol, bei welchem der Staat selbst das größte Interesse hat, den Tabakbau nach Möglichkeit zu fördern.

Die Fabrikatstener wird nach Gewicht und Art der im Inland hergestellten Tabakfabrikate erhoben. Sie ist unter zwei Formen verwirklicht, und zwar als:

I. Materialsteuer, d. h. wenn die Steuererhebung bei dem Eingang des Tabaks in die Fabrik stattfindet, wie dies in Griechenland der Fall ist ${ }^{4}$, und

II. Fabrikatsteuer, d. h. wenn die Tabakerzeugnisse beim Ausgang aus der Fabrik besteuert werden. Diese letzte Form kann durchgeführt werden:

a) als Fakturensteuer, welche nach den von den Fabrikanten auszustellenden obligatorischen Fakturen über die von ihnen verarbeiteten Quantitäten erhoben wird. Dieser Steuermodus bestand Anfang der sechziger Jahre in den Vereinigten Staten von Nordamerika, hat sich aber als unzureichend erwiesen, weil die Kontrolle auferordentlich schwierig ist, so daf. leicht bedeutende Hinterziehungen eintreten können ${ }^{5}$.

1) Kürti, Desider, a. a. O., S. 18.

2) Schönbergs Handbuch etc., S. 573.

3) Siehe: Schleiden, Zur Frage der Besteuerung des Tabaks, Leipzig 1878, S. 26.

4) Lewinstein, G., Die Belastung usw., a. a. O. S. 7.

5) Conrad a. a. O., S. 113. 
b) Sie wird nach Gewicht und Art der Fabrikate bemessen.

Dieses System ist in den Vereinigten Staaten von Nordamerika (seit 1868), Rußland (seit 1839). Bulgarien und Rumelien dlurchgeführt. Die Erhebung der Steuer geschieht durch Anwendung von Stempelmarken (in Amerika stamps, in Rufland, Bulgarien und Rumelien Banderollen genannt), welche der Fabrikant von den Behörden bezieht. Jedes Paket mit zum Verkauf bestimmter Ware muß, bevor es in den Handel gebracht wird, mit einer bestimmten Stempelmarke oder Banderolle versehen werden, welche bei dem Verbrauch zerstört werlen muß.

Unter diesem System. Tabakstempelsteuersystem, auch Banderollensystem genannt, ist die Tabakkultur und -fabrikation frei, was einen blühenden Tabakbau und Export ermöglicht. Als Beispiel dafür dienen die Vereinigten Staaten von Nordamerika; dort hat sich die Stempelstener für 'Tabakkultur und fabrikation sehr günstig erwiesen ${ }^{1}$ ).

Als ein bedeutender Vorteil der Stempelsteuer kommen noch die beträchtlichen finanziellen Ergebnisse hinzu, wie die Vereinigten Staaten solche aufwiesen. Nicht das gleiche Resultat zeigt dieses System in Rußland; hier sind die Tabakkultur und die finanziellen Erträgnisse noch weit entfernt von den eben hervorgehobenen Vorteilen.

Im Vergleich zu der Urproduzentensteuer ist die Fabrikatsteuer berleutend günstiger, denn sie stellt einen wesentlichen Fortschritt dar. Die Steuerzahlung liegt dem Konsum näher, und es ist eine befriedigende Rückvergütung (ler Tabakfabrikate beim Export möglich ²). Ferner gestattet dieses System einigermaben eine Beriicksichtigung der Qualität, insoweit eine Abstufung der Steuersätze nach den Gattungen der Fabrikate (Rauch-, Schnupf-, Kautabak, Zigarren und Zigaretten) möglich ist, aher es gestattet keineswegs die Durchführbarkeit einer realen qualitativen Abstufung. Wohl wurden Versuche für eine weitergehende Beriicksichtigung der Qualität gemacht, aber keine zufriedenstellende Resultate damit erzielt; sie wurlen aufgegeben, weil man die Stenerhinterziehung nicht zu verhindern vermochte ${ }^{3}$ ).

Um Defraudationen auszuschalten, sind strenge Kontrollmaßregeln getrotfen, welche den Tabakbau von der Produktion bis zur

1) Siehe: Felser, Tabakmonopol und die amerikanische Tabaksteuer, Leipzig 1878.

2) Eheberg a. a. O., S. 291.

3) Konrad a. a. O., S. 113. 
Konsumtion rerfolgen, wie die bezüglichen resetze der Vereinigten Staaten von Nordamerika ${ }^{1}$ ) und Rufland ${ }^{2}$ ) es beweisen.

Daraus entsteht im allgemeinen eine teilweise Hemmung der Industrie, die Begünstigung des (rofbetriehs und damit in engem Zusammenhang stehend die Abhängigkeit der Tahakbauern. Neuerdings haben die Truste auch den Tabak in den Kreis ihrer Tätigkeit gezogen, und es wurde ein Tabaktrust gebildet ${ }^{3}$ ). Infolgerlessen können wir sagen, daß auch in Amerika ein Tabakmonopol besteht, nicht zugunsten des Staates, wohl aber zugunsten einer privaten Organisation.

Eingangszoll. Bei dieser Besteuerungsart wird der vom Auslande eingeführte Tabak durch den Zoll bestenert. Es kann dies ein Zoll sein:

a) mit Verbot des heimischen Tabakbaues (Portugal seit 1864 bis 1884, Großbritannien und Ägypten) und

b) mit Zulassung steuerfreien heimischen Tabakbaues (Niederlande. Dänemark, Schweden, Norwegen. Finnland, Schweiz und viele andere auBereuropäische Gebiete.)

Zweifellos besteht der Zoll auch in jenen Ländern, wo schon eine andere Besteuerungsart vorhanden ist, weil sonst die inlïndische Tabakproduktion und -fabrikation nicht mit der ausländischen konkurrieren könnte. Bei beiden Arten dieses Systems findet man als Ergiinzung eine Spezialsteuer (Lizenz) auf Fabrikation und Verkauf zum Zweck der Erzielung höherer Erträge.

Von diesen zwei Arten kommt aber nur die erste, Monopolzoll. system oder das englische System genannt, in Betracht. Es beruht auf dem Verbot des inländischen Tabakbaues und der Bestenerung der Einfuhr durch hohe Zollsätze, unterstützt durch eine Lizenz von 100 Proz. des Wertes.

England verfolgt mit diesem System erstens den Zweck, große Ertrïge zu erzielen und zweitens für seine Schiffahrt und seinen See-

1) Siehe: Lewinstein, G., Der Tabak als Objekt für Finanzmaßregeln und der jetzige Stand der Tabaksteuerfrage in Deutschland, Berlin 1892, S. 27, 28; Kürti a. a. O., s. 28, 29.

2) Siehe: Mayr, G., Das Deutsche Reich und das Tabakmonopol, S. $79 \mathrm{ff}$.

3) Sempronius, Der Tabak und seine Steuerkraft. Monatsschrift für christliche Sozialreform, XXIV. Jahrg. 1902, Heft 5, S. 217. - Nach Semler steht an der Spitze dieses Tabakyndikats der bekannte Rockefeller. Die vier Kontrolle ausübenden Gresellschaften stellen zusammen ein Kapital ron 200 Millionen Dollar dar. Die tropische Agrikultur 2 Aufl., Wismar1903, Bd. III, S. 346. 
handel das \Ionopol zu erlangen. um das britische Reich mit Rohtabak zu versehen.

Der Vorteil dieses Systems liegt in seiner Einträglichkeit, ihm gegenüber stehen jedoch auch große Nachteile. Vor allem hat es die Cnterdrïckung und selhst das Verschwinden der Tabakkultur zur Folge, und es kamn nicht geleugnet werden, daß dies eine schwere Schädigung der landwirtschaftlichen Interessen hedeutet. Selbstrerständlich kam dieses System auch nicht da eingeführt werden, wo sich eine gut entwiclielte Tabakiultur vorfinlet. In England. wosellost zur Zeit der Einführung dieses Srstems (17. Jahrhundert) die Tahalikultur wenig entwickelt war, konnte es nur nach gewaltigem Widerstand zur Anwendung gelangen.

Ferner verteuert dieses System nicht nux die Tabalifabrikate infolge der außerordentlich hohen Zölle, wodurch die Zigarren und die Zigarretten in England teuerer sind als in Monopolländern ${ }^{1}$ ), soudern es erzeugt auch, wie kein anderes, schlechte Fabrikation und Schmuggel, letzteren trotz der insularen Lage des Landes, welche einen verhältnismäßigen Schutz gegen ihn bietet. Wenn wir des weiteren berücksichtigen, dab auch hei diesem system ein genügender Qualitätssteuerful. nicht möglich ist und tie Lizenzgehëhluren eine betrïchtliche Höhe erreichen. dab infolgelessen nur tinamziell gut situierte Personen begïnstigt werden, so ist dieses System als sehr mangelhaft anzuerkennen.

IV. Monopol. Das Monopol ist eigentlich keine Steuer, sondern nur eine Form der Steuererhebung, welche darin besteht, daf der Stat sich das ausschliebliche Recht der Kulum. Einfuhr. Fahrikation und des Verschleißes des Tabaks oder nur einzelne dieser Geschäftszweige vorbehält.

Normalerweise ist das Monopol staatlich, und es ist im Rohtabakmonopol und Vollmonopol verwirklicht. Bei dem Rohtabakmonopol ist der Staat alleiniger und ausschließlicher Käufer des gesamten zum inländischen Verhrauche hestimmten Rolnmaterials, und er verkauft es wieder zu erhöhten Preisen an die Privatfabrikanten. Der Verkaufsgewinn bildet die Stener ${ }^{2}$ ). Das Vollmonopol, welches die hïutigste Form ist, hesteht darin, dilli der Stat alle Geschäftszweige (ler Tabakindustrie in seinem Besitz hat ${ }^{3}$ ).

1) Sempronius, Der Tabak etc. a. a. O., S. 219.

2) Diese Monopolart besteht in Nicaragua und Guatemala.

3) Es besteht in Frankreich, Österreich-Ungarn, Italien, Spanien, Portugal, Rumänien, Serbien und der Türkei. 
Der Tabahbau ist im Prinzip frei, aber er unterliegt bestimmten

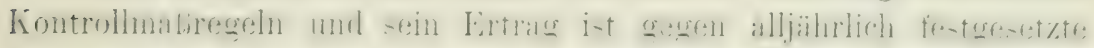
Preise an den Staat abzuliefern. Im Falle eines dem Tabakbau ungünstigen Ḱlimas und ebensolcher Bodenbeschaffenheit bezieht der Staat das notwendige Material von dem Auslande.

Jede Herstellung von Tabakfabrikaten oder Surrogaten ist vollständig ausgeschlossen, und schwere Strafen sind für diejenigen festgesetzt, die im Besitz von Maschinen oder Werkzeugen, welche

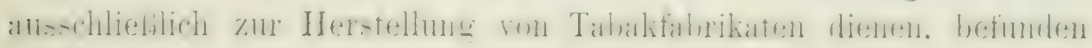
wer(len ${ }^{1}$ ),

Das Vollmonopol kann in drei Formen durchgeführt werlen:

a) als das in eigener Regie betriebene Monopol (Frankreich, Österreich-Ungarn, Italien, Rumänien):

b) als verpachtetes Monopol (Spanien, Portugal, Serbien) und

c) als hointeressierte Regie, welche dem Staat durch Vertragsbedingungen eine gewisse Anteilnahme sichert (die Türkei).

Als die vorteilhafteste dieser drei Arten erscheint, wie es die Erfahrung der Länder, in denen sie besteht, lehrt, die erste. Die beiden anderen Arten sind wegen ihrer großen Nachteile im Vergleich zu ihrer Erträglichlieit zu verwerfen.

Über die Frage, ob die Monopolsteuer den anderen Besteuerungsarten vorzuziehen sei, gehen die Ansichten weit auseinander. Die reichhaltige Literatur über diesen Gegenstand beweist, welche weit-

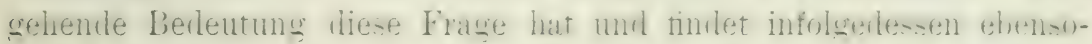
viel Anhänger wie Gegner. So sind z. B. die Meinungen der National-

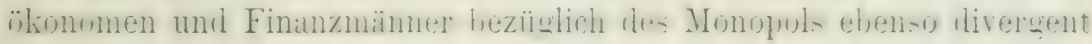
wie diejenigen der interessierten Praktiker.

Stellen wir nun die für und gegen das Monopol geltend gemachten Gründe vergleichend einander gegenüber:

Man wirft dem Monopol vor, es schade der Tabakkultur sowohl durch deren Beschränkung auf bestimmte Gegenden behufs Verein-

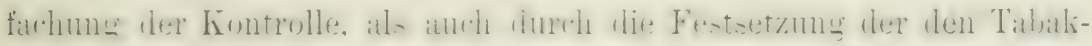
bauern für ihr Produkt zu zahlenden Preise. Dadurch wïrden dieselben geringere Preise erzielen, als es bei freier Konkurrenz der Fall sei.

In der Einschränkung der Tabakliultur sehen wir keinen Tachteil für die Landwirtschaft, weil die Anzahl der TabakpHanzer doch immerhin in lerhaltnis zur lie-antzihl iler Landwire eine seringe

1) Schünbergs Handb. etc., S. 5̄i5. 
ist. Auferdem zeigen gerade die Monopolländer eine stete Zunahme der Tabakkultur ${ }^{1}$ ). Die Frage, ob bei freier Konkurrenz die Tabakpflanzer bessere Preise erzielen würden als beim Monopol, wurde zugunsten des Monopols beantwortet. So bezahlt die französische Regie den Tabakiproduzenten höhere Preise, als es bei freier Konkurrenz geschehien würde ${ }^{2}$ ). Wenn dies auch nicht in allen Nonopolländern der Fall ist, so wird dieser Mangel jedoch durch andere Vorteile ausgeglichen, so z. B. durch die Sicherheit des Verkaufs der gesamten Ernte, die Beseitigung der Ausbeutung durch den Zwischenhändler, die (ieldrorschüsse, die die Regieverwaltungen den Tabakbanern zum Zweck des Tabakbaues gewähren u. a. m.; alle diese Vorteile sind bei freier Konkurrenz ausgeschlossen. Dazu kommen noch die Bestrebungen der Regie, den Tabakbauer durch Belehrung, Verteilung von Samen guter Tabakpftlanzenarten, finanzielle Beihilfen zur Errichtung von Trockenhläusern, Prämien u. a. m. zu unterstïtzen und dadurch gleichzeitig den Tabakbau zu heben und zu verbessern. In dieser Beziehung ist das Beispiel Frankreichs lehrreich. Dort ist man in der Lage, einen erheblichen Teil des Rohtabakbedarfs für die wohlfeilen Zigarren mit inländischem Erzeugnisse zu befriedigen ${ }^{3}$ ).

Auch die Tabakindustrie und der Tabakhandel stehen dem Tabakmonopol ablehnend gegenüber, mit der Begründung, dafo sie unter der Herrschaft des Monopols zu leiden hätten. Bis zu einem gewissen Punkt scheint dies in Ländern mit hochentwickelter Tabakindustrie und blühenden Tabakhandel, wie es z. B. in Deutschland der Fall ist, zuzutreffen; immerhin dürfte aber selhst unter diesen Verhültnissen das IIonopol nicht strikte zu verwerfen sein, wie es auf gegnerischer Seite geschieht.

Durch das Monopol wird die Tabakindustrie keineswegs aufgehoben, sie tritt nur in den Besitz des Staates; infolgedessen werden die Arbeiten in ihrer Erwerbstätigkeit weder unterbrochen noch gestört. Lediglich die geringe Zahl der selbständigen Zigarren-Arbeiter würde zu einem Wechsel ihres Erwerbes genötigt sein, falls nicht auch sie rom Staate bezw. der Regie heschäftigt werden kömnen $\left.{ }^{4}\right)$.

1) Kürti a. a. O., S. 3ॅ ff.

2) Mohl, Moritz, Denkschrift für eine Reichs-Tabakregie, Sluttgart 1878, S. 16,38 .

3) Schönbergs Handb. S. 577.

4) In der Reichstagsrede vom 12. Juni 1882 sagt Bismarck in dieser Beziehung folgendes: „Denn die 110000 Tabakarbeiter und die 10000 Leute, die der Tabakhandel beschäftigt, würden von der Regie mit Leichtigkeit absorbiert und untergebracht ...... 
Wohl würde im ersteren Falle die Hausindustrie geschädigt werden, aber in Anbetracht der meist schlimmen Zustïnde derselben in gesundheitlicher Beziehung wïrle dies eher einen Vorteil als einen Nachteil bedeuten, denn „Ein und derselbe Raum" — wird in den Jahresberichten pro 1883 von dem Fabrik- Inspektor für Bremen ausgeführt ,wird als Schlaf- Wohn- und Arbeitszimmer, in einzelnen Fällen auch noch als Küche benutzt. Dabei widerstrebt im allgemeinen dem Arbeiter eine entsprechende Ventilation, weil sie dem Raume zu viel Wärme entzieht" ${ }^{61}$ ). Unter dem Monopol ist der Arbeiter besser versorgt.

Aber auch der Tabakhandel wird durch das Monopol nicht betroffen, er besteht weiter fort. Der Export steht den Monopolländern im gleichem Maße offen, wie den anderen Ländern auch. Die TabakAusfuhr Österreich-Ungarns und Frankeichs²) beweist zur Genüge daß der Export auch mit Monopolbesteuerung vereinbar ist.

Die Behauptung der Monopolgegner, daß die Monopolverwaltung kostspieliger ist und unter ihr schlechter gearbeitet werde als es bei der Privatindustrie der Fall sei, ist durch nichts bewiesen. Im Gegenteil ist dem Staate die Möglichleit geboten, durch die Zentralisierung des Betriehs, Anwendung von Maschinen, Arbeitsteilung, Verminderung der Sorten Tabakfabrikate billiger herzustellen, als dies der Privatindustrie möglich ist, bei welcher wegen der Zersplitterung des Geschäfts die Ausgaben wachsen. Die durch Reisen, Frachten, Ausstattung, Reklamen usw. verursachten Ansgaben fallen beim Monopol gänzlich weg, wodurch ebenfalls erhebliche Ersparnisse erzielt werden.

Des weiteren fehlt jeder Beweis dafür, daß die Regie schlechte Ware liefern würde. Das Gegenteil trifft zu: die Regie bedient das Publikum besser als die Privatfabrikanten, denn die Regie hat liein Interesse, ihre Fabrikate zu rerfülschen, eine Gepflogenheit, welche nicht selten in der Privatindustrie vorkommt, wo Runkelrübenblätter, Kartoffelkraut, Zichorienblätter und andere minderwertige Surrogate statt Tabak verwendet werlen. Daß die unter Monopolverwaltung hergestellten Tabakfabrikate jedenfalls besser und infolgedessen beliebter sind, als die aus dem Terhältnis der freien Konkurrenz herrorgehenden, dafür zeugt in beredter Weise der stetig wachsende Export Österreichs an Zigarren und Tabak.

Die verhältnismäßig geringe Anzahl Tabaksorten in Monopolländern fällt nicht schwer ins Gewicht, weil sic den Anforderungen

1) Statistik des Deutschen Reiches, Bd. XLII.

2) Schönbergs Handb., S. $576 / 77$. 
der Bevölkerung vollauf genügt. Erfahrungsgemäß zeigt selbst das Publikum der Monopolländer nur für gewisse Sorten Neigung. Auch ist die Zahl der Sorten in den MIonopolländern hinsichtlich der Qualität und Preislage nicht derartig unzureichend: in Frankreich ist dieselbe durch Dekret vom 9. Mai 1894 bedeutend erhöht worden ${ }^{1}$ ), in Österreich ist sie fast zu groß. Die Sortenzahl wird ferner noch durch importierte fertige Waren vergrößert, so daß dem konsumierenden Publikum eine große Auswahl geboten ist.

Gegen das Monopol führt man weiter an, daß es den Schmuggel und đen Cnterschleif viel nìehr befördere als die anderen Stenersysteme. Es ist nicht zu leugnen, daß der Schmuggel und der Unterschleif in Monopolländern stark ist, demn je höher die Stener eines Gegenstandes ist, in um so größerem Umfang wird er geschmuggelt. Es ist aber nicht weniger Tatsache, dab die Defraudation auch in den Nichtmonopolländern, z. B. in England ${ }^{2}$ ), Preußen oder Rußland ${ }^{3}$ ) sehr stark betrieben wird.

Endlich wird noch dem Monopol zur Last gelegt, daß der Mißbrauch der Staatsgewalt durch die Verteilung der Anbaubezirke an (iie Tabakibater und das Anstellungsrecht der vielen Tabakidebitanten in berlenklicher Weise vermehrt werde. Diesem Übelstande ist aber sehr leicht abzuhelfen, z. B. durch das System der Verpachtung der Verkaufsstellen, wie es 7. B. in Österreich-Tngarn besteht. und schließlich gibt es in konstitutionellen Ländern genug Mittel, einem Mißbrauch der Staatsgewalt entgegenzutreten.

Diesen gegen das Monopol geltend gemachten Gründen stehen folgende für dasselbe gegenüber:

a) Das Monopol gestattet die volle Freiheit der Steuer nach der Qualität der Ware abzustufen;

b) die Steuererhebung erfolgt zur richtigen Zeit unmittelbar bei dem Konsumenten;

c) es gestattet Kostenersparnis durch Zentralisierung des Betriebes und die Beseitigung des Zwischenhandels;

d) es gewährt Sicherheit gegen Fälschungen;

e) es bewirkt sicheren und leichten Absatz für den Tabakpflanzer und Befreiung desselben von Schikanen der Zwischenhändler, durch Bekanntmachung der im voraus bestimmten Preise;

1) Bulletin de statistique et de Législation 1894, S. 610 nach Schönbergs Handb. zitiert.

2) v. Pronay a. a. O., S. 27.

3) Kürti a. a. $\Theta$., S. 42. 
f) die inländische Tabakkultur wird durch den Einfluß der Monopolverwaltung gehoben;

g) es tritt bessere Fürsorge und gerechtere Berücksichtigung für die Arbeiter ein, und endlich

h) gewährt das Monopol größte Sicherheit bezüglich der Höhe des Steuerertrages.

„Unter diesen Umständen“ — sagt Zeller mit Recht — „kann ein in der Sache begründeter Zweifel darüber nicht bestehen, daß dem Tabakmonopol vom steuerlichen und finanziellen Gesichtspunkte der unbedingte Vorzug vor allen übrigen Formen der Tabakbestenerung einschließlich der Fabrikatsteuer zukommt $\left.{ }^{1}\right)^{6}$ "

Diese volkswirtschaftlichen und finanziellen Vorzüge des Tabakmonopols veranlaßten verschiedene europäische Staaten zur Einführung desselben. Heute besteht das Tabakmonopol in acht europäischen Lündern. deren Einwohnerzahl to Proz. der gesamten europäischen Bevölkerung beträgt ${ }^{2}$ ).

Was der Monopolisierung des Tabaks in den anderen Staaten hindernd im W'ege steht, beruht nicht auf prinzipiellen Gesichtspunkten, sondern hier sind andere Faktoren volkswirtschaftlicher, politischer und finanzieller Natur maggebend, welche ihrerseits wieder durch die allgemeine ,Abneigung gegen alle staatlichen Monopole, durch die Beseitigung einer viele beschäftigenden Privatindustrie und nicht in letzter Linie auch durch die Frage nach Höhe und Umfang der Entschädigung für die aus ilırem bisherigen Wirkungskreis entfernten Industriellen und Handeltreibenden ihre Begründung finden“"3).

Das klarste Beispiel in dieser Beziehung bietet Deutschland, woselbst trotz der Bemühungen Bismarcks, der als letztes Ziel der Tabakbestenerung bekanntlich das Monopol erblickte ${ }^{4}$ ), die Einführung des letzteren dennoch unterblieb. Der Hauptgrund hierfür dürfte wohl darin zu suchen sein, daß in Deutschland Industrie und Handel in Tabak auf hoher Entwicklungsstufe stehen. Infolgedessen würde nicht nur die Entschädligungsfrage bedeutende Schwierigkeiten bereitet haben, sondern es wären auch durch die Änderungen in der Steuerform unäbersehbare wirtschaftliche Umwandlungen hervorgerufen worden.

1) Schönbergs Handb., S. 579.

2) Mayr, G., a. a. O., S. 89.

3) Eheberg a. a. O., S. 293.

4) Reichstagsrede rom 22. Februar 1878 .

Volkswirtschaftl, u. wirtschaftsgeschichtl. Abhandlungen. H. 4. 
In letzter Zeit macht sich das Bestreben nach Einführung des Monopols auch in anderen Lündern bemerkbar, wie in der Schweiz ${ }^{1}$, und Bulgarien 2), und es diurfte voraussichtlich die Zeit nicht mehr allzufern sein, in welcher man in dem Tabakmonopol den idealsten Zustand der Tabalisteuer sämtlicher Staaten Europas erblicken wirl ${ }^{3}$ ).

1) Milliet, E. W., Die Beschaffung der Hilfsmittel zur Durchführung der Unfall- und Krankenversicherung, insbesondere durch Bestenerung des Tabaks, ver̈̈ffentlicht in der Schweizerischen Yeitschrift für Gemeinnützigkeit, XXX V'III Jahrg., Zürich 1899.

2) Leipziger Tageblatt 1904, Juli.

3) v. Stein, Lehrbuch der Finanzwissenschaft 1878, Bd. II, S. 272. 


\section{Der Tabak und die Tabakbesteuerung in Rumänien bis zum Jahre 1864.}

Die Einführung des Tabaks in Rumänien geschah ziemlich lange Zeit nach seiner Verbreitung in der europäischen Türkei, wohin er zu Anfang des 17. Jahrhunderts, während der Regierung des Sultans Achmet I., durch englische Seeleute seinen Weg gefunden hatte.

In dieser Zeit und auch später noch stand Rumänien unter der Herrschaft der Osmanen. Die große Menge von Türken, die nach Rumänien kam und die hier lange Zeit, sei es als Beamte, sei es als Kaufleute blieben, brachte die Sitte des Tabakrauchens mit sich. Außerdem trug auch der lange Aufenthalt der türkischen und der rumänischen Truppen in den verschiedenen Kümpfen der Türkei gegen andere Staaten viel dazu bei, daß sich die Sitte des Tabakrauchens unter allen Schichten des rumänischen Volkes verbreitete. Einen sicheren Beweis dafür liefert die diesbezügliche Terminologie: tutun ${ }^{1}$ ) (Tabak), luleà (Pfeifenkopf), ciubuc, Worte türkischen Ursprungs, wie anch der rumänische Ausdruck „Tabak trinken“ den türkischen Ausdruck „ütschmek tütün" ${ }^{2)}$ wiedergibt.

Die alte Sitte, die in Rumänien bestand, daß man aus sehr langen Pfeifen (Tsubuck genamnt) oder aus kurzen Pfeifen mit Tonküpfen rauchte und dafi man den Besuchern Kaffee und eine frisch angezündete Pfeife anbot, gilt noch als weiterer sicherer Beweis dafür, dals das Tabakrauchen in Rumänien durch die Türken eingeführt wurde.

Einmal eingeführt, verbreitete sich das Tabakrauchen sehr schnell. wurle bald zur Gewohnheit und nahm solche Dimensionen an, dal. es als unentbehrlich angesehen wurde ${ }^{3}$ ). „Tabak", schrieb Andreas

1) Rumänien, Bulgarien und Serbien nennen den Tabak Tutun, ein türkisches Wort, das Rauch bedeutet, während fast alle anderen Länder die Benennung Tabak bis heutzutage beibehalten haben.

2) Tabakzeitung 1877, Nr. 32.

3) Geschichte der Moldau und Walachei, Leipzig und Frankfurt 1790, S. 118. 
Wolf, ,wird in der Noldau häufig erzeugt, weil das männliche Geschlecht olne sonderliche Ausnahme des Alters hier zu Lande bis zum Ekel raucht und schnupft."

„Auch weibliche Personen habe ich nicht selten Tabak rauchen sehen, hauptsächlich Griechinnen und Zigeunerinnen, die sich in der Farbe des Gesichts so ziemlich gleich sehen. Geborene MIoldauerinnen j)thegen nie zu rauchen und halten es vielmehr für einen Spott, wenn sie sehen, daß Konstantinopolitanerinnen ihren Mund zu einem Rauchfang machen $\left.{ }^{1}\right) . " 6$

Wie in anderen Ländern, so erhob auch in Rumänien die Geistlichkeit ihre Stimme gegen das Tabakrauchen, da sie es für nicht rereinbar mit den religiösen Vorschriften erklärte, denn die griechischorientalische Firche hielt das Rauchen für eine Sünde ${ }^{2}$. Die Geistlichkeit nannte den Tabak .,teuflisches líraut" und das Rauchen ,das Teufelswerk" und in ihrem Kampf stützte sie sich auf die Schriftstelle: „Was aus dem Munde geht, ist unrein."

Jedoch bestanden in Rumänien nicht die schweren Strafen, wie dies in anderen Ländern der Fall war, der Raucher hatte also weder körperliche Strafen noch Verbannung aus dem Lande zu befürchten. Es bestand kein direlites gesetzliches Verbot des Tabakrauchens, wie z. B. in der Schweiz ${ }^{3}$ ) oder Deutschland ${ }^{4}$ ).

Nach der Einführung des Tabakrauchens fing man nummehr an, den Tabak in Rumänien selbst zu bauen. Mit der Ausbreitung des Rauchens und Schnupfens wuchs natürlich rasch tie Nachfrage nach Tabak und dadurch entwickelte sich in gleicher Weise der Anbau desselben. Das Ḱlima und die Bodenbeschaffenheit waren ihm damals, wie heutzutage noch, sehr günstig. .Der Tabak kommt glücklich“ schriel, Raicewich - ..und mit grölter Leichtigkeit fort: zwar scheint er nur von gemeiner Art, aber über den möglichen Wert desselben läbt sich nicht urteilen. da nicht die geringste Sorge orler Verfeinerung auf den Bau desselben verwendet wird ${ }^{5}$ ).

Zweifellos konnte zur damaligen Zeit von einem sorgfältigen rationellen Tabakban nicht die Rede sein, um so mehr als das rumä-

1) Wolf, Andreas, Beiträge zu einer statistisch-historischen Beschreibung des Fürstentums Moldau, Hermannstadt 1805, S. 39.

2) Parieu a. a. O., Bd. I1, S. 78.

3) Schweizerische Zeitschrift für Gemeinnützigkeit, XXXVIII. Jahrg., Zürich 1899, Heft 3, S. 383.

4) Lewinstein a. a. O., S. 5.

5) Bemerkungen über die Moldau und Walachei, Wien 1789, S. 20. 
nische Volk noch unter der schwer drückenden IIerrschaft der Türken stand, wo für Leben und Vermögen lieine Sicherheit bestand, üh)erall größte Unwissenheit herrschte und jeglicher Fortschritt ausgeschlossen war. Jedoch gab es auch Gegenden, z. B. in der Nähe des Siretflusses, wo vorzügliche Tabaksorten erzengt wurden, deren Preis sich noch einmal so hoch stellte, als der im allgemeinen für den polnischen Tabak gezahlte. Infolgedessen wurden sie auch häufig nach der Türkei, Tatarei und nach Polen verkauft ${ }^{1}$ ).

Der Tabakbau entwickelte sich nun im Laufe der Zeit immer bedeutender. Der preuBische Konsul Neigehaur herichtet im Jahre 18ts, daß. sehr viel Tabak gebant und nach der Türkei verschifft werde, weniger nach Europa und dann nur in den besseren Sorten dorthin einigen Absatz finde, wenn die Preise gedrückt seien \%). Ferner zeigt er, daß unter den Waren, die im Werte von 276878 Piaster im Jahre $18: 36$ durch das Zoliamt Michaileni nach Österreich ausgeführt wurden, sich auch Tabak befand ${ }^{3}$ ).

Anfangs war der Tabakbau vollständig frei und erlitt keinerlei Beschränkungen. Für den Handel mit Rohtabak und für die Tahakinclustrie, wenn man zu diesen Zeiten von einer solchen überhaupt sprechen kamn, bestanden ebenfalls keine speziellen Belastungen. Jedermann durfte Tabak bauen, verarbeiten und rerkaufen, ohne besonderen Abgaben unterworfen zu sein.

Von dem Verkehr mit Tabak aller Art wurden nur die allgemeinen Zoll- und Acciseabgaben erhoben, wie von den anderen Nahrungs- und Genufmitteln auch. Zum ersten Male finden wir in der zweiten Hälfte des 17. Jahrhunderts den eingeführten Tabak mit einem Zollsatz von 80 Bani $^{4}$ ) pro Oka ${ }^{5}$ ) belegt ${ }^{6}$ ).

Eine Besteuerung des inländischen Tabaks finden wir sodann im Jahre 1693 in Moldau. Die Veranlassung, den Tabak zu besteuern, entsprang nicht dem Bestreben, das Rauchen zu verhindern oder zu vermindern, sondern dem Fürsten Einnahmen zu verschaffen. Durch Schenkungen an Klöster und Günstlinge, sagt Creanga ${ }^{7}$ ), wurde die Anzahl der Staatsolomänen stark vermindert, so dab die Fürsten nur

1) Geschichte der Moldau und Walachei, Leipzig und Frankfurt 1790, S. 123.

2) Neige ba ur, Beschreibung der Moldau und Walachei, Leipzig 1818, S. 248.

3) Neigebaur a. a. O., S. 264.

4) 80 Bani $=3 / 4$ Lei alter Währung, 1 Lei alter Währung $=0,37$ Fres.

5) $\mathrm{Oka}=1 \mathrm{~kg} 285 \mathrm{~g}$.

6) Archiva, Anul X, Jassy, 1899, S. 621.

7) Creanga a. a. O., S. 118. 
auf die Stenereinnahmen angewiesen waren, deren Erhebung um so leichter möglich war, als in den Donaufürstentümern von einem Steuerbewilligungsrecht der Stände nicht die Rede war. Da nun die Ausgaben immer melr wuchsen, so mußten infolgedessen auch die Einnahmen vergrößert und andere neue Steuerquellen gesucht werden. Das kam am deutlichsten in der Zeit der sog. ,phanariotischen Epoche“ zum Ausdruck, in welcher die aus Phanar ${ }^{1}$ ) stammenden Fürsten über die Donaufürstentümer herrschten. Selbstverständlich erhielten diese Fürstensitze die Personen, die dem Sultan am meisten dafür zahlten. Die Fürsten ihrerseits rerfehlten aber nicht, die dem Sultan für die Erlangung des Thrones gezahlte Geldsumme wieder aus dem Lande herauszuziehen und außerdem noch große Reichtümer anzusammeln. Daraus entstand die Vielseitigkeit der Steuern und am meisten der indirekten Angaben. Ebenso wurden sehr viele neue Stenern eingeführt. „Es kam eine Zeit" - sagt der Historiker Xenopol „wo die Fürsten alle Termögensgegenstände mit einer Steuer belegt hatten und sie schlieflich nur mit Hilfe des Wörterbuches eine neue Benennung finden konnten. Es wurde sogar eine Schornsteinstever eingeführt $\left.{ }^{2}\right),{ }^{6}$

Die auf den Tabak gelegte Steuer, genannt „Tutunaritul“, war eine Flächensteuer ohne Berücksichtigung der Ertragsfähigkeit des Bodens, also eine einfache Flächensteuer und stellte somit die primitirste Form der Tabakbesteuerung dar.

Sie war auf „Pogon"3) berechnet und man bezahlte 4 Lei (= MIk. 1,20) für jerlen mit Tabak bebauten Pogon $\left.{ }^{4}\right)$. In der Walachei war diese Steuer etwas höher. Man bezahlte $t$ Lei 16 Paras (= Mk. 1,30) pro Pogon und die Stener wurde im Monat August erhoben ${ }^{5}$ ).

Die Schriftsteller und Chronisten dieser Zeiten geben keine nähere Beschreibung über die Ausdehnung der dem Tabakbau gewirlmeten Fläche und die Erträge dieser Steuer, sondern wir finden nur hie und da liurze und unklare Erwähnungen darüber. Demnach scheint der Tabakban nicht sehr verbreitet gewesen zu sein und infolgedessen die Stener nicht die ganze Berölkerung getroffen zu haben ${ }^{6}$ ).

1) Eine Burg in Konstantinopel.

2) Xenopol, Istoria Rominilor, Jassy, Bd. XII.

3) Ein Pogon $=0,501179$ ha.

4) Letopisetele Munteniei si Moldovei gesammelt, von M. Kogalniceanu, Bd. II, S. 249.

5) Carra, M., Histoire de la Moldavie et de la Walachie, Paris 1778, S. 264.

6) Idieru, Studii de Economie politica si finante, Bukarest 1895, Bd. II, S. 241 . 
AuBerdem ptlegten wohl der Torsicht halber die Fürsten die Register ihrer Eimnahmen beim Verlassen des Thrones mitzunehmen und damit verschwand auch jede Spur des Nachweises über die Einnahmen irgendwelcher Steuer. Es ist bekannt, daß die Einnahmen der Tabaksteuer

$$
\begin{aligned}
& \text { im Jahre } 17595000 \text { Lei (1498,50 Mk.) } \\
& \begin{array}{llllll} 
& \quad & 1766 & 4200 & \text { Lei }(2058,70 & \text { Mk. }) \\
. \quad & \quad & 1767 & 7950 \text { Lei }(2382,60 & \text { Mk. }) \text { und }
\end{array} \\
& \text { " } \left.\quad 177115000 \text { Lei (4495,50 Mk.) betrugen }{ }^{1}\right) \text {. }
\end{aligned}
$$

Die lohe fast doppelte Einnahme des Jahres 1771 ist in der reichen Tabakernte dieses Jahres begründet. Wenn wir bedenken, dal, der Tabak in dieser Zeit eine sehr ausgichige Einnahmequelle in Frankreich bildete, woselbst das Tabakmonopol schon bestand und dem Staat eine Pachtsumme von 500(000 Livres brachte (etwa t25000 Mk.) *) und in Österreich das verpachtete Tabakmonopol für das Jahr 1759 $778800 \mathrm{H}$. (1326 $600 \mathrm{Mk}$.) brachte $\left.{ }^{3}\right)$. so kam man sehen, wie ungemein klein die Tabaksteuereinnahmen in Rumänien gewesen sind.

Es war aber gut, daß die Steuerkraft des Tabaks nicht ausgenutzt wurde, denn die Einnahmen dieser Steuer, wie die vieler anderer flossen gemäf der mittelalterlichen Staatsauffassung, laut welcher die Privatkasse des Fürsten und die Staatskasse als identisch angesehen wurden, in die Privatkasse des Fürsten, und sie war ein Mittel, die Eimnahmen desselben zu vermehren, trug aber nicht zum staatswirtschaftlichen Nutzen des Landes bei.

Bis zum Jahre 1831 trat keine Änderung in der Besteuerungsart des Tabaks ein. Nur der Steuersatz erlitt Abänderungen. So wurde in der Periode von 1806 bis 1812 der Stînjen ${ }^{4}$ ) mit Tabak bebauten Terrains mit 10 Paras $^{5}$ ) besteuert. In dieser Zeit wurde die Tabaksteuer, wie auch alle anderen Steuern ${ }^{6}$ ) verpachtet. Wegen der aus der Tabaksteuer erzielten kleinen Eimnahme wurde diese Stener nicht allein verpachtet, sondern im Verein mit zwei anderen, nämlich:

1) Carra, M. a. a. O., S. 264.

2) Forbonnais, Recherches et considerations sur les finances de la France depuis 1595 jusqu'en 1721, Liège 1758, T III, p. 222, zitiert nach Prónays Tabaksteuern, Leipzig 1880, S. 42.

3) Wickett, B. A., Studien über das österreichische Tabakmonopol, Stuttgart 1897 , S. 9 .

4) Ungetähr 2 qm.

5) Eine Para ist $1 / 40$ von 1 Lei alter Währung.

6) Urechia, V. A., Istoria Rominilor, Bukarest 1896, Vol. IX, p. 499. 
Dijmarituli ${ }^{1}$ ) und Pogonaritul2). Welche Höhe die Eimnahmen aus der Tabaksteuer erreichten, ist nicht festzustellen, weil die bei der Zuteilung erzielte Pachtsumme summarisch und ohne Spezifikation der einzelnen Steuersorten angegeben ist. Nur für das Jahr 1812 sind die Einnahmen der Tabakstener angegeben; sie betrugen in der Walachei 60000 Lei (17982 Mk.) und in der Moldau 50000 Lei $\left(14985 \mathrm{Mk}^{3}\right)$.

In diesem Zeitraum wurde der ausländische Schnupftabak mit 50 Paras pro Oka und der inländische Schnupftabak mit 10 Paras pro Oka bestenert $\left.{ }^{4}\right)$. Die schon bestehende Tabakstener von 10 Paras pro Stinjen blieb auch von 1812 bis 1816 in Kiraft und wurde ron da an auf 17 Para erhöht ${ }^{5}$ ), Die Bojaren waren wie früher so auch jetzt ron der Tahaksteuer befreit. Die Art der Stenererhebung blieb dieselbe. nämlich die Verpachtung mit Dijmaritul und Pogonaritul. Das Flächensteuersystem bestand bis zum Jahre 1831 fort, ron diesem Zeitpunkt an trat sorlann eine gründliche Änderung in dem politischen, wirtschaftlichen und finanziellen Leben zum Wohl der Donaufürstentiimer ein.

Es sei hier noch erwähnt, daß in dieser ganzen Periode die Einfuhr des ausländischen und die Ausfuhr des inländischen Tabalis keinem besonderen Eingangs- oder Ausgangzoll unterlag. sondern demselhen Zoll wie jedle andere Ware auch, nämlich 3 Proz. ihres Wertes ${ }^{6}$.

Durch den Frieden von Adrianopel (14. September 1829) bekam Rubland das Protelitorat über die Moldau und Walachei, und es verlich ihnen, den Friedlensbedingungen gemäß, ein neues Staatsgrundgesetz. das sogenannte Organische Reglement, welches zwar von den Bojaren beider Länder ausgearbeitet, aber in Petersburg im Interesse Ruflands geändert worlen ist. Dasselbe trat $1 \times 31$ in Kraft, nachdem es nur zum Schein den rumänischen Bojaren unterbreitet worden war. Es wurde ron der Türkei und Rußland genehmigt ${ }^{7}$ ), was die Rumänen

1) Dijmaritul war die Steuer auf die Bienen- und Schweinezucht.

2) Pogonaritul war auch eine Flächensteuer, welche man für die Weinberge pro Pogon bezahlen sollte.

3) Xenopol a. a. O., Bd. X, S. 123.

4) Urechia a. a. O., Bd. IX, S. 537.

5) Urechia, Din Domina lui Joan Caragea. Avenirea la tron, Miscari contra Grecilor, Finante, Bukarest 1900, p. 149.

6) Baicoianu, C. Dr., Geschichte der rumänischen Zollpolitik seit dem 14 . Jahrhundert bis 1874 , Stuttgart 1896, S. 57 .

7) Brezoianu, J., Vechile institutiuni ale Rominiei, Bukarest 1882, p. 167. 
mit vollem Recht als eine Verletzung ihres Rechtes der Selbstregierung ${ }^{1)}$ ansahen. Das Organische Reglement, welches man als erste politische Staatsverfassung bezeichnen kamn, lat den Donaufürstentümern bedeutende Vorteile gebracht, indem es ihnen die Entwickelung zum modernen Staat erleichtert hat $\left.{ }^{2}\right)$. Bezüglich des Finanzwesens führte das Organische Reglement ein ganz neues System ein. Im Gegensatz zu dem bisherigen Modus konnte der Fürst nicht mehr die Steuer auflegen und mit den Einnahmen nach seinem Belieben schalten. Alle Steuern wurden als Staatseinnahmen erklärt und dem Fürsten eine jährliche Zivilliste ausgesetzt. Die Einnahmen wie anch die Ausgaben wurden festgestellt, also zum ersten Male trat das Bulget im finanziellen Leben der Donaufürstentümer in Kraft.

Die bisherigen indirekten Steuern, sogenannte Rusumaturi3), wie auch die Naturalabgaben, die ihrer Natur und ihrer Erhebungsart nach für das Volk ungemein drückend waren, wurden abgeschafft ${ }^{4}$ ), und an ihre Stelle traten als Eimnahmequelle die Zölle, Salzeimmahmen. die Kopfsteuer und Gewerbesteuer. Die meisten der bis dahin bestehenden Privilegien wurden ehenfalls abgeschafft, nur einige wurlen beibehalten ${ }^{5}$ ). Der provisorischen russischen Verwaltung war es unmöglich, die seit Jahrhunderten bestandenen, in das Volkswohl tief einschneidenden Miß̧bräuche mit einem Schlage zu beseitigen, 1 sı sı mehr, als seitens der Bojaren wie anch der Geistlichkeit ihr die größten Schwierigkeiten in den W'eg gelegt wurden. Bojaren und (ieistliche

1) Die Selbstregierung der Donanfürstentümer war auch in dem Adrianopeler Frieden anerkannt worden. Der beziigliche Art. V lautet: „Les principautés de Moldavie et de la Valachie s'étant, par suite d'une Capitulation, placées sous la souzéranité de la Sublime Porte et la Russie ayant garantie leur prospérité, il est entendu qu'elles conserveront tous les privilèges et immunités qui leur ont été accordés, soit par leurs capitulations, soit par les traités conclus entre les deux enıpires ou par les hatti - chérifs émanés en divers temps. En conséquence, elles jouiront du libre exercice de leur culte, d'une sureté parfaite, d'une administration nationale indépendente et d'une pleine liberté du commerce: les clauses additionelles aux stipulations antécédentes, jugées nécessaires pour assurer à ces deux provinces la jouissance de leurs droits, sont consignées dans l'acte séparé ci - joint, qui est et sera considéré comme faisant partie intégrante du présent trâité“.

2) Baicoianu, C. Dr., Geschichte der Zoll- und Handelspolitik Rumäniens (Istoria politicei noastre vamale si comerciale), Bukarest 1904, S. 3. bedeutet.

3) Rusumaturi, ein Wort türkischen Ursprungs, das ,indirekte Steuer"

4) $\$ 61$ des Organischen Reglements der Walachei.

\$ ti6 " " " , Moldau.

5) Das Organische Reglement der Moldau, Anexe P. S. 184. 
benutzten ihre frühere Stellung und ihr Ansehen und wollten nach wie vor auch ihrerseits aus dem Lande Nutzen ziehen. Dies geht aus folgenden Worten des Generals Ki iselef, des damaligen russischen Verwalters der Donaufürstentümer, klar hervor: „Nachdem die provisorische russische Verwaltung ihre ganze Aufmerlisamkeit auf diesen Umstand gerichtet hat, hat sie sich überzeugt, daß die Bojaren, die die Reformen verlangten, die Begrenzung der fürstlichen Macht bezweckten, aber sie haben sich nie vorgestellt, daß diese Reform, die das durch die fürstliche Macht entstandene C̈bel vertilgen sollte, auch das pflichtwidrige System ihrer eigenen, auf die ungerechten Naturalabgaben gegründeten Interessen treffen wirde, welche in Ermangelung einer guten Wirtschaftsweise das einzige Nittel ihrer Existenz bildeten.

Unter diesen Verhältnissen für die neue Reform von den Bojaren eine aufrichtige Mitarbeit zu erwarten, wäre gleichbedeutend gewesen mit dem Verlangen der Verzichtleistung auf ihre Rechte, welche sie doch im (iegenteil mit allen möglichen Mitteln zu verteidigen suchten. Unter den gleichen Umständen war auch auf eine Mitarbeit seitens der Geistlichkeit nicht zu rechnen, welche ihrerseits ebenfalls die Rechte zu verlieren fürchtete, die sie unter der Regierung der Fürsten gewonnen hatte ${ }^{1}$. 6

Weil durch das Organische Reglement die Städte eine gewisse Selbständigkeit erlangten und dadurch ihre Ausgaben sich vermehrten, wurle die Tabakstener zur stältischen Stener erhoben, die im Verein mit anderen Verzehrungssteuern die Ausgahen der Städte zum Teil decken sollte. Diese Tabakaccise wurde direlit ron den Städten selbst olne Vermittelung des Staates und nur von der einheimischen Produktion erhoben oder aber verpachtet ${ }^{2}$ ).

Als Tabakaccise blieb die Tabakstener bis zum Jahre 1863 in Krraft, von welchem Zeitpunkt ab dann durch das Gewerbegesetz dieses Jahres den Tabakhändlern eine Verkaufsstener neben der schon bestehenden Tabakstener auferlegt wurde. Demgemäß wurden die Tabakhändler in vier Klassen eingeteilt, und die entsprechende Gewerbesteuer wechselte je nach der Art des Verkaufs - en gros oder en detail - und nach der Größe der Stadt-Bevölkerung, durch welche der Tabakhandel betrieben wurde, wie folgende Tabelle es veranschaulicht:

1) Codrescu, T., Uricariu, Vol. X, p. 288 (nach Alesandrini).

2) Baicoianu, C., Geschichte der rumänischen Zollpolitik etc., S. 82. 


\begin{tabular}{|c|c|c|c|c|}
\hline \multirow[b]{2}{*}{ Klassen } & \multicolumn{4}{|c|}{ Bevölkerung der Städte } \\
\hline & $\begin{array}{l}\text { von } 20000 \\
\text { Seelen an }\end{array}$ & $\begin{array}{c}\text { von } 5-20000 \\
\text { Seelen }\end{array}$ & $\begin{array}{c}\text { von } 3-5000 \\
\text { Seelen }\end{array}$ & $\begin{array}{c}\text { von } 300 \text { Seelen } \\
\mathrm{ab}\end{array}$ \\
\hline I. & 300 Lei & 200 Lei & 130 Lei & 80 Lei \\
\hline II. & 140 & 100 & $75 \quad$, & $35 \quad$, \\
\hline III. & $65 \quad,$. & $50 \quad$, & $35 \quad$, & $12 \quad$. \\
\hline IV. & $25 \quad$, & $20 "$ & 12, & $6 \quad$, \\
\hline
\end{tabular}

Was diese Verkaufssteuer dem Fiskus eingebracht hat, ist nicht zu ermitteln, weil die entsprechenden Einnahmen in den statistischen Angaben nicht spezifiziert sind. Jedenfalls kann behauptet werden. daß dliese Verkaufsstener sehr wenig einträglich war und wegen der schlechten Finanzlage Rumäniens der damaligen Regierung den Anlab bot, das Tabakmonopol einzuführen.

Aus dem oben Gesagten geht hervor, daß der Tabak seit seiner Einführung bis zum Jahre 1864 zwei Besteuerungsarten unterlag:

a) einer einfachen Flächensteuer bis zum Jahre 1831 und

b) einer Tabakaccise bis zum Jahre 1864, verbunden mit einer Verkaufssteuer im Jahre 1863.

Ihrer Natur nach waren diese beiden Steuersysteme nicht imstande, die große Steuerfähigkeit des Tabaks auszunutzen und dem Fiskus bedeutende Einnahmen zu bringen. Während fast alle Staaten Europas Mittel gefunden hatten, aus der Belastung des Tabakkonsums erhebliche Beiträge für ihre finanziellen Bedürfnisse zu ziehen. war dies leider in Rumänien nicht der Fall, was unter den bisher obwaltenden Verhältnissen nicht zu verwundern ist. 


\section{Die Einführung des Tabakmonopols, seine Dauer und die bis zum Jahre 1872 an seine Stelle tretende Tabak- steuer.}

Das heutige Königreich Rumänien bestand bis zum Jahre 1859 aus den beiden Donaufürstentümern Walachei und Moldau, jedoch waren ihre Bewohner, da beide Fürstentümer in früheren Jahren einen Staat bildeten. gleichen Stammes und Blutes, wie auch ihre Sprache, Sitten, Gel)räuche und Religion - die Hauptmerkmale einer Nation sich nur durch wenig unwesentliche Abweichungen voneinander unterscheiden, in den Hauptzïgen aber die gleichen sind. Beide Fürstentïmer waren aber politisch nicht unabhängig, sondern standen unter der Irückenden Herrschaft der Osmanen.

Sowohl die Türkei als auch Rußland $\left.{ }^{1}\right)$ waren bestrebt, die beiden Fürstentümer ihrem Reiche einzuverleiben und traten (leshall) dem eifrigen Bemühen derselben, sich ron jedwedem fremden Einflub zu befreien, um nach späterer Vereinigung und Regeneration und Annahme sowie Verbreitung europäisch-abendländischer Lultur in die Reihe der zivilisierten Staaten als gleichberechtigt einzutreten, stets hindernd entgegen. Jedes der beiden Reiche sah in diesen Bestrebungen der beiden Fürstentümer seine eigenen Interessen gefährdet. Die Türkei befürchtete den Verlust ihrer Oberhoheit, weiche sie aber erst im Jahre 1877/7s durch die segensreiche Regierung König Karls, des Gründers des modernen Rumäniens, verlor. Rußland andererseits befürchtete dadurch die Gelegenheit 7. verlieren, seinen im stillen längst gehegten Plan ausführen zu können, nämlich bei der ersten

1) Dieses Reich würde durch Einverleibung der beiden Donaufürstentümer einen offenen Weg nach Konstantinopel erreicht haben. 
sich bietenden Veranlassung die Fürstentümer zu annektieren, Giemäß Ilem Pariser Frieden vom 30. März 1856 trat eine definitive Regelung der staatlichen Verhältnisse Rumäniens im Jahre 1859 ein, als die beiden gesetzgebenden Versammlungen am 17. Januar und 5. Februar den Oberst Alexander Cuza zum Fürsten wählten, welcher den Thron als Alexander Joan I. bestieg. Dadurch wurde die Personalunion der beiden Fürstentümer eine vollendete Tatsache. und mit Freule sahen die Rumänen ihren alten Wunsch in Erfüllung gehen.

Ein neues Leben begann. Ein reformatorischer Geist für modernen Aufbau des Staates machte sich überall bemerkbar. „Die Fürstentümer" - wird u. a. in der Thronrede ausgeführt - „sind der frucht- und ziellosen Versuche müde. sie wollen sich von diesem ihre Kraft vernichtenden Zustande hefreien. Sie wollen vorwärts schreiten, sie wollen ein Lebenszeichen von sich geben. Die rein politische Epoche ist abgeschlossen, und die Zeit ist gekommen, in der wir uns vorwiegend mit den unser Land betreffenden wirtschaftlichen Fragen beschäftigen müssen ${ }^{1}$ ).

Dementsprechend übernahm der Fürst die Reorganisation der Finanzen, der Justiz, der Armee, der öffentlichen Bauten, des Ackerbaues, Handels und Verkehrs.

$\mathrm{Zu}$ diesem Zweck bedurfte Fürst Cuza aber Geld, welches in jener Zeit nicht vorhanden war, denn bei der Übernahme seiner Regierung bestand keine glänzende finanzielle Lage. In der Walachei hatte das Budget ron 1857 mit einem Defizit von 5507097 Piaster und 1858 mit einem solchen von 5030442 Piaster abgeschlossen 2), während das Budget der Moldau ein Defizit von 5277583 Piaster ergeben hatte ${ }^{3}$ ). Die Staatsschuld der ILoldau betrug im Jahre 185 29905318 Piaster und diejenige der Walachei 18914292 2 Piaster ${ }^{4}$. Die öffentlichen Kassen waren leer; in der Moldau hatten die Offiziere ihr Gehalt auf mehrere Monate nicht bekommen, die Soldaten fehlten, ebenso Ḱleidung und Schuhe, die Dorflehrer waren seit einem halben Jahr, die Finanzkontrolleure seit 7 Monaten nicht bezahlt worden. Der Staat erbettelte von den Privaten das Geld und schämte sich nicht, es anzunehmen ${ }^{5}$. - Trotzdem wurden die Ausgaben selbst in dem

1) Baicoianu a. a. O., S. 105 .

2) Analele economice 1860 , Nr. 1, p. 6.

3) Butgetele Moldaviei, p. 736.

4) Monitorul oficial 1869 2. Decembre.

5) Xenopol, Domnia lui Cuza - Voda, Jassy 1903, Bd. II, p. 186. 
ersten Jahre iler Regierung noch stark erhöht. - Das Budget der Walachei wuchs von 40000000 Lei in 1859 auf $740000001860^{1}$ ) und dasjenige der Moldau von 22000000 1859 auf 44000000 Lei $18(50 \%$. Die Ausgaben wurlen vermehrt, aber an die entsprechenden Deckungsmittel nicht gedacht; die Eimnahmen waren höher geschätzt als sie in Wirklichkeit waren, so daß das Gleichgewicht zwischen Ausgaben und Einnahmen, wie dies bei einer geordneten Finanzwirtschaft (ler Fall sein soll ${ }^{3}$ ), fehlte. So wurden die tatsächlichen Einnahmen der direkten Steuer von 53000000 Lei auf 76000000 Lei, die (ler Stempelsteuer von 27000000 auf 38000000 geschätzt ${ }^{4}$ ), ohne Rücksichtnahme auf die durch so verschiedene Umstände bedingte Insicherheit der Höhe dieser Einnahmen. So wollten z. B. die früheren Privilegierten die Stenern nicht zahlen und suchten sich ihren Verptlichtungen soweit als möglich zu entziehen ${ }^{5}$ ). In der Thronrede vom 4. Dezember 1861 wird u. a. ausgeführt: „Die größte Schwierigkeit hestand darin, in Lande ein auf der Gleichheit basierendes Stenersystem statt iles hisher auf Privileg beruhenden einzuführen $\left.{ }^{6}\right) . "$ Auch die Nachlässigkeit der Behörden bei der Einkassierung der Steuern, sowie der Mangel einer regelrechten Rechnungsführung trug viel dazu hei, den Unterschied zwischen Einnahme und Ausgahe zu vergrößern. Wenn wir ferner noch in Betracht ziehen, daß die Kammern kein Bestrehen zeigten, das Budget zur rechten Zeit zu votieren, wie sich aus den Worten der Thronrerle ergiht: ,Seit Besteigung meines Thrones konnte man nur ein einziges Budget votieren und auch dieses erst 6 Monate nach Beginn des Finanzjahres ${ }^{7}$ )", so mußten selbstverständlich bedeutende Defizite entstehen und die schon geschilderte, den Verhältnissen nicht entsprechende günstige Veranschlagung der Einnalmen zu unberechtigter Steigerung der Ausgaben und weiteren Fehlbeträgen führen ${ }^{8}$ ). Statt die Ausgaben soweit als möglich zu beschränken und durch eine strenge Steuerkontrolle und Heranziehung neuer Steuerquellen zu einer Vermehrung der Einnahmen beizutragen, gringen die verschiedenen Regierungen auf dlem alten Wege weiter.

\footnotetext{
1) Monitorul oficial, al tärei Rominesti 1860,13 . Octobre.

2) Monitorul oficial al Moldovei 1860 10. August.

3) Eheberg, Finanzwissenschaft, Leipzig 1898, S. 321.

4) Expunerea proectuli de budget pe anul 1863.

5) Xenopol, Domnia lui Cuza. Voda Vol. II, p. 187.

6) Monitorul oficial al Moldovei 18619 . Decembre.

7) Monitorul oficial al Moldovei 18619 . Decembre.

8) Eheberg a. a. O., s. 323.
} 
Zur Deckung der Ausgaben wurde durch das Gesetz rom 5. März 1862 das System der Schatzanweisungen eingeführt, weil man eine Anleihe im Auslande für nicht ratsam hielt $\left.{ }^{1}\right)$. Wegen des Mangels an Geld waren die Anleihen mit großen Opfern verbunden, wurden des weiteren aber auch nicht zweckentsprechend angewendet. Es konnte daher nicht aushleiben, daß in den folgenden Jahren wiederum neue Anleihen erfolgten, was schließlich zur Gewohnheit wurde 2) und (lal. die Aufnahme nener Anleihen nur unter größten Schwierigkeiten und erschwerenden Bedingungen möglich war. So erklïrte sich z. B. der Bankier Halfon bereit, dem Staat einigeMillionen Lei zu borgen, wenn ihm die Zolleinnahmen verpfändet würden. Im Jahre 1864 wuchsen die Ausgaben von 127 Mill. auf 204 Mill. Lei ${ }^{3}$ ). In diesem Jahre hatte der Staat neben den ordentlichen Ausgaben auch noch 12 IIIll. Lei den Gemeindekassen und den rechtlichen (ielddepositen zurückzuzahlen ${ }^{4}$ ).

Diese finanzielle Notlage zwang die Regierung, Mittel und Wege zu suchen, um dem Bankrott, der den Staat bedrohte, zurorzukommen. Sie richtete ihr Augenmerk vor allem auf den Tabak, in der richtigen Annahme, daß durch dessen rationelle und ausgiebige Bestenerung eine bedeutende und sichere Einnahmequelle zur Deckung der wachsenden Ausgaben sich ergeben würde. Die Wahl des Steuerobjektes beweist, dab die Tabalibestenerungsfrage eine Lieblingsheschäftigung der Finanzmänner in Zeiten der Geldnot ist. Der Staat vindizierte sich das Recht und die Pflicht, die Ergiebigkeit der Tabakstener als eine gerechtfertigte Abgabe in der größtmöglichsten Weise auszunutzen; dies war bei der bisher bestehenden Tabaksteuer, bei welcher von einer Vermehrung der Einnahmen keine Rede sein konnte, nicht möglich. Bei der momentanen finanziellen Lage Rumäniens war es dringend nötig, einen Modus der Bestenerung in Vorschlag zu bringen, dessen finanzielles Resultat zur Füllung der leeren Staatskasse in hervorragendem Maße beitrug.

Die hohen und sicheren Einkünfte, die der Tabak den Monopolländern gewährte, dienten als Beweggrund für die Einführung des Tabakmonopols, wodurch die für den Staat notwendigen Summen wenigstens zum Teil besehafft werden sollten. Die Einführung geschah durch das Gesetz vom 5. Dezember 1864.

1) Monitorul ofical 1862 26. Febr.

2) Monitorul oficial 1869, 11. Dec.

3) Xenopol, Domnia lui C. Vol. II, p. 191.

4) Monnitorul oficial 1864, 13. Juli. 
Diesem Gesetz gemäß hatte das eingeführte Monopol den Charakter eines Vollmonopols, denn der Staat behielt sich ausschließlich das Recht des Tabakbaues, der Fabrikation und des Verkaufs vor. Der Tabakbau durfte entweder nur für die Regie oder nur für den Export hetrieben werden. Der Tabakpflanzer mubte sich in jedem Jahre eine Erlaubnis 7.mm Tabakanbau auf 50 qm Ackerland von der Regieverwaltung besorgen; die Erlaubnis war persönlich und wurde von einer speziellen Kommission erteilt. welche aus dem Präfekt des Bezirks, dem Bezirksfinanzkontrolleur und aus einem Mitglied des ständigen Bezirksrats bestand. Der Tabakpflanzer war rerptlichtet, die ganze erlaubte (ríundtürche zu bebauen, die er aber ohne Genehmigung der Regie nicht übertragen dlurfte. Die gesamte Tabakernte mußte er der Regie liefern. Wenn die Ernte, infolge irgend eines Unfalles, nicht die erwartete Quantität brachte, so sollte dies der TabakpHlanzer den hetreffenden Behörden kund gehen. Die Erlaubnis, Tabak zum Export zu bauen, wurde nur solchen Personen bewilligt, die behördlicherseits als zahlungsfähig anerkannt waren. Der Tabakexport mußte bis zum 1. August des folgenden Erntejahres stattfinden. Man hewilligte eine Verlängerung von einem Monat, wenn die gleiche Quantität konstatiert war. Falls wegen einer gerechtfertigten Ursache der Export nicht stattfinden konnte, wurle noch eine Verlängerung gestattet, aber in diesem Fall war der Tabakpflanzer verptlichtet, die Tabakernte in die Lagerhäuser der Regie zu hringen und dafür eine bestimmte Gebühr zu zahlen.

Das Gesetz enthielt ferner Maßnahmen in Bezug auf die Fabrikation, Bezirksmagazine, den Verkauf, die (ieneralverwaltung, sowie IIaßregeln verbietender und strafender Art. Alle Tabalihändler und Privatpersonen waren verpflichtet, ihren Vorrat an Tabak bis zum 1. Mai 1865 zu exportieren: andernfalls mubten sie denselben an die Regierung verkaufen, und zwar zu folgenden Preisen: für 1 Oka türkischen Tabak erster Qualität 38 Piaster; für 1 Oka geringerer Qualität 22 Piaster; für 1 Oka persischen Tabak, je nach der Qualität, 7-16 Piaster; für 1 Oka rumänischen Tabak von tür?ischem Samen, je nach der Qualität, 7-12 Piaster; für 1 Oka rumänischen Tabak von rumänischem Samen 2-7 Piaster. Diese von der Regierung bezahlten Preise waren um 100 Proz. niedriger als die, zu welchen die Tabakhändler den Tabak verkauften. Das liefert den Beweis, welchen ungeheuren Nutzen die Tabakhändler bei ihrem Geschäft gehabt haben.

Freilich ging die Wandlung der Tabakaccise zum Monopol nicht olme Kämpfe ah; heftige Angriffe erfolgten und die Interessenten 
waren damals sehr erregt, denn das neue Gesetz brachte dem Tabakhandel. welcher allein zu jener Zeit in Rumänien noch blühte ${ }^{1}$ ), starlie Störung. Das Gesetz liomnte wegen der großen Unzufrierlenheit, die in Lande herrschte, nicht in Liraft treten und wurde zurüicligestellt ${ }^{2}$ ). Der Fürst Cuza kam aber wegen der dringenden Finanznot auf sein Dekret zurück und setzte durch den fürstlichen Beschlıß rom 3. Juli 1865 das Gesetz von 1864, allerdings in vollständig veränderter Form, wieder in Kraft. Der Staat behielt nur das Recht des Tabakverkaufs, er hatte also ein Handelsmonopol. Er verkaufte den Rohtabak durch seine Spezialagenten und den rerarbeiteten Tabak durch Debitanten, indem er die Tabakfabrikate sowohl aus dem In- als aus dem Auslancle bezog: Die Debitanten bekamen einen Rabatt von 20 Proz. aus ıem Reinertrag. Die Beamten des äuberlichen Dienstes sollten Garantie leisten, nämlich: die Chefs der Zentralmagazine eine solche von 25000-30000 Lei, je nach der Bedeutung des Magazins; die Chefs der Bezirksmagazine 15000 Lei, die Magazinaufseher I. Ǩlasse 12000 Lei und II. Klasse 8000 Lei; für die anderen Beamten verlangte man die Garantie einer als zahlungsfähig anerkannten Person. Das Gesetz trat am 1. August in Kraft. Die außerordentlich hohen Preise des Verkaufstarifs seitens der Regierung - der Fiskus beanspruchte einen Nutzen von 100-300 Proz. im Vergleich zu den früheren Preisen - verbunden mit der Unzufriedenheit der Tabakhändler und -ptlanzer, riefen aber eine so grobe Erbitterung und Aufregung gegen die Regierung hervor, daß sich am 3. Angust ${ }^{3}$ ) ein nicht unbedeutender Aufstand in Bukarest erhob, welcher nur mit Gewalt nach zweistündigem Kampf unterdrückt werlen konnte ${ }^{4}$ ). Diejenigen Tabakhändler. welche nicht rumänische Untertanen waren, wollten die Tabakvorräte der Regie nicht abliefern und bestürmten die lionsulate, um von denselben Schutz zu erlangen; aber nur der österreichische Agent laat im Auftrage seiner Regierung bei dem Ministerrat einen sehr energischen Protest eingereicht, in welchem verlangt wurde, dals der rumänische Fiskus den eingezogenen Tabak bar und nach seinem Werte bezahlen solle. Der russische Konsul hat es den Untertanen seiner Regierung freigestellt, ihre Tabakvorläte nicht abzuliefern, je-

1) Allgemeine Zeitung 1865, Beilage zu No. 5.

2) Sturza, A. D., Treizeci de ani de Domnie ai Regelui Carol, Bukarest Vol. I, p. 70. 1897.

3) Xenopol, Domnia lui Cuza, Vol. II, p. 32.

4) Henke, Rumänien, Land und Volk, Leipzig 187\%, S. 101. Allgemeine Zeiturig 1865, No. 229.

Volkswirtschaftl. u. wirtschaftsgeschichtl. Abhandlungen. H. 4. 
doch mit der Bedleutung, daß sie dieselben auch nicht verkaufen dürften ${ }^{1}$. Es war eine Zeit, in welcher die fremden Händler frei schalten und walten konnten ohne Rücksicht zu nehmen auf das nationale wirtschaftliche Streben. Ihre Interessen fanden Schutz durch ihre Regierungen und diplomatische Interventionen. Sie konnten die Donaufürstentümer ausbeuten, ohne zu den Lasten des Staates, aus welchem sie jhren reichen Gewinn zogen, irgend etwas beizutragen, wozu gerade sie am ersten in der Lage waren, weil sie nicht nur zahlreicher, sondern auch reicher als die rumänischen Händler waren. Auch dieses Gesetz ließ viel zu wünschen übrig. Vor allem führte es das Tabakhandelsmonopol ein, diejenige Form des Monopols, welche im Vergleich zum vollen Monopol sehr nachteilig ist. Sie erheischt eine viel strengere Kontrolle und kann doch nicht die hohen Erträge sichern, wie es das volle Monopol tut, denn der An- und Verkauf des Tabaks bietet den Beamten reichlich Gelegenheit, den Fiskus zu betrügen. Deshalb ist diese Form nur da durchführbar, wo man auf einen ausgebildeten und pttichtbewußten Beamtenstand rechnen kann, was leider zu jener Zeit in Rumänien nicht derFall war.

Von Anfang an wurde den Mißbräuchen seitens der Monopolbeamten Tür und Tor geöffnet. Der Ankauf der Tabakware sollte durch Kommissionen Sachverständiger geschehen, deren je eine für jeden Bezirk bestimmt war. Diese Kommissionen aber haben den Tabak verschieden klassifiziert, denn eine Norm wurde für die Kontrolle dieser Krlassifizierung nicht festgestellt; viele haben ver(lorbene Tabakiblätter und-fabrikate und solche ohne Wert angenommen; und niedrige Tabakqualitäten wurden als höhere abgeschätzt ${ }^{2}$ ). Daneben bezahıte die Regierung den früheren Tabakhändlern eine Entschädigung ron 15 Proz. aus ihrem Geschäftsgewimn, so daf die Regierung eine Summe ron 19600000 Lei ausgeben mußte. Wegen des Nangels an Debitanten verkaufte der Staat dieselbe Tabakware wiedler an den früheren Tabakhändler mit einem Rabatt von 20 Proz. Da das Gesetz die Verpackung der in den Handel kommenden Tabakwaren nicht vorgeschrieben hatte, was das einzige Nittel gegen die Steuerhinterziehung ist und auch dem Fiskus sichere Erträge gewähren konnte, wurde den Debitanten die (ielegenheit gehoten. den Staat durch Schmuggel und das Publikum durch die Vermischung verschiedener Tabaksorten zu betrügen.

1) Allgemeine Zeitung No. 1865, 229 .

2) Sturza, a. a. O. S. $71 \mathrm{ff}$. 
Die Monopolverwaltung ließ sehr viel zu wünschen übrig, sie besaß alles andere nur nicht die Eigenschaft einer guten und geschickten Verwaltung. Der Ankauf des Produkts bedingte eine Reihe von einzelnen Maßregeln, die theoretisch wenigstens nicht bestimmt waren, da kein Reglement bestand; hieraus entsprang eine Willkïrherrschaft der einzelnen Beamten und Debitanten, welche an sich schon zu verwerfen war, dem Monopol selbst aber nur zum Schaden gereichen mußte. Mit Recht wird in der Rede des Regierungsrates vom 28. April 1866 folgendes angeführt: „In der Verwaltung des Tabakmonopols - wemn man überhaupt noch von Verwaltung und Monopol reden kann - ist dem Staate wie dem Publikum eine doppelte Lockspeise dargeboten worden, und beide, Staat wie Publikum, sind darauf hineingefallen; beide wurden die Opfer der Habsucht der Tabakdebitanten und derjenigen Personen, die mit der Einführung und Verwaltung dieses Monopols beauftragt wurden ${ }^{1}$ )."

Zweifellos konnte auch unter solchen Umständen das Tabakmonopol dem Fiskins nicht die Einnahme bringen, auf welche gerechnet wurde. Während der ganzen Zeit seines $1 \frac{1}{2}$ jährigen Bestehens hrachte rlas Tabakmonopol 14711527 Lei als Bruttoeimnahmen und 5500000 Lei als Nettoeinnahmen, d. h. die Ausgaben im Betrag von 10211527 Lei betrugen 63 Proz. der Gesamteinnahmen. Wie klein diese Eimnahmen waren, ergibt sich aus der Tatsache. daß zwei Privatgesellschaften im Laufe dieser Zeit um die Pachtung des Tabakmonopols sich bewarben. Eine Gesellschaft griechischer Kaufleute") stellte der Regierung den Antrag, das Tabakmonopol für 24 Jahre in Pacht zu nehmen und ihr für je eine Periode von 6 Jahren jährlich folgende Summe zu zahlen $\left.^{3}\right)$ :

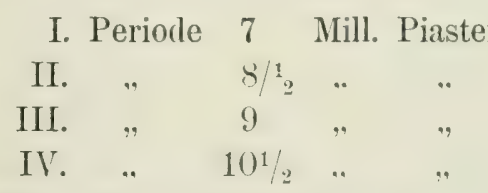

Eine lediglich zu diesem Zweck konstituierte Gesellschaft unter dem Namen „Erste rumänische Gesellschaft für das Tabakmonopol", deren Betriebskapital von 40 Mill. Piaster in $400(00$ Aktien zu 1000 Piaster geteilt war ${ }^{4}$ ), machte ein noch vorteilhafteres Angebot, und zwar wollte dieselbe zahlen:

1) Allgem. Zeitung, Beilage zu No. 336, 1865.

2) Sturza, a. a. O. S. 83.

3) Allgem. Zeitung, 1865, No. 135.

4) Monitor offic. 1871, No. 272. 


$\begin{array}{ccccccc}\text { für die } & \text { I. } & \text { Periode } & 12 & \text { Mill. } & \text { Piaster } \\ ", & " & \text { II. } & " & 14 & . & " \\ " & " & \text { III. } & . & 16 & . & " \\ . & . & \text { IV. } & . & 18 & . . & "\end{array}$

Die erzielten kleinen Einnahmen beweisen, daß das Tabakmonopol nur damn die Möglichkeit bietet, erhebliche Einnahmen aus dem Tabak zu ziehen, wenn es gut verwaltet wird. Dieser unbefriedigende Erfolg des Monopols sowohl, zu welchem der Mangel an geeigneten und gewissenhaften Beamten, die ungünstigen politischen V'erhältnisse und der hartnäckige Widerstand der Tabakhändler viel beigetragen haben, als auch die zunehmencle Unzufriedenheit der Konsumenten mußten naturgemäß zur Abschaffung des Tabakmonopols führen, welches vorher mit so großer Mühe und Schwierigkeit eingeführt war, dies geschah schon nach einer Dauer von nur $1 \frac{1}{2}$ Jahren, in welcher Zeit es so schlecht verwaltet wurde, daß Universitïtsprofessor Disescu (Bukarest) mit Recht sagen konnte: „Ich weif nicht, ob das Tabakmonopol wirklich funktioniert hat 2)." Durch das Gesetz vom 27. Januar 1867 wurde es aufgehoben und der Tabakhandel erfreute sich wieder der Freiheit. Es wurde demselben nur ein Einfuhrzoll auferlegt, nämlich:

$$
\begin{array}{ccc}
\text { für } 1 \mathrm{~kg} \text { Rauchtabak } & 16 \text { Lei } \\
" 100 \text { Zigarren } & 16 \text { " } \\
\text { " } 1 \mathrm{~kg} \text { Schnupftabak } 20 \text { ", }
\end{array}
$$

ohne Unterschied der Qualität.

Der Tabakexport war frei von jeder Gebühr. Die Tabaktrafikanten multen eine Lizenz vom Staat besitzen und waren nach dem Umfang

\begin{tabular}{|c|c|c|c|}
\hline zweite & $n$ & 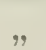 & 740 \\
\hline dritte & " & $"$ & 370 \\
\hline vierte & $"$ & $"$ & 185 \\
\hline fünfte & $"$ &, & 37 \\
\hline
\end{tabular}
des monatlichen Verkaufs in 5 Klassen eingeteilt:

Die erste Klasse bezahlte 1480 Lei v.

Dieselben verkauften die Tabakfabrikate nach Belieben, aber sie waren verpffichtet, eine gewisse Quantität pro Monat von der Regie anzukaufen, um die in den Regiemagazinen noch lagernden Tabakmengen zu räumen, da ein Verkauf in anderer Weise nicht angängig erschien. Der Ausverkauf fand nach folgendem Tarif statt:

Türkischer Tabak, genannt Jaka 1 Oka 28,50 Lei

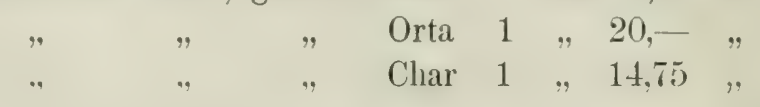

2) Disescu, C. G., Dreptul public Romān, Bukarest, Bd. III, S. 1094. 
Tabak, genannt Persicean oder Basma

$\begin{array}{lrrr}\text { I. Qualität, Oka } & 12,50 \text { Lei } \\ \text { II. } \quad " \quad & \quad & 10,75 & \\ \text { III. } \quad, \quad & 9,50 & ,\end{array}$

Rumänischer Tabak von tiirkischem Samen

$\begin{array}{llll}\text { I. Qualität, Oka } & 9,50 \text { Lei } \\ \text { II. } \quad " & " & 6,75 & \\ \text { III. } \quad " & " & 6,- & \end{array}$

Rumänischer Tabak von einheimischem Samen

$\begin{array}{llll}\text { I. Qualität, Oka } & 5,- & \text { Lei } \\ \text { II. } \quad " \quad \text { " } & 3,- & . . \\ \text { III. } & \text {. } & 2,- & \end{array}$

Russischer Tabak (Mahorka) Oka 3,- Lei

Havannazigarren I. Qualität pro 100 Stück 35,75 Lei

II. $\quad . \quad \ldots 100 \quad$.. 17.0$) \quad$..

Ausländische Zigarren verschiedener Qualität, pro 100 Stück 8,50 Lei

Einheimische Zigarren I. Qualität pro 100 Stück 4,70 Lei

II. . . $100 \quad, \quad 3,35 \quad$.

Schnupftabak Carot I. . . . Oka " 20,- . .

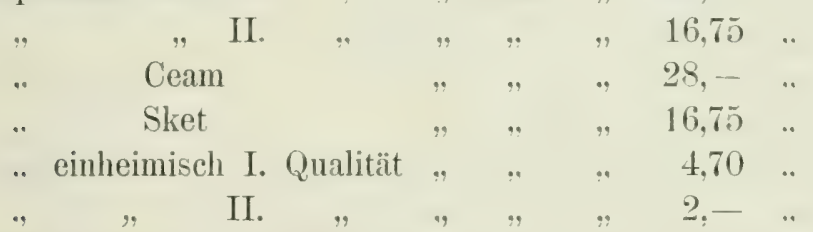

Dieser Maßregel gemäß hoffte die Regierung in 2 Jahren ihren sämtlichen noch lagernden Tabak ausverkaufen zu kïmnen und damit noch einen guten Ertrag zu erzielen. Diese Hoffnung erfüllte sich nicht. Die Schuld daran lag wiederum an der Nachlässigkeit der Verwaltung hinsichtlich der strikten Durchführung der ron der Regierung lezüglich des Verkaufs des Tabaks erlassenen Verfügungrg. Dic noch vorhandenen Tabakmengen wurden nicht ausverkauft. Die Regierung sah sich genötigt, den gesetzgebenden Kö̈rperschaften einen Gesetzentwurf vorzulegen, welcher einen doppelten Zweck hatte: einerseits den unbedingten vollständigen Ausverkauf des in den Regiemagazinen gebliebenen Tabals, andererseits die Einführung einer ausgiebigeren Besteuerungsart als das frühere Srstem, welches in dem Zeitraum von 181', Monaten ${ }^{1}$ ) nur 3408 14² Piaster ${ }^{2}$ ) an Eimnahmen einbrachte. Der Gesetzentwurf schlug eine (iewichtssteuer ron to Bani

1) Seit dem 27. Januar 1827 bis 12 . August 1868 .

2) Monitor ofic. 1871 , No. 272. 
pro Kiilogramm inländischen Tabaks ror, olne Unterschied der Qualität. Er wurde angenommen, und als Gesetz trat er am 31. Mai 1868 in Kraft.

Infolge dieses Gesetzes sollten die Tabakpflanzer einer dazu bestimmten Kommission den Ausfall der Tabakernte in Büscheh und Hanfen ${ }^{1}$ ). sowie das Gewicht des geernteten Tabaks bekannt geben. Die Deklarationen wurden von dem Lnterkassierer des Bezirks geprüft hezw. kontrolliert. Ungenaue oder unterlassene Deklarationen wurden mit Creldstrafen geahndet, jerloch wurle eine Minderdeklaration bis zu 15 Proz. des Gesamtgewichts zugelassen. Die Einkassierung der Tabakstener geschah im Monat Juli des nach der Ernte folgenden Jahres durch den Steneremnehmer, denen ein Rabatt ron 21/2 Proz. bewilligt war. Der Tabakhandel war, wie früher, frei, aber die Tabaktrafikanten waren gesetzlich rerpflichtet, pro Monat eine der Klasse des Debits entsprechende bestimmte Menge Tabakfabrikate im Werte ron 37 bis 1480 Lei aus den noch im Besitz des Staates befindlichen früheren Monopolbeständen zu entnehmen, um dem Staate die Möglichkeit zu bieten, seine Tabakvorräte vollständlig ausverkaufen zu liömen. Der Tahakhandel blieb unberücksichtigt, wurde demnach ebenso wie der mit allen anderen Waren betrieben.

Der zur damaligen Zeit bestehende Tabakeinfuhrzoll wurde erhöht und man bezahlte:

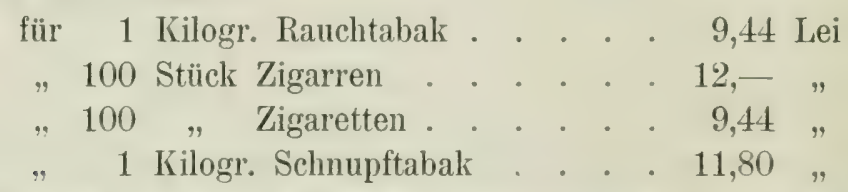

Den Reisenden war aber für ihren persönlichen Gehrauch ohne Einfuhrzoll der Import von 600 g Rauchtabak lose orler in Zigarettenform, oder 50 Stiick Zigarren, orler $150 \mathrm{~g}$ Schnupftabak, ohne Unterschied der Qualität, erlaubt. Einfuhrzollfrei waren ferner die für den persünlichen Gebranch ler Vertreter der verschiedenen Mächte in Rumänien eingeführten Tabakfabrikate. Der Export war ebenfalls zollfrei; in diesem Falle wurde die Steuer ron to Bani pro Kilogramm zurückgegeben.

Das neue Besteuerungsystem brachte weder den Tabakpflanzern noch dem Fiskus Vorteil. Den Tabakipflanzern war es nachteilig, weil dieselben neben dem Betrielsskapital noch das zur Bezahlung der Steuer notwendige Kapital besitzen mußten, demn sie waren rerpflichtet, die

1) Die Kommission bestand aus dem Bürgermeister, Pfarrer und Lehrer des Dorfes, wo die Tabakernte lag. 
Steuern zu bezahlen, ehe sie die Ernte verkauften. Weil die meisten Tahakpflanzer aus lileinen Landwirten hestanden, die iiher ein grofies Kapital nicht verfügten, waren sie, um die Steuern zahlen zu können, genötigt, die Ernte zu jedem Preise zu verkaufen. Der Stenerfuß von 40 Bani pro Kilogramm war zu hoch und dadurch sehr drückend, dies um so mehr. wenn man herücksichtigt, dafi infolge der primitiven Anbaumethode der durchschnittiche Ertrag eines ha :300 kg betrug. Der Tabakpflanzer sollte aber als Steuer 190 Lei bezahlen, während der Bruttoertrag eines ha nur 270 Lei ergab, da die Preise für Rohtabak sehr niedrig waren; ein Kilogramm desselben kostete 90 Bani. Aber auch dem Fiskus war die Gewichtsstener nicht günstig. Die Kontrolle wurle von den L'nterkassierern ausgeüht: dieselhen komnten ilı Amt nicht gewissenhaft versehen. weil sie von Zirkumskription zu Zirkumskription gehen mußten; auferdem hatten sie anch noch anderweitige Amtsptlichten zı erfüllen, so daß eine tatsächliche liontrolle illusorisch wurde und der Steuerhinterziehung hinreichend (relegenheit zur Betätigung gegehen war Dem entsprachen die Einnahmen, nämlich vom 12. August bis Ende des Jahres

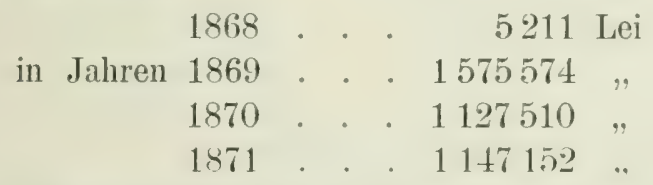

Wie ein Rückblick uns zeigt, war der Tabak in dem Zeitraum von 7 Jahren drei Besteuerungssystemen unterworfen: einem Tabakhandelsmonopol, einer Handelssteuer und einer Gewichtsteuer. In dieser ganzen Periode erlitt der Tabakbau keine Einschränkung. er war frei, doch konnte er keine Fortschritte machen. Im Gegenteil bemerken wir große Schwankungen sowohl in der Größe der dem Tabakbau dienenden Bodenfläche als auch in der durchschnittlichen Produktion, wie aus folgender Tabelle ersichtlich ist ${ }^{1}$ ).

\begin{tabular}{l|c|c|c}
\hline \hline Jahre & Hektar & $\begin{array}{c}\text { Die gesante } \\
\text { Produktion } \\
\mathrm{kg}\end{array}$ & $\begin{array}{c}\text { \% } \mathrm{kg} \\
\text { pro Hektar }\end{array}$ \\
\hline 1865 & 3602 & 1347148 & 374 \\
18665 & 2818 & 676753 & 240 \\
1867 & 2371 & 944627 & 398 \\
1865 & 1161 & 531421 & 457 \\
1869 & 2131 & 504934 & 237 \\
1870 & 3114 & 1002022 & 321 \\
1871 & 3207 & 1313541 & 409
\end{tabular}

1) Die Ziffern sind aus Monitorul oficial vom 20. Martie 1879 entnommen. 
Diese Schwankungen finden ihre Erklïrung in den verschierlenen Bestenerungsversuchen und den schon in dieser Periode bestehenden Besteuerungssystemen, die nicht ohne Einfluß auf die Tabakkultur bleiben konnten, denn der Tabakpflanzer hatte nicht mehr den Mut, seine Kräfte (lem Tabakbau zu widmen, da er tagtäglich gewärtig sein mufte, einem neuen Besteuerungsystem unterworfen zu werden. Tom finanziellen Standpunkt aus aher betrachtet, charakterisiert sich diese Periode in Anbetracht der Stenerkraft des Tabaks als wenig einträglich, denn in diesem 7 jährigen Zeitraum lieferte die Tabakstener den Gesamtbetrag von: 12520902 Lei r., also einen jährlichen Durchschnittsbetrag von 1788715 Lei v.

Auf die durchschnittliche Bevölkerung dieser Periode von 4131349 Seelen ${ }^{1}$ ) kommt also pro Kopf 0,43 Lei v., ein viel zu geringes Steuermaß, wenn wir uns die große Stenerkraft des Tabaks vergegenwärtigen. Die Ursachen liegen teils in der Natur der eingeführten Tabakbestenerungsysteme selbst, teils in der schlechten Verwaltung, welche im Anfang dieser Periode in allen Zweigen des öffentlichen Lebens herschte und in der Beantwortung der Tronrede rom 27. Dezember 1866 folgendermaken geschildert wird: „Die sichtharen Mißbräuche in unserem Lande in den verschierlenen Zweigen der öffentlichen und der Gemeinde-Terwaltung entspringen aus der Anarchie und der bei uns eingeführten Licenz, unter dem Druck ron Ideen und Bestrehungen, die nachdem sie so traurige Resultate gezeitigt haben, vom ganzen Land verurteilt werden. Der Mangel einer Kontrolle, der Mangel einer strengen V'erantwortung derjenigen, denen öffentliche Gelder zur Verwaltung anvertraut sind, hat den Mißbräuchen in einem bisher noch nie gekannten Grade die Türen geöffnet $\left.{ }^{2}\right)^{\text {". }}$.

1) Der Bevölkerungsdurchschnitt ist nach den Angaben in Alexandrinis Statistik, S. 94 gerechnet.

2) Allgem. Zeitung, No. 4, 1867. 


\section{Wiedereinführung des Tabakmonopols.}

Als Fürst Karl von Hohenzollern am 10. Nai 1866 den Thron Rumäniens hestieg und dadurch den allgemeinen W'unsch der 5 Nillionen Rumänen, die ihr Schicksal ihm anvertrauten, erfüllte, fand er eine hedrohte finanzielle Lage vor, die eine hesondere Aufmerksamlieit erforlerte und eine schmelle und sichere Abhïlfe verlangte. Leider hatte der Fürst Cuza bei seinem unfreiwilligen Rücktritt die Finanzen des Landes in einem derartigen Zustande hinterlassen, daß selbst bei größter Ordnung und Sparsamkeit Jahrzehnte notwendig waren, um die entstandenen Schäden auszugleichen und den Kíredit dles Landles wiedler auf die Höhe zu erheben, auf der er vor der unverantwortlichen Wirtschaft der letzten Regierung gestanden hatte. Trotz ilem Eifer, womit Fürst Karl in alle Einzelheiten der verschiellenen Verwaltungszweige Einsicht zu nehmen und Mißbräuche alozustellen suchte. gelang es ihm vorerst nicht, Rumänien auf gesunde politische und wirtschaftliche Bahnen zu lenken. Das Übel saß zu tief und hatte sich zu fest eingewurzelt, um es mit einem Schlage beseitigen zu können; dazu gehörten Jahre, vielleicht viele Jahre, wenn nicht Jahrzehnte.

Anfang des Jahres 1867 gaben die Zeitungen von der Lage Rumäniens ein sehr trauriges Bild. „Romînul” äuljerte sich folgenderweise: „Demoralisation und Verderbtheit herrschen in der Justiz und der Verwaltung; der Handel ist in der größten Not. Vollständige Verarmung hedroht einen großen Teil des Landes. Der Staat ist mit Schulden belastet; die Steuern sind so hoch, daß sie nicht mehr zu erschwingen sind, und ein naher Untergang steht zu erwarten ${ }^{1}$ )". Trotzdem bemühten sich die Finanzpraktilier Rumäniens nicht dem Ühel zu steuern, und die schlechte finanzielle Lage bestand weiter fort. Die Budgets stellten nur ein scheinbares Gleichgewicht zwischen den Einnahmen und den Ausgaben her, denn unter den Eimmahmen befanden

1) Romînul 1867 , 3. Januar. 
sich verschierlene Posten, deren Höhe illusorisch war. Deshalh schloB naturgemäß jedes Jahr mit einem größeren orler kleineren Defizit ab. Wegen der Höhe der Stewern und der Undurchführbarkeit des kostspieligen aus Frankireich eingeführten Stenererhehungssystems blieben grobe Stenerrückstände. Beim Antsantritt Mavrogheni's als Finanzminister im Jahre 1871 hetrugen dieselben 10 Millionen Lei ${ }^{1}$ ). Von Tag zu Tag wuchs die Finanznot, so daß im Jahre 1871 die staatliche Existenz Rumäniens selbst bedroht war. Der Tribut an die Hohe Pforte für das Jahr 1870 war noch nicht bezahlt und wurde eingefordert, aber die Staatskassen enthielten selhst nicht eimmal den fälligen Betrag von $3896+1 / 2$ türkische Lire $(865000$ Lei). so dafo das Finanzministerium einen Wetthewerb für diejenigen Bankiers auszuschreiben genötigt war, welche die Zahlung des Tributs für Rechnung der Regierung vorschußweise zu übernehmen geneigt sein sollten ${ }^{\circ}$ ). In einem an die Präfekten der Landeshezirke erlassenen Rundschreiben legte der Minister des Imnern. Catargiu, die finanzielle Lage folgendermaßen dar: „Der Staat befand sich damals in einer schrecklichen Lage, die Kassen waren erschöpft und von Gläubigern bedrängt, die Beamten warteten auf Gehalt, die Armee auf Sold, die Kreditlosigkeit war allgemein $\left.{ }^{3}\right) . "$

Dieser finanziellen Katastrophe lionnte die damalige Regierung nur dlurch eine Anleihe entgegentreten. Aber das Gelr war auf den europäischen Märkten wegen der großen von Frankreich zu leistenden Kriegsentschärligung schwer zu bekommen. Der Staatsmechanismus Rumäniens wäre dlamals auf alle Fälle lahm gelegt worlen, wenn die Banque de Roumanie der Regierung nicht noch Hilfe geleistet und $1 \frac{1}{2}$ Millionen Francs geliehen hätte. Damit machte man aber der finanziellen Not kein Ende. Die damalige Regrierung wurde nummehr gezwungen, das Buclget von 1872 gegen das Vorjahr um 11 Millionen Lei Ausgaben zu verringern (Allg. Ztg., No. 134, 1871), und man samn gleichzeitig auf Mittel, der Staatskasse neue Einnahmequellen zu eröffnen.

Zweifellos konnte bei diesem Bestreben ein so ergiebiger Gegenstand, wie der Tabak, nicht unberiicksichtigt bleiben. Die Regierung wies wiederum auf ihn hin, als auf das heilliräftige Krraut, das jedes Finanzgebrechen heilen könne. Man beschlof die Wiedereinführung des Tabakmonopols, welches als die beste Besteuerungsart des Tabaks

i) Allgemeine Zeitung, Beilage zu Nr. 97, 1871.

2) Allgemeine Zeitung, Nr. 131, 1871.

3) Allgemeine Zeitung, Nr. 134, 1873. 
angesehen wurde, da sie dem Staat hohe und sichere Erträge zu gewähren imstande sei. Die W'ierlereinführung des Tabalimonopols erschien zur Verbesserung der Finanzlage durchaus notwendig, und es wurde dies in der Thronrede von 1871 folgendermaßen dokumentiert: .Meine Regierung wird die Votierung der schon in früheren Sitzungsperioden vorgelegten Entwürfe des Tabakmonopols 11. a. m. unterstïtzen und verlangen. Diese Gesetzentwürfe sind durchaus notwendig und so schnell wie möglich zur Beratung zu bringen, damit bei Beginn des künftigen Jahres die Sicherheit geboten ist, sämtliche Staatsausgaben ordnungsgemäß regeln zu können und nene finanzielle Schwierigkeiten vermieden werden, welche die guten Erfolge des Werkes, das wir Alle übernommen haben, illusorisch machen würden ${ }^{1}$ )."

Denselben Grund finden wir in dem Bericht der Delegiertenkommission. „Zwei Kammersessionen" 2), sagte der Berichterstatter G. Bratianu, ,verliefen, ohne daß dieses fesetz zur Beratung gekommen wäre, weil man wahrscheinlich den Moment des In-Kraft-tretens einer solchen finanziellen Maßregel aufschieben wollte, deren schlechter Eindruck im ganzen Land sich aus früherer Zeit noch fühlbar machte ${ }^{3}$ ). Die Aufschiebungen und die Unschlüssigkeit jener Kammer waren nur noch in einer Epoche möglich, in welcher sich die Burlgetanforderungen nicht in einer" so offenkundigen Weise ermitteln liefen, wie dies jetzt der Fall ist, wo jerler Zweifel ausgeschlossen ist. Die Delegierten waren nicht so staatsmännisch veranlagt, die Vorteile eines bei der Berölkerung so wenig beliebten Bestenerungssystems wie des Monopols stark genug hervorzuheben und ihre Ansichten dem Tolke gegenüber energisch zu vertreten 4)." Die Ausbeutung dieser neuen Einnahmequelle war um so mehr notwendig, als man bereits für das Jahr 1873 ein Defizit von 18 Millionen Lei voraussah. „Sie sehen also", sagte der damalige Finanzminister, „daf. bezüglich der Berechtigung der Besteuerung ein Zweifel nicht mehr besteht. Die von Ihnen verlangten Steuern sind berechtigt, sind dringend erforderlich ${ }^{5}$ )."

1) Sturza, a. a. O. S. 261.

2). Im Jahre 1869 wurde ein Gesetzentwurf zur Einführung des Tabakmonopols vom Finanzminister Golescu vorgelegt, welcher die Einführung des Tabakmonopols als „kointeressierte Regie“ bezweckte. Im folgenden Jahre (1870) legte der damalige Finanzminister Gradisteanu einen neuen Gesetzentwurf vor, der die Einführung des Tabakmonopols als Pachtform bezweckte. Alle beide Gesetzentwürfe kamen aber wegen des oben angegebenen Grundes nicht znr Beratung.

3) Anspielung auf das Tabakmonopol von $1861-1867$.

4) Bratianu, G., Monitorul oficial, Nr. 296, 1871.

5) Monitorul oficial, Nr. 272, 1871. 
Trotzalledem hat die Einführung des Tabakmonopols, die doch zur Verbesserung der Finanzlage Rumäniens unbedingt notwendig war, große Erbitterung hervorgerufen. Wiederum tritt in der altgewohnten Heftigkeit die Agitation der Tabakhändler zur Terteidigung ihrer Forderungen in die Schranken; wenn schon nicht in demselben Grade, wie es im Jahre 1864 der Fall war. Der Grund dieser Unzufriedenheit versteht sich von selbst; die Händler konnten nicht mehr solche kolossalen Gewinne erzielen, wie bisher, wo sie eine Oka Tabak mittlerer Qualität mit 60-70 Lei verkauften ${ }^{1}$ ). Eine Zahl von 20-30 Großtabakhändlern hatte den ganzen Tabakhandel in Händen und diktierte auf dem Markt rlessen Preise. Mit Recht konnte man deshalb sagen, laß das Tabakmonopol schon bestehe, jerloch nicht im Interesse des Staates ${ }^{2}$ ). Bei der Beratung des Gesetzentwurfs in der Kammer wurden von einigen Abgeordneten wieder die allgemeinen Einwände gegen das Tabakmonopol herrorgehoben. Im besonderen beriefen sie sich auf die schon in der Periole ron 1865-1867 gemachten traurigen Erfahrungen und auf die Nachteile, welche damals dem Staate aus dem Tabalmonopol erwachsen waren, wie auch auf die Tatsache. daf diese Nenerung den Sitten und Anschauungen der rumänischen Bevölkerung widerspreche. „Niemals", sagte ein Abgeordneter, „bestand das Tal)akmonopol in unserem Land, niemand hat bei uns je so etwas gesehen. Wohl haben wir eine vorübergehende ähnliche Bestenerung um 1865 gehabt. Wir haben aber auch damals schon die Stimme des Publikums gehört, welche sich so stark gegen diese Nenerung erhob, daß das Tabakmonopol abgeschafft wurde ${ }^{3}$ )."

Die Einsprüche fanden aber bei der Mehrheit keinen Anklang. Dieser stand die Finanznotlage vor Augen und ihr Bestreben war auf deren Beseitigung gerichtet: das wichtigste Hilfsmittel zu diesem Zweck erblickte man aber im Tabakmonopol. Viel heftiger noch wurde die Frage beraten. ob die Regierung das Tabakmonopol in eigener Regie hetreihen oder es einer Privatgesellschaft rerpachten solle. Gegen die Pachtform wurle. wenn auch ohne Erfolg, das große Mißtrauen hervorgehohen, welches man den Konzessionären sntgegenl,ringen müsse. Diese hätten schon verschiedene Unternehmungen anderer Art geleitet und diese in wenig vertrauenerweckender Weise zu Ende geführt. „Ja, sagte der Abgeordnete Jonescu in bezug darauf, „wir haben leider immer an Unternehmungen abgegeben; mir ist nichts bekannt,

1) Monitorul oficial, Nr. $296,1871$.

2) Boliac, Monitorul oficial, Nr. 274, 1871.

3) Monitorul oficial, Nr. 272, 1871. 
was uns geblieben und nicht durch Unternehmungen bewirkt würde: die Eisenbahnen, die Flußbrücken. Sie haben gesehen, was wir mit den letzteren erlebt haben, die Briicken über den Olt und Trotus sind zerbrochen 1)." Trotz alledem wurde das Pachtsystem seines Vorteils halber angenommen, obschon es im allgemeinen zu verwerfen ist, weil zwischen den Staat und den Konsumenten, zwischen den Fiskus und den Steuerzahler eine Mittelperson tritt, die natürlicherweise für ihre Tätigkeit belohnt werlen muß und außerdem sehr oft für die Angehörigen des Staates einen Blutegel darstellt. Unter den herrschenden Umständen jedoch mußte die Wahl der Pachtform als das Zweckentsprechendste angesehen und gutgeheifen werden, dem einerseits lionnte der Staat auf sichere Erträge und V'orschiisse rechnen. und andererseits hätte der Nangel an dem zum Regiebetriebe erforderlichen Kapital, wie dies schon die traurigen Erfahrungen der ersten Tal alimonopolperiode $\left(1 \mathrm{r}\left(i_{5}\right)-186 \mathrm{i}\right)$ bewiesen hatten, auch diesmal die Durchführbarkeit des Monopols unmöglich gemacht.

Dazu trug auch das Beispiel anderer Monopolländer bei, die el,enfalls ursprünglich das Pachtsytem gewählt und zufriedenstellende Resultate damit erzielt hatten, wie z. B. Frankreich, Österreich und Italien. Ein weiterer sehr berechtigter Grund zur Wahl des Pachtsystems beruhte in dem Mangel an geeigneten Beamten für die Ausführung des Tabakmonopols. Das Gesetz wurde von der Nationalversammlung angenommen und trat durch das fürstliche Dekret am 5. Februar 1872 in Kraft. Das Tabakmonopol war also wiederum eingeführt, und zwar als verpachtetes Monopol. Es war ein volles Monopol, und enthielt dementsprechend die drei Zweige der Tabakindustrie: Tabakbau, -fabrikation und -verkauf.

Der Tabakbau wurde durch dieses Gesetz nicht beeinträchtigt; er war im ganzen Lande erlaubt und nur gewissen Malsregeln unterworfen.

Die anderen diesbezüglichen gesetzlichen Bestimmungen waren gleich denen des Gesetzes vom 5. Dezember 1864, die oben bereits erwähnt sind ${ }^{2}$ ). Die Pachtzeit war auf 15 Jahre festgesetzt; sie war in drei Perioden zu je fünf Jahren mit einer Erhöhung des Pachtschillings von $20 \%$ für jerle fünfjährige Periode eingeteilt. Am s. Mai 1872 wurde das Tabakmonopol durch öffentliche Lizitation einem

1) Monitorul oficial, Nr. 274, 1871.

2) S. S. $49,50$. 
großen ungarisch-jürlischen Hause aus Budapest verpachtet ${ }^{1}$ ). Dieses Haus, genannt „Franko-Ungarian Bank ${ }^{6 \%}$ ), machte die „Banque de Roumanie" zur Teilhaberin. Alle beide waren finanziell starke Anstalten und infolgedessen konnte man auf ihre Zahlungsfähigkeit und die Ausführung des Vertrages rechnen. Das Geschäft gestaltete sich also für beide Teile glänzend und am meisten für die Finanzen Rumäniens, da man vorher glaubte, nur 3-4 Millionen Lei für die erste Periode erzielen zu können ${ }^{3}$ ). In dem abgeschlossenen Vertrag ist im wesentlichen bestimmt worden:

1. Die .Franko-Ungarian Bank" ïbernimmt das Recht des Tabakmonopols in ganz Rumänien für eine Periorle von 15 Jahren, welches Recht sie gemäß dem Gesetz rom 5. Februar 1872 ausüben wird.

2. Der Unternehmer soll seinen gerichtlichen Wohnsitz in Rumänien haben und durchaus der rumänischen Gerichtsbarkeit unterworfen sein; er darf keinen fremden Schutz in Anspruch nehmen.

3. Während der Pachtdauer soll die Regie nicht als ein privates, sondern als ein öffentliches Institut angesehen und behandelt werden. Sie ist bezüglich ihrer Geschäftsführung von jeder Gebühr befreit.

4. Die „Franko-Ungarian Bank" verpflichtet sich, eine jährliche Pachtsumme ron 8010000 Lei für die ersten fünf Jahre, 9612000 Lei für die zweiten fünf Jahre und 11534400 Lei für die dritten fünf Jahre in monatlichen Raten pränumerando der Regierung zu zahlen. Unpünktliche Zahlung gibt der Regierung das Recht einer zweiten öffentlichen Lizitation auf Rechnung und Gefahr des Lnternehmers, und dies nur nach einer eimmaligen einfachen Aufforderung zur Zahlung.

5. Die Regierung hat das Recht, über die Einhaltung ihrer Bestimmungen und die Interessen der Tabakpflanzer und Konsumenten zul wachen.

6. Der Unternehmer verpflichtet sich zur Hebung und Förderung der inländischen Tabakkultur, und er ist gehalten, die ganze Quantität des Rohstofies, die für Tabakfabrikate $3 . .4$. und 5. Qualität notwendig ist, nur vom Inlande zu beziehen.

7. Der Unternehmer wird zwei Fabriken, wie auch die notwendigen Magazine auf seine eigenen fiosten bauen lassen. Alle diese Bauten bleiben nach dem Verlauf der Pachtzeit Besitztum des Staates.

1) Aus dem Leben König Karls von Rumänien, Aufzeichnungen eines Augenzeugen, Stuttgart 1894, Bd. II, S. 271.

2) Allgemeine Zeitung, Nr. 89, 1876.

3) Monitorul oficial, Nr. 272, 1871. 
Hieraus ergibt sich, daß der Zweck der rumänischen Regierung nicht nur ein rein finanzieller war, sondern sie wollte auch die Tabakkultur und -industrie im Lande heben und fördern. Wenn nun auch der letzte Zweck nicht voll erreicht worden ist, wie wir spåter sehen werden, so übertraf der erste die kühnsten Erwartungen, denn die Höchstangebote von s, $91 / 2$ und $11 \frac{1}{2}$ Millionen, im Gegensatz zu den je 5 Millionen des Toranschlages der Regierung ${ }^{1}$ ), billeten eine nicht unberlentende Summe bei der ungünstigen Lage der rumänischen Finanzen. Im ersten Jahre der Pacht gestaltete sich die Sache zur Unzufriedenheit der Pächter, die am 11. Juli 1872 mit Genehmigung (ler Regierung in eine Aktiengesellschaft mit einem Betriebskapital von 25 Millionen Lei sich umwandelten. Das Gesetz hatte einige Bestimmungen, die der Pachtgesellschaft nachteilig waren. Dasselbe schrieb vor, daß alle Bauern, die Tabak bauen wollten; verpflichtet seien, der Regieverwaltung kundzugeben, wieviel Hektare sie bebauen wollten; die Regieverwaltung sollte diese Anmeldungen in einem Zeitraum von 10 'Tagen beantworten. Wenn der Bauer in dieser Frist keine Antwort bekam, dann konnte er die angemeldete Anbauflïche mit Tabak bebanen, und die Regieverwaltung war verpflichtet, die Ernte anzukaufen. Die Frist war aber zu kurz bemessen, um seitens der Regieverwaltung alle Anbaubittschriften beantworten zu kömmen. Infolgedessen erhielt die Regieverwaltung größere Mengen Tabak als sie verwenden konnte, und es wurden ihr daher übertlüssige Ausgaben verursacht. Den größten Scharlen erlitt aber die Pachtgesellschaft infolge des Tabakschmuggels, welcher große Ausdehmung gewonnen hatte und dem man nicht erfolgreich entgegentreten konnte, weil das Gesetz keine genügenden diesbezüglichen Bestimmungen enthielt. Dasselbe schrieb nur eine bestimmte Geldstrafe gegen Schmuggel vor, die aber in den meisten Fällen nur illusorisch war, weil die Schmuggler zum größten Teil vermögenslos sind. Außerdem war die Feststellung der Kontrebande sehr schwierig, weil eine Haussuchung nur mit Genehmigung des Tribunalpräsidenten angeordnet werden konnte; die Ausführung dieser Formalität nahm aber $6-7$ Tage in Anspruch, so daß der Schmuggler Zeit hatte, jedes Verdachtsmoment zu beseitigen.

Unter solchen Umständen verlangte die Pachtgesellschaft die Änderung des Gesetzes in dem Sinne, es mit schärferen und sichereren Maßregeln gegen den Schmuggel auszustatten und dadurch die Lücke des Gesetzes zu beseitigen. Die rumänische Regierung war derselben

1) Aus dem Leben usw., Bd. II, S. 264. 
Meinung, weil durch den Schmuggel nicht nur das Interesse der Pachtgesellschaft, sondern anch das des Fiskus selbst geschädigt wurde. Das Tabakmonopol sollte unterstützt werden, weil es eine beileutende Einnahmequelle bildete, die durch gesetzliche Mittel gesichert werden mußte. Demgemäß wurde nach heftig geführter Beratung das Gesetz am 9. Nai 1873 geändert. Die wichtigeren Bestimmungen des noch in demselben Jahre in Wirksamkeit getretenen Gesetzes sind folgende:

1. Die Zeitfrist, in welcher die Regieverwaltung sich über die Anbaubittschriften der Tabakpflanzer auszusprechen hatte, wurde von 10 auf 25 Tage erhöht.

2. Niemand darf an Tabakblättern orler -fabrikaten mehr als 100 g Rauchtabak oder $50 \mathrm{~g}$ Schnupftabak oder 25 Stück Zigarren hesitzen. wenn der Betreffende nicht selbst TabakipHanzer ist oder die Tabakfabrikate nicht mit der Marke der Regie versehen sind.

3. Auch der Friedensrichter kann die Genehmigung zur Haussuchung geben, falls am Orte selbst ein Tribunalpräsident nicht vorhanden ist.

4. Die nicht bezahlten Strafen für den Schmuggel werden in Gefängnisstrafe umgewandelt.

Dadurch änderte sich jedoch der frühere Zustand nicht, denn die wahren Ursachen dieses Ühels wurden nicht beseitigt, nämlich der Hangel an einer einheitlichen und geschickten Leitung. In den ersten zwei Jahren machte die Pachtgesellschaft schlechte Geschäfte, indem sie einen beträchtlichen Teil ihres Kapitals verlor, und zwar 4390128 Lei $^{1}$ ). Der Grund dafür lag darin, daß die Gesellschaft die Tabakregie erst von Grund aus organisieren, Fabriken bauen und tüchtige Beamte heranbilden mußte. Danach und solange der Engländer Wingfield an der Spitze der Regie stand, gingen die Geschäfte etwas besser. Derselbe brachte Ordnung und Pünktlichkeit in die ('eschäfte, so daß eine mäßige Verzinsung des Betriebskapitals gesichert war. Im Jahre 1875 wurde ein Nettogewinn von 951328 Lei erzielt, oder 3,98 Proz. $\left.{ }^{2}\right)$. Unter der Leitung des Generaldirektors Lange gingen dhe Regiegeschäfte wieder schlecht, obschon derselbe (len Aktionären goldene Berge versprach ${ }^{3}$ ). Im Jahre 1876 erzielte die Pachtgesellschaft einen Reinertrag von 143136 Lei $^{1}$ ). Der Grund

1) Allgemeine Zeitung, Nr. 335, 1875.

2) Allgemeine Zeitung, Nr. 335, 1875.

3) Allgemeine Zeitung, Nr. 89, 1876.

4) Cicalek, Theodor, Dr., Der Tabak, dessen Anbau, Verarbeitung und Verbrauch, sowie seine Bedeutung für den Welthandel und die Staatsfinanzen, 
dafür lag einerseits in der großen Höhe der Ausgaben, wie wir später sehen werden, - hier führen wir nur an, daß der Generaldirektor der Regie einen jährlichen Gehalt ron nicht weniger als 120000 Lei bekam, außerdem hatte er freie Wohnung, Licht, Heizung etc.; ein Fabrikdirektor bekam 40000 Lei jährlich ${ }^{1}$ ), - andererseits in der Nachlässigkeit der Verwaltung. Das Land war nicht mit den notwendigen Tabakfabrikaten versorgt. In vielen Gemeinden gab es kein Debitlokal, und wo ein solches bestand, konnte man nicht die gew ünschten (Qualitäten erhalten. Zahlreiche diesbezügliche Beschwerden wurden laut und verlangten von den Präfeliten amtliches Einschreiten.

Wenn die Regieverwaltung den Art. 15 des Gesetzes erfüllt hätte, in dem es heißt: „Alle Behörden der Unternehmung, wie auch alle Debitanten sollen Rumänen sein“, dann konnte die Regieverwaltung Debitanten in allen Gemeinden finden. Dann würde der Konsum nicht leiden und sich auch keine dieshezügliche Kilage mehr erheben. Die Regieverwaltung wollte davon nichts wissen und stellte in ihren Dienst so viele Fremde, zum größten Teil Juden, daß der damalige Minister des Innern sich gezwungen sah, ein sehr ernst gehaltenes Rundschreiben an alle Distriktspräffekten des Landes zu erlassen, worin dieselben aufgefordert wurden, auf das strengste darüber zu wachen. daß unter den Beamten der Regie sich keine „Fremden befünden, d. h. solche Personen, welche nicht das volle rumänische Staatsbürgerrecht besitzen" 2).

Die Tabakfabrikate waren im allgemeinen schlecht und die Preise zu hoch. In einem Handelsbericht des Kaiserlichen Deutschen Konsulats zu Galatz finden wir darüber folgendes: „Da nun aber auch die Bierbereitung durch hohe Stenern an Staat und Kommunen sehr verteuert wirl (10 Maß Bier ca. 8 Sgr.), wodurch auch der Genuß des Bieres der ïrmeren Kilasse sehr erschwert wird (das Mab leichten Bieres kostet im Einzelverkauf 5 Sgr.), so ist es gewil um so bedauerlicher, daf das jüngst ins Leben getretene Tabakmonopol auch noch Einschränkungen im Genusse des Rauchens, natïrlich ebenfalls rorwiegend den armen Leuten, anferlegt. Der dem Tabakrauchen in hohem Grade huldigende Rumäne wird durch die besleutende Verteuerung des Tabaks in der Tat sehr hart betroffen, da ihm das Tabakrauchen sozusagen angeerbt und von früher Jugend auf zur ein-

veröffentlicht in dem Achten Jahresbericht des Vereins der Wiener Handelsakademie 1880, Wien 1880, S. 204.

1) Monitorul oficial, Martie, 1879.

2) Allgemeine Keitung, Nr. 258, 1872.

Volkswirtschaftl. u. wirtschaftsgeschichtl. Abhandlungen. H. 4.

Busuiocescu, Das Tabakmonopol in Rumänien. 
gefleischten, kaum zu bekämpfenden Angewohnheit geworden ist ${ }^{1}$ )." Vier Jahre später schrieb die „Allgemeine Zeitung“ darüber folgendes: .,Das vor vier Jahren hier eingeführte Tabakmonopol ist für die an starken Konsum von Tabak gewöhnte Bevölkerung von Rumänien außerordentlich drückend und vermehrt nicht wenig die allgemeine Unzufriedenheit. Die übrigen Steuern treffen häuptsächlich die ärmere Berölkerung hart; das Tabakmonopol erregt aber auch den Mißmut der Wohthabenden, welche selbst für teneres (reld keinen guten Tabak mehr erhalten können." Die billigeren Tabakqualitäten waren am schlechtesten, wie aus der folgenden Schilderung des Abgeordneten Pruncu hervorgeht: „Das Tabakpaket, welches dem Bauer rerkauft wirl, bleibt drei Monate in dem Lagerhause der Fabriken liegen, ferner noch zwei Monate in den Distriktslagerhäusern, ferner einen Monat beim Bezirksentreposeur. bis es endlich an den Debitanten der Gemeinde gelangt, so daß dann, wann es der Bauer sich kauft, der Tabak in dem Paket nur aus Pulver, aus Kleie besteht. Nun gut, der arme Bauer kauft es so wie es ist, denn er kann nicht sehen, was darin ist; er geht auf das Feld, und wenn er das Tabakpaket aufmacht, dann bläst der Wind ihm den ganzen Tabak weg." Ein anderer Abgeorlneter bestätigte im Parlament, daß in den Tabakpaketen der Regie Laub gefunden worden sei). Dem Vertrag gemäß war die Regieverwaltung verpflichtet, die zum Verkauf gelangenden Qualitäten der Tabakfabrikate nicht schlechter herzustellen, als die auf dem Finanzministerium deponierten Proben seien. Aber es wurde bewiesen, daß die im Yerkauf sich befindenden Qualitäten um 30 Proz. schlechter waren als die deponierten Proben. Auch hatte die Regierung die Pflicht und das Recht, darüber zu wachen, daß die 'Tabakkonsumenten nicht ausgebeutet würden, doch hat sie es allem Anscheine nach an dieser Überwachung fehlen lassen. Unter diesen Umständen wurde die Tabak konsumierende Bevölkerung mit Notwendigkeit auf den Unterschleif und Schmuggel hingewiesen. Der Bauer, welcher sich den Luxus nicht gestatten konnte, teuere Tabakfabrikate zu rauchen, zog sich, getrieben ron dem Beelürfnis nach einem narkotischen Cenußmittel, in irgend einem versteckten Winkel seines Gartens oder Feldes einige Tabakpflanzen für sein eigenes Bedürfnis. Andere Leute legten sich auf das Rauchen von geschmuggeltem Tabak. In den an der türkischen Grenze gelegenen rumänischen Bezirken wurde sehr viel türkischer Tabak wegen seiner

1) IIandelsarchiv, Jahrg. 1872, Bd. II S. 538.

2) Vergati, D. C., Mouitorul oficial 1879, Martie 16. 
Billigkeit und guten Beschaffenheit geraucht, was vor vier Jahren niemand für möglich gehalten hätte, und in den an der österreichischungarischen Grenze gelegenen Bezirken bediente man sich ebenfalls sehr viel des Tabaks der österreichischen oder ungarischen Regie 1). $\mathrm{Zu}$ der Ausdehnung des Schmuggels trug auch der Umstand bei, daß im Jahre 1873 das wichtige Gesetz der Regelung der Schanklizenz auf dem platten Lande eingeführt wurde. - Bis zu diesem Jahre waren Schankwirte fast nur Juden, welche die Bauern nach allen Richtungen ausnutzten. Sie machten alle Versuche, den Bauer nicht nur bei jerler Gelegenheit zum Trinken anzuregen, sondern waren auch stets bereit, ihm Geld auf Wucherzinsen zu leihen, so daß in kurzer Zeit die Zinsen größer waren als das geliehene Kapital; außerdem fälschten sie fast durchgängig die Getränke durch Beimischung gesundheitsschädlicher Substanzen 2). Diesem (iesetze gemäß durften die Juden in den Dörfern keinen Ausschank mehr halten und ebenso keinen Tabak verkaufen. Dadurch hat man sie zu den ärgsten Konterbandiers gemacht ${ }^{3}$ ).

Hierzu kommt noch die Periode des 1877er Krieges, welcher die Lage des Monopols derart verschlechterte, daß die „Allgemeine Zeitung“ folgendes schreiben konnte: „Das Monopol der Gesellschaft, welche das Tabakmonopol in Rumänien um die beträchtliche Summe von 8 Mill. Francs per Jahr gepachtet hat, ist illusorisch geworden. Die russische Armee und die Tausende von Juden, welche in ihrem Gefolge sind, bringen aus Rußland und der Türkei so viel Tabak nach Rumänien, wie ilmen beliebt, obgleich die russische Regierung in der mit Rumänien abgeschlossenen Durchzugskonvention sich ausdrücklich verpflichtet hat, den Tabakbedarf für die russische Armee von der rumänischen Regie zu kaufen ${ }^{4}$."

Nach der Angabe der Regie betrugen die unerlaubte Kultur und der Schmuggel:

$\begin{array}{lrr}\text { Jahre } & \text { Unerlaubte Kultur } & \text { Schmuggel } \\ 1875 / 76 & 445 \text { Pogoane } & 6581 \mathrm{~kg} \\ 1876 / 77 & 820 \text { " } & 16452, \\ 1877 / 78 & 1416 \quad " & 32330 ",\end{array}$

Die Ausdehnung der unerlaubten Kultur ist nicht so zu verstehen, daßs die Bauern unter den Augen der Regieverwaltung so grobe Flächen

1) Allgemeine Zeitung 1876.

2) Creanga, C. D., Die Finanzen Rumäniens in Schanz' Finanzarchiv, Jahrg. 16, 1899, Bd. II, S. 141.

3) Leben König Karls, a. a. O. Bd. II, S. 305.

1) Allgemeine Zeitung 1877, Nr. 229. 
unerlaubterweise mit Tabak bepflanzen konnten, denn das war nicht möglich, sondern die Regieverwaltung ließ durch ihre Agenten die einzelnen Tabakpflanzen zählen, die die Bauern im Geheimen zogen, und 10 (100 Tabakpflanzen wurden einer Pogone (= $49.89 \mathrm{Ar})$ gleichgeachtet. Dadurch erlitt die Pachtgesellschaft empfindliche Einbuße an ihren Einnahmen. und sie drohte. ihre Zahlungen einzustellen und Scharlenersatz zu verlangen 1 . wenn die Regierung nicht die gewïnschte Modifizierung des ursprünglichen Vertrags bewilligen wür(le \%, obschon dieselbe für dreses Jahr (1875/7 $)$ einen reinen Ertrag von 325526s Lei gehaht hatte:3). Die Pachtgesellschaft verlangte: die derzeitige V'erbindlichkeit von jährlichen 8010000 Lei ohne jerle weitere Steigerung bis zum Ablauf des Lontraktes beizubehalten. Dagegen sollten, sobalı die Jahreseinnahmen der Pegie 18 Millionen überstiegen, von dem Überschusse t5 Proz. der rumänischen Regierung zufallen. Die rumänische Regierung war geneigt, diese Modifizierung anzunehmen und wollte der Nationalversammlung einen diesbezüglichen Gesetzentwurf rorlegen; lies wurle aber durch die politische Situation verhindert. Die Pachtgesellschaft führte jedoch das Monopol weiter in der Yoraussetzung, daf die Modifikationen angenommen werden würden. Im Jahre 1878, nach dem Ende des Russisch-Türkischen Kr rieges, erlangte Rußland Beßarabien, obgleich ersteres Land durch die am 16. April 1876 mit Rumänien abgeschlossene Konvention die Verpflichtung übernahm, die Rechte und die Integrität Rumäniens den Verträgen gemäß zu respelitieren. Dies veranlaßte die Pachtgesellschaft, wiederum ihre früheren Ansprüche geltend zu machen, indem ihr jetzt der juridische Grund zur Seite stand, daß das Objekt des Vertrags vermindert sei. Es ist hier nicht der Ort, darauf einzugehen, ob dieser Grund zur Auflösung des Vertrags genïgte odler nicht, die Pachtgesellschaft nahm das erstere an und liündigte am 30. September 187s den Vertrag ${ }^{4}$ ). Gleichzeitig stellte sie solange die Zahlungen ein, bis die Angelegenheit in der einen oder der anderen Weise erledigt wäre. Die damalige Regierung legte ler Nationalversammlung einen bezüglichen Gesetzentwurf vor, welcher folgende Hauptpunkte enthielt:

1. Der Tabakbau wird nur noch in sechs Bezirken erlaubt; 2. (ler Tabakibau behufs Exports wird strengeren Maßregeln unterworfen: 3. die Untersuchungsmaliregeln und die Strafe gegen den

1) Aus dem Leben usw., Bd. III, S. 417.

2) Allgemeine Zeitung 1877, Nr. 245.

3) Monitorul oficial 1879, 16. Martie.

3) Monitorul oficial 1879, 20. Martie. 
Schmuggel werlen rerschürft: 4 . (ler jährliche Pachtschilling von 9610000 und 11534400 Lei wird auf 8115000 Lei ohne jede Steigerung bis zum Ablauf des Vertrags festgesetzt, und der Staat beteiligt sich mit $45 \%$ an dem Überschusse, wenn die Jahreseinnahmen der Regie 18 Millionen Lei übersteigen. Dieser Gesetzentwurf bezweckte, dlas System der ..kointeressierten Regie* eimzuführen. wie es bereits in Italien bestand. In der Hauptsache lag der Regierung daran, sichere Tabakeinkünfte zu haben; die Form, unter der sie eingehen wïrden, war Nebensache; aus diesem (irunde entschlof sie sich, dlas Gesetz zu ändern, ohne damit einen bestimmten Plan zu verfolgen. Im ganzen genommen entsprach der Gesetzentwurf rollstäurlig den Ansprüichen der Pachtgesellschaft, während die Regierung die Furcht bewog, keinen Pächter mehr zu finden, welcher wenigstens 8 Millionen Lei dem Fiskus gewähren könnte, falls der Vertrag aufgelöst würde. Diese Furcht war bis zu einem gewissen Punkt gerechtfertigt, denn jetzt umfaßte das Tabakmonopol ein kleineres (iebiet als früher. Das Verlieren der sicheren Pachtsumme von 9 610000 Lei wäre eine große Einbuße gewesen, die das Budget nicht vertragen hätte und eine grofe Gefahr für die durch den siegreichen lirieg von 1877 T zerritteten Finanzen Rumäniens. Hierzu kam noch die Furcht der Regierung, die rumänischen Finanzen im Auslande diskreditiert zu sehen. „Meiner Meinung nach”, sagte der damalige Finanzminister, der gegenwärtige Ministerpräsident D. A. Sturza. ..verschafft uns die Regie des Tabakmonopols nicht nur eine sichere Staatseinnahme, sondern auch einen Teil unseres Kredits auf den Börsenplätzen ron Paris und London $\left.{ }^{1}\right) . "$

Die Beratung über diesen Gesetzentwurf wurde sehr lebhaft. Die Gegner des Monopols griffen, wie früher, das Monopol an und verlangten dessen Abschaffung, ohne die geeigneten und genügenden Mittel und Wege zu zeigen, die die Einnahmen des Monopols ersetzen lönnten. Dies wäre eine ungesunde Finanzpolitili gewesen, denn eine Abschaffung des Tabakmonopols hätte in jener Zeit eine berleutenle Stenervermehrung und -ausdehnung zur Folge gehaht. Die finanzielle Not forlerte zwingend das Weiterbestehen der Regie, deren Reinein-

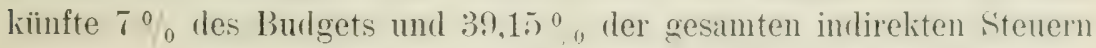
bildeten - also ein befriedigendes Ergebnis. Die Mehrheit der Abgeordneten war für weitere Beibehaltumg des Monopols, aber sie lehnte den Entwurf ab. Damit verlor die Pachtgesellschaft jerle Hoftumng

1) Monitorul oficial 1879 , S. 1957. 
und sie verharrte bei der Auflösung des Pachtvertrages. Am 2 t. März 1s7? legte die Regierung einen dieshezüglichen Gesetzentwurf vor, aus dessen Begrïndung wir folgendes entnehmen: ,Wegen der wiederholten Deklarationen der Tabakmonopolsregie behufs Auflösung des heute noch zu Kraft bestehenden Vertrages und der Gefahr, die der Existenz dieser wichtigen Staatseimnahme dadurch entstehen könnte, wenn wir wegen der Regie den gerichtlichen Weg beschreiten würden. und. wegen der Notwendigkeit, daß der Staat das Forthestehen dieser Verwaltung nicht unterbricht, ist eine Auflösung des Vertrages unvermeidlich. Durch diese Maßnahme wird ein verwirter Prozeß vermierlen, die Fortdauer der Regieverwaltung weiter beibehalten, und der Staat wird bei rler nächsten Lizitation, die gesetzmäßig stattfinden wirl, einen klaren und deutlichen Weg einschlagen $\left.{ }^{1}\right)_{\text {." }}$ Das Gesetz wurde angenommen und der Vertrag mit gegenseitiger Übereinstimmung gelöst. Die Gesellschaft verkaufte dem Staate dic Vorräte im Betrag von 3638805 Lei, und zwar gegen die rückständigen Raten der Pachtung im Betrag ron 3380000 Lei ${ }^{2}$ ). Alle Bauten wie auch Maschinen. Werkzenge und Zubehör gingen in den Besitz des Staates iiber gemä3 dem Y'ertrag(3) und der Übereinkunft, jedoch unter der Bedingung ${ }^{4}$ ), daß der Staat der Pachtgesellschaft den Betrag von 740000 Lei zahle, welche Summe die Amortisationsquote für die unbeendete Zeit des Vertrages darstellte ${ }^{5}$.

Das Gesetz vom 28. März 1879 sanktionierte diese Übereinstimmung, und damit endigte die Wirtschaft der Pachtgesellschaft. Die Verwaltung ging auf die Regierung über. An der Spitze stand ein Rat ron acht Mitgliedern und ein durch fürstliches Dekret ernannter Generaldirektor. Diese V'erwaltung war aber nur provisorisch und sie sollte nur bis zu einer neuen Lizitation, die aber nicht mehr stattfand, bestehen. Diesmal wurde das Monopol derartig verwaltet, daß man für immer darauf rerzichtete, es wieder zu verpachten. Das Gesetz vom 7. April 1881 beseitigte das Monopol in seiner Pachtform und führte den eigenen Regiebetrieb ein. Derselbe besteht ununterbrochen bis heute unter der Herrschaft des Gesetzes vom

1) Monitorul oficial $1879,27$. Martie.

2) Monitorul oficial 1879, Leben, Bd. IV, S. 187.

3) Monitorul oficial 1879, S. 1852.

4) Art. 21 und 22 der Konvention.

5) Art. 6 der Konvention. 
28. Februar 1887, welches sich in nur ganz wenigen und unbedeutenden Punliten ron dem vorhergegangenen Gesetz unterscheidet. Werfen wir einen Rückblick auf die Entwicklung der Dinge dieser Periode, so können wir sehen, daß die Durchführung des Tabakmonopols nur unter großen Sehwierigkeiten sich vollzog. Wegen der Höhe der Preise und der schlechten Tabakfalsikate wurde der Monopolverpachtung von der Bevölkerung das größte Mißtrauen entgegengebracht. Daher zeigt diese Periode einen ununterbrochenen liampf mit dem Schmuggel und der unerlaubten Kultur, der seit dem Rücktritt der Pachtgesellschaft und der Übergabe des Monopols an den Staat ganz von selbst aufhörte. 


\section{Die Regie in ihrer heutigen Gestaltung.}

Obschon das in Folge des siegreichen Krieges von 1877/78 gewonnene (iebiet Dobroudscha schon seit 1878 dem rumänischen Teritorium angehört, erstreckte sich doch das in Rumänien bestehende Tabakmonopol bis zum Jahre 1882 noch nicht darauf.

Die Verschiedenheit der Nationalitäten, wie Türken, Tartaren, Russen, Bulgaren. Griechen, Armenier, welche die Bevölkerung dieser Provinz billeten und welche bis $z u$ jener Zeit eine ganz andere Lebensweise unter der Herrschaft der Türkei führten. machte die Ausbreitung des Tabakmonopols, wie auch anderer (iesetze. die in Rumänien in Kraft waren, für einige Zeit noch unmöglich. Durch das Reglement, betreffend die Festsetzung und die Erhebung der Stenern in der Dobroudscha ${ }^{1}$ ), wurden der Tabakhandel und -bau frei gelassen. Es wurde eine Zollgebühr von 500 Lei pro $100 \mathrm{~kg}$ zu Gunsten des Fiskus für die Einfuhr der Tahak- und Schnupftabaksorten, sowie Zigaren erhoben. Eine Gewichtsteuer von 75 Lei pro $100 \mathrm{~kg}$ belastete die im Innern der Dobroudscha kultivierten Tabaksorten. Durch diese hohe Zollgebühr beabsichtigte die damalige rumänische Regierung die Einfuhr fremder Tabaksorten zu erschweren und die Bewohner dieser Provinz mehr auf die Tabaksorten Rumäniens hinzuweisen, zu welchem Zweck die aus Rumänien stammenden Tabaksorten bei ihrer Einfuhr in Dobroudscha nur einer Taxe von 75 Lei pro $100 \mathrm{~kg}$ unterworfen wurden. Damit verfolgte man gleichzeitig den politischen Zweck, die Terbindung mit den Bewohnern dieser Provinz zu einer engeren zu gestalten, sowie dieselben an die rumänischen Regiefabrikate zu gewöhnen, um dadurch die Einführung des Tabakmonopols dort zu erleichtern.

Vier Jahre dauerte dieser Zustand, worauf das Tabakmonopol dam ohne Schwierigkeit auf dieses Gebiet ausgedehnt wurde, und

1) Monitorul oficial $1878,17 . / 29$. November. 
zwar durch das Gesetz vom 2. Juni 1882. Seitdem bildet das ganze Köonigreich Rumänien ein einziges Honopolgebiet. Es ist aber nicht so umfangreich, wie das anderer Länder. Während das französische Tabakmonopol ein Gebiet von $536+6 \pm q \mathrm{~km}$ mit 33961945 Seelen, das österreichische ein solches von 67588.7 q $\mathrm{kmm}$ mit 48141961 Seelen und das italienische ein Gebiet von 286682 1lmm mit 32961247 Seelen umfabit, erstreckt sich das rumänische Tabakmonopol nur auf ein Gebiet von 131353 qkm mit 6081572 Seelen ${ }^{1}$ ). Seinem Ressort gehören aber, wie den obenerwähnten Monopolen, alle drei Zweige der Tabakindustrie: Tabakbau, -fabrikation und -verkauf an.

Der Staat hat sich diese Rechte ausschlieBlich vorbehalten, indem er sich verptlichtet, jedes Konsumtionsbedürfnis an Tabak zu befriedigen, und betreibt das Monopol kiraft des (iesetzes von 1887. welches die Grundlagen der gegenwärtigen Organisation enthält. So ist es niemandem gestattet, Tabak zu bauen ohne Erlaubnis des Staates, nur dieser darf Tabakfabrikate herstellen und verkaufen. Deshalb ist es auch ausgeschlossen, aus anderen Stoffen Rauchfabrikate zu erzengen. Dies geht, ohschon das dieshezügliche Gesetz hier ergänzungshedürftig ist, aus $\$ 76$ hervor, welcher folgendermaßen lautet: „Es werden als betrügerische Fabrikanten betrachtet die Privatpersonen, welche Werkzeuge für die Tabakfalrikation hesitzen. Die Werkzeuge werden lionfisziert und der Zuwiderhandelnde wird einer Geldstrafe von 5()$-5()$, Lei unterworfen, außer der in $\S 75$ vorgeschriebenen Geldstrafe." Auch die Einfuhr von Rohtabak und Tabakfabrikaten ist verboten. Ausnahmweise können Privatpersonen für ihren eigenen Bedarf Tabak einführen, unter der Bedingung für jedes Kilogramm Tabak denselben Preis zu hezahlen, welcher im V'orkaufstarif der rumänischen Regie für die entsprechende Qualität festgesetzt ist. Diese Gebühr kamn his 60 Lei pro Kilogramm Rauchtabak steigen. Diese Ausnahme erschien erforderlich wegen der Raucher. die nicht an den rumänischen Tahak gewöhnt sinrl. Die eingeführten Tahakfabrikate für den Verbrauch des königlichen Hauses und denjenigen des diplomatischen Kö̈rper's sind ohne Gebühr belassen. Den Reisenden ist eine Einfuhr bis zu $100 \mathrm{~g}$ Rauchtabak oder 100 Stück Zimaretten orler 20 Zigarren oder 1.16 kg Schnupftalak ohne Gebühr erlauht. Wenn fremde Schiffe in rumänischen IHäfen ankommen, müssen sie den mitgehrachten Tahak in antliche Verwahrung gehen: andernfalls müssen sie eine (ieldstrafe ron 50 Lei für je $1 \mathrm{~kg}$ Tabak zahlen, und der Tahak wird auberdem

1) Die statistischen Daten sind aus den geographisch-stalistischen Tabellen aller Länder der Erde von Fr. v. Juraschek, Frankfurt 1904, entnommen. 
noch konfisziert. Der Staat betreibt das Tabakmonopol durch eine speziclle verantwortliche V'erwaltung. nämlich durch die Regie, die ihre eigene Organisation besitzt und dem Finanzininisterium untersteht. Obschon die Regie die Eigenschaft von Landwirt. Händler und Industriellem in sich rereinigt, ist trotzlem ihr Hauptzweck die Erheluung der Tabaksteuer, also ein Zweck mehr fiskalischer als landwirtschaftlicher orler industrieller Art. Das rechtfertigt rleutlich ihre Abhängrigleit rom Finanzministerium. (ranz ähnlich ist es auch in Frankreich, Österreich-Lngarn, Italien. An der Spitze der Talakregie steht ein Rat von 9 Mitgliedern und ein Generaldirektor, die zusammen die Generaldirektion bilden. Der Generaldirektion steht folgender Wirkungskreis z11:

a) Sie hat die Aufgabe, dem Tabakbau im ganzen Lande die Ausdehnung zu geben, welche zur vollen Deckung des Regiebedarfes erforderlich ist und auch noch einen Absatz in das Ausland ermöglicht.

b) Die Leitung des technischen Teils des Ankaufes der Tabakblätter.

c) Die Sorge für die Bearbeitung der eingelösten rohen Tabakblätter zu Fabrikationszwecken, deren Aufbewahrung, Versendung und zweckmäßigste Verwendung.

d) Die Besorgung des Einkaufes und Bestellung des für den Fabrikbetrieb erforderlichen ausländischen Rohstoffes.

e) Die Leitung des Betriebes der Fabriken in administrativer und technischer Hinsicht.

f) Die Sorge für den Verkauf der Tabakfabrikate.

Also leitet die rumänische Regieverwaltung, wie die italienische auch ilen rerkauf, im Unterschied ron Frankreich und ÖsterreichLngarn, wo dieser (lem Finanzministerium zusteht ${ }^{1}$ ). Die Mitglieder des Rates werden durch königliches Dekret auf 3 Jahre ernannt. Sie hahen die alløemeine Überwachung und Kontrolle ïber den Geschäftsgang der Regie; sie entscheirlen über die Ausgahen, welche die Summe von 3000 Lei überschreiten, wie auch über die Ernennung des Beamtenpersonals und über dessen Gehalt. Zu diesem Zweck sollen die Mitglieder wenigstens zweimal monatlich zusammenkommen. Das Finanzministerium hat das Recht des Einspluchs hezw. des Verhots jerler Maßregel gegenüber, die dem Gesetz wirlerspricht oder die es für den Staat schädlich erachtet. Der Generaldirektor, welcher ver-

1) Laurent, F., La Régie des Tabacs en Autriche-Hongrie et en Italie, veröffentlicht im „MIémorial des Manufactures de l'état, Tome Troisième, Deuxième Livraison Paris 1901, p. 281. 
pflichtet ist, alle gesetzlichen Anordnungen auszufuihren, wird ebenfalls durch königliches Dekret auf 5 Jahre ernannt. Ihm stehen alle anderen fungierenden Beamten verschiedenen Grades mit einer etatsmäßigen Besoldung von 631416 Lei (1902) zur Verfügung. Es wirl niemand zum Beamten ernannt. welcher nicht das Bürcerrecht hesitzt oder der die bürgerlichen Ehrenrechte verloren hat. Sie sind Regierungsheamte und ilure Ernenumng wie Entlassung erfolot bei den lieanten mit einem monatlichen Gehalt von 200 Lei und darüber durch königliches Dekret, für die anderen durch die Generaldirektion ${ }^{1}$ ). Bezüglich (ler Sicherheit ihrer Stellung besteht keine Bestimmung. Sie sind dem Verfügungsrecht der Vorgesetzten unberingt unterworfen, was als sehr nachteilig anzusehen ist. Noch mehr, alle Beamten sind von den politischen Einflüssen ah)hängig und kïnnen infolgerlessen ihrem Beruf nicht mit dem nötigen Fleiß sich widmen. Dazu besteht noch in Rumänien die alte und schlimme Gewohnheit, daß jede politische Partei ihre eigenen Beamten hat. Dieselben steigen und fallen mit ihrer Partei, so daß eine ernste Tätigkeit in der kurzen Zeit, in welcher gerade eine politische Partei am Ruder ist, nicht möglich ist $\%$. Als Beispiel führen wir an, daß in dem Zeitraum von 25 Jahren, seitclem das Monopol von dem Staat verwaltet wird, 7 Generaldirektoren an der Spitze der Regie standen; daraus ergibt sich, daß diese im Durchschnitt nur $3 \frac{1}{2}$ Jahre im Amte gewesen sind, obschon sie auf 5 Jahre ernannt waren. Diese Unsicherheit und Furcht, jeden Augenblick abgesetzt werlen zu können, entmutigt die Beamten und infolgerlessen können pflichttrene tüchtige Angestellte nicht ausgehildet werden. Das ist desto schlimmer, wenn es sich um ein Unternehmen handelt, welches ein gut ausgewähltes geschultes Personal beansprucht, 1 m die gewünschten Ergebnisse liefern zu können, denn eine gute Entwicklung res Tahakmonopols hängt von der gewissenhaften Tätigkeit der Beamten ab. Die Sicherheit einer Stellung hietet aufierdem den Vorteil, daß das Beamtenpersonal durch die längere Praxis eine gewisse Fachbildung gewinnt und darlurch besser in der Lage ist, den vielen und verschiedenen Anforderungen des Berufs zu entsprechen. Gesetzlich besteht bei der Anstellung der Beamten der Nachweis einer speziellen Vorbildung nicht; ihre Anstellung geschieht olne vorherige Prüfung. Dieses System entspricht lieineswegs dem

1) In Österreich- Ungarn werden nur Direktoren und Inspektoren durch kaiserliches I)ekret ernannt.

2) Creanga, G. D., Die Finanzen Rumäniens, in Schanz' Finauzarchiv, Jahrg. 16, 1899, Bd. II, S. 187. 
Charakter des Monopols. Das Personal muß unter besseren Bedingungen angestellt werden. Eine höhere Aushildung befähigt den Beamten, seine Kräfte dem Fortschritt der Regie auch in höherem Grade zu widmen, und das ist um so notwendiger, als es bekannte Tatsache ist, daf der Beante, dem das persönliche Interesse fehlt. nicht dieselbe Arbeitsfreudigkeit besitzen kamn, wie sie bei einem Angestellten der Privatindustrie des öfteren zu finden ist. Die Vorbildung des Beamtenpersonals muß in enger Beziehung zu den drei Tätigkeitszweigen der Regie: Tabakbau, -fabrikation und -verkauf stehen, denn der Geschäftsgang der Regie ist sehr wenig bureaukratisch. Es ist vor allem aber notwendig, das primitive System der Anstellung zu ändern und eine ähnliche Prüfung einzuführen, wie in Italien, wo selhst die Kandidaten zur Ablegung einer solchen verpflichtet sind.

In Italien besteht das technische Personal aus Diplomingenieuren einer Ingenieuraliademie oder ausnahmsweise aus Diplomierten einer chemischen Schule, die wenigstens zwei Jahre als Präparator einer Universität angehört haben. Sie werden aus der Zahl der Bewerber gewählt. In dieser Wreise setzt sich auch das kaufmännische Personal aus Diplomierten einer Universität oder wenigstens aus den Bakkalaureaten und das technische Personal der Kultur aus den Bakkalaureaten orler den Diplomierten einer landwirtschaftlichen Akademie zusammen. Später miissen die Kandirlaten, welche die Prüfung gut bestanden haben, eine Praxis durchmachen, und zwar das technische Personal der Manufakturen sechs Monate das chemische Laboratorium der Manufaktur in Rom besuchen und das technische Personal der Kultur die Schule von Scafati ${ }^{1}$ ) absolvieren ${ }^{2}$ ). Diesen Lücken (les rumänischen Gesetzes tritt die Regieverwaltung bei der Besetzung der höheren Stellen durch die Bevorzugung derjenigen Bewerber entgegen, welche die polytechnische Schule in Bukarest oder eine solche in Deutschland oder Frankreich absolviert haben, und durch eine bessere Auswahl des Beamtenpersonals der Tabakkultur, indem die Regieverwaltung hier diejenigen Bewerber bevorzugt, die das Zeugnis einer praktischen oder höheren landwirtschaftlichen Schule Rumäniens oder des Auslands, oder das Diplom eines landwirtschaftlichen Instituts oder einer Universität des Auslands (mit Berorzugung Deutschlands und Frankreichs) besitzen. Für die Beförlerung (ler Beamten besteht ebenfalls keine Bestimmung; alles hängt von dem Willen der Generaldirelition und des Generaldirelitors ab, die gut oder schlecht beeinflußt werden liömen. Die schlechten

1) In der Nähe ron Neapel.

2) Laurent, F., a. a. O. S. 284. 
Folgen dieses Systems lirauchen nicht weiter hervorgehohen zu werden. da sie sich von selbst verstehen.

Hoffentlich wird die rumånische Regierung, die in den letzten zwei Jahren den Beamten der öffentlichen Verwaltung und des Polizeiwesens Sicherheit der Stellung und Regelung der Beförlerung gewährleistet hat, auch die Regiebeamten baldmöglichst dieser Wohltat teilhaftig werden lassen. Die Gehaltsverhälnisse der Regiebeamten, wie iiberhaupt der anderen Staatsbeanten waren his zum Jahre $19(1)$ : 901 durchweg gut und zufriedenstellend, oft zu hoch bei den höheren Beamten. Im Jahre 1901/1902 reduzierte die Regierung wegen der Krisis ron 1899, die besonders in den Statsfinanzen und im Landesliredit zutage trat, alle Gehälter nach einer progressiven Skala von 1-20 Proz. ${ }^{1}$ ), so (laß gegenwärtig die Beamtengehälter bedeutend niedriger sind. Die beifolgende Tabelle I veranschaulicht es:

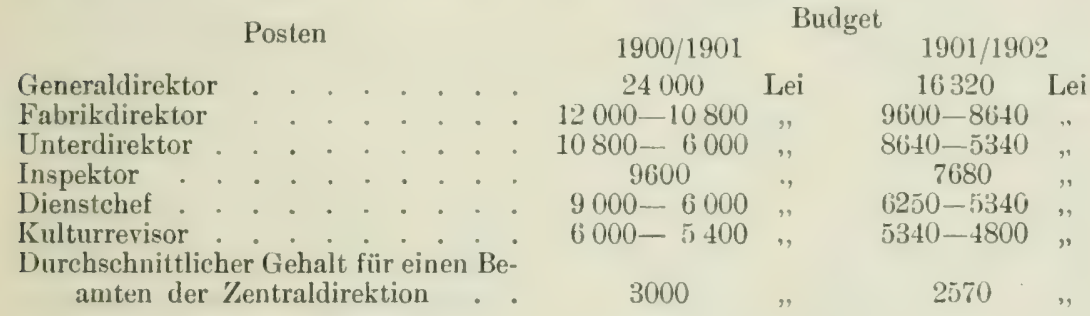

Tatsächlich erhalten die Regiebeamten etwas weniger Gehalt, weil sie infolge des Gesetzes vom 16. Dezember 1899 eine Gehaltssteuer von 5 Proz. monatlich entrichten müssen.

Trotz der Mängel, die sich hie und da zeigen, beruht die Organisation der Regie im allgemeinen auf gesunden Grundlagen, welche rlie Erreichung eines regelmäljigen Betriebes ermöglicht hahen.

1) Creanga, D. G., Die Finanzpolitik Rumäniens in ihrer neuesten Gestaltung und die fïr die Sanierung der Finanzkrisis getroffenen Maßnahmen, veröffentlicht in Schanz' Finanzarchiv, Jahrg. 20, 1903, Bd. 1, S. 1 u. 25. 


\section{Der Tabakbau unter dem Monopol.}

\section{Technisches.}

Die Tabakpflanze gehört nach dem System von Linné der 5. Klasse ${ }^{1}$ ) an und nach dem System von Jussieu und Eichler ${ }^{2}$ ) zur Familie der giftigen Solanaceen. Sie bildet in dieser Fanilie eine eigene Gattung: die Nicotiana. Der Tabak ist eine einjährige Pflanze, die eine Höhe von $1-2 \mathrm{~m}$ erreicht. Ihre Blätter sind ungeteilt, wechselständig, sehr groß, ei- bis lanzettförmig, mit Drüsenhaaren besetzt. Die Blüten erscheinen an der Spitze des Stengels als glockenförmiger Kelch. Die Blumenkrone ist trichterförmig und die Samenkapsel hat zwei oder vier Fächer, welche viele kleine runde gelbbraune Samenkörner enthalten. Das Wurzelsystem ist gradläufig, mit starken, wenig verzweigten und fast gleich dicken Fibrillen.

Die Hauptsorten der Tabakpflanze sind folgende: Nicotiana macrophylla (der Naryland-Tabak), Nicotiana tabacum (der Virginische Tabak) und Nicotiana rustica (der Banern- oder Veilchentabak). Durch die Verschiedenartigkeit des Bodens und der Behandlung der Pflanze entstehen verschiedene Nebenarten, die aber mehr eine botanische Bedeutung haben. Die in Rumänien gebauten Tabaksorten sind türkischen Lrsprungs und gehören der Nicotiana macrophylla odler dem MarylandTabak, und zwar der Lnterart: gestieltem Maryland-Tabak ${ }^{3}$ ) an. Sie heißen: Jaka, Samsun und Persicean und wurden deshalb gewählt, weil sie solche Blätter erzengen, die für den geschnittenen Rauchtabak sehr geeignet sind und dies für die rumänischen Tabakkonsumenten als ein Hauptvorzug des Tabaks gilt. Es sei gestattet, eine kurze Charakteristik dieser drei Tabaksorten zu geben ${ }^{4}$ ).

1) Kissling, a. a. O. S. 15.

2) Koning, Der Tabak, Studien über seine Kultur und Biologie, 1900, Leipzig und Amsterdam, s. 2.

3) Kissling, a. a. O. S. 18.

4) Popovici, M., Tutunul, Bukarest 1896, S. $26 \mathrm{ff}$. 
Jaka. Der Stengel erreicht eine mittlere Höhe und verzweigt sich an der Spitze. Die Blätter sind klein, schmal und lanzettförmig: sie haben keinen Blattstiel und stehen ron dem Stengel in kleinen Zwischenräumen spitzwinklig ab. Die Blattsulstanz ist dünn und die Farbe der Blüten ist rosa. Das Wurzelsystem ist wenig entwickelt. Diese Tabakart ist sehr früh reif, und alle Blätter werden ungeführ gleichzeitig reif. In der Türkei erzeugt sie die renommiertesten Tabake Europas. Mit der Zeit gewöhnt sie sich an Klima und Boden, und es entsteht eine Nebenart mit größeren Blättern und dickerer Blattsubstanz, aber ergiebiger im Ertrag.

Sa msun. Diese Nebenart erreicht die Höhe von $1 \frac{1}{2} \mathrm{~m}$, der Stengel ist nur sehr wenig an der Spitze verzweigt. Die Blätter sind ron mittlerer Größe und ellipsenförmiger Gestalt. Sie besitzen Blattstiel und ihre Blätter stehen dichter als die Jakablätter und von dem Stengel meist rechtwinklig ab. Die Blattsubstanz ist dicker als bei ter Jaka und die Blïten sind ungefähr gleichfarbig. Das Wurzelsystem ist stark entwickelt. Die Blätter sind später reif und reifen nicht gleichzeitig. Sie entartet aber nicht so schnell wie die Jaka.

Der Persicean verzweigt sich stark in der oberen Hälfte des Stengels. Die Blätter besitzen elliptische Form und stehen meist rechtwinklig, jedoch nicht dicht ab. Die Blattsubstanz ist dick und die Blüten sind rötlich. Das Wurzelsystem ist gleich dem der Samson. Diese Sorte ist etwas früher reif als die vorhergehende Art und wird nicht gleichzeitig reif.

Nur der Anbau dieser drei Tabaksorten ist gestattet. Die Regieverwaltung sollte aber zum Zweck der Ausfuhr noch andere Tabaksorten einführen bezw. pflanzen lassen, und zwar solche, die große, also gut für die Zigarrenfabrikation sich eignende Blätter erzengen. Bei dem günstigen Kilima und der guten lodenbeschaffenheit Rumäniens diurfte eine gute und reiche Ernte erzielt werden. Der Tabakhau ist nicht frei, sondern, wie in allen Monopolländern, auf bestimmte Distrikte beschränkt und verschiedenen Naßregeln unterworfen. Gegenwärtig ist der Tabakbau in folgenden 10 Distrikten gestattet: Ilfor, Jalomitza. Dimbovitza, Romanati, Vlasca, Tutova, Muscel, Vilcea, Tulcea und Constantza. Diese Einschränkung ist eine vernüntige und dem Fiskus vorteilhafte Mabregel, denn jedes neue Pflanzgebiet fordert grolje Ausgaben. Man muf nicht nur die zur Ablieferung der Ernte notwendigen Lagerhüuser bauen lassen oder mieten und das bezügliche Personal bezahlen, sondern auch das notwendige Überwachungspersonal unterhalten. um dem Betrug entgerenzutreten. Auberdem ist es der hegie- 
verwaltung dadurch, daß sie berechtigt ist, die Gebiete, auf denen Tabak gebaut werden darf, zu bestimmen, gelungen, solche LandHächen auszuschließen, die für eine gute Kultur nicht geeignet sind. Der Tabakibau darf nur entwerler auf Rechnung der Regie oder zum Export getrieben werden. Die Regieverwaltung bezw. der Generaldirektor reröffentlicht jedes Jahr im Laufe des Monats Oktober die Anzahl der für den Tabakbau des folgenden Jahres zuzulassenden Hektare. (ileichzeitig werden die Hauptbedingungen, unter welchen die Tabakpflanzer arbeiten müssen, wie auch die Preise, welche bei Ablieferung der Ernte bezahlt werden, bekannt gemacht. Diese Preise werden alljährlich im Oktober von der Regieverwaltung festgesetzt und nach (ienehmigung des Finanzministeriums im Staatsanzeiger verïfentlicht. Ihre Festsetzung geschieht nach den Ptlanzzonen und nach der Qualität, und zwar folgendermaßen:

\begin{tabular}{|c|c|c|c|c|c|c|}
\hline & Zone & von & 0 & Le & das & Kilograr \\
\hline III & $"$ & $"$ & $0,30-1,80$ & $"$ & ", & , \\
\hline UI & & " & $0,30-2,10$ & 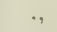 & ", & ., \\
\hline IV & " & " & $0,20-3,00$ & , & " & " \\
\hline & & $"$ & $0,20-4,00$ & & , & 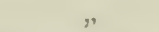 \\
\hline
\end{tabular}

Bei der Feststellung der Preise orientiert sich die Regieverwaltung nach der Lage und Beschaffenheit des Bodens, den klimatischen Verlıältnissen und der Qualität der erzeugten Tabake, so wie deren Herstellungskosten. Berorzugt sind aber die Tabake, die in hügeligen Gegenden gezogen sind. Diejenigen Ptlanzer, welche Tabak bauen wollen, hahen in den bezeichneten Bezirken bei ihren Gemeindeäntern in einer schriftlichen Erklärung anzugeben, wie riele Hektare sie zu bebauen gerlenken und ob sie auf Rechnung der Regie oder zum Exprort pflanzen wollen. Es wird niemand zum Tahalibau zugelassen. der nicht das bestimmte Flächenminimum zum Anbau benutzt und zwar 25 ym für die líultur auf Rechnung der Regie und 10 ha für den Export. Zur Erleichterung der Kontrolle darf die Anbautläche nicht geteilt sein. Die Anmeldungen der Kultur auf Rechnung der Regie müssen spätestens bis zum 20. Januar und zum Export bis zum 1. März des Erntejahres bewirkt werden. Die Ragiedirektion entscheidet üher diese Anmeldungen l,is spätestens 10. Februar resp. 10 März und erteilt die Erlaubnisscheine üher die festgesetzte Größe der Fläche olme Gebühr. Die Erlaubnis ist nur für das laufende Jahr gültig und der Tabakpflanzer muß jährlich von neuem die Erlaubnis dazu einholen, die ihm auch erteilt wirl, insoweit er dieses Recht nicht durch reglementswidrige Handlungen oder eine durch seine Nachlässigkeit entstandene schlechte Ernte verwirkt hat. Die Erlaubnis ist streng per- 
sönlich und ohne Genehmigung der Regieverwaltung an dritte Personen nicht ïhertraghar. Aber selbst in diesem Fall darf man den Erlaubnisschein nur an einen anderen Tabakpflanzer übertragen. Der Tabakpflanzer, welcher ohne Erlaubnis Saatbeete bestellt, wird mit einer Strafe von 2 Lei für jedes Hundert Pflänzlinge bestraft und zur Vernichtung der Bepflanzung rerpflichtet. Diese Strafe darf aber 2:) Lei nicht iibersteigen. Eine (ieldstrafe ron ¿) Bani für jede Pflanze hesteht für unerlaubte Tabakkulturen.

Der Tabakpflanzer ist verpflichtet, die volle im Erlaubnisschein festgesetzte Anbautlïche zu heptlanzen; andernfalls hat er für je 100 unbehaute Quadratmeter ¿) Lei als Strafe zu entrichten. Nur besondere Hinderungsgründe können ihn von dieser Strafe befreien. Alle diese Maßregeln bezwecken, daß die Regie genau weiß, wer baut, wo und wieviel gebaut wird. Sie sind unbedingt notwendig, um dem Unterschleif und schmuggel entgegenzutreten. Die Tabakptlanzer, die auf Rechnung der Regie bauen, dürfen ferner nur die drei von der Regie erlaubten Tabaksorten bauen und nur mit solchem Samen, der ilınen zu diesem Zwecke von der Regieverwaltung, und zwar unentgeltlich verabfolgt wird. Jede andere Sorte wird vernichtet und den schuldigen Pflanzern für die Zukunft das Recht, weiterhin Tabak zu bauen, entzogen. Der Tabaksamen wird teils im Lande erzeugt, teils eingeführt. Man führt ihn aus den durch guten Tabaksamen bekannten Bezirken Macedoniens jührlich im Werte von 6-18000 Lei ein ${ }^{1}$ ). Diese Maßregel liegt ebenso im Interesse der Regie wie des Tabakpflanzers. Würde man den PHanzern bezüglich der Samenwahl freie Hand lassen, dann würde man auf keinen Fall eine Ernte gleichartigen Tabaks erzielen, sondern jeder Tabalibaner würle schlieflich eine andere Samensorte verwenden. Die Regieverwaltung hingegen wäre gar nicht in der Lage, die Ernte auch nur einigermaßen voraussehen zu können, die ihr geboten werden würde, und die Menge der Tabakarten und -Nebenarten würde von Jahr zı Jahr größer werden, bis endlich eine Übersicht völlig zur Unmöglichkeit würde. Ferner verlangt die Verschiedenheit der Blïter eine verschiedene Behandlung in Fabriken und Magazinen, die grobe Kosten verursachen. Die Tabakfabrikate würden nicht mehr gleich sein und dadurch zu Unzufriedenheit und lilagen des Publikums führen. Es sind äbrigens auch nicht alle Tabakiptlanzer befähigt, gute samenerzeugende Pthmzen auszu-

1) Ollaneseu, D., Raport general, Participarea Rominiei la expositia universala din Paris 1900, Bukarest 1901, p. 397.

Volkswirtschafu, u. wirtschaftsgeschichtl. Ahhandiungen. H. 4. 
suchen: viele kennen nicht einmal die richtige Art der Behandlung, guten Samen zu erzielen; sie kennen oder beseitigen ferner nicht die Ursachen der Sortenrermischung und der daraus entstehenden Entartung. Die meisten werden demnach einen Samen von geringerer oder höchstens mittlerer Qualitåt verwenden und die Folge davon würde eine dürftige und Pflanzenkrankheiten erweckende Ernte, unsichere Klassifizierung und bedeutender Schaden sein. Zugegeben selbst, daff die meisten Tabak bauenden Länder ausländischen Samen nicht mehr einfülıren. sonder'n inländische Samenprodukte verwenden, so dlarf doch nicht auljer acht gelassen werlen, dab in diesen Ländern der Tahakibau auf einer hohen Entwicklungsstufe steht und man deshalb in der Lage ist, guten Samen im eigenen Lande zu erzielen. Die rumänische Regie sollte ihre Aufmerksamlieit auch diesem wichtigen Punkt zuwenden und die Erzeugung des Samens im Inland befördern. Dies würde einen doppelten Vorteil haben: erstens die Erzeugung von Samensorten. deren fruchtbare Eigenschiften dem lokalen Bedürfnis entsprechen. und zweitens, die für den importierten Samen jührlich zu zahlenden Summen von 6-18000 Lei brauchten nicht mehr über die Grenze zu gehen. In der letzten Zeit wurde auch im Inland Samen durch Zuchtwahl erzielt, aber nur in ilen Gegenden, welche zur Erzengung der geringeren Tabaliqualitäten hestimmt sind. Der Tabakbau beginnt am'1. März und dauert bis Ende September. Um einen Scharlen durch Fröste, die zu Beginn des Tabakbaues meist noch vorherrschen, zu umgehen, wird der Same nicht direkt auf dem Tabakacker, sondern zuerst in Saatbeeten ausgesät. Die einzig gebräuchliche Art der Saatbeete ist das Gartenbeet. Bei Nacht und frostigen Tagen hedeckt man diese Saatheete und hefeuchtet sie täglich, his die Pflänzlinge $5-6$ Blättchen besitzen. Ist das Saatbeet zweckentsprechend und in richtiger Weise angelegt, so erzielt man fast stets befriedigende, selbst gute Erfolge. Es kommt allerdings häufig vor, daß die Saatbeete nicht gut vorbereitet oder zu wenig geschützt sind, wodurch dann naturgemäß bedeutende Schäden entstehen kïnnen, sei es, daß die Ptlänzlinge sich zu spät entwickeln, sei es, daß sie wegen Frösten oder kaltem Regen eingehen. Die im Saatbeet gezogenen P’hänzlinge werden num, sohalıl sie. wie bereits erwähnt. j-6 Blättchen hesitzen, ohne Beinischung anderer Ptlanzensorten auf rlas freie Feld rerptlanzt. und zwar nach Schnur und Linie und in gleichen Abständen. Das Versetzen geschieht im Monat Mai. Die Reihen- und Pflanzenalsstinde stehen im Zusammenhang mit der Bodenart und den anzu- 
bauenden Tabaksorten. Im allgemeinen sind folgende Abstände gebräuchlich:

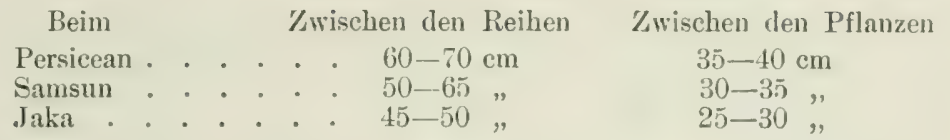

Das Versetzen bedarf großer Aufmerksamkeit, weil hiervon die Entwicklung der Pflanzen abhüngig ist. Stehen dieselben zu dicht, so werden nicht alle Blïtter von der Somne getroffen und die Qualität wird infolgedessen. einbüßen; stehen sie hingegen in zu weiten $\mathrm{Ab}$ stinden voneinander, so wird eine geringere Quantität resultieren und die Erntemenge vermindert werden. Die beste Versetzungsmethode ist die von den Tabakbauern in Dobrogia angewandte. Sie graben kleine Löcher, die sie mit Wasser füllen. Naclidem das Wasser von der Erde absorbiert ist, setzen sie den Pflänzling linein. Diese Methode findet mehr und mehr Verbreitung. Die Unkräuter, die auf dem Tabakfeld zwischen den Tabakpflanzen wachsen und ihre Entwicklung hindern können, werden durch Jäten entfernt. Dieses findet ein- oder zweimal statt. Das erste Mal soll es 14 Tage nach erfolgtem Versetzen stattfinden. Das Behacken geschieht nur einmal, und zwar 15-20 Tage nach dem ersten Jäten. So oft es nötig erscheint, muß begossen werden. Sobald die Tabakpflanzen jene Entwicklung erreicht haben, die sich durch den beginnenden Ansatz der Blütenknospen kennzeichnet, beginnt das Köpfen, d. h. man entfernt die Blüten, damit sich die Blätter besser entwickeln können. Ausbrechende Seitensprossen werden durch Geizen rernichtet, welche Prozedur so oft als nötig stattfindet. Wenn die Blätter eine hellgelhe Farbe angenommen haben, leicht brechen und ihre Oberfläche schwach gerunzelt erscheint, dann ist die Tabakpflanze reif und wird geerntet. Dies geschieht im Monat August und Anfangs September, manchmal auch noch Anfangs Oktober.

Nach Abfuhr der geernteten Blätter von der Ackerfläche sind die Tabakbaner verpflichtet, alle zurückgebliebenen Stengelstümpfe und Wurzeln zu vernichten; bei Unterlassung dieser Vorschrift wird diese Vernichtung von amtswegen auf Kosten des Tabakbauers angeordnet. Die gepflückten Blätter werden sortiert und in grolie. luftige. aber gegen die Sonne schützende Schuppen gebracht. Hier bleiben die Blätter 12-24 Stunden liegen, in welchem Zeitraum die erste Fermentation eintritt. Hierauf reiht man Blatt für Blatt mit einer Nadel auf 3-4 m lange Bindfaden. Werden die Blätter zu dicht 
gereiht, d. h. derart, daß Blatt auf Blatt dicht anliegt, ohne der Luft Durchlaß zu gewähren. so verursacht dies oft bedeutenden Schaden, weil in diesem Fall der mittlere Teil der Blattsubstanz verbrennt oder fault und dadurch wertlos wird. Die Tabakschnüre sollen gleich lang sein. Sie bleiben in freier Luft und werden der Wirkung der Sonne ausgesetzt, bis sie dachreif, d. h. trocken werden. In der Nachtzeit werden sie zum Schutz gegen Regen und Wind zugedleckt. Diese Iethode ist zwar schon sehr alt, allein, wie die Erfahrung lehrt, für das Aroma der Blätter von dem größten Nachteil ${ }^{1}$ ), und zwar ist der in dieser Nethode liegende Nachteil für die rumänische Tabakkultur größer, als dies vielleicht in anderen Tabakländern der Fall ist. Wie durch die Lulturrersuche der Regie festgestellt wurde. brauchen die in Rumänien angebauten Tabaksorten vom Versetzen der Pflänzlinge an bis zur Reife der Blätter folgende Vegetationsperioden:

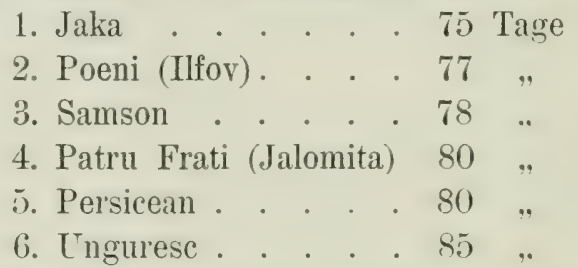

Da es nun bei den rumänischen Tabakbauern öfters vorkommt, daß das Versetzen der Pflänzlinge erst im Juni stattfindet, so kann naturgemäß die Reife der Tabakblätter nicht im Monat August, sondern erst im September, manchmal sogar noch später eintreten. In solchen Fällen kann man kaum mehr auf eine zum Trocknen des Tabaks unbedingt notwendige, ununterbrochene Periode von 20-25 schönen warmen Tagen rechnen, und so erfolgt dann ein nur notdürftiges Trockinen $\left.{ }^{2}\right)$ unter miflichen Witterungsverhältnissen. Dazu macht sich oft noch der IIangel an nötigen Hilfskräften fühllbar, wenn es sich um schnelle Beseitigung der Tabalsschnüre wegen eintretenden Taues, Regens oder Frostes handelt usw. ${ }^{3}$ ). Welch weittragende Berleutung gerade das Trocknen des Tabaks hat und wie nötig es ist, auf die Tachteile der günzlich reralteten, aber trotzciem noch jetzt gebräuchlichen Methode hinzuweisen, geht wohl am besten aus folgenden Ausführungen Semlers ${ }^{\ddagger}$ ) hervor: „Die erste Methode - nämlich das Trocknen in der Sonne - ist urwüchsig, sie sollte von strebsamen

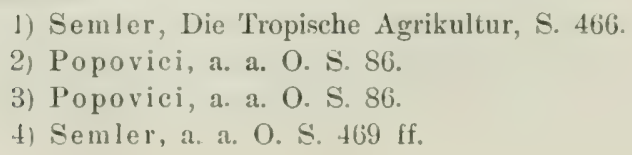


züichtern gar nicht in Betracht gezogen werden. Den Wilden darf man nicht verargen, wenn sie ihre geernteten Tabakblätter auf eine Schnur reihen und so lange in der Sonne hängen lassen, bis sie dürr greworlen sind. Findet man in halbzivilisierten Ländern, dal. die Sonne nur zum Nachtrocknen benutzt wird, so sollte man daran schon einen Fortschritt erkennen; wenn aber ein zivilisierter Tabakzüchter seine Ernte an der Sonne trocknet oder nur nachtrocknet, so kann er nicht entschuldigt, geschweige gelobt werden ..."

"Um darüber klar zu werden, muf man wissen, daß die Güte des Tabaks in hohem Grade von seinem Gehalt an aromatischen Ölen abhängt. Dies vorausgeschickt, braucht nur an die Behandlung der aromatischen Kräuter erimnert zu werden. Wer trocknet dieselben in der Somme? Doch nur der, dem jede Sachlienntnis und Erfahrung fehlt. Jerles Dorfkind weif, daßs sie im Schatten getrocknet werden müssen, unıl bei dler geschäftsmäBigen Zubereitung geht man in neuerer Zeit noch einen Schritt weiter und trocknet sie unter der Presse, ein Verfahren, das man auch auf den Safran ausgedehnt hat. Die Sonne verflüchtigt, richtiger ausgedrücht, zersetzt das aromatische ()] rasch, woron man sich leicht überzengen kann, wenn man eine abgeschnittene Rose in eine Schublade legt und eine andere auf ein sonnenbeschienenes Fenstergesims. Selbst das Tageslicht übt einen zersetzenden Eintlub auf das aromatische Öl aus, weshalb man alle PHanzen, in welchen man diesen Bestandteil zu erhalten wünscht, besser noch als im Schatten, im Dunkel trocknet und aufbewahrt. Wenn auch der Tabak im gewöhmlichen Leben nicht zu den aromatischen Kiräutern gezählt wird, so gehört er doch in Wirklichkeit zu ihnen, mub also in gleicher Weise behandelt werden. Er sollte also, soweit es durchführbar ist, unter Ausschluß des Lichtes getrocknet werden. Das wird auch von vielen intelligenten Tabakzüchtern verstanden und beachtet, nur wollen manche eine Ausnahme gemacht wissen, wenn es sich um die Produlition von hellfarbigem Tabak handelt. $\mathrm{Zu}$ den Mitteln, welche die Erzeugung dieser, übrigens nicht häufig begehrten Farbe möglich machen, soll auch das Trocknen bei einfallendem Licht gehören, mit anderen Worten, das Trockenhaus soll mit Fenstern versehen sein. Andernfalls soll es nur Türen haben. Noch in anderer Weise ist das Trocknen an der Sonne nachteilig: es vollzieht sich zu schnell, zum mindesten da, wo die Sonne eine empfindliche Wärme ausstrahlt, und wenn die Witterung nicht dauernd günstig ist, schweben die aufgehängten libäter überdies in steter Gefahr, vom Regen verdorben zu werden. Es ist 
oben ${ }^{1}$ ) dlarauf hingewiesen worden. daß in lufttrockenen Klimaten die Schwierigkeit des allmählichen, sleichmäßigen Trocknens eines der wichtigsten Hindernisse für den Tabaklau sei; es wurde ferner gesagt, das Ernten der ganzen Pflanzen sei demjenigen der Blätter vorzuziehen ${ }^{2}$ ), weil dann das Trocknen der letzteren langsamer und gleichmäBiger verlaufe. Damit steht gewif. nicht die Benutzung der Sonne zum Trocknen im Einklange, zumal wenn die Blätter und nicht die Pflanzen geerntet werden. Allerdings ist auch eine Grenze für die Dauer des erfolgreichen Trocknens grezogen, doch liegt die Gefahr der Übereilung viel näher. Auch fördert es die Ausschwitzung des Klebstoffes, welcher den Blättern Glätte und Elastizität verleiht, wenn die Poren sich langsam schließen; ferner möge man herücksichtigen, daß die Säfte eines Blattes in allen Teilen zur gleichzeitigen Verdunstung gelangen müssen, da sonst die Farbe, Gilätte und Elastizität nicht gleichmäßig sein können. Während des Trocknens fließen aus dem Stengel in die Riplyen und aus diesen in die Gewebe Säfte nach, und zwar sind es wertrolle Säfte, denn sie enthalten viel aromatisches Öl. Die Größe dles Tabakblattes macht es leicht verständlich, daß die Verteilung des nachrückenden Saftes nur langsam erfolgen kann. Bei übereiltem Trocknen würden die Ränder des Blattes ihre Aufsaugefähigkeit verloren haben, wenn das mittlere Gewebe noch mit Saft gefüllt wäre, und nachdem dieses getrocknet, würden die Rippen noch feucht sein. Ton den bereits erwähnten Nachteilen abgesehen, wäre zwischen den beiden Übeln zu wählen: entweder das Trocknen des Gewebes zu weit fortschreiten zu lassen oder die Blätter mit feuchten Rippen zu verpacken, wodurch sie in steter Gefahr des Verderbs schweben. Durch Ausschneiden der Mittelrippe kann allerdings dem Verderb mit einiger Sicherheit vorgeheugt werden, und es geschieht auch zuweilen, allein es geschieht zum Schaden des Züchters."

Durch die Einwirkung der Regieverwaltung wurden in letzter Zeit eine Zahl von Trockenanstalten errichtet, in welchen die Blätter durch die einzig richtige Methode ${ }^{3}$ ) des Trocknens mit Luft behandelt werden, aber sie ist verhältnismäßig noch zu wenig verbreitet, und die alte Methode mit ihren Nachteilen dominiert noch bei den meisten Tabakpflanzern. Das Trocknen der Tabakblätter dauert 2-4 Wochen. Von dem Augenblick des Blätteranreihens ab beginnt der Verifikateur die Tabakschnüre zu zählen und sie sowohl in seinem Journal als
1) Semler, 1. c. S. $37 \pi ; 78$.
2) Semler, l. c. S. $463 / 64$.
3) Semler, a. a. O. S. 466. 
auch in dem des Tabakpflanzers einzutragen. Gleichzeitig bezeichnet ersterer den Zustand der Tabalischnïre; für jede fehlende Tabalischnur hat der Tabakbauer eine Geldstrafe von 6 Iei zu zahlen und eine gleiche Zahl von Tabakschnüren wird ihm konfisziert.

Nachdem die Tabakblätter einen gewissen Grad ron Trockenheit erreicht haben, hegimnen der Verifikateur und der Bürgermeister deDorfes, in dem die Tabulkernte stattfand, mit dem allgemeinen Wiegen: sie nehmen ein Protokoll auf, in welchem die Zahl der Tabakschnüre und deren Gewicht verzeichnet wird. Bis zur Ablieferung der Ernte, welche gewöhnlich im Monat Dezember stattfindet, läßt man ein Sinken von 10 Proz. des Gesamtgewichts der Tabakernte zu. Für jedes darüber fehlende Kilogramm jedoch bezahlt der Tabakibauer als Geldstrafe 5 Lei und es wird ihm eine gleiche Quantität Tabak konfisziert. Wenn der Tabak trocken ist, schreitet der Tabakbauer zur Sortierung und zum Binden in Büschel von 25-30 Blatt. Die Büschel müssen so gebunden sein, daß die oberen Seiten der Blätter in gleicher Richtung liegen, jedes Büschel wird mit einem Blatt der gleichen Qualität zusammengebunden. Vernachlässigt dlies der Tabaliptlanzer. so läuft er Gefahr, seine Ernte niedriger eingeschätzt zu sehen. Die Büschelarbeit (Papusitul) fängt im Oktober an und dauert bis Ende November.

Die fertigen Büschel werden in Haufen von $50-60 \mathrm{~cm}$ Höhe und einer der Lünge zweier Büschel entsprechenden Breite arrangiert, bis die Büschelarbeit beendet ist. Die Herstellung der Haufen geschieht kontraktgemäß und, zwar müssen:

1. die Haufen I. Qualität aus solchen Büscheln bestehen, die die kleinsten, am schönsten hellgell, gefärhten, ganzen und gesuncien Blätter enthalten;

2. die Haufen II. Qualität solche Büschel aufweisen, welche mittlere, gesunde und ganze Blätter von derselben Farhe (gelb) enthalten;

3. die Haufen III. Qualität endlich solche Büschel repräsentieren, deren Blätter gleicher Größe und Farbe sind; die Blätter können wenig gebrochen und die Farbe darf etwas dunkler sein. Die zurückgebliebenen. nur die schlechten Blätter enthaltenden Büschel werlen ebenfalls in Haufen, sogen. Furda, gelegt. Die gleichartigen IInufen niedrigerer Qualitäten werden hierauf in Ballen zu 30-40 kg Gewicht verpackt, die der besseren Qualitäten in solche von $25-30 \mathrm{~kg}$ Gewicht. Alle Kulturarbeiten wie auch die Wahl der Blätter, die Büschelarbeit, die Terpackung geschieht nach den Anweisungen des 
verpflichteten Kulturpersonals. Diese Mafnahmen sind sowohl im Interesse der Regie als auch in dem der Tabakbauer notwendig. Erstere wird vor Schaden bewahrt, letztere sind überzeugt, daß sie dadurch die Ware nach ihrem vollen Werte bezahlt erhalten. Da nun dem Tabakpflanzer die Pflicht obliegt, seine Ernte der Regie abzuliefern, so muf er sie zu diesem Zweck mit obrigkeitlichem Begleitschein und auf seine Rechnung zu dem Lagerhaus bringen. Jedem Tabakipflanzer ist das Magazin wie auch der Tag, an dem er abliefern soll, vorgeschrieben. Solche Magazine bestehen 15, nämlich:

$$
\begin{aligned}
& 9 \text { in Bukarest } \\
& 1 \text {." Isacea (Dobrodgia) } \\
& 1 \text { " Ghimpati (Vlasea) } \\
& 2 \text {." Gaesti (Dimbovitza) } \\
& 2 \text {, Vladuleni (Romanatzi). }
\end{aligned}
$$

Sie wurden in der Zeit der Staatsbetriebperiode errichtet, denn die Staatsregieverwaltung hatte als Erhschaft von iler Pachtgesellschaft, welcher sehr wenig am Fortschritt der Tabakkultur lag, nur einige Magazine en planche ..... übernommen, die ungenügend und nicht zweckentsprechend waren. Sie wurden nach den Entwürfen des höhereri technischen Staatsrats erbaut und ron den Regieingenieuren ausgeführt. Sie bestehen aus Mauerstein und hesitzen große Räumlichlieiten, die ca. $6000000 \mathrm{~kg}$ einheimische und $500000 \mathrm{~kg}$ ausländische Tabakblätter aufzunehmen vermögen. Hinsichtlich der lokalen Verhältnisse ist die Anzahl der Magazine aber immerhin zu gering, denn viele Tahakpflanzer müssen große Wegstrecken bis zum rorgeschriebenen Lagerhaus zurückzulegen. Eine entsprechende Vermehrung dieser Magazine ist deshalb wünschenswert, denn sie dürfte einen günstigen Einfluß auf die Tabakkultur ausüben.

Der Mangel an Nagazinen könnte aber auch durch die in Österreich hestehende Maßregel ausgeglichen werden. Dort bewilligt die Regie den Tabalipflanzern eine bestimmte Entschädigung für die entstehenden Frachtunkosten und zwar je nach der Größe der zurückgelegten Entfernung ${ }^{1}$ ). Die Ablieferung (der Ern'e dauert von Dezember his Ende Januar. Die zum Lagerhaus transportierte Tabakernte wird von einem oder zwei Delegierten der Regie angenommen, die in Gegenwart des Tabakpflanzers Ballen für Ballen hinsichtlich der Qualität prüfen und letztere gleichzeitig feststellen. Dies ist der wichtigste Moment für den Tabalbauer, weil von einer richtigen Abschätzung

1) Laurent, F., a. a. O. S. 286 . 
der Ernte der Lohn seiner Jahresarbeit abhängt. In dieser Hinsicht scheint mir das Expertenwesen nicht die genügende Garantie dafür zu bieten, daß die Ernte ihrem wirklichen Wert entsprechend eingeschätzt und dem Tabakbauer der Lohn zuteil wird, der ihm von Rechts wegen gebührt. Es unterliegt wohl keinem Zweifel, daß die Experten der Regie gewissenhafte Beamte sind, die weder zu (imusten der Regie noch zu Gunsten der Tabakbauer handeln, aber es ist doch nicht ausgeschlossen und liegt in der menschlichen Xatur begrünlet. daß sie unwillkürlich oder beeinflußt von andern in Fehler verfallen.

Beschwerden seitens der Tabakbauer, daß ihre Ernte zum Preis einer nierlrigeren Qualität eingeschätzt worden sei, hahen nicht grefehlt, traten sogar öfter zu Tag. Zur größeren Sicherung einer richtigen Ernteeinschätzung und zur wenigstens teilweisen Beseitigung obiger Beschwerden sollte die rumänische Regieverwaltung das französische Expertenverfahren einführen. In Frankreich wird die Qualität der Ernte durch eine Kommission festgestellt, welche aus fünf Personen besteht, nämlich aus dem Verwalter des Tabakentrepots (dem Entreposeur), dem Magazinkontrolleur und drei vom Präfekten ernannten Tabakpflanzern, welche keinen Tabak mehr bauen ${ }^{1}$ ). Zwar ist nicht zu leugnen, daß dort auch heute noch Klagen seitens der Tabakbauer wegen zu niedriger Einschätzung bestehen, aber immerhin bietet dieses System eine viel größere Sicherheit für eine richtige Einschätzung. Die Kilagen gänzlich zu heseitigen, dürfte schon aus psỵchologischen Gründlen zur Unmöglichlieit gehören, da der Mensch im allgemeinen bekanntlich seinen Wert, sei dieser nun moralischer, intellektueller orler materieller Art, stets höher einzuschätzen ptlegt. als es der Tatsache entspricht.

Sodann wird bei Anwesenheit des Tabakpflanzers eine nochmalige Abschätzung der Tahakernte nach der Qualität vorgenommen. und noch am gleichen Tage erhält der Tabakpflanzer seinen Berechnungsschein, auf dem die Anzahl der Büschel, die Qualitait, das Rruttound Nettogewicht, der Preis, der Gesamtwert, die Abzüge und die zu zahlende Summe verzeichnet sind, worauf der Erhebung des Geldes nichts mehr in Wege steht. Bei dieser (ielegenheit unterrichtet man die TahakpHanzer üher die Behandlung dler Tahakernte. lebt nötigenfalls das Recht des weiteren Tabakbaues bei denjenigen Pthanzern auf. die eine durch Nachlässigkeit oder ähnliche (irüncle hervorgerufene schlechte Ernte abgeliefert haben, man tadelt oder loht und helohnt die

1) Creizenach, a. a. O. S. 77. 
tïchtigsten Tahakpflanzer durch Prämien. Nit ıler Zahlung ıles Gelıles endet die mühsame und mit vielen Unannehmlichkeiten verbundene Arbeit des Tabakbauers. In dieser ganzen Zeit, nämlich seit dem Augenblick der Erlaubnis zum Anbau bis zur Ablieferung der Ernte, stehen die Tabakpflanzer und die behauten Tabaliflächen unter strenger Regieliontrolle, die durch Verifikatoren. Überwachungsagenten, Unterinspektoren und einen Generalinspektor ausgeübt wird. $\mathrm{Zu}$ diesem Zweck erhält jerler Tabakbauer ein Buch, in welchem die Größe des ihm bewilligten Pflanzterrains eingetragen ist und in dem gleichzeitig die Kontrollbeamten den Befund ihrer Kontrolle (Anzahl der Tabakfurchen, der Ptlanzen. (ler Blätter an jeder PHanze, Ernteergelnnis usw.) verzeichnen.

Für die Kontrolle des Tabakbaues zahlte die Regie im Jahre 1902 194.709 Lei, also 2,31 Proz. der Gesamtausgaben jenes Jahres im Betrage ron 8426400 Lei. In Frankireich $\left.{ }^{1}\right)$ machen diese Kíosten 1, 66 Proz. und in Italien nur 0,95 Proz. Fres. ${ }^{2}$ ) der Gesamtausgaben aus, obschon in Italien die Tabakkultur sehr zerstreut ist ${ }^{3}$ ). Der italienische Tabakptlanzer hat aber für die Beanfsichtigung des Tabakbaues eine kleine Abgabe (tassa di vigilanza) zu zahlen, die im Jahre 1901/1902 pro $100 \mathrm{~kg} 97$ Centimes betrug. In Österreich-Ungarn gehört die Beaufsichtigung der Tabakkulturen zum Ressort der Finanzrerwaltung. Die verhältnismäßig hohen Kosten der Kontrolle in Rumänien sind durch die Ausdehmung der Tabakkultur in den neuen Gebieten verursacht worden. Die in den Magazinen eingelieferte Tabakernte unterliegt vor der V'erarbeitung dem Fermentationsprozeb. Dieser besteht in einer Gärung, die durch den Einfluß von Luft, Wärme und Feuchtigkeit hedingt wird. Die Zersetzung wird durch einige Mikroorganismen hervorgerufen. In der Zeit der Fermentation steigt die Temperatur von $25^{\circ}$ bis auf $60^{\circ}$. Dabei entweichen rerschiedene organische Gase, wie auch der noch rorhandene Feuchtigkeitsrückstand. Durch die Fermentation erst bekommt der Tabak seinen typischen Geruch und Geschmack, sowie die bekannte braune Farbe. Der Fermentationsprozeß ist der Hauptfaktor zur Erzielung eines guten Rauchprodukts und die schwierigste Manipulation der Tabakherstellung, weshalb auch

1) Berechnet nach den Angaben in „Compte en matières et en déniers rle l'exploitation du Monopole des Tabacs pour l'année 1902“", Paris, Imprimerie Nationale, 1903.

2) Idem aus „Azienda Dei Tabacchi, Relatione e Bilancio industriale per l'escreizio dal 1. Juglio 1901 al 30 Guigno 1902, Roma 1903.

3) Laurent, F.; a. a. O. S. 282. 
der Fermentation stets die größte Aufmerksamkeit und Sorgfalt gewidmet werden muB. Die Lagerungssysteme des Tabaks zum Zweck der Fermentation wechseln je nach dem Stand und der Art des Tabaks. So ordnet man die besseren Tabakqualititen zu Haufen von 0,5$)(0-0,60 \mathrm{~m}$ Höhe und in der Länge zweier durchkreuzter Büschel an und die Tabakqualitäten III und IV zu großen Haufen von $1,20-1,50 \mathrm{~m}$ Höhe, 1,20 m Breite und beliebiger oder aus den jeweiligen Verhältnissen sich ergebender Länge. In der Zeit der Fermentation legt man die Haufen um, und zwar derart, daß die Randbüschel nummehr in die Mitte zu liegen kommen. Dadurch bezweckt man, eine gleichmäBige Gärung hervorzurufen. Für die besseren Tabakqualitäten fixiert man die Temperatur zwischen $25^{\circ}$ und $35^{\circ}$, für die niedrigeren zwischen $30^{\circ}-45^{\circ}$ und für grünen Tabak zwischen $45^{\circ}$ und $60^{\circ}$.

Der Fermentationsprozel, beginnt im Frühling des nächstfolgenden Jahres und endet im Juni, worauf die Büschel' wiederum nach der Farbe ausgewählt und die besseren Tabakqualitäten zu Ballen von $25-30 \mathrm{~kg}$, die niedrigeren zu solchen von $70-90 \mathrm{~kg}$ verpackt werden. Der verpackte Tabak wandert sodann in das Zentrallagerhaus (Bukarest). Hier wird er einer nochmaligen, aber nur geringen Fermentation unterworfen, wodurch sich eine neue Umlagerung der Büschel im Spätfrühling nötig macht; doch beschränkt sich diese letztere Prozedur lediglich auf den feineren Tabak. Der vollständig fermentierte feinere inländische wie auch ausländische Tabak wird mit besonderer Sorgfalt behandelt und aufbewahrt. Er wird jährlich Ballen für Ballen mehrmals untersucht. Dabei ist man bestreht, nicht nur den guten Ruf des Tabaks zu wahren, sondern auch seine Beschaffenheit noch möglichst zu verbessern. Zu diesem Zweck besteht ein spezielles Personal, welches die Behandlung der Tabaliblätter in den Lagerhäusern von Macedonien und Österreich erlernt hat; außerdem sind einige sehr geschickte Arheiter aus Macedonien vertragsmäßig engagiert, um die richtige Behandlung der Tabakblätter den anderen Arbeitern zu lehren. Der fermentierte Tabak bleibt bis zu seiner Verarbeitung in der Manufaktur in Zentrallagerhaus auf Lager.

\section{Wirtschaftliche und statistische Ergebnisse.}

Die Kultur des Tabaks eignet sich mehr als die jeder anderen Pflanze für den Kleingrundbesitzer, weniger für den mittleren oder großen Landwirt. Diese Eigentümlichkeit erklärt sich aus der be- 
ständigen Arbeit, die, wie bekannt, der Tabakbau verlangt. Von der Zeit der Ausstreuung des Samens in die Saatbeete an bis zum Verkauf der dachreifen Blätter sind, wie schon gezeigt, eine große Zahl von Handarbeiten nötig, die meist auch durch Frauen, Kinder oder altersschwache Personen ausgeführt werden können. Der kleine Landwirt kamn beinahe kostenlos die erforderlichen Arbeiten leisten, weil ihm die günstige Gelegenheit geboten ist, seine Familienglieder als unentgeltliche Arbeitskräfte zu verwenden, während dem großen Landwirt der Tabakbau wegen der großen Ausgaben erschwert, wenn nicht ummöglich gemacht wird, da er doch alle erforderlichen Arbeiten durch fremde Leute gegen hohen Alikord- oder Tagelohn verrichten lassen muß. Dabei arbeiten fremde Personen bekanntlich nicht mit einem solchen Interesse, wie der kleine Landwirt mit seinen Angehörigen auf der eigenen Scholle. Infolgedessen wird die Ernte des Großlandwirts weniger gut und dementsprechend iler Nettoertrag niedriger ausfallen als heim kleinen Landwirt. Es verliert auch bei einer schlechten Ernte der Großgrundbesitzer mehr als der kleine. Letzterer kann auch durch eine Reihe weniger guter Jahre in seinem Wirtschaftshetriebe nicht odler wenigstens nicht erheblich gestört werden, weil er den Tabakbau nur als lukrative Nebenbeschäftigung betreibt. Auslagen hat er nicht oder doch nur geringe, er verrechnet also seine Arbeit in diecem Falle. als hätte er sie teilweise umsonst getan und schränlit seine Lehensherlürfnisse, wenn er nicht in dem besseren Ernteausfall der von ihm neben dem Tabakhau betriebenen Kulturen genïgenden Ersatz gefunden hat, den Verhältnissen entsprechend ein. Berüichsichtigt man des weiteren, daß die Tabakkultur unter dem Monopolsystem einer strengen und lästigen Kontrolle unterworfen ist. daß die Überwachung der Arbeiten eines großen Gutes seitens des Besitzers unzureichend, wenn nicht gar unmöglich ist und ein solcher Umstand zum Unterschleif ron Tabakblättern geradezu aufforlert, dab schließlich der Besitzer auch für die Handlungen seiner Arbeiter verantwortlich, also strafbar ist, so haben wir die Erklärmng und Begrïndung dafür, warum die Tabakikultur in den Monopolländern in viel höherem Mafe als in anderen nur von kleinen Landwirten betrieben wird.

So hat die Einführung des Tabakmonopols in Rumänien bewirkt, dab fast alle diejenigen Grobgrumbesitzer, die vorher Tabaklitultur hetrieben hatten, sie nummehr aufgaben. Die Folge war ein Rückgang der Größe der Anbaufläche, die von $306 ; 3$ ha (im Jahre 1872) plötzlich auf +17 ha (in Jahre 1873) sank. Diesem Rückgang der Anbautläche folgte naturgemäß derjenige der Produktion; so finden wir für Rumänien 
im Jahre 1873 eine solche von nur $79786 \mathrm{~kg}$ oder im Durchschnitt $189 \mathrm{~kg}$ pro ha (auf 417 ha Anbaufläche). Allerdings mögen zu diesem Rückgang auch die grolen Tabakvorräte, welche sich zur damaligen Zeit im Lande befanden, das ihrige mit beigetragen haben; wurde doch im Jahre 1871 allein Tabak im Werte von 2928782 Lei und im Jahre 1872 solcher im Werte von 10756736 Lei eingeführt ${ }^{1}$ ). In den folgenden Jahren der Pachtperiode stieg die Anbautlizche anf 46 is 1 ha mit einer Produktion von $2800000 \mathrm{~kg}$ oder im Durchschnitt $610 \mathrm{~kg}$ pro ha (im Jahre 1876); sie hielt sich aber nicht auf dieser Höhe, sondern sank hierauf ununterbrochen bis zu 2249 Hektar mit einer Produktion von $762436 \mathrm{~kg}$ oder im Durchschnitt 339! kg pro Helitar (im ,Jahre 1879); dies entspricht einem jährlichen Sinken der Anbaufläche in dieser Periode um 3,4\% (s. graphische Darstellung A). Der Grund dafür ist darin zu suchen, daß die Pachtgesellschaft den Tabakbau einschränkte, um die Ausgaben der Verwaltung und die für die Verfolgung des Schmuggels und Unterschleifes entstehenden nicht unbedeutenden Kosten zu vermindern. Am deutlichsten zeigt sich der Rückgang in der oberen Moldau selbst, wo der Tabakbau, der einst einen gewaltigen Umfang besaß und gute Erträge lieferte, seit der Einführung (les Tabakmonopols fast vollstündlig aufhörte $\left.{ }^{2}\right)$. A uch mögen die vielen Schikanen mit dazu beigetragen hahen, die die Tabaktlanzer bis zur Ablieferung der Tabakernte seitens der Regieagenten zu erdulden hatten ${ }^{3}$ ). Während dieser Periode wurden im Durchschnitt $528 \mathrm{~kg}$ yro Heltar geerntet und das Kilogranm mit 78 Cts. hezahlt, sodalo der Ertrag pro Helitar ca. 41르 Lei betrug. Diese Summe würle für den Tabakbauer eine gute Belohnung seiner Arbeit gewesen sein, wenn er sie tatsächlich bekommen hätte; aber er war das Opfer von Mittelspersonen, die ihn ausbeuteten, denn die Regieverwaltung kaufte die Tabakernte nicht direkt von ihm, sondern durch Vermittler. Außerdem wurden die Tabakbauer nicht mit dem von der Kommission festgestellten Einlösungspreis bezahlt, sondern sie bekamen weniger. wie es aus der vom damaligen Finanzminister Sturza in der Kammersitzung rom 20. März 1879 gemachten Mitteilung hervorgeht: „Ihr wilst, dals die Konzessionäre bei den Tabakhanem schlecht angeschrieben sind .... ich habe IIafregeln ergriffen, dals letztere sicher sein dürfen mit dem

1) Monitorul oficial 1879, 1. April.

2) Bericht über das Ernteergebnis in der oberen Moldau in Jahre 1876 und den Getreideexport nach Deutschland. Preußisches Handelsarchiv, Jahrg. 1877, Bd. I, S. 438.

3) Monitorul ofical 1879, Martie 20. 
ron der Iiommission festgesetzten Einlösungspreis bezahlt zu werden und daß sie fermerhin bei der Verwiegung und Ablieferung der Tabakernte nicht mehr, wie dies bisher der Fall war, Schikanen unterworfen sind."

Mit dem Übergang der Regie in die Hände des Staats im Jahre 1879 nahm der Tabakbau eine größere Entwicklung an, obgleich er nicht mehr im ganzen Land, sondern nur in bestimmten Bezirken erlaubt war. Schon im folgenden Jahre (1880) stieg die Zahl (ler mit Tabak bebauten Hektare Ackerland ron 2249 auf $46+1$ ha mit einem Produlitionsertrag von $5157806 \mathrm{~kg}$. Der Tabakbau hatte sich also um dias Doppelte vergrößert. In den folgenden Jahren wurde die Anbaufläche zwischen 4000 und 7000 ha beibehalten mit einer Produktion zwischen 3-5 Mill. kg. In den Jahren 1883, 1886, 1898 und 1899, in denen weniger bebaut wurde, betrug die Anbaufläche 2-3000 ha mit einer Produktion von $1-2 \frac{1}{2}$ Mill. $\mathrm{kg}$. Die größte Ausdehnung fand sie im Jahre 1889, wo 7809 ha dem Tabakbau gewidmet wurden und die Produktion 5 t95:371 kg betrug. Seit 1879-1902 wurden 114664 ha mit Tabak bebaut, also durchschnittlich 4778 ha pro Jahr. Die Gesamternte betrug $79406656 \mathrm{~kg}$, wofür die Regieverwaltung den Tabakbauern 4\% 48128 Lei zahlte. Im allgemeinen zeigt, wie aus der graphischen Darstellung A ersichtlich ist, die Anbautläche in dieser Periode große Schwankungen. Diese wurden hervorgerufen durch die seitens der Regieverwaltung wegen zu großer Ansammlung der Tabakrorräte getroffene Einschränkung des Anbauareals, mehr aber noch wegen der Niedrigkeit der dem Tabakłauer gezahlten Einlösungspreise. wie später klargelegt werden wird. In der Gesamtheit vergrößerte sich während dieser Periode die Anbautläche um 52 Proz.. was einer durchschnittlichen jährlichen Zunahme von allerdings nur 2.17 Proz. entsprechen würle. Jedoch wäre es unpraktisch und unklug gewesen. dem Tabakbau eine schnellere Ausdehnung zu geben, um so mehr als die Tabakptlanze eines guten Bodens und einer sehr sorgfältigen Behandlung bedarf ${ }^{1}$ ). Der Tabakbau würde in den seitens der Regie erlaubten neuen Anbaugegenden in Frage gestellt worden sein, würde man die Ausdehnung von Anfang an zu intensiv betrieben haben und olne vorerst über einen nötigen Stamm von Tabakpflanzern zu verfügen, die ihre Erfahrung durch gute Ernteerzengnisse bewiesen hatten. Mit der Tabalkultur beschäftigten sich auch in dieser Periode nur Kleingrundbesitzer,

1) Konrad, a. a. O. S. 111 . 
deren Zahl von $8019 \mathrm{im}$ Jahre 1879 auf $12960 \mathrm{im}$ Jahre 1902 stieg. Es rermehrte sich demnach ihre Zahl in dieser Periode um mehr als (lie Hälfte (62 Proz.). Durchschnittlich wiohmeten sich jährlich 13000 Tabakpflanzer dem Tabakbau, so daß auf jeden Pflanzer 35 qm entfallen. Im Vergleich mit anderen Ländern ist die Ausdehnung der Anbauthäche von nicht geringer Bedeutung; der Prozentsatz im V'erhältnis zur Flächengröße Rumäniens gleicht dem Deutschlands. Frankreichs und ist sogar höher als der Italiens, wie es die Tabelle II veranschaulicht (siehe S. 40).

Die durchschnittliche Produktion eines Hektars Ackerland ist aber eine bei weitem geringere als diejenige der genannten Länder. Während in Deutschland von einem Hektar 2359 $\mathrm{kg}$, in Frankreich $1532 \mathrm{~kg}$, in Österreich $1141 \mathrm{~kg}$ und in Italien $1104 \mathrm{~kg}$ geerntet werden, erreicht das Ernteergebnis in Rumänien kaum $653 \mathrm{~kg}$. Dies beweist, wie wenig die Tabakkultur Rumäniens im Vergleich zu der anderer Länder vorgeschritten ist. Es findet seine Erklärung in dem Mangel an landwirtschaftlicher Bildung, den veralteten Kultursystemen und den ungünstigen wirtschaftlichen Bedingungen, unter denen der gröhte Teil (ler Pflanzer zu arbeiten gezwungen ist ${ }^{1}$ ). Hinzu kommen noch der Mangel einer rationellen Düngung der dem Tabakbau dienenden Borlenfläche, die unvorteilhafte Koppelwirtschaft und die Beschaffenheit des Tabaksamens, der verschiedentlich Pflanzen mit kleinen und dünnen Blättern liefert. Dort, wo die Tabakkultur sorgfältig betrieben wird, resultiert auch eine höhere Durchschnittsprodulition. So wird im Bezirk Jalomitza und in der Dobrodscha pro Hektar $1000 \mathrm{~kg}$ Tabak geerntet und die Versuchskulturen erzielten im Jahre 1495 sogar eine Ernte von durchschnittlich $1300 \mathrm{~kg}$ pro Hektar.

Die Tabakkultur als solche hat in dieser Periode einen Fortschritt zu verzeichnen, wie dies die durchschnittliche Produktion pro Helitar beweist (graphische Darstellung B). Während im Jahre 1s69 nur $339 \mathrm{~kg}$ pro Hektar geerntet wurden, erzeugte die gleich grolie Fläche im Jahre $1902653 \mathrm{~kg}$, mit anderen Worten: der Durchschnittsertrag stieg während der ganzen Periode um 48 Proz., bezw. pro Jahr um 2 Proz. Die schwächste Ernte wurde 1879 erzielt, in welchem Jahr sie pro Hektar nur 339 lig ergal), den stäksten durchschnittlichen Ertrag haben die Jahre 1880 und 1898 zu verzeichnen, und zwar mit 1111 bezw. 1055 kg pro Hektar. Innerhalb der ganzen Periode beziffert sich die durchschnittiche Produlition auf 700 ke pro

1) P'oporici, a. a. O. S. 101. 
II.

\begin{tabular}{|c|c|c|c|c|c|c|c|c|c|c|}
\hline L iinder & $\begin{array}{c}\text { Flächen- } \\
\text { inhalt } \\
\text { qkın }\end{array}$ & $\begin{array}{c}\begin{array}{c}\text { Tabakanbau- } \\
\text { fiăche } \\
\text { ha }\end{array} \\
\end{array}$ & $\begin{array}{l}\text { Ver- } \\
\text { hältnis } \\
\text { in } \%\end{array}$ & $\begin{array}{l}\text { Zahl der } \\
\text { Pflanzer }\end{array}$ & $\begin{array}{l}\text { Zahl der } \\
\text { qua auf } \\
\text { einen } \\
\text { Pflanzer }\end{array}$ & $\begin{array}{c}\text { Gresamtnro- } \\
\text { duktion in } \\
\mathrm{kg}\end{array}$ & $\begin{array}{c}\text { Gesamt. } \\
\text { werte der } \\
\text { Tabak- } \\
\text { ernte } \\
\text { Fres.- } \\
\end{array}$ & $\begin{array}{l}\text { Dureh- } \\
\text { schnitts- } \\
\text { prisis } \\
\text { pro } \\
100 \mathrm{~kg} \\
\text { Fres. } \\
\end{array}$ & $\begin{array}{c}\text { Durch- } \\
\text { schnitts- } \\
\text { ertrag } \\
\text { pro ba } \\
\mathrm{kg} \\
\end{array}$ & $\begin{array}{c}\text { Durch- } \\
\text { schnitts- } \\
\text { ertrag } \\
\text { pro ha } \\
\text { Fres. } \\
\end{array}$ \\
\hline $\begin{array}{l}\text { Frank- } \\
\text { reich }\end{array}$ & 526464 & 15936 & 0,03 & 54639 & 29 & $\mid 24420772$ & $22009226^{\circ}$ & 90,12 & 1532 & 1381 \\
\hline Österreich & 675887 & 27766 & 0,04 & 54523 & 51 & 31675205 & 14058581 & 44,38 & 1141 & 506 \\
\hline Italien & 286682 & 4977 & 0,02 & 一 & - & 5492534 & 3609058 & 65,71 & 1104 & 725 \\
\hline Rumänien & 131353 & 4022 & 0,03 & $12296^{\circ}$ & 32 & 2630454 & 1555495 & 59,00 & 653 & 388 \\
\hline $\begin{array}{l}\text { Deutsch- } \\
\text { land }\end{array}$ & 540743 & 17340 & 0,03 & 117922 & 15 & 37698570 & 38995332 & $\left.103,20^{*}\right)$ & 2174 & 2249 \\
\hline
\end{tabular}

*) Einschließlich der Steuer.

Hektar, während dieselbe in der früheren Pachtperiode nur $528 \mathrm{~kg}$ pro Hektar betrug. Im allgemeinen weist die Tabakproduktion bedeutende Schwankungen auf, die jedoch mehr oder minder auf die klimatischen Verhältnisse des Landes zurückzuführen sind. In dieser Beziehung ist trotz der allgemein anerkannten Fruchtbarkeit des Bodens die rumänische Landwirtschaft gegenüber der des gesamten Westeuropas ungehener benachteiligt. Das Kilima ist auferordentlich veränderlich: änferst strenge Winter und mit grofer Hitze und Dürre verbunlene Sommer sind nicht selten; letztere machen sich seit einigen Jahren sehr fühlhar und sind jerlenfalls eine Folge der im allgemeinen in sehr unrationeller Weise betriebenen Abholzungen ${ }^{1}$ ).

Als ein Beweis dafür, daß die Tabakkultur der letztbesprochenen Periode eine Verbesserung erfahren hat, dürfte des weiteren das jrozentuale Verhältnis der Rohtabakqualitäten dienen. Am deutlichsten wird dies seit 1897 durch das Sinken der geringsten (Qualität (Furda) von 28 Proz. (1897) auf 1 Proz. (1902) (s. graphische Darstellung C) veranschaulicht. Der prozentuale Rückgang gerarle dieser (billigsten) Tabakqualität ist deshalb bedeutsam, weil sie die Preise der übrigen (Sualitäten stark heeinflubt und infolgerlessen ten Bruttoertrag bestimmt, (li bei keinem anderen Produlit die Qualität eine so große Rolle spielt als beim Tabak. So wird z. B. der beste Tabak aus einer hügeligen (iegend mit 4 Lei pro Kilogramm, das gleiche Quantum gewöhnlichen Tabaks aber mit nur 2()—:30 Bani bezahlt"2). Demzufolge hängt der Durchschnittspreis von dem Verhältnis der verschiedenen Qualitäten ab, wie

1) Creanga, D. G., a. a. O. S. 147.

2) Regia Monopolurilor Statului, Bukarest 1903. 
dies auch aus der graphischen Darstellung C zu ersehen ist. Die Linie des Durchschnittspreises weicht nach derselben Richtung ab. wie das prozentuale Verhältnis der Tabakqualitäten I und II und in umgekehrter Richtung der Qualität III, im besonderen aher der (billigsten) Qualität Furda. Hieraus ergibt sich auch der Grund der seit 1897 steigenden Preistendenz mit alleiniger Ausnahme des Jahres 1901, in welchem der allzu großen Produktion der III. Qualität (72 Proz.) halber ein Preisrüickgang eintrat. Deshalb ist auch die Höhe des Bruttoertrags pro Helitar der durchschnittlichen Prorluktionshöhe nicht stets gleich. So ist der Bruttoertrag, welcher der Linie der Durchschnitsprodulition his 1895) folgt, im Jahre $18 x 6$ gewachsen, die Durchschnittsproduktion hat sich aber gegenüber der des Jahres 1885 vermindert. Das Gegenteil bemerken wir in den Jahren 1889 und 1897, indem hier die Durchschnittsprodulition zunimmt. der Durchschnitsbruttoertrag hingegen sinkt. - Betrachten wir die Durchschnittspreise dieser drei Jahre, so sehen wir, daß die Höhe des Durchschnittspreises im Jahre 1886 gestiegen, 1889 und 1897 jedoch gesunken ist. Dies ist eine weitere Bestätigung des oben Gesagten, daß die Qualität des Tabaks den Bruttoertrag bestimmt. Im allgemeinen verfolgt der Bruttoertrag die Bewegung der Durchschnitsproduktion, er steigt von 217 Lei pro Hektar im Jahre 1889 bis auf 653 Lei pro Hektar im Jahre 1902. Die Gesamtsteigerung beträgt 67 Proz. oder jährlich 2,8 Proz. und stellt für diese Periode einen Durchschnitt von 400 Lei pro Hektar dar. Zweifellos bringt gegenwärtig der Hektar einen Bruttoertıag doppelter Größe, als dies in Jahre 1872 der Fall war, aber es ist doch immerhin nur ein schwacher Ersatz der Hoffnungen und Erwartungen, zu denen der Tabakbauer durch seine fortdauernile. mühsame Arbeit während des ganzen Jahres jedenfalls berechtigt ist. Wie niedrig der Bruttoertrag ist, geht aus der Tabelle II hervor. wo wir sehen, daß der Bruttoertrag in Deutschland beinahe siebenmal, in Frankreich mehr als viermal, in Österreich zweimal und in Italien mehr als zweimal höher ist als in Rumänien. Wohl ist es wahr, daß die Herstellungskosten dort höher sind als in Rumänien, aber trotz alledem ist der Reinertrag geringer. Nach Poporici ergibt sich in Deutschland ein Reinertrag von beinahe 40 Proz., in Frankreich ein solcher von mehr als 50 Proz. und in Österreich-Ungarn von 30 Proz., während in Rumänien der Reinertrag nur 7 Proz. beträgt ${ }^{1}$.

1) Popovici, a. a. O. S. 103.

Volkswirtsehaftl. u. wirtschaftsgeschichtl. Abhandlungen. II, 4. 
Die Ursachen dieses niedrigen Ertrages liegen nicht nur in der geringen Durchschnittsprodulition, sondern auch in den kleinen Einlösungspreisen, welche die Regieverwaltung den Tabakpflanzern für ihre Tabakernte zahlt. Ein kurzer Überblick auf die in der graphischen Darstellung B dargestellte Linie der Durchschnittspreise zeigt im Großen und Ganzen eine sinkende Tendenz. Während im Jahre 1879 ein Durchschnittspreis ron (it Bani pro Kilogramm hezahlt wurde, erhielt der Tabakiptlanzer im Jahre 1902 für das gleiche Quantum nur 59 Bani. Innerhall, dieser Periode gibt es nur 5 Jahre (184:3, 1884, 1886, 1887 und 1858). in denen höhere Durchschnittspreise als lit Bani bezahlt wurden; in den übrigen Jahren stehen die Preise unter 64 Bani, im Jahre 1 Kos wurden sogar nur 46 Bani pro Kilogramm als Durchschnittspreis gezahlt. Es ergibt sich für die gesamte Periode ein Durchschnittspreis von as Bani pro Kilogramm. Die Regie aber verkaufte den Konsumenten ein Kílogramm verarbeiteten inländischen Tabakis mit 4-12,50 Lei. Daf die Einlösungspreise verhältnismäßig niedrig sind, geht auch aus einem dieshezüglichen Vergleich mit anderen Lündern hervor: so wurden im Jahre 1902 für $100 \mathrm{~kg}$ folgende Preise gezahlt:

in Deutschland . . . . 106,78 Fres.
"Frankreich . . . . 90,12 "
"Österreich . . . . . 44,38 "
"Italien . . . . . . 55,71 "
und in Rumänien . . . 59,00 ".

Es könnte der Einwand erhoben werden, daß in Österreich der Durchschnittspreis niedriger ist als in Rumänien. In Bezug hierauf sei darauf hingewiesen, daß in Österreich die Transportliosten nicht, wie bereits oben erwähnt, in den Einlösungspreisen hegriffen sind, wie dies in Rumänien der Fall ist; außerdem muß man bedenken, daß in Österreich auf einem Hektar Ackerland die dopyelte Menge der in Rumänien auf der gleichen Fläche erzielten PHanzen geerntet wird, wodurch sich eo ipso der Ertrag erhöht. Aus dem Gesagten ergibt sich, - laß die Kultur des Tabaks in Rumänien sehr wenig lohnend ist; deshalb ist die Meinung einiger, dab der Anbau des Tabaks als ein für die Bauern sehr lohnender anzusehen sei, nicht zutreffend. Eine verlockende Aussicht hätte die Tabakkultur nur dam. wenn die Regieverwaltung die Einlösungspreise so bemessen würde, daß es dem Grundbesitzer vorteilhafter erschiene, Tabak statt Weizen zu bauen.

Wenn nun die Tabakkultur für den rumänischen Bauer wirklich so wenig ertragreich ist, so drängt sich unwillkürlich dlie Frage auf, warum die Pflanzer sich noch damit beschäftigen und sich nicht einer 
anderen Kultur zuwenden. Darauf ist zu erwidern, daß sich die TabakpHanzer auf die Ernte eines guten Jahres verlassen, dessen Ertrag die früheren Schäden ausgleichen soll. Außerdem werden die Tabakbauer durch die ron der Regieverwaltung geleisteten Geldvorschüsse angelockt, die ihnen bei augenblicklichen (iellbediurfnissen immer sehr zu statten kommen. Es liegt aber im eigenen Interesse der Regie und des Staates, dem Tabakbauer einen solchen Preis für seinen Tabak zu zahlen, daß er dabei bestehen kann und sein Auskommen findet. Dadurch wird ein tüchtiger und strebsamer Arbeiterstamm herangebildet, der in der Lage ist. wesentlich zur Entwicklung und Verbesserung der Tabakkultur beizutragen. Außerdem bietet der Tabakbaı während des ganzen Jahres Beschäftigung, wodurch dem verilerblichen Einflub des Müssiggangs und den sich daran knüpfenden bösen Folgen vorgebeugt wird; auch dieser Umstand ist von nicht geringer Berleutung für die Bauem, welche im allgemeinen während der Wintermonate beschäftigungslos sind.

\section{Die Bestrebungen der Regie zur Verbesserung des Tabakbaues.}

In der festen Überzeugung, daß sich die Tabakkultur unter dem Monopolsystem der verschiedenartigen amtlichen Vorschriften wegen nur langsam entwickeln, und nur dann zur Blüte gelangen kann, wenn die Regierverwaltung sich ihrer kraftroll ammimmt, bestrebte sich diese, die inländische Kultur zu begünstigen und zu verbessern. Das war um so notwendiger, als die Tabakkultur während der Pachtperiode vollständig vernachlässigt wolden war, denn die Pachtgesellschaft hatte sich zur Hebung derselben sehr wenig, vielleicht gar keine Mühe gegeben. Zu diesem Zweck richtete die Regieverwaltung Versuchskulturen ein. um zu sehen, welche Tabaksorten bezüglich der ()ualität und Quantität der daraus hergestellten Fabrikate am hesten seien. Gleichzeitig sollten diese Versuche auch als Richtschnur für die Auswahl der für den Tabakbau greeignetsten Gegenden dienen. Der erste Kulturversuch mit 7 verschiedenen Tabakpflanzensorten (Jaka, Smyrna, Persicean, Samsun, Havana, Scaferlaty und Palatinat) fand im Jahre 1890 im Bezirk Prahova statt. Gleichzeitig stellte die Regiever waltung Versuche mit dem Anbau dieser Tabakptlanzen in den dortigen, durch die Reblaus vernichteten Weinbergen an. Das Ergebnis war sehr zufriedenstellend; die Versuche wurlen in den Jahren 1891 und 1892 weiter fortgeführt und ergaben folgendes Resultat: 


$\begin{array}{crrr}\text { Tabak } & \text { I. Qualität } & 10,7 \% \\ \text {, } & \text { II. } & , & 33,7 \% \\ . & \text { III. } & \text { " } & 33,4 \% \\ \text { Furcla } & \text {. . . . . . } & 22,2 \%\end{array}$

Auch erlangte die Regierverwaltung die Überzengung, daß die Weinherge sehr vorteilhaft für den Tabakbau seien; trotzdem konnte sie ihn in dieser Gegend nicht verbreiten, weil die Bauern vorzogen, statt des Tahaks ihre Weinberge mit amerikanischen Weinstöcken aufs neue zu bepflanzen. In den folgenden Jahren (ausgeschlossen das Jahr 1897) wurden die Versuche fortgesetzt, und zwar in den Bezirken Tulcea, Dimbovitza, Romanati, Vlasca und Falciu. Man konstatierte schlieflich. daß die Tabaksorten Persicean, Samsun und Jaka die für die Kultur geeignetsten seien. Diese fanden demzufolge auch Terbreitung. Seit 1898 versuchte man ausländische. im besonderen macedonische Tabaksorten zu bauen. Die Ergebnisse zeigten, daß sich Klima und Boden Rumäniens gut zur Produktion dieser Tabaksorten eignen und als Ersatz der aus Hacedonien zum Preis von 5 -, 50 Lei pro Kílogramm gekauften Tabaksorten gut verwendlbar sind. Dadurch bietet sich der rumänischen Tabakkultur einerseits die Aussicht. allmählich die aus der Türkei und Griechenland eingeführten Tabaksorten zum größten Teil ersetzen zu können, worlurch ein großer nationalökonomischer Vorteil gewommen wird, andererseits wird der Export dieser Tahaksorten, sei es als Rohtabak oder Fabrikat (Zigaretten), bedeutend erleichtert werden. In folgender Tabelle III sind die erzielten Erträge für die Jahre 1898 bis 1901 angegeben (siehe nächste Seite).

Aus der Tabelle ergibt sich, daß die Weinberge, hauptsächlich die der Ortschaften Dragasani und Valea-Calugareasca, die besten Tabake erzeugen, denen sich in zweiter Linie die der Ortschaften Macin und Leordeni anschließen. Diese Ergelmisse veranlaßten die Regieverwaltung, die Tabakkultur in diesen riegenden auszudelmen. Gleichzeitig dienten einige Weinherge zu hulturversuchen, besonders um zu erkennen, welche Tabaksorten und Bodenarten sich am besten für die Tabakkultur eignen, des weiteren wurden sie aber auch als praktische Schule für das untere Beamtenpersonal der Tabakkultur und als MusterpHtanzung für die Tabakzüchter der L'mgebung benutzt. Die Regieverwaltung ihrerseits war in der Lage, die Gegenden, die sich am hesten für den Tabakhau eigneten und den Unterschied der auf den Weinbergen und dem flachen Lande erzeugten Tabakqualitäten festzustellen, desgleichen die zur Tabakikultur geeignetsten Mittel 


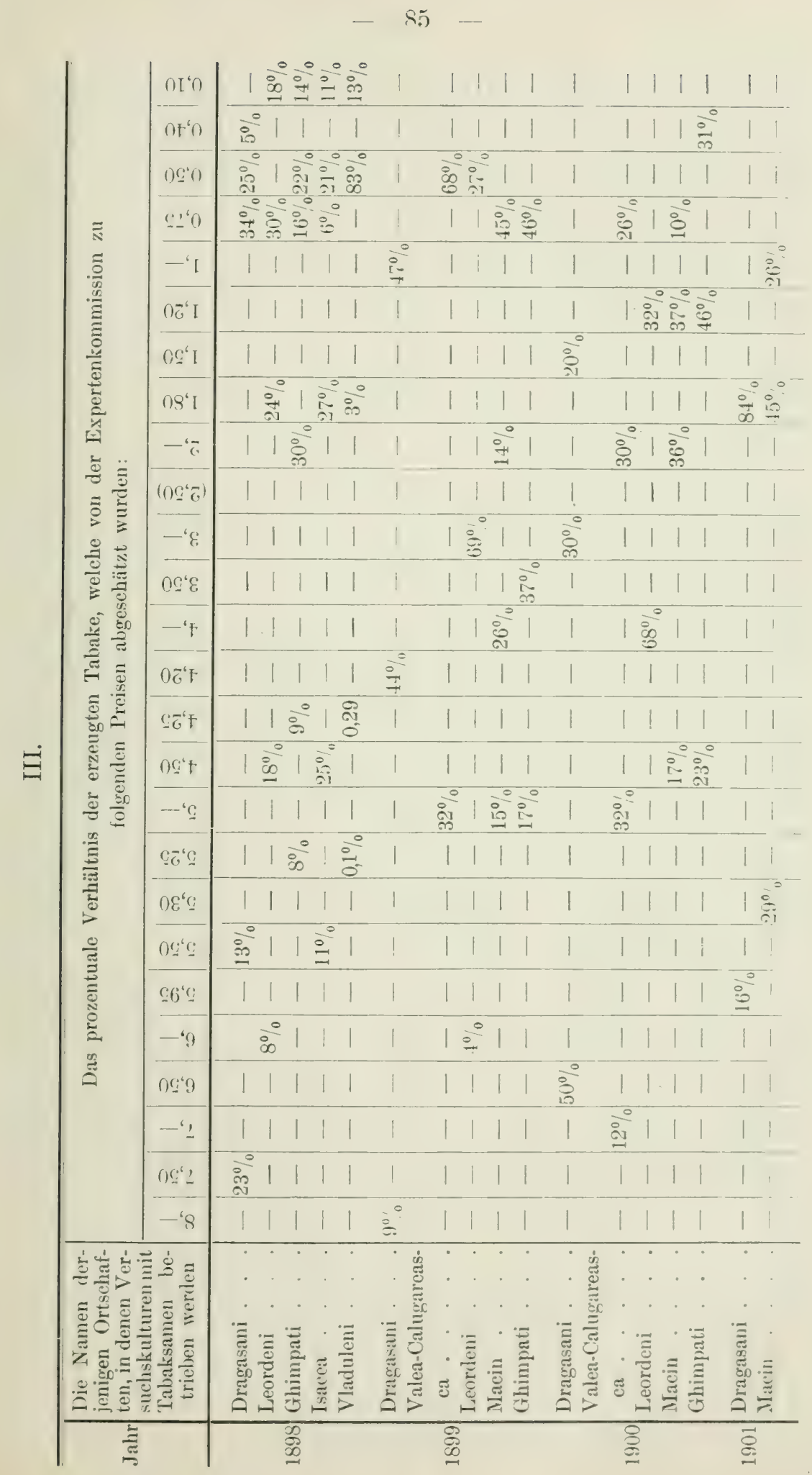


sowie die Zeitpunkte, an denen die verschierlenen Tabakarbeiten stattfinden sollen, anzugeben. Ebenso bestimmte die Regieverwaltung die Einrichtung der für Rumänien an besten geeignete: Tabaktrockenanstalten und schlieflich fixierte sie die Einlösungspreise für den Rohtabak.

Um eine gute Anbaumethode unter den Pflanzern zu verbreiten, richtete die Regie MusterpHlanzungen ein, in denen man die geprüften und als vorteilhaft erkannten Methoden anwendete. Diese Musterpflanzungen bilden das praktischste Mittel, den Tabakhauer gute Kúulturmethoden zu lehren, llenn es ist bekannt, daf das Beispiel leichter als das Wort den Bauer überzeugt. Yon dem Personal dieser Musterpflanzungen werden praktische Kurse für die Tabakbauer abgehalten ${ }^{1}$ ).

Da bekanntlich die Bodenart speziell für den Tabakbau von großer Berleutung ist, so dürfte es nicht ohne Interesse sein, die Ausführungen Semlers²) wiederzugeben, welcher hinsichtlich der Wahl des Tabakackerlandes sagt: .Nach Abwägun der Gunst und Ungunst des Klimas für den Anbau ist die Wahl des Borlens in Betracht zu ziehen, die, das sei mit scharfer Betonung gesagt, von der höchsten Wichtigkeit ist. Wenn man die Weinrebe ausnimmt, gibt es keine Nutzpflanze, deren Prorlukt in gleichem Maße durch den Boden beeinflußt wird, wie es bei der Tabakptlanze der Fall ist. Keine noch so sorgfältige Kultur und Erntebereitung liann den Fehler ausgleichen, der in der Wahl des Bodens gemacht wird." Auch die Regieverwaltung lies, von der hohen Wichtigkeit der Bodenart und dem Einfluß derselben auf die Vegetation der Tahakptlanzen überzeugt, den für den Anbau mit Tabak bestimmten Borlen mechanischen und chemisch-analytischen U'ntersuchungen unterzichen. Infolge der mechanischen Analysen wurde festgestellt, daß der Boden zum gröften Teil lehmhaltig und sehr schwer zu bearbeiten ist, letzteres namentlich dann, wenn ihm ein gewisser Grad von Feuchtigkeit fehlt. Er hat aber den Vorteil, daß er das einsickernde Wasser schnell absorbiert und nur allnählich wieder ahgibt, was bei der in Rumänien öfters eintretenden Dürre von nicht zu unterschätzender Bedeutung ist. Der Boden vom Bezirk Tulcea ist für den Tabakbau am geeignetsten, weil der größte Teil desselben nur 6 Proz. Lehm, aber ca. 50 Proz. Kies enthält. Lehmartiger Borlen liefert zwar einen größeren Ernteertrag

1) Das Personal wird aus den Schülern genommen, die die höheren und praktischen landwirtschaftlichen Schulen gut bestanden haben.

2) Die Tropische Agrikultur, 2. Auflage Bd. III. S. 380, Wisuar 1903. 
an Tabak, aber er erzeugt dicke und wasserhaltige Blätter, während Schlammboden Blätter von erster Qualität erzeugt. Durch die chemischen Analysen wurde erwiesen, daß der Boden nur wenig Stickstoff (höchstens 0,15 odler 0,16 Proz.) enthält. In dieser Beziehung sollte die rumänische Regie noch weiter gehen und das Vorbild Frankreichs nachahmen. welches die Hilfe der Chemie in der Tabakkultur schon seit lange anerkannt und gewürdigt hat. Bei der großen Bedeutung des Sticlistoffes ergibt sich für die Tahakhauer die zwingende Notwendigkeit, den Borlen mit Stalldünger zu düngen; eine Kulturarbeit, die leider in Rumänien noch wenig bekannt ist. So schreibt z. B. E. Flor in seiner ,Monographie eines Landgutes in Rumänien" (Leipzig 1904): „Der Bauer Rumäniens benutzt den Stalmist als Brennmaterial“, und weiter: „Wäre für den Kulturboden odler das Ackerland . . wirklich eine Düngung von Nöten, so würde man auf alle Fälle gezwungen sein, entweder den Stallmist anlerwïts zu heziehen orler aber käuflichen Kunstdünger zu verwenden."6 Wenn nun auch der rumänische Tabakbauer seinem Stallmist die bessere zweckentsprechendere Verwendung auf dem Acker sichert, so läBt es sich doch nicht verkennen, daf die Regie hinsichtlich der Aufklärung der Bauern üher Düngung und rationelle Terwendung des Dïngers noch viel zu leisten hat, ehe in dieser Beziehung die anderen Kulturländer erreicht sind. Wenn, wie es in Rumänien der Fall ist, das Rindvieh sich vom Frühjahr bis Herbst auf der freien Weide befindet und infolgedessen gerarte für die Bestellperiorle im Herbst kein Stallmist vorhanden ist, weil die denselben produzierenden Tiere kine Stallfütterung crhielten, damn müssen die Bauern auf die künstlichen Düngemittel hingewiesen umı ihnen nötigenfalls deren Wirkung auf einem Versuchsfolı arl orulos demonstriert werden. Der Dank des Ackers in Form reicher Ernten wïrle schon von selbst dazu beitragen, den Bauer auch an kïnstlichen Dünger zu gewöhnen.

So besteht z. B. in Frankreich eine Bestimmung der Regieverwaltung, wonach der zum Anbau mit Tabak angemeldete Acker erst zu analysieren ist; der Befund der Analyse bedingt die Ammahme oder Ablehnung des Bauangebotes. Ja ,selbst bei bereits erlaubter Tabakkultur wird auf Grund der Analyse dem Bauern zur PHicht gemacht, die event. fehlenden Düngerarten dem Boden noch einzıverleiben, deren annähernde Menge ihm vorgeschrieben wird"1).

1) Semler, Heinrich, Die Tropische Agrikultur, 2. Auflage, Bd. III, Wismar 1903 , S. 383. 
Die rumänische Regierverwaltung sollte auch diesem Beispiel folgen, was der Tabakkultur zum Segen gereichen würde. Weil die meisten Tabakpflanzer Bauern oder kleine (rirundbesitzer sind, die ein nur kleines oder gar kein Betriebskapital besitzen, so gewährt die Regieverwaltung durch ihre Beamten den einzelnen Tabakpthanzern Yorschüsse auf Rechnung der künftigen Ernte. Dadurch erweist die Regie den Bauern eine große Wohltat, indem diese in Zeiten finanzieller Knappheit oder Not vor Betrug und Wucher geschützt werden. Die Einzelvorschüsse in den Jahren 1880 bis 1885 erreichten eine Höhe von 75 -103 Lei pro Hektar ${ }^{-1}$ ) und bis zum Jahre 1902 belief sich der Gesamtrorschuf auf 13 t56900 Lei. Im Durchschnitt kamen demnach 40,82 Lei auf 1 Tabakpflanzer oder 117,51 Lei auf 1 Hektar Kulturland. Im Verhältnis zum durchschnittlichen Bruttoertrag eines $\mathrm{Ha}$ Ackerland ergibt sich, daß die den Tabakpflanzern gewährten Vorschüsse 25 Proz. des Erntewertes übersteigen.

Die Fürsorge der Regieverwaltung ging noch weiter. Als sie sah, daß die Tabakernte wegen des Mangels an sy'stematischen Trockenanstalten viel an ihrem Wert verlor und dieser Schaden sowohl sie als auch die Tabakbaner traf, indem die Regie weniger feine Qualitäten Tabak, der Bauer aber einen dementsprechend geringeren Preis erzielte. war sie darauf berlacht, diesem Mangel abzuhelfen. Des weiteren war die Regieverwaltung bemüht, dem Übelstande Abhilfe zu schaffen, welcher die Bauern betraf, wenn die Ernte durch Hagel, Feuer oder andere Unfälle vernichtet wurde und somit die Arbeit eines vollen Jahres unbolohnt blieb. Demn der größte Teil der Bauern Rumäniens kennt die Vorteile der landwirtschaftlichen Versicherung nicht oder er hat unklare Vorstellungen ron ilınen. Um allen diesen Nachteilen entgegenzutreten, kam die Regieverwaltung mit den Tabaklbanern dahin ïherein, daß ihnen ein bestimmer Prozentsatz des Wertes der erzeugten Tahakernte jährlich abgezogen wird, und zwar 6 Proz. den Tabakbauern aus der Moldan und Walachei und 8 Proz. denen aus der Dobrodscha. Auf diese Weise bildete sich seit 1882 bis 1903 ein Fond von 806,060 Lei, welcher der Zentralsparkasse (Bukarest) zur Terzinsung übergeben ist und nach einem speziellen Reglement verwaltet wird $\%$. Diesem entsprechend wurden in den letzten 3 Jahren den Tabakbauern 129674 Lei ausgezahlı, für welche Summe 861 Trockenanstalten und Lagerhäuser er-

1) Alexandrini, Statistica Rominiei, Vol. II, p. 278, Jassy 1898.

2) Das Reglement für die Verbesserung des Tabakbaues und für die Versicherung, veröffentlicht in Monitorul oficial Nr. 71 rom 27. Juni 1903. 
richtet wurlen. Die Hälfte der verteilten Summe ist nicht rïckzahlbar. sondern freies Eigentum des Bauern, sie schwankt je nach der Ausdehnung der dem Tabakbau gewidmeten Grundthäche zwischen 100 und 300 Lei. Die andere Hälfte der Geldsumme ist der Tabakptlanzer bei der jedesmaligen Ablieferung der Ernte in 5 einjälırigen Raten mit à Proz. Zinsen zurüclizuzahlen verptlichtet: dieselhe schwanlit ebenfalls zwischen 100-300 Lei nach demselben Grundsatz. Die geborgte Summe betrug im Jahre 1903 27,625 Lei. Um tüchtige und strebsame Tabakpflanzer zu belohnen, teilt die Regieverwaltung auferdem jährlich verschiedene Prämien im Wert von 25-200 Lei für je einen Tabakptlanzer aus. Diese Prämien bestehen in Rindern, landwirtschaftlichen Geräten, Obstbäumen, Samen und selbst in Geld. Vom Jahre 1882 bis 1902 wurden 454942 Lei als Pråmien ausgeteilt. Erwähnenswert ist die Maßnahme der Regieverwaltung, wonach die für das Jahr 1904 bestimmten Prämien im Betrag von 5000 Lei nur in Reproduktionstieren bestehen sollen. Diese Maßnahme ist insofern von Berleutung, als bis jetzt die Viehzucht in Rumånien noch sehr im Argen liegt und nur wenige weitblickende Landwirte sie zu fördern bestrebt sind. Vom Jahre 1899 an zahlt die Regieverwaltung auch die Entschädigungen für die aus Hagel, Feuer etc. entstehenden Schäden. Sie hat seit dem genannten Jahre bereits 22379 Lei Entschärligungsgelder verteilen können. Nenerdings versorgt die Regieverwaltung aber auch den Tabakbaner mit den zum Tabakban nötigen Geräten unı anderen Material, wie Seile, I,einwanıl. Holz u. s. w. und zwar zum Selbstkostenpreis unter leichten Rückzahlungsbedingungen.

Auf diese Weise strebt die Regieverwaltung eine grindliche Verbesserung und Förderung der Tabakkultur an; sie wïrde aber ihr Werk baldigst gekrönt selıen, wenn sie den Tabakptlanzern höhere Einlösungspreise zahlen wïrde, weil dieselben anregender sind als Prämien, die nur einer kleinen bestimmten Zahl der Tabakpflanzer zugute kommen.

Natürlicherweise übte und übt auch die Regie diese Tätigkeit nicht ohne traurige Erfahrungen, denn die Ergebnisse entsprechen nicht immer ihren Hoffnungen. Zweifellos aber hat sich die 'Tabakkultur im Vergleich zu früher um vieles gebessert, aber sie steht noch lange nicht auf der Entwicklungsstufe anderer Länder, was jedoch in Anbetracht des Strebens der Regie und der Leschaffenhorit rles Klimas und bodens in viclleicht nicht allzuferner '/ukunft erreicht 
werden dürfte. Denn voraussichtlich wird die Regieverwaltung auf dem einmal betretenen Wege nicht stehen bleiben, sondern sie wird durch stetig fortgesetzte Versuche und durch Anspannung aller intellektuellen und materiellen Kräfte dem großen Ziele zustreben, die noch bestehenden Übel zu beseitigen und die Tabakkultur auf diejenige Entwicklungsstufe emporzuheben, die sowohl der Beschaffenheit des Bodens und Klimas, als auch der Tüchtigkeit des unter einer guten Leitung stehenden rumänischen Bauern entspricht. 


\section{Die Tabakverarbeitung.}

\section{Die Anschaffung von Rohmaterial.}

Für die Herstellung der Tabakfabrikate, die zum inländischen Verbranch notwendig sind, könnte die heimische Produktion durch eine größjere Ausdehnung der Tabakkultur wohl die gewünschten Quantitäten an Rohstoff liefern, aber die Regie kann eine gewisse Grenze der Verwendung heimischen Rohtahaks nicht üherschreiten, ohne die Qualität ihrer Fabrikate zu schädigen, und zwar aus folgenden zwei (rründen: 1. Die inländische Produktion liefert nicht genügende Quantitäten zur Herstellung der feineren Qualitäten und 2. kamn man nur durch eine richtige Mischung mit ausländischem Tabak solche Fabrikate herstellen, die der Konsumtion entsprechen. Deshalb ist die rumänische Regie nicht nur auf die inländische Produltion angewiesen, sondern sie ist auch genötigt, eine gewisse Quantität Rohtabak vom Ausland zu beziehen. Aus einer jährlich zur Fahrikation notwendigen Durchschnittsquantität von 4 Mill. $\mathrm{kg}$ im Werte von 5,6 Mill. Lei kommen 3,5 Mill. $\mathrm{kg}$ im Werte von 2 Mill. Lei aus der heimischen Produktion: also sie stellt 86 Proz. des Gesamtgewichts und 46 Proz. des Wertes der jährlich verkauften Tabakfahrikate dar. Der Rest wirl aus dem Ausland bezogen, und zwar kauft die rumänische Regie jührlich $500000 \mathrm{~kg}$ ausländischen Tabak im Wert von durchschnittlich 2-3 Mill. Lei. Von letzterem stammen $400000 \mathrm{~kg}$, also 80 Proz. aus der Türkei (Nacedonien), und zwar folgende Tabaksorten: Tschinbek, Tschinhek-Basma, Jaka, Kir-Basma, Smyrna und Tumbeky, die im Preise von 1-20 Lei pro Ḱilogramm einen Wert von $21 / 2$ Mill. Lei repräsentieren. Diese wie auch die aus Griechenland (Volo und Argos) hezogenen Tahaksorten werden am meisten zur Zigaretten- und Rauchtabalfalrriliation verwendet. Für die Zigarrenfabrikation bezieht Rumänien aus Amerika (Vereinigten Staaten. Kuba, Brasilien), Asien, (Sumatra, Japan), Europa (Holland und Ungarn) jährlich ungefähr $100(000 \mathrm{~kg}$ Tahais zum Preise 
von 1,50-12 Lei pro Kilogramm, im Werte von 350000 Lei. Außer dem Rohstoff bezieht die rumänische Regie auch fertige Zigarren feinerer Qualitäten. die im Inland nicht fabriziert werden können, wie z. B. Havannazigarren, die an der Quelle direkt oder in Hamburg, Antwerpen gekanft werden. Man bezieht auch Schnuftabak aus Rußland und Frankreich. Dieses Tabakprodukt genielit in Rumänien große Beliehtheit. Die heifolgende Tabelle IV (siehe nächste Seite) gibt eine C̈hersicht des eingeführten Rohtabalis und der elsenfalls eingeführten Tabakfabrikate während der Zeit von 1898 bis 1901 .

Die rumänische Regie kauft ihren ausländischen Tabak mittels öffentlicher Ausschreibung. Die Bedingungen werden in Bukarest festgesetzt, woselbst auch die Muster einzusehen sind, auf Grund deren die Tahakblätter übernommen werden. Eine spezielle Kommission, die aus den höheren Regiebeamten gelildet wird, untersucht und klassifiziert die vorgelegten Tabakmuster. Der Generaldirektor und der Verwaltungsrat verhandeln üher die vorteillaftesten Angebote sownl hinsichtlich der Qualität als auch des Preises, jedoch unterliegt ihre Entscheidung der (renehmigung des Finanzministeriums. Die durch Zuteilung angenommenen Tabakquantitäten sind halb beim Unterschreilen des Vertrages, halb 6 Monate später abzuliefern. Die Annahme der eingekauften Tabake geschieht ebenfalls durch eine Kommission, deren Tätigkeit der Kontrolle des Verwaltungsrates untersteht. Die nicht den vorgelegten Mustern entsprechenden Tabakballen werden nicht angenommen; in diesem Fall wirl ein gegenseitiges Übereinkommen getroffen, falls der Lnterschied der Qualität eine gewisse Grenze nicht überschreitet.

Diese Art des Einkaufes der fremden Tabake auf dem Wege ıler öffentlichen Ausschreibung ist im allgemeinen gut zu heifen, denn die Regie hat Gelegenheit, die Tabaksorten gut und billig anzukaufen, indem verschiedene Lieferanten sich um den Preis bewerben. Es kann aher auch rorkommen, dal. die Bewerbungen unbedeutend sind, wenn nicht gar fehlen. Viele Tabakhändler vermeiden an der Versteigerung teilzunehmen, um sich nicht zu verptlichten, eine Ware zu liefern, die man nur auf großen und weit entfernten Plätzen haben kann und die den verschiedenen Schwankungen des Marktes unterworfen ist. Viele andere erscheinen aus dem Grunde nicht, weil sie befürchten, daf. ihre aus weiter Entfernung und unter großen Kosten zugehrachte Ware ahgelehnt oder nur unter sehr nachteiligen Bedingungen angenommen werden könnte. In solchen Fällen kann von einer ernsthaften Bewerbung nicht mehr die Rede sein, und die Regie 
IV.

\begin{tabular}{|c|c|c|c|c|c|c|c|c|c|c|c|}
\hline \multirow{4}{*}{ Jahre } & \multicolumn{11}{|c|}{ Zigarren } \\
\hline & \multicolumn{3}{|c|}{ Deutschland } & \multicolumn{3}{|c|}{ Schweiz } & \multicolumn{3}{|c|}{ Belgien } & \multicolumn{2}{|c|}{ Amerika } \\
\hline & \multirow{2}{*}{\begin{tabular}{|c|} 
Zahl \\
der \\
Zigarren- \\
stiucke
\end{tabular}} & \multicolumn{2}{|l|}{ Wert } & \multirow{2}{*}{\begin{tabular}{|c|} 
Zahl \\
der \\
Zigarren- \\
stücke
\end{tabular}} & \multicolumn{2}{|l|}{ Wert } & \multirow{2}{*}{$\left|\begin{array}{c|}\text { Zahl } \\
\text { der } \\
\text { Zigarren- } \\
\text { stücke }\end{array}\right|$} & \multicolumn{2}{|c|}{ Wert } & \multirow{2}{*}{$\mid$\begin{tabular}{c|} 
Zuhl \\
der \\
Zigarren- \\
stücke
\end{tabular}} & Wert \\
\hline & & Lei & B. & & Lei & B. & & Lei & B. & & Lei \\
\hline 1 1. & $102(0)$ & 8352 & 40 & $26 ; 100$ & 3512 & 1s & 49800 & $1411 ;$ & $7 t ;$ & $120501)$ & ז \\
\hline 1899 & & & & 4350 & 7693 & $65 \mid$ & $|255425|$ & 73720 & 60 & 153925 & $53897 \mid 21$ \\
\hline 1900 & & & & 435001 & 7693 & $60 \mid$ & 165000 & 41153 & $20 \mid$ & 438925 & $115391 / 55$ \\
\hline 1901 & 25000 & 7647 & 05 & 65000 & 14510 & 85 & 20000 & 7026 & 59 & 25500 & $5328 \mid 45$ \\
\hline
\end{tabular}

\begin{tabular}{|c|c|c|c|c|c|c|c|c|c|c|c|c|}
\hline & \multicolumn{12}{|c|}{ Rohtabak } \\
\hline \multirow{3}{*}{ Jahre } & \multicolumn{3}{|c|}{ Amerika } & \multicolumn{3}{|c|}{ Ungarn } & \multicolumn{3}{|c|}{ Frankreich } & \multicolumn{3}{|c|}{ Türkei } \\
\hline & \multirow{2}{*}{$\begin{array}{l}\text { Quantität } \\
\text { in } \mathrm{kg}\end{array}$} & \multicolumn{2}{|l|}{ Wert } & \multirow{2}{*}{$\begin{array}{l}\text { Quantitat } \\
\text { in } \mathrm{kg}\end{array}$} & \multicolumn{2}{|l|}{ Wert } & \multirow{2}{*}{$\begin{array}{c}\text { Quantitit } \\
\text { in } \mathrm{kg}\end{array}$} & \multicolumn{2}{|c|}{ W'ert } & \multirow{2}{*}{\begin{tabular}{|} 
Quantität \\
in $\mathrm{kg}$
\end{tabular}} & \multicolumn{2}{|l|}{ Wert } \\
\hline & & Lei & B. & & Lei & B. & & Lei & B. & & Lei & B. \\
\hline $159 \mathrm{~S}$ & 59783 & 162624 & $s t$ & 296040 & $1156 ; 697$ & 90 & $i \div+1$ & 21375 & 51 & 191534 & 16257.4 & (is \\
\hline 1899 & 49.94 & 139766 & 95 & 36269 & $7 \div .259$ & 97 & 299.8 & $111271 !$ & 145 & 15.768 & 11121641 & (1.) \\
\hline 1900 & $3531 \%$ & 53713 & 0.5 & 113059 & (930) 1 is & 60 & 86795 & 3162 & $-(i ; 3)$ & $3+29633$ & $206.116(i)$ & 10 \\
\hline 1901 & 3136 & 11743 & 25 & 72619 & 6534.20 & 69 & 650 & $302 \cdot 2$ & $2-$ & 1378931 & 13667.766 & 69 \\
\hline
\end{tabular}

\begin{tabular}{|c|c|c|c|c|c|c|c|c|c|}
\hline \multirow{4}{*}{ Jahre } & \multicolumn{6}{|c|}{ Rohtabak } & \multirow{2}{*}{\multicolumn{3}{|c|}{$\begin{array}{c}\text { Schnupftabak } \\
\text { Rußland }\end{array}$}} \\
\hline & \multicolumn{3}{|c|}{ Griechenland } & \multicolumn{3}{|c|}{ Holland } & & & \\
\hline & \multirow{2}{*}{$\begin{array}{c}\text { Quantität } \\
\text { in } \mathrm{kg}\end{array}$} & \multicolumn{2}{|l|}{ Wert } & \multirow{2}{*}{$\begin{array}{c}\text { Quantität } \\
\text { in } \mathrm{kg}\end{array}$} & \multicolumn{2}{|l|}{ Wert } & \multirow{2}{*}{$\mid \begin{array}{c}\text { Quintitit } \\
\text { in } \mathrm{kg}\end{array}$} & \multicolumn{2}{|l|}{ Wert } \\
\hline & & Lei & B. & & Lei & B. & & Lei & B. \\
\hline 1898 & 3172 & 35227 & 95 & 15554 & 144032 & 22 & 32000 & 34050 & $1-$ \\
\hline $18: 99$ & 107692 & 469474 & 19 & 30469 & 65673 & 15 & 16200 & 17432 & 20 \\
\hline 1900 & 122609 & 313074 & 59 & - & - & - & 16000 & 15440 & - \\
\hline 1901 & 66811 & 154312 & 99 & $1803 \pi$ & 90938 & 38 & 800 & $6936^{\circ}$ & - \\
\hline
\end{tabular}


ist gezwungen, ihre Ankïufe event. unter ungünstigen Umständen bewirken zu müssen. In Italien kaufte die Regieverwaltung ihre ausländischen Tabake ebenfalls auf dem Wege der öffentlichen Zuteilung, aber seit 1897 ist dieses System aufgehoben und sie kauft gegenwärtig direkt. durch einfaches C̈bereinkommen mit den Tabakhïndlern. Dieses System hat sich als gut erwiesen; schon im ersten Jahre wurde eine Ersparnis von 1657000 Fres. (15,5 Proz.) erzielt ${ }^{1}$ ). ÖsterreichIngarn macht seine Ankäufe nicht auf dem Lizitationswege, sondern (lurch seine Konsuln ${ }^{2}$ ). In Frankreich werden die Ankäıfe teils durch Akkord mit den Lieferanten, teils (lurch direkten Einkauf bewirkt").

Keines dieser Länder handelt nach dem Lizitationssystem, aus dem einfachen Grunde, weil es unpraktisch ist und sich dem Fiskus nicht vorteilhaft erweist. Die Erfahrung dieser Länder sollte nicht auber Acht gelassen werden und der rumänischen Regie Veranlassung geben, das Lizitationssystem zu verlassen und ihre Ankäufe direkt oder durch Ühereinstimmung mit den Tabakhändlern abzuschließen; zum mindesten aber ist ihr dieses Recht dann zuzugestehen, wenn sie auf solche Weise vorteilhaftere Ankäufe abschliefen zu können glaubt, als es durch die Zuteilung möglich wäre.

Es dürfte nicht ohne Interesse sein, in folgender Tabelle $\mathrm{V}$ den U'mfang der rumänischen, französischen, österreichischen und italienischen Regieeinkäufe für das Jahr 1902 veranschaulicht zu sehen.

V.

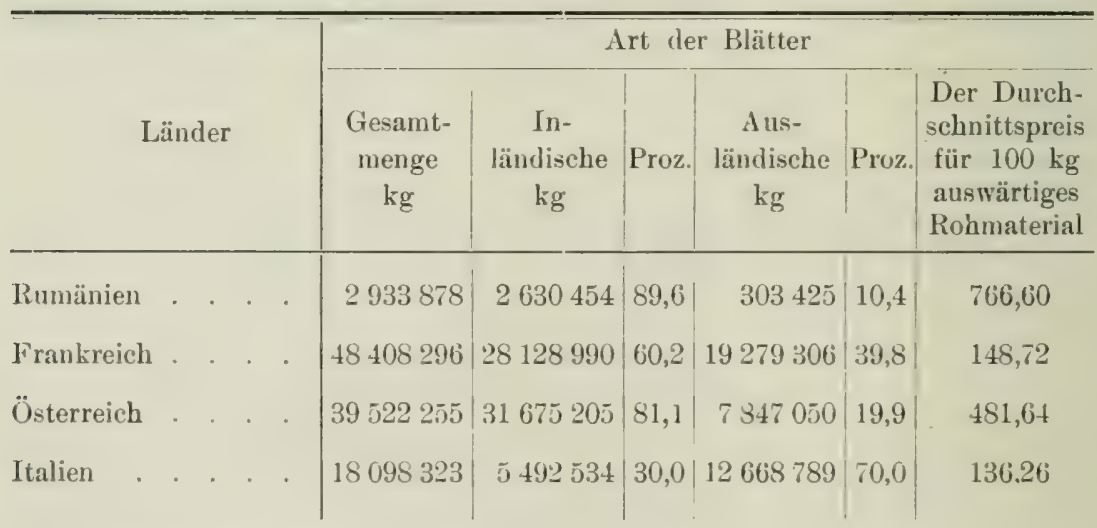

1) Laurent, F., a. a. O. S. 299.

2) Ebenda, S. 298.

3) Creizenach, a. a. O. S. 87. 
Die Zahlen reden dentlich von dem Streben der rumänischen Regieverwaltung, die Terwendung des ausländischen Rohtabaks möglichst zu beschränken und den größten Teil des benötigten Rohmaterials im Inland zu erwerben, obschon in Rumänien keine diesbezügliche Bestimmung vorhanden ist, die das Minimum des inländischen Rohtabaks in der Fabrikation feststellt. wie dies z. 13. in Frankreich der Fall war, woselbst laut Dekret von 1810 die französische Regieverwaltung 5,6 und lant späteren Gesetzes von 181614,1 in inländische Blätter zu verwenden hatte ${ }^{1}$ ). Das Gesetz von 1835 stellte ein Maximum von 1/5 ausländischer Blätter fest, die zur Verarbeitung kommen sollten ${ }^{2}$ ). Die letzte Spalte der Tabelle zeigt im Vergleich zu denen der anderen Staaten nur zu deutlich, zu welch teneren Preisen die rumänische Regie das ansländische Rohmaterial ankauft. Der Grund ist in der Tatsache gegeben, daß die Regie nicht in der Lage ist, die besten Qualitïten Rohtabak im Inland zu erzeugen und zu deren Ankauf im Ausland gezwungen ist. Infolgedessen ergibt sich für die Regieverwaltung die dringende Notwendigkeit, eine Verbesserung dieser Verhältnisse und der Tabakkultur herbeizuführen, damit der Tabakimport möglichst vermindert wird und die jührlich dafür nach dem Ausland gehende Summe von 2-3 Mill. Lei dem eigenen Lande erhalten bleibt.

Für das andere zur Fabrikation notwendige Material, wie Papier, Blech, Pappe, Kohle u. a. m. wird jährlich eine Summe von 400(000 Lei verausgabt. Diese Gegenstände werden zum größten Teil im Inland bezogen. Das Papier bildet das am meisten verwendete Material und wird jährlich im Betrag von 300000 Lei im Inland angekauft. Die sogenannten Chromo- und Glanzpapierarten werden aus Deutschland eingeführt; das Blech, die Messer und die Kohlen werden in Deutschland und England angekauft. Gegenwärtig versucht man die Kohlen durch Petroleumrückstände zu ersetzen. Wenn die Versuche, wie anzunehmen ist, den auf sie gesetzten Erwartungen entsprechen, wie dies ja auch bei den gleichen Versuchen, welche mit diesen Rückständen zur Heizung der Lokomotiven angestellt wurden, der Fall war, dann wirl die Regie viele Kosten ersparen, weil die Petroleumrückstände bedeutend billiger sind als die Kohlen. Der Ankauf des Materials geschieht auf dem Wege der öffentlichen Zuteilung

1) Laurent, F., a. a. O. S. 278.

2) Foville, Alf., La France économique, Paris 1887, S. 396. 


\section{Die Tabakfabrikation.}

Die Verarbeitung des Rohmaterials für den Konsum findet in den zwei staatlichen Manufakturen von Bukarest und Jassy statt, wélche noch von der Pachtgesellschaft errichtet wurden und beim Übergang des Tabakmonopols an den Staat mit in seinen Besitz gelangten. Dieselben wurden im Laufe der Zeit durch Um- und Neubau erweitert und, um den zunehmenden Forderungen der Fabrikation zu entsprechen, mit neuen Maschinen versehen. Zu diesem Zweck bestimmte die Revieverwaltung jährlich eine gewisse Summe, so das die Manufakturen, die bei ihrem Übergang in den staatlichen Besitz (1879) kaum einen Wert von 1200000 Lei hatten, gegenwärtig einen solchen von 5400000 Lei darstellen: dafür wurde während 23 Jahren im Durchschnitt ein jährlicher Betrag von 138260 Lei ausgegeben. Im Jahre 1903 wurlen allein 650000 Lei zu diesem Zweck verwendet $\stackrel{1}{1}$ ), die zum größten Teil zur Erweiterung der Manufaktur in Jassy dienten, weil diese viel kleiner ist als die in Bukarest und infolge der gesteigerten Ansprïche vergrößert werden mußte. Während die Manufaktur von Bukarest einen Raum von 14700 qm inmitten einer Ackerfläche von 140000 qm einnimmt, verfügt die Manufaktur von Jassy nur über 2500 qm inmitten einer solchen von 20000 qm. Alle beide liegen außerhalb der Stadt in der Nähe der Bahmhöfe, mit welchen sie zum Zweck eines erleichterten Transportes durch ein Schienengeleis verbunden sind. Die Gebäude der Manufakturen sind den hygienischen Anforlerungen entsprechend eingerichtet. Die Hauptforderung bezüglich der (iesumlheit der Arbeiter ist darlurch erfüllt; die technischen Einrichtungen sind rationell, zweckmäBig und den Anforlerungen der Neuzeit gemäß angelegt. Die notwendige Betriehskraft wird von drei durch Motore getriebenen Maschinen mit 200.100 und 20 Pferdekräften geliefert. Die Transmission der Betrielskiraft zu den entfernteren Räumen geschieht ilurch Elektrizität (Bukarest). 172 verschiedene Maschinen ${ }^{2}$ ) im Wert von 526612 Lei dienen zur Fabrikation des Rauch- und Schnupftabaks, teilweise auch zur Anfertigung der Zigaretten und in anderen Nebenbetrieben, wie zur. Herstellung ron Kartons, Paketen und Etiketten, dem Schneiden

1) Ziarul, Universul, Nr. 201, 1903.

2) Davon 40 in der Rauchtabakfabrikation,

$$
\begin{aligned}
& 2 \text { " " Schnupftabakfabrikation, } \\
& 68 \text { " "Zigarettenfabrikation, } \\
& 61 \text { " anderen Nebenbetrieben (Papierabschneiden, Verfertigung } \\
& \text { von Drucksachen, Vignetten usw.) }
\end{aligned}
$$


von Papier usw. Der Gesamtwert der Manufakturen, einschlieblich der Maschinen, Tabaks und des sonstigen Rohmaterials beträgt mehr als 12 Mill. Lei. Davon entfallen:

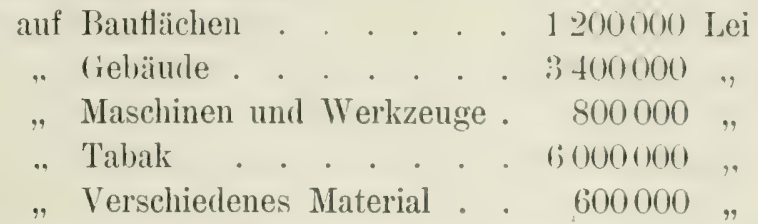

Die beiden Fabriken sind unabhängig roneinander und unterstehen der Leitung und der Kontrolle der Generaldirektion. Ihre Organisation ist der der französischen Manufakturen nachgebildet. Demgemäß steht an der Spitze jeder Manufaktur ein Direktor, der mit dem Entrepotvorsteher und dem Kontrolleur der Manufaktur ein Verwaltungskollegium bildet, welches die sich auf die Fabrikation beziehenden Fragen erörtert und diejenigen Maßregeln ergreift, welche für einen guten Geschäftsgang der Manufaktur als zweckmäßig erachtet wurden. Die Ausführung der Beschlüsse dieses Kollegiums, wie auch der Verfügungen der Generaldirektion steht dem Direktor der Manufaktur zu. Der Entrepotvorsteher trägt die Verantwortung für das gesamte Rohmaterial, welches in das Lagerhaus eingeliefert wird, wie auch für alle zur Fabrikation notwendigen Werkzeuge. $\mathrm{Er}$ ist ferner verpflichtet, für eine gute Aufbewahrung des Rohmaterials zu sorgen, welches er zur Verarbeitung nur kraft eines von dem Kontrolleur gegengezeichneten Direktorialauftrages abliefern clarf. Der Kontrolleur führt die Aufsicht üher die Verwendung des Rohmaterials und der 'Tabakfabrikate. Er hat von allen wichtigen Aktenstücken Kenntnis zu nehmen und deren Richtigkeit zu beglaubigen. Im übligen ist der Direktor der einzige Chef, welchem die allgemeine Leitung der Manufaktur zusteht und der für die Verwendung des Rohmaterials der Generaldirektion Rechnung ablegen muß. Ihm untersteht das ganze Beamtenpersonal, dessen Zahl in beiden Manufakturen 68 beträgt, und zwar: 2 Unterdirektoren, 2 verantwortliche Chets, 2 Verwalter, 2 Chefs der Sperlition und Fabrikation, 9 Beamte, 48 Chefs der verschienlenen Manufaliturriume und Warenlager, Aufseher und Kontrolleure, 1 Chef des chemischen Laboratoriums und 2 Chemiker. Besondere Vorschriften für die Anstellung eines Beanten bestehen nicht; für die technische Leitung werden jedoch nur solche Ingenieure angestellt, die eine entsprechende wissenschaftliche und praktische Bildung besitzen. Die meisten bilden sich in der Ecole d'application pour les manufactures de l'utat der französischen liegre

Volkswirtschaftl. u. wirtschaftsgeschichtl. Abhandlungen. H. 4.

Busuiocescu, Das Tabakmonopol in Rumanien. 
aus, wohin sie zu diesem Zweck von der rumänischen Regierung geschickt werden. Für die Besoldung des ganzen Beamtenpersonals der zwei Manufakturen wurden im Jahre 1902115260 Lei ausgegeben oder 1,4 Proz. der Gesamtkosten dieses Jahres. Obschon die Tabakmanufakturen voneinander unabhängig sind, wird trotzdem die Fabrikation der Tabaksorten in beiden nach genau denselben Prinzipien, denselben Methoden ausgeführt, also die Herstellungsweise ist durchaus identisch. „Auf strengster Festhaltung des Prinzips" - sagt Creizenach ${ }^{1}$ ) mit Recht im Bezug darauf - „daß in allen Fabriken zu gleichen Preisen ein gleichartiges Produkt geliefert werde, beruht die Möglichleit, ăaß die Regie bestehen kamn, denn jeder Geschäftsmann, der in derselben Lokalität mehrere, jedermann gleich zugängliche Etablissements unterhält, muß darauf bedacht sein, daß ron diesen Etablissements das eine dem anderen keine Konkurrenz macht. Hielte die Regie nicht daran fest und behielte eine Fabrik den Ruf, bessere Ware als die andere zu liefern, so wäre diese renommierte Fabrik bald von Käufern umlagert, die anderen müßten feiern und die ganze Ökonomie des Monopols wäre durchkreuzt."

Die Gleichförmigkeit und qualitative Gleichartigkeit der einzelnen Tabakfabrikate ist eine notwendige Berlingung für den Verbrauch, demn der Raucher, der im allgemeinen einen großen Wert darauf legt, wirl einige Tabaksorten zum Scharlen der anderen bevorzugen. Selbst das Interesse der Regie fordert gleichförmige Fabrikate, weil der kleinste Unterschied zwischen gleichartigen Fabrikaten der Manufakturen ron dem Konsumenten sofort bemerkt wird und dadurch Beschwerden hervorgerufen werden. AuBerdem erleichtert die Gleichförmigkeit die Kontrolle, verhindert Betrug und gestattet den Manufakturen in Notfällen sich aushelfen zu können; hekanntlich hat jede Manufaktur einen bestimmten Teil der Umgebung orler des Landes mit Fabrikaten zu versorgen. Schlechterdings kann man aber die (ileichförmigkeit nicht stets durchführen, da Einrichtung und Werkzenge unmöglich jeder\%eit die gleichen sein können. Eine absolute (ileichförmigkeit ist wohl das Ideal, wonach die Regie immer streben soll, welches sich jedoch niemals voll und ganz verwirklichen lassen dürfte. Bezüglich der herzustellenden Quantitäten hat nicht der Direktor der Manufaktur das Bestimmungsrecht, sondern die Cieneraldirektion, die durch ihren Generaldirektor stets genau über die Größe der Nachfrage informiert wird. Im allgemeinen richtet sich die Fabri-

1) Creizenach, a. a. O. S. 98. 
kation nach den Wünschen des die Tabalifabrikate konsumierenden Publikums. In Rumänien rauchte man sowohl vor als auch nach Einführung des Monopols mehr Zigaretten. welche man teils im fertigen Zustand kaufte. teils selbst drehte. Diese Gewohnheit besteht noch heutzutage. Manche Personen rauchen täglich 40 Zigaretten, deren Drehen für das lebhafte Temperament der Südländer einen beliebten mechanischen Zeitrertreil, bildet. Seit einigen Jahren macht sich aber eine Bevorzugung für Zigaretten in gebrauchsfertigem $\mathrm{Zu}$ stand mehr und mehr geltend, trotzdem diese naturgemäß teurer sind, als die entsprechende Qualität des geschnittenen Rauchtabaks. Diese Bevorzugung macht sich hauptsächlich für die besseren Qualitäten und am meisten für die Zigaretten mit Mundstück bemerkbar. (Diese werden nicht maschinell, sondern durch Handarheit hergestellt; mit dieser Manipulation waren im Jahr 190380 Proz. der Arbeiter beider Manufakturen beschäftigt). Der früher so beliebte Gebrauch des Rauchens aus der Tabalipfeife findet gegenwätig nur noch wenig Verehrer; an Stelle der Tabakpfeife trat die Zigarette, die ihren eroberten Platz während der ganzen Zeit siegreich zu behaupten gewußt hat.

Die aus ganzen Tabakblättern gedrehten Zigarren gelten als ansländische Rarität, als Luxus, den sich nur die reichen Leute erlauben können. Sie werlen meistenteils von den Ausländern geraucht. Von den inländischen Bewohnern rauchen nur solche Personen Zigarren, die sich diese Art des Rauchens im Auslande angewöhnt haben. Der alte Gebrauch Tabak zu schnupfen, der besonders in kaufmännischen Krreisen sehr verbreitet war, ist heutzutage beinahe gänzlich verschwunden; deshalb ist zur Zeit der Schnupftabak ein wenig gesuchter Artikel. Der Kautabak ist in Rumänien unbekannt. Die leidenschaftlich Tabak kauenden ausländischen Arbeiter, die in ziemlich großen Massen nach Rumänien kommen, wie auch die Seeleute in den rumänischen Hüfen haben in dieser Beziehung keinen Einfluf auf Herstellung oder Verbreitung des Kiatabaks ansuiben vermocht. Deshalb beschränkt sich die Fabrikation nur auf die bekannten vier Produlitionsarten: Rauchtalaake, Zigaretten, Zigarren und Schnupfabake. Die zum Rauchen dienenden Tabake gelangen nur in geschnittenem Zustand in den Handel, und zwar in folgenden 5 Qualitäten :

Luxustabak, Belitimis genannt, sehr dünn und in langen Fäden geschnitten, besteht nur aus dem feinsten macedonischen Tabak, nümlich aus dem Jaka von Xanti, im Preise von 60 Lei pro Kilogramm. 
Die I. Qualität besteht aus einer Mischung von diversen feinen Tabakarten aus Macerlonien und Kkleinasien: Preis pro Kilogramm 40 Lei.

Die II. Qualität ist aus 70 Proz. macedonischem und griechischem und 30 Proz. rumänischem Tabak zusammengesetzt und kostet 25 Lei pro Kilogramm.

Zur III. und IV. Qualität wird nur rumänischer Tabak verwendet. Das Kilogramm desselben wird zum Preise von 10 bezw. ๖ Lei verkauft.

Alle diese Tabakqualitäten werden nicht in gleichem, sondern in folgendem nach Quantität und Wert variierenden Naße hergestellt:

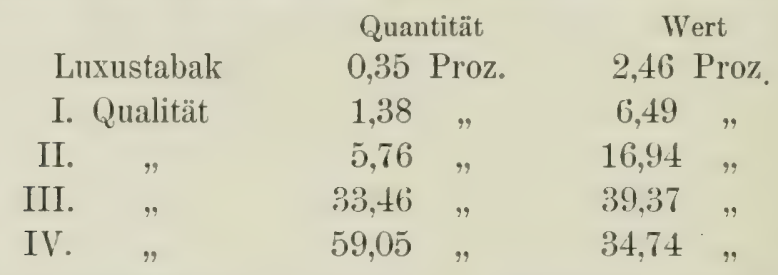

Die vorbereitenden Arbeiten zur Fabrikation des Rauchtabaks, wie das Zerlegen und Säubern der Tabakibündel, das Anfeuchten, Auslegen. Sortieren sind Handarbeiten, während das Ausrippen, Schneiden, Rösten und die Paketierung durch Maschinen geschieht. Außer den seitens der Regie hergestellten 16 Sorten Zigaretten, welche aus verschiedenen Mischungen der bekannten 5 Tabakarten bestehen, wirl ausnahmweise noch, wenn erforderlich, die Zigarettensorte „Comerciale“ aus 79 Proz. türkischem oder griechischem und 21 Proz. rumänischem Tabak und die Zigarettensorte "Militare", bestehend aus 40 Proz. türkischem oder griechischem und 60 Proz. rumänischem Tahak, angefertigt. Die meisten der gegenwärtig verfertigten Zigaretten werden durch Handarbeit hergestellt, womit, wie oben schon erwähnt, üher so Proz. der Arbeiter beider Manufakturen beschäftigt sind. Die Zigarren werden ausschließlich durch Handarbeit hergestellt. Wohl hat man eine Reihe von sogar patentierten Maschinen behufs Herstellung von Zigarren erfunden, um die doch immerhin teuere Handarbeit ersetzen zu können, aber einer solchen Maschine das feine Gefühl der Fingerspitzen der Zigarrenarbeiterinnen zu geben, damit keine zu festen oder lockeren Stellen bei der Verfertigung der Zigarren entstehen, dürfte der Technik wohl nie gelingen ${ }^{1}$ ). Die rumänische Regie fahriziert nur mittlere und niedrigere Zigarrenqualitäten, und zwar 11 Sorten, wovon 9 aus fremdem Tabak, wie Havanna-, Bra-

1) Lewinstein, G. Dr., Die deutsche Tabakindustrie, Berlin 1897, S. 38. 
silien-, Jara-, St. Domingo-, Sumatra-, holländischem und ungarischem Takak, die beiden anderen: Vevey-Sans- und Indigene-Zigarren aus 45 Proz. inländischem und 55 Proz. ausländischem 'Tabak bestehen. Die besseren und feinsten Zigarrenqualitäten im Preise von to Bani bis :) Lei pro Stück werden aus dem Ausland eingeführt. Als Schnułftabak werden nur zwei Qualitäten aus einer Mischung von 80 Proz. inländischem und 20 Proz. ausländischem Tabali fabriziert. In (ianzen werden von der rumänischen Regie demnach 33 Tabaksorten ${ }^{1}$ ) hergestellt. Diese Zahl ist indessen entschieden viel zu gering, und der Regieverwaltung kamn der Torwurf nicht erspart werden, dafis sie len so auberordentlich verschiedenen Geschmacksrichtungen nicht in genügrender Weise Rechnung trägt. In dieser Beziehung soll nicht etwa ein Vergleich mit Deutschland gezogen werlen, wosellsst so viele Tabalisorten bestehen, daß jede Geschmachsrichtung hefriedigt werden kann, wohl aber sollte sich die rumänische Regieverwaltung Frankreich, Italien und Österreich zum Vorbild nchmen, deren Sortenzahl wohl kleiner als die Deutschlands, jeloch hei weitem gröfer als die Rumäniens ist (siehe Tabelle VI).

VI.

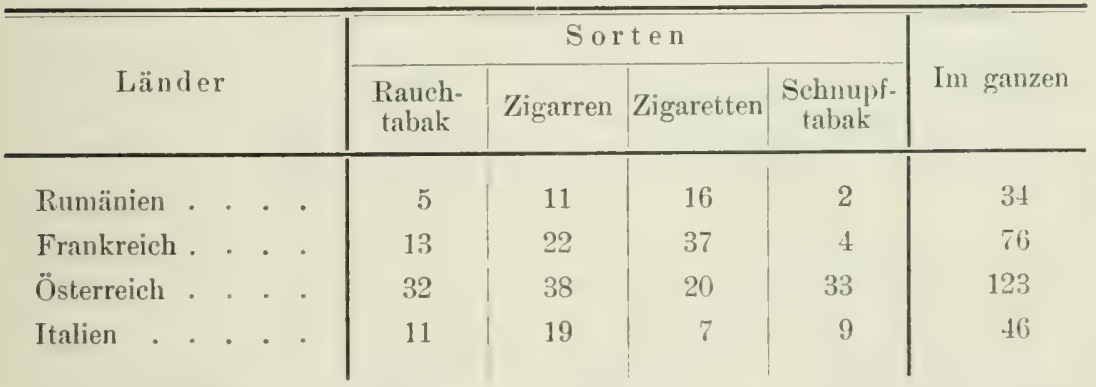

Die rumänische Regie müßte mindestens so viele Sorten Tabakfabrikate herstellen, als voranssichtlich den verständigen Wünschen des Tabak konsumierenden Publikums Rumäniens entspricht und genügt. denn ,,lie Hauptaufgabe der Fabrikation ist es. das Einzelprodulit in der Weise herzustellen, das dasselbe sich gleichzeition der Mamninfaltigkeit des Verbuauches vollständig anschlielst und die notwendigen Verschiedenheiten des Steuerfußes zuläBt*"2).

1) Die Zahl der in Konsum kommenden Fabrikatsorten beträgt ïber 43. Siehe unten S. 129.

2) v. Stein, Finauzwissenschaft, Bd. II, S. 280. Die ungemeine Verschiedenheit der österreichischen Tabaksorten erklärt Mo h l folgenderweise: „Da die einzelnen Kronländer in den letzten Jahrhunderten verschiedenen Tabaksprivilegien unter- 
Eine Yermehrung der Tabaksorten würde übrigens im eigenen Interesse der rumänischen Regieverwaltung liegen, denn es werden sich dadurch die lionsumtion und in analoger Weise die Einnahmen erhöhen. Zweifellos kann eine Regie dem Konsumenten nicht so vielerlei Fabrikatsorten zur Auswahl bieten, wie derselbe in falscher Würdigung der Verhältnisse vielleicht verlangen zu können glaubt. denn auch (iewohnheits- und Geschmacksrichtungen finden trotz der ungeheueren Mannigfaltigkeit derselben ihre Grenzen. Eine zu grofe Sortenzahl erfordert auferdem auch einen zu bedeutenden Aufwand an Herstellungskosten, ohne gleichzeitig eine entsprechende V'ermehrung der Einnahmen zu bieten. Die Erfahrung hat bewiesen, daß einige Fabrikatsorten gesuchter sind als andere. So sind unter den 16 rumänischen Zigarettensorten diejenigen zum Preis ron 21/2 und 5 Bani mehr begehrt als die anderen Sorten.

Schließlich aber handelt es sich doch lerliglich um die Hauptfaktoren: Form, Farbe, Qualität und die mit letzterer verbundene Bekömmlichkeit, d. h. ob ein Tabak leicht, mittelstark oder stark ist. Jedoch selbst diese wenigen Hauptfaktoren liommen für Rumänien noch nicht in Betracht, solange die Anzahl der Fabrikitsorten nicht beträchtlich rermehrt wird. Als ein Charaliteristikum der rumänischen Tahakfabrikation muf es bezeichnet werden, dab, die Erzeugung des Schnittabaks die Iauptstütze derselben bildet. Aus der im Jahre 1902 erzeugten Gesamtquantität von $3942588 \mathrm{~kg}$ beträgt:

$\begin{array}{lrcccc}\text { der Schnittabak } & 3689478 & \mathrm{~kg} & \text { oder } & 93,58 & \text { Proz. } \\ \text { die Zigaretten } & 202428 & & & 5,14 & \\ \text { die Zigarren } & 36726 & , & , & 0,93 & , \\ \text { der Schnupftabak } & 13955 & , & , & 0,35 & \end{array}$

Pro Kopf der Beyölkerung berechnet man insgesamt $0,657 \mathrm{~kg}$ Tabakfabrikate, und zwar $0,615 \mathrm{~kg}$ Rauchtabak, 33 Stück Zigaretten, ungefähr 2 Stück Zigarren und 2 (iramm Schniupftabak. Das

worfen waren und zum Teil auch der im Jahre 1783 gegrïndeten Kaiserl. Tabaksregie zu verschiedenen Zeiten unterstellt wurden, und der Tabakbau nach Boden, klimatischen Verhältnissen und Varietäten der landesüblichen Tabakpflanzen Rohtabake von sehr verschiedenen Eigenschaften liefert, so bildeten sich in einzelnen Kronländern auch verschiedene Sorten und Gewohnheiten für den Tabakbau (in Tirol, Galizien und in.den verschiedenen Gegenden und Naturverhältnissen Ungarns), sowie für die Fabrikation und den Verbrauch. Diesen verschiedenen Verhältnissen ist die Kaiserl. Tabaksregie bemüht . . zu entsprechen, und sucht... allen denkbaren Gewohnheiten und Geschmacksrichtungen zu genügen und entgegenzukommeı." (Moh), Denkschrift für eine Reichsregie, Stuttgart 1878, S. 72.). 
steht in scharfem regensatz zu der Fabrikation in Deutschland, woselbst der prozentuale Anteil der einzelnen Tahalifalrikate auf (irmul der Enquete ron 189:3 sich folgendermaßen beziffert: Rauchtahak 44,9 Proz., Zigaretten 1,1 Proz.. Zigarren 44,4 Proz., Schnupftabak 5,7 Proz. und Kautabak 3,9 Proz. ${ }^{1}$ ). Diese Charakteristik bleibt auch bestehen, wenn wir die Erzeugungsarten der rumänischen, französischen, österreichischen und italienischen Regie untereinander vergleichen (Tabelle VII).

VII.

\begin{tabular}{|c|c|c|c|c|c|c|c|c|}
\hline \multirow{2}{*}{ Tabakfabrikate } & \multicolumn{2}{|c|}{ Rumänien } & \multicolumn{2}{|c|}{ Frankreich } & \multicolumn{2}{|c|}{ Österreich } & \multicolumn{2}{|l|}{ Italien } \\
\hline & $\mathrm{kg}$ & Proz. & $\mathrm{kg}$ & Proz. & $\mathrm{kg}$ & Proz. & $\mathrm{kg}$ & Proz. \\
\hline Rauchtabak & 3689478 & 93,58 & 28246317 & 72,64 & $119.50+50$ & 65,75 & 2558031 & 15,98 \\
\hline Zigaretten & 202428 & 5,14 & 1897681 & 4,90 & 1783750 & 9,81 & 1017689 & 6,12 \\
\hline Zigarren & 36726 & 0,93 & 3007503 & 7,72 & 3091500 & 17,01 & 6883623 & 41,37 \\
\hline Schnupftabak & 13955 & $(1,35)$ & 467558 & $1 \geq, 1) 4$ & $6 \$ 2000$ & 13,75 & $6179 ! 36$ & $37,(11)$ \\
\hline Kautabak & -- & - & 1046150 & 2,70 & 668700 & $|3,68|$ & - & - \\
\hline Gesan & 3942588 & - & 38875509 & - & 18176400 & 9 & 16639279 & - \\
\hline
\end{tabular}

Die Herstellungskosten der Fabrikate belaufen sich jährlich auf die durchschnittliche Summe von 1-2 Millionen Lei. Für das Jahr 1902 herechnen sich dieselben auf 1341 15: Lei 2 ) und sind folgendermaßen verteilt:

\begin{tabular}{|c|c|c|}
\hline Gehälter & . & 115260 Lei \\
\hline Löhne & . & 8295054 \\
\hline Fournituren & & 2 องว 192 \\
\hline Mobiliar, Maschine & und Reparaturen & 84776 \\
\hline Diverse & . & 26377 \\
\hline
\end{tabular}

Demnach kostet die Herstellung von $100 \mathrm{~kg}$. 'Tabak durchschnittlich 33 Lei, während dieselbe in Frankreich 6르 Fres.. in Österreich $135 \mathrm{Kr}$. und in Italien 94 Fres. beträgt. Die geringen Herstellungskosten in Rumänien erklären sich einerseits, wie schon gezeigt wurde, durch die geringe Zahl der Fahrikatsorten. andererseits durch die verhältnismäßì niedrigen Löhne, die die rumänische Iegrie den Tabakarbeitern bezahlt.

1) Apelt, Kurt, Die Konsumtion der wichtigsten Kulturländer in den letzten Jahrzehnten, Berlin 1899, S. 152.

2) Einschließlich auch der Ausgaben für Herstellung der Tabaklauge. 
Außer den obenerwähnten Fabrikaten erzeugt die rumänische Regie aus den verhleibenden Rückständen der Tabakfabrikation und der Furda die Tabaklauge, welche eine große Rolle in der Landwirtschaft und Viehzucht spielt. Wegen ihres Nikotingehaltes, eines starken Giftes, dient sie zur V'ertilgung verschiedenen Ungeziefers und zur Heilung gewisser tierischen Hautlirankheiten, wie z. B. solcher, die durch Melophagus ovinus, Flöhe. Läuse und am meisten Scabies, die für Schafe oft tödlich ist, hervorgerufen sind. Die zum Zweck der Taballauge-Erzeugung bestehende Einrichtung ist sehr primitiv, und es wird nur die für den inländischen Verbrauch notwendige IIenge hergestellt. Nicht unrentahel wäre es, wenn die Regieverwaltung ihr Augenmerk darauf legen würde, dieser Erzeugung die Entwicklung zu geben, die sie bereits in Österreich und Italien erlangt hat. In Österreich wurde im Jahre 1898 Tabaklauge im Werte von ca. 400000 Fres. ausgeführt ${ }^{1}$ ) und im Jahre 1902 wurden aus deren Verkauf 289628 Fres. gelöst. Die italienische Regie erzeugte im Jahre $1902394224 \mathrm{~kg}$ Tabaklauge, die ihr eine Einnahme von $165201 \mathrm{Frcs}^{2}{ }^{2}$ ) brachte. Davon wurden $100869 \mathrm{~kg}$ im Inlande selbst und $293355 \mathrm{~kg}$ nach dem Ausland verkauft Die rumänische Regie fabrizierte die erste Tabaklauge im Jahre 1884, und es gelangte davon eine Quantität von $25725 \mathrm{~kg}$ in den Handel. Seitlem vermehrte sich der Konsum der Tabaklauge fortwährend und erreichte im Jahre $190272249 \mathrm{~kg}$; also fast das dreifache Quantum von 1884. Diese $72249 \mathrm{~kg}$ Tabaklauge, die 1,44 Proz. der Gesamtproduktion des erwähnten Jahres darstellten, brachten dem Fiskus die Summe von 57799 Lei. Der Verkauf erfolgt durch die Tabakdebitanten in hermetisch verschlossenen Blechkisten von $2-5 \mathrm{~kg}$ Inhalt zum Preis von 80 Bani pro Kilogramm. Weil bei Verwendung der gefärbten Tabaklauge die Pflanzen und Blumen schmutzig werden und ein nachträgliches Abwaschen sich nötig macht, wodurch ein berleutender Zeitverlust verursacht wird, benutzt die Regie ein besonderes Verfahren zur Herstellung einer farblosen Tahaklauge, bei deren Verwendung die obenerwähnten Nachteile der gefärbten Tabaklange in Wegfall kommen. Die farblose Lauge ist in jedem Tabaklagerhaus in Flaschen von $1 \mathrm{~kg}$ oder Blechkisten von $5 \mathrm{~kg}$ Inhalt zum Preis von 1 bezw. 1,25 Lei pro Kilogramm erhältlich. Des weiteren erzengt die rumänische Regie eine

1) Laurent, F., a. a. O. S. 315.

2) In dieser Summe ist auch der Gelderlös von $28381 \mathrm{~kg}$ Polvere insetticida enthalten. In den statistischen Mitteilungen sind die Einnahmen dieser zwei Arten von Prodotti secondari nicht getrenut. (Siche S. 31.) 
Tabaklauge enthaltende Seife. Zu der Fabrikation dieses einer Tahakregie fernliegenden Artikels wurde die Regieverwaltung einesteils aus (iründen technischer Natur veranlabit, andernteils ans Rücksicht darauf, daß die Regie um die Kontrolle nicht zu erschweren, kleinere Quantitäten als $2 \mathrm{~kg}$ Tabaklauge nicht verkaufen konnte. Den Landwirten, welche für ihre Zwecke nur kleinere Mengen Lauge brauchten, konnte aber nicht zugemutet werden, eine Flasche mit 2 Liter Inhalt zu kaufen. Die Tabaklaugenseife hat außer dem Vorteil, daß sie jedermann zugänglich ist, noch den weiteren, daß sie zur Reinigung der Haut der Tiere in hervorragender' Weise Verwendung finden kann. Gerade in dieser Mischung (Kali-Fett-Nikotin) bewirkt das in der Seife enthaltene Nikotin rasche und sichere Heilung der tierischen Hautkrankheiten. Die Tabaklaugenseife wird in Stücken von 100 und 50 Gramm zum Preis von 4 Lei pro Kilogramm verkauft.

Die Güte der Fabrikate. Im allgemeinen ist es schlechterdings schwer zu behaupten, daß diese oder jene Fabrikate gut oder schlecht seien, denn der Tabakgenuß ist ganz entschieden eine Geschmackssache und infolgedessen von (lem einzehnen Tabakraucher ah)hängig. Jeder rancht, schnupft oder kaut denjenigen Tabak am liebsten, an den er sich im Laufe der Zeit gewöhnt hat und dadurch ist es möglich, daß dem Einen eine Sorte Tabak oder Zigarre vortrefflich mundet, während der Andere dieselbe als geschmacklos oder schlecht bezeichnet. Der Geschmack und die Gewohnheit sind zum größten Teil die Beurteilungsgründe eines guien oder schlechten Fahrikats und wie diese, so sind auch die Neinungen üher die Güte desselben verschieden.

Immerhin kann man sich aber eine richtige, unparteiische Meinung bilden, wenn man über die Qualität des Rohtabaks und dessen Verarbeitung Kienntnis besitzt. Sind diese Forderungen entsprechend erfüllt, so kann man unfehlbar über die Güte der Fabrikate urteilen, denn es ist nicht zu leugnen, daß die Güte der Fabrikate in engem Zusammenhang damit steht. Daß der rumänische Rohtabak nicht von geringer Qualität ist, beweisen die verschiedenfach über ihn geäußerten Meinungen, die wir hier in Kürze folgen lassen. Vor allem sei erwähnt, daßs sieben rumänische Tabakptlanzer auf der Pariser Weltausstellung von 1867 wegen der (Qualitï ihrer ansgestellten geschnittenen Tabake und Tabakblätter durch Medaillen prämiert wurden ${ }^{\%}$. In seiner Schrift „Rumänien“ äußert sich Rudolf Henke darüber folgendermaken: „Der rumänische Tabak liommt dem tïrkischen ziem-

1) Exposition universelle de 1867 à Paris: Catalogue officiel des exposants récompensés par le Jury international, Paris, p. $62 \mathrm{ff}$. 
lich gleich und unterscheidet sich von diesem nur durch eine etwas dunklere Farbe. Der beste rumänische Tabak, welcher besonders vorzüglich in den Gegenden von Husi (Husch) gebaut wird, gibt dem türkischen nichts nach, und was man in Deutschland und Österreich an echtem türkischen Tabak rerkauft, ist meistenteils rumänischer ${ }^{1}$ )." Das wird auch von $\mathrm{Kis}$ sling berichtet: „In Rumänien werden relativ ansehnliche Tabakmengen (2_-:3 Mill. kg) produziert und zwar geben die erzeugten Sorten den türkischen an Güte wenig nach. Einer gewissen Berühmtheit erfreut sich in dieser Beziehung die Ungebung von Husi (Husch)2). Rommerhöller geht noch weiter, inclem er darïber in folgender Weise sich äufert: ..Le tabac de Roumanie est certainement le meilleur de toute la péninsule, très odorant, des feuilles longues et peu larges très bonnes pour sous-cap et excellentes pour la coupe. Toujours la régie essaye dles semences étrangères et voue tous ses soins à l'ennoblissement des sortes existentes"33)

Wenn wir auch nicht zu behaupten wagen, daß der rumänische Tabak „le meilleur de toute la péninsule* ist, denn die Türkei liefert ohne Frage die feinsten Tabaksorten ${ }^{4}$ ), so pflichten wir (loch roll und ganz den folgenden Worten bei: „Le tabac roumain est égal à de très bon hongrois ${ }^{5}$ ), il fera bientôt son apparition sur le marché hollanrlais, où il sera l'égal de la meilleur qualité du tabac hongrois ${ }^{6}$ )" und erkennen den Ausspruch, ,le tabac roumain est d'aussi bonne qualité que le tabac turc $\left.{ }^{7}\right)^{6:}$ teilweise als richtig an.

Wenn dem hinzugefügt wird, daß die Be- und Verarbeitung des Rohmaterials nach den gleichen erprobten Methorlen erfolgt, die auch in den mit einer entwickelten Tabakindustrie versehenen Ländern bestehen, so kann man den Schluß ziehen, dab die rumänischen Tabakfabrikate gut sind. Tatsächlich trifft dies auch für die letzte Periode zu, denn, wie bereits früher (siehe oben) hervorgehoben wurle, liefen die Tabakfal)rikate in der Zeit der Pachtperiode im allgemeinen viel zu wünschen übrig und veranlaßten zu manchen Klagen, die sich

1) Henke, Rumänien, Leipzig 187\%, S. 196.

2) Kissling, a. a. O. S. 14.

3) Rommenhöller, C. G., La Roumanie, Étude économique et commerciale, Rotterdam 1898, p. 115.

4) Kissling, a. a. O. S. 13.

5) Rommenhöller, a. a. O. S. 255 .

6) Ebenda S. 116.

7) Yres Guyot et A. Raffalovich, Dictionnaire du Commerce, de l'industrie et de la banque, Paris 1901, Bd. II, p. 1224. 
allerdings mehr anf die Mängel richtiger Mischung und guten Schnitteder gewöhnlicheren Tabaksorten bezogen. als auf die qualitative Beschaffenheit des Tabaks.

Das Urteil der Generaldirektion der Wiener Ausstellung von 1873: „Die Tabakregie in Bukarest hatte außer einigen Blättern anch drei Sorten geschnittenen türkischen Rauchtabaks und Zigaretten gesendet; der Talak ist gut sortiert und zeigt einen reinen feinen Schnitt" bezieht sich auf die besseren Qualitäten ${ }^{1}$ ).

Jedoch halten wir die folgende von Felser'2) in der Tabakzeitung ${ }^{3}$ ) gemachte Xitteilung ühertriehen, welche lautet: ... Iuch der rumänische Regietabak ist so schlecht, daß er von den russischen Soldaten verschmäht wird." Der wahre Grund dieser Verschmähung ist von der „Allgemeinen Zeitung" gegeben, indem sie berichtet, daß die russische Behörde bei den Beschwerden der Honopolgesellschaft gegen die Einführung des russischen Tabaks antwortète: „Die russischen Truppen sind an (den rumänischen Tabak nicht gewöhnt ${ }^{4}$ ).

Die Übertragung des Betriebes an den Staat hatte eine nicht unbedeutende Verbesserung des Fabrikats zur Folge. Jeder wirkliche Raucher der damaligen Zeit erkannte rückhaltlos den großen Unterschied an, der zwischen dem heifienden Fabrikat der Pachtperiode und dent leichten angenehmen Fabrikat der heutigen liegieverwaltung lag. Die Regieverwaltung hat ein besonderes Interesse gute Fabrikate zn produzieren, denn sie weiß. daß der Konsum zunimmt und damit auch ihre Eimnahme; auferden ist sich dieselhe des gesundheitsschädlichen Einflusses der schlechten Fabrikate auf die Konsumenten wohl bewul. so daß sie diesen niemals aus Rüben- oder Kartoffelblättern etc. hergestellte Frzeugnisse zu rauchen zumuten oder als Regieware liefern würde. Auch gegenwärtig noch erheben sich vereinzelte Klagen gegen die Tabakfabrikate, die meist unhegründet sind. In allen Monopolländern ist der Hang, die Regiefah)rikate ohne Recht zu verleumden. zu beobachten, dies ist aber nur zu natürlich und liegt in der Tatsache des Monopols begründet. d. h. der Cnmö̈glichlieit des líonsumenten. seinen Lieferanten zu ändern. Bis zu einem gewissen Punkt scheinen allerdings die den Rauchtabak IY. Qualität betreffenden Kiagen, welcher wegen seines dicken Schnittes große Schwierigkeiten beim Rollen

1) Wiener Weltaustellung 1873, offizieller Bericht der General-Direktion, IVien 1873, Bd. II, Heft 11.

2) Felser, a. a. O. S. 23.

3) Tabakzeitung, Beilage zu Nr. 18 vom 4. Mai 1877.

4) Allgemeine Zeitung 1877 . 
einer Zigarette bietet, begründet zu sein. Hiervon abgesehen, muß man anerkennen. daf. die rumänischen Regiefabrikate den Fabrikaten der französischen oder österreichischen Regie an Güte wenig - wenn üherhaupt - nachgeben, was durch folgende zwei Tatsachen bewiesen wird: 1. Die internationale Jury der Pariser Weltausstellung von 1!100 hat der rumänischen Regie für die (Qualität ihrer Fabrikate den großen Preis verliehen ${ }^{1}$ ). 2. Die Ausfuhr der Fabrikate nach Ländern, wie Dentschland *), Belgien "), Holland ${ }^{4}$, nimmt stetig zu, trotzdem diese Fabrikate. abgesehen selbst ron den eigenen guten Fabrikaten jener Länder, noch mit hohen Zöllen belegt werden.

Unter diesen Verhältnissen erscheint die Ansicht Semlers nicht als stichhaltig. wemn derselhe bezüglich des rumänischen Tabaks sagt: „Die Ausländer, welchen Gelegenheit geboten war, diesen Tabak zu versuchen, wissen Rühmliches von ihm nicht zu sagen $\left.{ }^{5}\right)$."

\section{Die Arbeiter.}

Sämtliche Monopolländer zeigen außer der starken Konzentration des Retriehes ein bedeutendes Überwiegen der weiblichen Arbeitsliräfte in der Tabakfabrikation. Selbst in Deutschland macht sich dies charakteristisch bemerkbar. trotz der in diesem Lande herrschenden Zersplitterung dieser Fabrikation. Die Gründe dafür sind in der Natur der Tabakindustrie selbst zu suchen; sie sind herrorgerufen durch den gewaltigen Umschwung in der Konsumtion der Fabrikate, d. h. dem massenhaften und stets weiter zunehmenden Verbrauch an Zigarren und Zigaretten während der letzten Jahrzehnte. Diese so begehrten Tabakfabrikate werden aber mehr durch Hand- als Maschinenarbeit hergestellt. und da bekanntermalien die weiblichen Personen von Natur aus größere Sauberkeit, Schnelligkeit und Geschicklichkeit als die Männer besitzen, so ist es erklärlich, daB in der Tabakfabrikation die Zahl der weiblichen Personen die der männlichen übersteigt. Berücksichtigen wir ferner, daf durch die Einführung nener

1) Ollanescu, D., Raport general. Participarea Rominiei la expositia universala din Paris 1900, p. 399.

2) Nach dem Gesetz von 1879 wird an Eingangszoll erhoben, von $100 \mathrm{~kg}$ a) Zigarreu und Zigaretten $270 \mathrm{Mlk}$, b) geschnittenem Tabak $180 \mathrm{Mk}$.

3) Der Eingangszoll beträgt: 100 Frcs. pro $100 \mathrm{~kg}$ geschnittenen (bearbeiteten) Tabak, 300 Fres. pro $100 \mathrm{~kg}$ Zigarren.

4) Nach dem bestehenden Zolltarif beträgt der Eingangszoll auf: Tabak geschnitten, gebeizt, Schnupftabak und alle anderen Fabrikate für $100 \mathrm{~kg} 12 \mathrm{fl}$., Zigarren für $100 \mathrm{~kg} 40 \mathrm{H}$.

5) Semler, a. a. O. S. 332. 
zweckentsprechender Maschinen die mämnliche Arheitskraft mehr und mehr entbehrlich wird, die bei intensiver Maschinenbenutzung sich noch eribrigende menschliche Arbeit aber bequem von Frauen geleistet werden kann, dab ferner der Lohn der Frauen immerhin ein bedeutend niedrigerer als der der Männer und die Erlermung der Herstellung von Zigarren und Zigaretten schlieblich eine auberordentlich leichte ist, so sind in wesentlichen die Gründe für die Tatsache gegeben, daß heutzutage die Tabakfabrikation üherwiegend von weiblichen Arbeitskräften ausgeübt wird. Die folgende Zusammenstellıng möge dies veranschaulichen (Tabelle VIII):

VIII.

\begin{tabular}{|c|c|c|c|c|c|c|c|}
\hline \multirow[b]{2}{*}{ Länder } & \multirow{2}{*}{$\mid \begin{array}{c}\text { Zahl } \\
\text { der Be- } \\
\text { triebe }\end{array}$} & \multicolumn{6}{|c|}{ Arbeiter } \\
\hline & & $\begin{array}{l}\text { männ- } \\
\text { liche }\end{array}$ & $\%$ & \begin{tabular}{|l|} 
weib- \\
liche
\end{tabular} & $\%$ & $\begin{array}{c}\mathrm{Zu}- \\
\text { sammen }\end{array}$ & $\begin{array}{l}\text { Durchschnitt } \\
\text { pro Betrieb }\end{array}$ \\
\hline Deutschland ${ }^{1}$ ) & 29357 & 52108 & | $41 \mid$ & $\mid 74588$ & 59 & 126696 & 4 \\
\hline Frankreich & 21 & 2344 & 13 & 15092 & 87 & 17436 & 830 \\
\hline Österreich . & 30 & 4621 & $|11|$ & 35824 & 89 & 40445 & 1348 \\
\hline Italien . & 16 & 2094 & 12 & 15025 & 88 & 17119 & 1070 \\
\hline Rumänien . & 2 & 493 & 27 & 1350 & 73 & 1843 & $92:$ \\
\hline
\end{tabular}

Aus obiger 'Tabelle ergibt sich, daß auch in der Tabakfabrikation Rumäniens die weiblichen Arbeitskräfte vorherrschen, obschon hier der entsprechende Prozentsatz kleiner ist als in den anderen zum Vergleich gestellten Monopollïndern. Die große Zahl «ler weiblichen Arbeiter hat für Rumänien aber noch eine sozialpolitische Bedentung insofern, als dadurch sehr wenig fremde Arbeiter in den Manufakturen Beschäftigung finden, während in den früheren Privatindustrieen. trotz des Industriegesetzes vom 12. Mai 1887 - wonach in den ersten ¿) Jahren des Betriebes einer neugegrünleten Fabrik zwei Drittel der Arbeiter rumänischer Staatsangehörigkeit sein sollten ") - nur 10 Proz. der gesamten Arbeiterschaft dieser gesetzlichen Anforderung entsprach. Selbstverständlich beschäftigten die zwei rumänischen Manufakturen anfangs nur eine kleinere Anzahl, und zwar gegen 1000 Arbeiter 3). die naturgemälo mit der fortschreitenden Ausdehnung des Betriehes

1) Mayr, G., Tabak und Tabakbesteuerung, in Handw. etc. S. $53 / 54$.

2) Rumänien, seine Handelspolitik und sein Handel 1890-1900, v. Metzler

3) Allgemeine Zeitung 1874, Nr. 301. 
stetig zunahm. Diese Zumahme betrug in clem Zeitraum von 30 Jahren 84,3 Proz. odler jährlich 2,81 Proz. Die Annahme der Arbeiter geschieht, wie in jeder Industrie, nach dem Verhåltnis von Angebot und Nachfrage. Da die Manufakturarbeiter sichere dauernde Stellung und, wie wir spåter sehen werden, sonstige Vorteile genießen, die in einer Privatindustrie ausgeschlossen sind, so verursacht es auch den Manufalituren keine Mühe, stets die nötigen Arbeitskräfte zu erlangen, und zwar unter günstigeren Berlingungen. als es der Privatindustrie möglich ist. Die Stellen von Zigarettenarbeiterinnen sind im allgemeinen gesuchter, als diejenigen von Zigarrenarbeiterinnen, weil im ersten Falle die Erlernung viel leichter und schneller ist. Die Manufaktur stellt nur solche Arbeiterinnen und Arbeiter an, die gesund und nicht jünger als 15 resp. 21 Jahre oder älter als 30 resp. 35 Jahre sind. Die letztere Forderung ist darin begründet, daß die über 30 resp. 35 Jahre alten Arbeiter und Arbeiterinnen gewöhnlich nicht mehr die schnelligkeit und (ieschicklichkeit besitzen, die lei der Verfertigung der Zigarren und Zigaretten durchaus notwendig ist. Man könnte dagegen einwenden, daf diese Forderung eine unbillige und unnötige sei, da doch im allgemeinen Stücklohm rereinbart und jeder Arbeiter im Verhältnis zu seiner Leistung bezahlt werde. Diese Maßregel der Manufaktur wird aber dadurch gerechtfertigt, daß jedem Arbeiter gleiches Recht an der Beteiligung der Unterstïtzungs- und Pensionskasse zusteht. sodala es im beiderseitigen Interesse - der Manufaktur als auch der Arbeiterschaft — liegt, bejahrtere Arbeiter fernzuhalten. Vor der Annahme der Arbeiter werlen sie von den Ärzten der Tabakregie hinsichtlich des (iesundheitszustandes untersucht; für die Annahme ist auber einer liräftigen Körperhonstitution die gesunde Beschaffenheit der wichtigsten inneren Organe notwendig, da, wie leicht erklärlich, festgestellt wurde ${ }^{1}$ ), dab die Tabalifabriliation - durch die Ausdïnstung des Tabaks und den sog. Tabakstaub - auf diese Organe je nach (ler Disposition (les Körpers einen mehr²) orler weniger ${ }^{3}$ ) schärdigenden Einfluls ausïh)t und dies in um so höherem Grade, falls der Arbeiter schon vorher leidend sein sollte. Im Interesse der körperlichen Entwickelung ler Arheiter wäre es geboten, „lie seitens der österreichischen

1) Sombart, W., Die deutsche Zigarrenindustrie und der Erlaß des Bundesrates vom 9. Mai 1888 (im Archiv für soziale Gesetzgebung und Statistik, Jahrg. 1889, S. 112).

2) Wörishoffer, Die soziale Lage der Zigarrenarbeiter im Großherzogtum Baden, aus dem Tabakarbeiter 1903, Nr. 22 zitiert.

3) Kissling, a. a. O. S. $23 \mathrm{f}$. 
Regieverwaltung seit 1902 eingeführte Naßregel nachzuahmen. wonach die Einstellung und Annahme jugendlicher Arbeiter nur in Alter üher 16 Jahre erfolgt. Die Manufakturarbeiter unterscheilen sich nur nach (ler Art und Weise ihrer Beschäftigung Rauchtahak-, Zigurren-, Zigaretten- usw--Arbeiter) und der dadurch bedingten Lohnskialis: im ülorigen arbeiten alle Arheiter derselhen Selition unter gleichen Bedingungen. Die Arbeiter sind sellst im Falle des Zusammenarbeitens gegenseitig völlig unabhängig voneinander: jerler derselhen erhält den ihm in l'orans zugesprochenen Lohn: so wirl z. B. bei der durch Maschinen bewirkten Fabrikation von Zigaretten in der Weise verfahren, dal.s vom Erlös an die Arbeiterinnen je nach den (Qualitïten der Zigaretten s(1)—9) Proz., an die Maschinenmeister 5-20 Proz. verteilt werden. Den letzteren wird von diesem Anteil für den Maschinenmeisterchef 1 , o und für die (iehilfen ${ }^{1 / 4}$ Teil in Abzug gebracht. Auf diese Weise wird die T'nterdrückung einzelner vermieden, ein Mißstand, der bei Arbeiten in freier Konkurrenz nicht selten zu verzeichnen ist. Sombart sagt: „Ein durch die heute übliche Technik der Zigarrenfabrikation in vielen (iegenden hervorgerufener. besonderer Mißstand der Arheiterlohnverhältnisse hesteht noch darin, daß der Roller, der selbst im Akkordlohn arbeitet, sehr häufig sich seine eigene Wickelmacherin amimmt und dieser ron seinem Verdienst einen Teil als Wochenlohn auszahlt. Die wirtschaftliche Cngleichheit der beiden Kontrahenten (Roller und Wickelmacherin) hat nun in vielen Fällen eine materielle Benachteiligung, ein unliebsames Abhängigkeitsverhältnis für den schwächeren Teil zur Folge gehabt. Der ausbedungene Lohn wird unregelmäbig. vielleicht erst nach langen Paktieren rom Roller der Wickelmacherin ausgezahlt ${ }^{1}$ )." Die Entlohnung ter Arbeiter erfolgt den vereinbarten Lohnsätzen gemäß nur durch die Regieverwaltung, und zwar nicht an jedem Sonnabend der Woche, wie in der Privatindustrie, sondern jeden fünfzehnten Tag, was im wirtschaftlichen und sittlichen Interesse der Arbeiter liegt. Die Lohnsitze werden jährlich von der Regieverwaltung bestimmt und zwar ist die Art der Entlohnung eine dreifache: Tagelohn, 15-Tage-Lohn und Akkordlohn.

Einen Fünfzehntagelohn erlalten nur die Vorsteher (Aufseher, Aufseherinnen. Chefmechaniker, Arheitleiter. Werkführer) und eine geringe Zahl Arbeiter heiderlei (ieschlechts; er schwankt zwischen 36 und 136 Lei (1902); Tagelohn wird nur an ungefähr 5̆ Proz. des (iesamtarbeiterstandes gezahlt. und zwar als Lohn fïr Arbeiten, die

1) Sombart, a. a. O. S. 113. 
weder an eine hestimmte Zeit gebunden sind oder deren Vergütung nach dem Maße der darauf verwendeten Kraft nicht berechenbar ist. orler deren Resultat nicht meBhar noch wieghar ist. Derselbe schwankt zwischen 80 Bani und 6 Lei, aber der Lohnsatz von 1,50 Lei ist der häufigste. Die dritte Art von Entlohmung. der Akkordlohn, überwiegt bei weitem. Diese Entlohnung ist gerechter, weil sie den fleißigen Arbeiter begünstigt. Aber sie hat die Schattenseite, daß manche Arbeiter ohne Aufmerlisamkeit arbeiten, nur 1 m möglichst viel fertig stellen zu können. Deshalb ist es nötig, daß diese Arbeiter einer strengen Kontrolle unterstehen und ihre Fabrikate müssen Stück für Stück von den Aufsehern untersucht werden. Letzterer ist darlurch, daß er den Namen des betreffenden Arbeiters nicht kennt, in der Lage, ohne in den Ruf der Parteilichlieit zu kommen, die ihm nicht gut erscheinenden Arbeiten zurückzugeben bezw. zu beanstanden, während er die tadellosen Arbeiten, für welche dann auch der bedungene Akkordlohn bezahlt wird, annimmt. Der Akkordlohn wird nach der Gïte und Menge der Fabrikate, des Rohstoffes etc. etc. berechnet. Der durchschnittliche Tagesverdienst betrug im Jahre 1902 für Albeiter 2,75 Lei, für Arbeiterinnen 2 Lei. In demselben Jahre zahlte die Regie an Löhnen die Gesamtsumme von 829555 Lei, d. h. einen jährlichen Durchschnittslohn von tö) Lei. In Anbetracht dessen, daß die Lebenshaltung in Rumänien nicht teuer ist, liam man demnach den Arbeitslohn als hefriedigend ansehen. Ein Vergleich mit Österreich und Italien, in welchen Ländern die Lebenshaltung bedeutend teurer als in Pumänien ist, zeigt lieine großen Difterenzen zwischen den entsprechenden Durchschnittsjahresverdiensten, denn im gleichen Jahre (19) erzielte ein Tahakarheiter an durchschnittlichem Jahreslohn: in Österreich $497 \mathrm{Kr}$. (522 Fres.) und in Italien 5011 Fres. Auch in dieser lieziehung kann Frankreich wierlerum als Vorbild für alle anderen Ironopolländer dienen, denn der Tabakarbeiter verdiente dortselhst (ehenfalls 1902) einen durchschnittlichen Jahreslohn von 1051 Fres. - Dafür, daß die Löhne für den rumänischen Tabakarbeiter befriedigende sind, fülıren wir folgende Tatsache als Beweis an: Als im Jahre 1900 (laut Gesetz vom 17. März des gleichen Jahres) das Zigarettenpapiermonopol eingefüht wurde, machte sich die Neubesetzung ron 150 Arbeitsstellen nötig, für welche sich nicht weniger als 2000 Bewerber meldeten. Dieser Andrang zu den Stellen erklärt sich lediglich aus den zufriedenstellenden Löhnen und den anderweitigen Vorteilen, welche die Regieverwaltung in richtiger Würdigung der sozialen Verhältnisse der Arbeiter diesen zu teil werden läßt. Außer 
ilırem verdienten Lohn erhalten die Männer noch eine monatliche

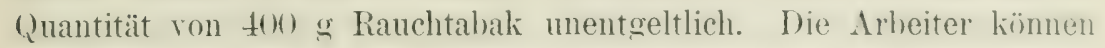
bei guter Führung viele Jahre im Regiedienst bleiben, trotzdem die Manufaktur nur auf Bestellung Fabrikate herstellen lïbt und grolie Vorräte wegen der geringen Haltbarkeit der leichten Tabaksorten untunlich erscheinen. Die Regieverwaltung ist darauf helacht. Entlasimgen. welche übrigens ohne rorherige Kündigung erfolgen, zn vermeilen. Nur in schweren Fällen ron Yachlässigheit. Tnhotmäloblieit oder (iehorsamsverweigerung wird von der Entlassung Gebrauch gemacht, welche von den Arbeitern deshalb als harte Strafe angesehen wird. Bei nur linapy einlaufenden Bestellungen arrangiert die Manufakturverwaitung die Arbeitszeiten durch Verkürzung derart, daß alle Arbeiter noch Beschäftigung finden. wemn auch täglich einige Stumblen weniger als sonst. Der umgekehrte Fall tritt ein bei großen oder rasch zu erledigenden Bestellungen. Es ist selbstrerständlich, dal.j durch diese Mafnahmen ein Stamm langjührig bewähter tüchtiger Arbeiter geschaffen wird, welche durch genaue lienntnis ihrer Obliegenheiten der Manufaktur von großem Yorteil sind. Außer der Entlassung gelten noch als Strafe das Verbot der Arbeit während eines gewissen Zeitraums von Tagen, Wochen oder Monaten, oder Geldstrafe, welch letztere allerdings wegen ihrer großen Härte für den Arbeiter aufgehoben werden soll. Die Arbeitszeit beträgt durchschnittlich 10 Stunden täglich und die Arbeitspause 1 Stunde; das gleiche Verhältnis besteht in Frankreich. Dadurch gibt die rumänische Regie der Privatindustrie, in der gewöhnlich eine längere Arbeitsdauer besteht, ein nachahmenswertes Beispiel. Des Weiteren soll in Anbetracht dessen, daß der größte Teil der Arbeitskräfte aus Franen besteht. eine Änderung in ler Arbeitszeit insofern eingefuihrt werden. als die Arbeit an allen einem Sonn- oder Festtag vorangehenden Nachmittagen ausfält, um darurch den Arleiterimnen Zeit und (ielegenheit zur Besorgung ihres Haushaltes zu geben.

Hinsichtlich der im Interesse der Arbeiter getroffenen hygienischen Mabnahmen ist zu erwähnen, dab Apparate eingefiihnt worlen sind. welche die oben schon bezeichmeten der Tabakindustrie anhaftenden gesmulheit:schädlichen Eigenschaften teilweise aufhehen. während die allgemeinen krankheitsverhütenden orler -vorhengenden Mabregehn schon seit Besinn der Mamufaktur bestehen. Die Arbeitssäle sind geräumig. gut rentiliert und mit Apparaten zur Entfernung des Staubes versehen. Die Bukarester Manufaktur ist mit Zentralheizung und elektrischem Lichif ausgestattet, während die Manufaktur von Jassy noch IIol\%heizung und Volkswirtschaftl. u. wirtschaftsgeschichtl. Abhandlungen H. 4.

Busuiocescu, Das Tabakmonopol in Rumänien. 
P'etroleumhelendhtung liesitzt. Zum Zweck der Reinlichkeit sind Waschapparate. Spucknäpfe etc. vorhanden; und ebenso sind Sicherheitsmafiregeln zur Cnfallverhütung getroften. Jede Tabakmanufaktur hesitzt einen Arz.t. ler den Arheitern wöchentlich zweimal Sprechstunde zu erteilen verptlichtet ist. Bei Unfällen wird er zur Erteilung der nötigen Hilfe sofort gerufen: aulierdem ist er verpttichtet. die Kiranken bis zu deren Wiederherstellung zu behandeln. Die mit ansteckenden Krankheiten behafteten Arbeiter bleiben bis zur völligen Genesung zu Hause. Während der Arbeitszeit tragen die Arbeiter gleichartige Uniform; die Aufbewahrung der eigenen Kleider geschieht in besonderen. nach Geschlechtern getrennten (iarleroheräumen. Zur Wahrung der Sittlichkeit sind die Arbeiter von den Arbeiterimnen getrennt, eine wegen der kleinen Zahl der Männer sehr leicht durchführbare Nafiregel. Trotzılem hat sich diese Trennung als völlig erfolglos wezeigt, demn leider mub zugegehen werden, dab das sittliche Verhalten der Regiearbeiterimen auf einem niedrigen Niveau steht. Teilweise findet diese beklagenswerte Tatsache einen entschuldl)aren (irund in der Art der Beschäftigung selbst.

Sombart sagt darüber folgendes: „Die notorisch sexuell aufregende Luft in mit Tabak erfüllten Räumen, die verhältnismäßig leichte Arbeit, die unter einer beschränkten Anzahl ron Personen zur Wechselrede gleichsam auffordernde Ruhe des Betriebes. dlas Überwiegen jugendlicher Elemente. alles macht es begreitlich, dati gerate kein sittsamer Ton unter unseren Arbeitern herrschen wird. Die halberwachsenen Burschen und Mädchen. deren viele in der Tabakfabrikation beschäftigt werden. saugen schon frühzeitig das (rift dieser auch sittlich oft unreinen Atmosphäre ein ${ }^{1}$ ).“

Leider ist der Arbeiter im allgemeinen sehr wenig auf die Zukunft bedacht. Einer materiellen Not gegenüber. die infolge Krankheit. Betriebsunfall oder Tod eintreten kann, vermag er weder sich noch seine Ansehörigen zu schützen. Die Segnung der Versicherung ist ihm teils fremd, teils ist ihm eine solche für seine Verhältnisse zu kostspielig. Bedlanerlicherweise tut aber auch der Staat in dieser Hinsicht gar nichts und die Privatinitiative infolgedessen noch weniger. Fü die Regieverwaltung aher hesteht die ernste Verpttichtung, ilır Augenmerk auf solche Vorschläge zu richten, welche im Interesse des Wohles der ihr unterstellten Arbeiter geschehen, und damit eine neue Ära für Rumänien herbeizuführen, welche einen berleutenden Schritt zur Hehung der sozialen

1) Sombart, a. a. O. S. 114 . 
Verhältnisse darstellen würde. In gewisser Beziehmng hat die Regieverwaltung bereits eine Etapje auf dem vorgeschlagenen Wege zurückgelegt, indem sie im Jahre 1897 eine Kasse für unterstützungsund pensionsberlürftige Arbeiter beider Manufakturen gründete und deren Zukunft, soweit man schon jetzt darüber urteilen darf, gesichert erscheint ${ }^{1}$ ). Der Zweck derselben ist: a) den Arbeitern oder deren Familien in Krankheits- oder Todesfällen die meist so nötige Ifilfe angedeihen zu lassen; b) die Errichtung ron Konsumniederlagen und Kantinen für die Arbeiter zu erleichtern; c) den arbeitsunfähig weworlenen Arbeitern oder nach deren Tod ihren Angehörigen Pension zu erteilen; (l) Kinderbewahranstalten zu errichten.

Die Zahl der Mitglieder dieser Unterstiitzungs- und Pensionskasse, welche im Jahre 18981207 Arbeiter betrug, nahm langsam, aber fortschreitend zu, so daß im Jahre 19031791 Arbeiter als Mitgrlieder eingetragen waren. Diese Zilhl stellt so Proz. der (iesamtzahl der Arbeiter dar. Die Einnahmen der Unterstützung- und Pensionskasse bestehen aus: a) einer Subvention (ler Regie 2): b) einem jährlichen Abzug vom Lohn der Arbeiter in Höhe einer dem Ertrag von 6 Arbeitstagen entsprechenden Summe. Statt dieses Abzuges gestattet aber die Regie an sogenannten kleinen Feiertagen zu arbeiten und zieht den dafür entfallenden Lohn so lange ein, bis die betreffende Summe (=6 Arbeitstage) gedeckt ist; c) aus den Geldstrafen der Arbeiter (diese dürften aber in Zukunft, wie oben erwähnt, wegfallen); d) aus den Zinsen des Kapitals; e) aus einem Teil der Nettoeinnahmen der Konsumniederlagen, uml endlich f) aus freiwilligen Gaben und Geldleistungen.

Das auf diese Weise gesammelte Kapital spiegelt sich in folgender Tabelle IX wieder:

$$
\text { (siehe Tabelle IX S. 76.) }
$$

Gemäß des Zweckes der Unterstïtzungs - und Pensionskasse wurde im Jahre 1900 eine Kinderbewahranstalt in Bukarest errichtet. sie bildet den tiiglichen Aufenthaltsort von 20-30) his 2.Jahre alten Kindern cler in der Fabrik arbeitenten Franen. Die Hütter hringen sie rormittags, wenn sie zur Arbeit gehen, und nehmen sie abends nach der Beendigung der Arbeit mit nach Hause. In der Anstalt werden die Kinder gut geptlegt, und die Eltern bezahlen dafür 10 Bani täglich: der Rest der Kosten wird won der Unterstïtzungs- und Pensionskiasse gedeckt.

1) Dieser Kasse gehören auch die Arbeiter der Streichhölzerfabrik an.

2) Diese Subrention stellt 30 Proz. c. aus den Gesanteinnahmen dar. 
IX.

\begin{tabular}{|c|c|c|c|c|c|c|c|c|c|c|c|c|}
\hline & \multicolumn{12}{|c|}{ Einnahmen } \\
\hline & \multicolumn{2}{|c|}{$1897 / 98$} & \multicolumn{2}{|c|}{$1898 / 99$} & \multicolumn{2}{|c|}{$1899 / 1900$} & \multicolumn{2}{|c|}{$1900 / 01$} & \multicolumn{2}{|c|}{$1901 / 02$} & \multicolumn{2}{|c|}{$1902 / 03$} \\
\hline & Lei & B. & Lei & B. & Lei & B. & Lei & B. & Lei & B. & Lei & B. \\
\hline Staatssubrention & 20000 & $1-1$ & 34480 & $1-$ & 37500 & $1-1$ & 18970 & $1-$ & 15960 & - & 15980 & - \\
\hline Lohnabzug & 16806 & 10 & $\mid 19076$ & 55 & 17094 & 85 & 19013 & 35 & 16551 & 30 & 21904 & 95 \\
\hline Geldstrafe & 1785 & วิ0| & 2720 & 35 & 1893 & $80 \mid$ & 1774 & $|10|$ & 1137 & 35 & 981 & 105 \\
\hline Kapitalzins & 7306 & 50 & 5072 & 37 & 7483 & 10 & 11607 & $1 \tilde{5}$ & 12 วัวั1 & 15 & 12737 & 97 \\
\hline $\begin{array}{l}\text { Teil der Nettoein- } \\
\text { nahme der Kon- } \\
\text { sumniederlagen }\end{array}$ & 1792 & 50 & 2778 & - & 2760 & - & 2955 & 90 & 3625 & 05 & 2664 & $1-$ \\
\hline Diverse & 97 & 10 & 145 & 55 & 529 & 70 & 391 & 40 & 442 & 30 & ร๊า & 55 \\
\hline Gesamteinnahme & 47787 & 70 & | & 82 & $67 \cdot 216$ & 4.5 & .7411 & 90 & 5006 & 15 & $5+82 i$ & .72 \\
\hline
\end{tabular}

Die bis zum Jahre 190:3 geleisteten Lnterstützungen belaufen sich auf 855863 Lei und dienten zur teilweisen Bestreitung der Kosten für Arzneien, ärztliche Besuche, Begräbnisse und Pensionen. Darüber gibt die nachstehende Tabelle $\mathrm{X}$ den nötigen Aufschluß.

I.

\begin{tabular}{|c|c|c|c|c|c|c|c|c|c|c|c|c|}
\hline & \multicolumn{12}{|c|}{ Ausgaben } \\
\hline & \multicolumn{2}{|c|}{$1897 / 98$} & \multicolumn{2}{|c|}{$1898 / 99$} & \multicolumn{2}{|c|}{$1899 / 1900$} & \multicolumn{2}{|c|}{$1900 / 01$} & \multicolumn{2}{|c|}{$1901 / 02$} & \multicolumn{2}{|c|}{$1902 / 03$} \\
\hline & Lei & B. & Lei & B. & Lei & B. & Lei & B. & Lei & B. & Lei & B. \\
\hline Arzneien & +194 & 9.) & $52.5 \%$ & 20 & 5003 & . & +126 & 99 & 3737 & 47 & 3556 & 59 \\
\hline Ärztliche Besuche & 3639 & - & 6299 & 50 & 6063 & - & 6312 & - & 6622 & 50 & 7077 & - \\
\hline $\begin{array}{l}\text { Wöchnerinnen- } \\
\text { unterstützung }\end{array}$ & 3389 & - & 2704 & 60 & 2585 & 55 & 2919 & - & 2801 & 10 & 3207 & 80 \\
\hline $\begin{array}{l}\text { Begräbnisunter- } \\
\text { stützung }\end{array}$ & 759 & - & 805 & - & 780 & - & 970 & - & 613 & 05 & 1055 & - \\
\hline $\begin{array}{l}\text { Kinderbewahran- } \\
\text { stalt }\end{array}$ & - & - & - & - & 2439 & 45 & 476 & 5 & 725 & 60 & 474 & $=70$ \\
\hline Pensionen & 600 & $1-$ & 525 & - & 190 & - & 70 & - & - & - & - & - \\
\hline Verwaltung & 436 & & 363 & 70 & 240 & $1-$ & 2119 & 95 & 1131 & 25 & 1093 & 75 \\
\hline Gesamtausg & 13018 & 15 & 15954 & - & 17301 & 75 & 16993 & 90 & 15630 & 90 & 16464 & 84 \\
\hline
\end{tabular}

Im Jahre 1902 wurde seitens der Manufaktur von Bukarest eine Lionsumniederlage gegründet, welche bezweckt, den Arbeitern derselben 
die mumgänglich im Haushalt notwenligen Artikel in guter Qualität zu mäbigen Preisen zu liefern. Das (irund- und Betriehskapital im Betrage von 45000 Lei wurde zu 5 Proz. verzinsbar von der Unterstützungsund Pensionskasse unter der Bedingung geliehen, dali diese Summe binnen 30 .Jahren durch jährliche Amortisationsiquoten wieder zurückerstattet würde. Auch diese Konsumniederlage scheint sich zu bewähren; der rege Geschäftsverkehr derselben gibt Veranlassung zu den besten Hoffnungen. Im Jahre 1903 konnte man bereits, nachlem die entsprechende Zins- und Amortisationsquote hezahlt. alle Retriebsausgaben gerleckt unl ein Reservefond von 1000 Lei gebildet worden war, an die Konsumenten noch 4 Proz. Dividende verteilen. AuRerdem besteht schon seit 1891 eine durch die Manufaktur von Bukarest verwaltete Sparkasse für die kleinen Ersparnisse der Tabakarbeiter, welche heute bereits die stattliche Summe von 280000-290000 Lei enthält. Dadurch gibt die Regie ein schönes Beispiel, indem sie zur Entwicklung des Sparsamkeitssinnes unter den Arbeitern beiträgt. welche leider den Wert des deutschen Sprichwortes: „Spare in der Zeit, so hast du in der Not" noch nicht zu würdigen verstehen. Jeder Arbeiter ist verpflichtet, 5 Proz. seines Lohnes an diese Sparkasse abzuführen. Das so nach und nach entstehende Kapital wird nur in hestimmten Fällen zurückgezahlt, wie hei Heirat. Immobilienankauf, Torlesfall oder Verlassen des Dienstes: dieser letzte Fall jedoch ist als eine Seltenheit zu bezeichnen. ein weiterer Beweis dafür daß die ITohltat der geschilderten Einrichtungen von den Arheitern anerkannt wird. Es wäre wünschenswert, daß diese Maßnahmen auch auf die Arbeiter der Manufaktur von Jassy erstreckt würden.

Hier sei noch erwähnt, daß im April des Jahres 1904 anläßlich des 25jährigen Bestehens der in Staatsverwaltung hefindlichen Regie an 2!) Arheiter für ununterbrochene 25jührige Tätigkeit in der Mannfaktur ,die Medaille für treue Dienste" verliehen und an über $40 \mathrm{Ar}$ beiterinnen eine Ehrengabe verteilt wurde ${ }^{1}$ ).

Alle diese Tatsachen beleuchten das Streben der Regieverwaltung, nach Möglichkeit zur Linderung des bisweilen harten Loses eines Arheiters heizutragen und gilst dadurch der Privatimdustrie. woselhst die Lage der Arheiter öfters eine wenig beneidenswerte ist. ein beherzigenswertes Leispiel. Die Regie gibt darlurch zu erkennen, dals sie es als Arbeitgeherin für ihre Ptlicht hält. diejenigen Arbeiter. deren Krä̈te in ihrem I)ienst abgenutzt wurden, nicht nur für die geleisteten Arbeiten zu bezahlen,

1) Universul 1904, Nr. 13:3. 
sondern ilmen im Alter und bei sonstigen Srhicksalen eine kräftige Stütze zu sein ${ }^{1}$ ). Die Regie wird aber auch, wie zu hoffen ist, auf dem hetretenen Wege rüstig fortschreiten und weitere Einrichtungen zum Wohle der Arbeiter schaffen, um so mehr, als sie in dieser Beziehung hinter den anderen Kulturstaaten noch zuriicksteht. Ratsam würde sein, wenn sie die Wohlfahrtseinrichtungen der österreichischen Regie, welche man nach heutigen Erfahrungen als ideal bezeichnen mul, als Richtschnur ihrer ferneren eigenen Einrichtungen ansehen würde. Es dürfte nicht ohne Interesse sein, zu erwähnen, daß die österreichische Regie ihr besonderes Augenmerk der Einrichtung von Speiseanstalten zugewendet hat. Dadurch wird nicht nur alleinstehenden, sondern auch solchen Arbeitern Gelegenheit \%ur Erlangung eines reichhaltigen und hilligen Mittagessens geboten, die ihr Heim ler zu groben Entfermung oder unfreundlicher Witterung lablber währenıl der Mittagspause nicht aufsuchen kömnen. In Jahre 19(r) bestanden schon 17 solcher Speiseanstalten, welche einen liostenaufwand ron s1 ti3 Kronen heanspruchten. Unter diesen Anstalten spielen die sog. Suppenanstalten, in denen den Arbeitern Supue zum Selbsthostenpreis verahfolgt wirl, eine grobe Rolle. Diese Anstalten ühen einen wohltätigen Einthulis auf die Gesundheitsverhälnnise der Arbeiter dadurch aus, dab. die Suppen auf die Verdauung wirkend zubereitet sind. Diese Maßregel soll bezwecken, den gesundheitsschädlichen Genuß der in die Fabrik mitgebrachten meist kalten orler irrationell zubereiteten syeisen zu paralysieren. Die Suppenanstalten sind demnach auch in hygienischer Beziehung von einigem IV ert. Derartige Beispiele von speiseanstalten finden wil auch in Deutschland. So hat eine Firma in Dresten eine Fahrikliüche mit hesonderem EGram eingerichtet. welche den 'Tabakarbeitern Mittagessen und Ḱaffee zu folgenden Preisen liefert: eine Portion Fleisch mit Gemüse 25 Pf., 1/2 Ltr. Kaffee mit Milch und Zucker 5 Pf. ${ }^{2}$ ). - Andere erwähnenswerte, dem Wohl der Tabakarbeiter dienende Fimrichtungen der österreichischen Regie sind die Arbeiterbäder und -bibliotheken. Elf Fabriken besitzen Badeanstalten, in denen den Arbeitern unentgeltlich mit oder olne ärztliche Anweisung Bädre verabfolgt werden. Anfertem sorgt die Regieverwaltung dafür, daß ihre Arbeiter auch in allen Fabrikstationen gegen geringes Entgelt Barlegelegenheit haben. falls eigene Arheiter-

1) Unger, Heinrich, „Die sociale und ethische Wirkung der Arbeiterversicherung", Berlin 1897, S. 5.

2) Zeitschrift res Königlich-sächsischen statistischen Bureaus 1892 (Heft I Ind II), S. 184 . 
bäder noch nicht, wohl aber Privatbadeanstalten vorhanden sincl. In dieser Weise ist den Arbeitern ron 2:3 Fabriken entweder unentgeltliche Barlegelegenheit oder loch wenigstens solche zu elmäbigten Preisen geboten. Von hervorragender Bedeutung ist eine weitere, von der österreichischen Regie im Jahre 1900 unter Anwendung erheblicher Liosten ins Lehen gerufene Wohlfahrtseinrichtmug: nämlich die Arheiterbibliotheken, welche die geistige Förderung der Tabakarbeiter bezweckens. Trotz der hedeutenden Sohwierigkeiten. welche hauptsä̈lilich darin bestanden. dab die Tahalifahriken in verschierlenen Sprach- unı Kulturgebieten gelegen sind, wurde die Aktion derart energisch gefördert. daß zu Ende des Jahres 1!102 schon 15̆ österreichische Tabakfabriken mit Arbeiterbibliotheken versehen waren. Ton diesen Bibliotheken rerfügten die größten über eimen Bestand ron ungefähr 1500 Bänden. während die kleinsten mindestens 1ju, in sanzen s.o.) bände

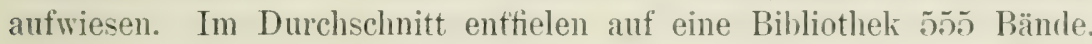
Selten wird es Volksbibliotheken geben, welche eine derartige Vielsprachigkeit aufweisen, wie diese; es bestanden nämlich 8 deutsche. 4 polnisch-ruthenische, 2 böhmische und eine italienische Arbeiterbibliothek. Der Gesamtaufwand dafür betrug Ende 1902 ca. 11800 Kronen. wobei die Ausgaben für Drucksachen und Verwaltung auber Betracht blieben, so daß sich für jede ein durchschnittlicher Aufwand von 786 Kronen ergibt. Die Beteiligung der Arbeiterschaft an diesen Institutionen ist erfreulicherweise eine sehr rege; Ende 1902 wurden schon 3817t Entlehnungen nachgewiesen, somit im Durchschnitt pro Woche 70 Bücher entliehen. Daran zeigt sich deutlich, wie tief das Bedürfnis nach geistiger Erholung in der menschlichen Natur begründlet ist. Man kann die soziale Berleutung dieser Einrichtung, welche in Rumänien sich um so fühlbarer macht, als die Zahl der Analphabeten 82,67 Proz. ${ }^{1}$ ) beträgt, nicht hoch genug anschlagen. Es ist geradezu eine Pflicht der rumänischen Regie, daß sie auch in dieser leziehung ilner Arheiterschaft helfend entregenkommt und aut rlese Weise ihrerseits zur allgemeinen Bildumg des Volkes mit heitränt.

In Anbetracht dessen, daß die Tabakarbeiter Pumäniens durch ilre Arbeit nicht zum wenigsten dazu beitragen, daß die Regie dem Fislius so bedeutende Einnahmen aus dem Monopel zu überweisen in der Lage ist, halte ich nach meinem Ermessen die Regie auch für verptlichtet, alle die Wohlfahrtseinrichtungen einzuführen, die den

1) Anuarul statistic al Rominiei 1904, p. 537. 


\section{$-120-$}

Arbeitern dienlich und niitzlich sind und wie solche in allen Kulturländern bereits in mehr und minder vorzüglicher Weise bestehen. Nicht allein ilie Technik iles Betriebes soll fortschreiten, sondern anch dem Arbeiter muf mehr und mehr ausreichender Schutz gegen gesundheitsichädliche Einwirkungen gewährt werden und durch weitgehende Wohlfahrtseinrichtungen ist er in kultureller wie geistig-sittlicher Beziehung zu stützen und zu fördern.

Auch hierin müßte die rumänische Regie bestrebt sein, in $\mathrm{Zu}$ kunft allen anderen heimischen Privatgesellschaften und gewerblichen Etablissements zu eigener Befriedigung und zum Wohl ihrer Untergebenen als Musteranstalt zu dienen. 


\section{Der Verkauf.}

\section{Das Verschleißsystem.}

Während der Yerkauf der Tabakfabrikate der österreichischen Regie dem Finanzministerium untersteht, gehört derselbe in Rumänien zum Ressort der Regieverwaltung, was wir aus folgendem Grunde für vorteilhafter erachten: Die Regieverwaltung wird tles guten Renommees ilırer Fabrikate lialber, d. h. um dieses nicht zu verlieren den Verkauf viel strénger beaufsichtigen, als die Finanzbehörde.

Die vorschriftsmäßig verpackten fertigen Fabrikate werten an die 38 Lagerhäuser abgegeben. An der Spitze eines jeden derartigen Hauses steht ein Vorsteher, welcher verptlichtet ist, die Fabrikate nur an die Tabakdebitanten und nur gegen bar zu verkaufen, sowie die gute Aufbewahrung ter Fabrikate bei den Debitanten zu kontrollieren. Sie sollen einen Tabakvorrat für wenigstens 10 bis 15 Tage haben. Die Tabakilebitanten gliedern sich in Tabakgrofalebitanten (intrepositari) und Tabakkleindebitanten oder Trafikanten. Die ersteren sollen das Tabakmaterial unmittelbar von den Lagerhäusern beziehen und an die ihnen zugewiesenen Tabakkleindebitanten alyeben. Es wird ihnen diese Verkaufshefugnis im Wege der öffentlichen Konkurrenz auf 5 Jahre verliehen. Sie wird demjenigen erteilt, der für sich den geringsten Anteil am Verkaufserträgnis fordert. Sie sind kautionspttichtig. Die Höhe der Kaution wechselt je nach der Bedeutung des Bezirks. Sie stehen zur Regieverwaltung in einem Vertragsverhältnisse und sind verpthichtet. die für den Verschleil, in ihrem Verkanfsgehiete erforderlichen Tabakfabrikate des allgemeinen Verkaufstarifes auf ihre liosten und (iefahr ron dem ilmen bezeichneten Lagerhaus und nur gegen bar zu heziehen. Anberdem hahen sie ein bestimmtes Minimum jälırlich zu rerkaufen; unterlïlit der Debitant es, olme sich darüher genügend rechtfertigen zu künnen, so kann die Ergänzung der Verkaufsulifferenz aus der Kaution gedeckt werden. Dardurch sichert sich die Regie einen Minimalahsaty, auf den sie in allen Fällen rechnen kann, was für eine gute Leistung des Betriebes von der größten Bedentung ist. Des weiteren sind sie verptlichtet, dafür 
Sorge zu tragen, daß die Bezirkskleindebitanten rechtzeitig und genügend mit Ware versehen werlen; der Verkauf an diese erfolgt auf Rechnung und Gefahr des Lieferanten, also des Großdebitanten. Als Vergïtung erhalten sie einen Rabatt von 7,75 - 11,20 Proz., wovon den Kleindebitanten 5 Proz. zu bewilligen sind. Sie sind auch mit lem Verkauf der Spielkarten, Stempelmarken und -papiere beauftragt, wofür ihnen ein Rabatt von 10 Proz. unter der Bedingung, den Kleindebitanten einen Rabatt von $6 \mathrm{Pro}$. zu bewilligen, gewährt wird.

Die Tabakkleindebitanten werden von der Regieverwaltung ernannt und ihre Ernennung wird im Staatsanzeiger (Monitorul oficial) veröffentlicht. Sie sollen Rumänen orler naturalisiert sein. Die Befugnis zum Verkauf wirl vorzugsweise verliehen an:

a) Unteroffiziere, die mindestens 12 Jahre gedient haben;

b) Beamte, die wegen Gebrechlichkeit und ohne Pension zu beziehen, den Dienst zu verlassen gezwungen sind;

c) nicht pensionsberechtigte Beamtenwitwen.

An sich betrachtet ist diese Maßregel gewiß gut und lobenswert, indem sie derartigen Personen eine angemessene und sichere Existenz bietet; der erwartete Erfolg ist aber leider bis heute wegen der sozialen Präjudizien und der immerhin kleinen Einnahme aus diesem Handel ausgeblieben.

Jedem Debitanten wird als Beweis seines Rechtes ein Regie-Erlali verliehen. Diese Erlasse sind streng persönlich und können weder direkt noch indirekt auf andere Personen übertragen werden. Die Debitlokale werden dem Publikum durch bekannte, im ganzen Lande gleichartige Plakate bezeichnet, welche an der Türe angehängt sind. Die Lokale dürfen nicht feucht orler dumptig sein und miissen stets sauher gehalten werden. Gegenstände, welche einen den Tabakfabrikaten schädlichen Geruch entwickeln und diesen auf die Fabrikate ühertragen könnten, dürfen im gleichen Raume nicht aufberahrt werden. Leider bestehen die Debitlokale vielfach nur aus engen, schmalen Räumen, denen gegenüber die deutschen Tabakï̈len Paläste vorstellen. Da die Beschaffenheit des Debitlokals unzweifelhaft sehr viel zur Haltbarkeit der zum Verkaufe gelangenden Tabakfabrikate beiträgt, so müßte die Regieverwaltung im Interesse der Hebung des Tabakverschleißes diesem Moment die größte Aufmerlisamkeit zuwenden. Außer den Tahakfahrikaten sind die Tabakkleindehitanten auch berechtigt und auf Verlangen des Finanzministeriums sogar verpthichtet, Postwertzeichen (Briefnarken, Liorrespondenzkarten etc.) sowie (iebührenwertzeichen stempelmarken, -papiere. Frachthrief- und Wechselh)lankette etc.) 
nach den hierfür geltenden Vorschriften zu verkaufen. Außerdem können die Trafikanten auch den Verschleiß von Losen der Wohltätigkeitslotterien gegen bestimmte Provision ïbernehmen.

Die Tabakkleindebitanten werden als Staatsdiener betrachtet: sie sind keine Kaufleute und bezahlen aus diesem Grunde keine Gewerbestemer: wenn sie aber neben dem Tabak und Rauchutensilien andere Sachen rerkaufen, dann sind sie die entsprechende Gewerbestener zu zahlen verptlichtet.

Das nötige Material beziehen die Tabakkleindebitanten aus den Bezirkshauptstädten von dem betreffenden Lagerhaus, welches ihnen als Versorgungsstelle rorgeschrieben ist, während die Tabakgroßdebitanten sie mit der notwendigen Ware zu versehen haben, wie oben schon gezeigt wurde. Besondere Sorgfalt haben die Trafikanten auf die gute Konservierung (ler Tabakfabrikate zu verwenden: sie müssen dafür sorgen, daß dieselben nicht verstauben, nicht auf feuchten Plätzen stehen. aber auch nicht allzusehr austrocknen. Ebenso sollen sie clarauf berlacht sein, dab der Bestand an Tabakfabrikaten ein vollständiger und ausreichender ist, damit das Publikum befriedigt werden kann und seine Zuflucht nicht zu Schmuggel und Unterschleif nehmen braucht. Die Tratikanten sind verptlichtet. in dem hehördlich genehmigten Lokale die Tabakfabrikate an die Konsumenten nur zum tarifmäßigen Konsumentenpreise zu verkaufen. Änderungen des V'erschleißtarifes seitens der Regieverwaltung erstrecken jerloch ihre Wirkung auch auf das in den Debitlokalen befindliche Tabakmaterial. (1. h. es ist für die am Tage der Preisänderung in den Debitlokalen voruätigen Tahalifabrikate von den Konsumenten der neu festgesetzte höhere oder niedrigere Preis zu zahlen.

Mit dem Debitanten ist in diesem Fall insofern eine Ausgleichung vorgesehen, als dieser entweder die durch teneren Terkauf sich ergebenden Differenzbeträge abliefert oder ihm das durch Herabsetzung der Preise für ihn entstehende Defizit zurückgezahlt wird.

Zur Kontrolle hat der Trafikant in seinem Verkaufslokale ein amtlich beglaubigtes Preisverzeichnis, sowie die ilnm erteilte Lizenz an einem dem Publikum leicht in die Augen fallenden Platze zu befestigen. Die eigenmächtige Änderung dieses Preisverzeichnisses berlingt nicht nur den Verlust der Lizenz, sondern hat auferdem noch strafrechtliche Anzeige zur Folge. Wenn ferner die Debitanten an das Tabalifabrikate kaufende Publikum das Ansimmen stellen sollten, außer dem Tabak noch andere im Verkaufslokale befindliche Waren zu liaufen. so verlieren rliese Debitanten ebenfalls ihre Lizenz und worklen noch mit einer Gelistrafe von 50 Lei belegt. 
Der Detailverkauf der Rauch- und Schnupftabake geschieht nur in ter Originalverpackung und ter ler Zigarren und Zigaretten teils in Originalverlackung. teils in kleineren Quantitäten: sellsst ein einzelnes Exemplar aus geöffneter Verpackung ist verkäuflich.

Auf jedem zum Verkauf gelangenden Paket ist die Fabrik rerzeichnet, in welcher die Ware erzeugt worden ist, desgleichen die Qualität, das Gewicht und der Preis des Fabrikats. Dadurch soll ein Betrug seitens des Debitanten vermieden und dem Konsumenten die Möglichlieit segrehen werden. stets frische Talsalkfahrikate kaufen zu können, nicht aber solche, die vielleicht einen schon zu Pulver gewordenen Tabak enthalten.

Die Preise der Tabakfabrikate sind im ganzen Lande die gleichen, Ein Limitoverschleil., wie in Frankreich. Österreich und Italien, l,esteht nicht. Es werden nämlich in diesen genannten 3 Ländern an die Soldaten und Unteroffiziere der Landarmee und die Mannschaften der Kriegsmarine die Regiefabrikate zu billigerem Preise verkauft. als an die anderen Konsumenteń.

Eine solche Begünstigung enthält inclessen ihre Schattenseiten und erscheint nicht empfehlenswert, ,einerseits weil sie zum Verkauf solcher Soldatentabake an Dritte zu Preisen unter den übrigen Regiepreisen. andererseits aber dazu führt. dab die Soldaten sich ans Rauchen gewöhnen, was mancher sonst unterlassen hätte und nach seinem Austritte aus dem Militär nur mit größerem Aufwande fortsetzen kann" I).

Die französische Einrichtung in den Grenzdepartements, Tabake zu billigeren P'reisen zu verkaufen. um dem Schmuggel entgescenzutreten. würde hingegen auch für Rumänien berechtigt erscheinen. und zwar als Iraliregel gegen den Schmuggel aus Pufland und Bulgarien. Dadurch aher würden die Regieeinkünfte große Verluste erleilen, weil wegen der hedeutenden (irenzansilehnung die begünstigten Zonen aus einem beträchtlichen Länderteil Rumäniens bestehen würden.

Selbst in Frankireich wurden diese Zonen bedeutend beschränkt, und zwar in Anbetracht der für die Staatskasse entstehenden Verluste 2), sowie des internen Schmuggels; letzterer wurde insofern betrieben, als aus den Grenzbezirken zu billigem Preis gekaufter Tabak in solche Gegenden gebracht wurde, in denen der normale Tarif bestand. Creizenarh heschrieh diesen schmuggel in folgenter Weise: ..Be-

1) Mohl a. a. O., S. 36 .

2) Mohl, ibid. S. 30 . 
sonders Kinder und berittene Männer wurden truppweise zu diesem Schmuggel verwendet. Er war sehr einträglich dadurch, daß man alle Zonen, welche begreiflicherweise lauter enge Gürtel bilden, in einer Nacht passieren und die Konterbande aus der äußersten Grenzzone weit genug in das innere Land fortschaffen konnfe, wo schon die hohen Monopolpreise galten ${ }^{1}$."

Die Trafikanten Rumäniens erhalten für ihre Nühewaitung einen der Mienge der rerkauften Tahakfabrikate entsurechenden Rahatt, und dieser während des Bestehens des Tabakmonopols gewährte Rabatt mub in der Zeit der Pachtperiorle als sehr hoch bezeichnet werden. Er betrug in den Jahren 1873, 1874 und 187616 Proz. und in anderen Jahren 13 Proz.; ausnahmsweise 11 Proz. in 1872. Dieser Umstand erklärt sich dadurch, daß die meisten Debitanten damals wie heutzutage auch Gastwirte waren. Bis zum Jahre 1873 besaßen die Juden auf dem platten Land das Recht. Wirthä̈user zu besitzen, und aus der großen Zahl solcher Wirte ergab sich auch das zahlreiche Vorhandensein von Tabalidebiten. und demzufolge mulste der Rabatt niedrig sein. Im Jahre 1873 wurde das noch heute zu Recht bestehende Gesetz eingeführt, welches den Juden verbot, Gastwirtschaft auf dem Lande zu betreiben. Dadurch verminderte sich die Zahl der Debitanten, und der Rabatt wurde ein entsprechend höherer, um neue Debitanten zu gewinnen.

Seit dem Jahre 1879 ist der bewilligte Rabatt immer geringer geworden. Die fortwährende Zunahme der Tabakkonsuntion und der sichere Ertrag, den die Debitstellen den Trafikanten gewähren, vermehrte den Zudrang der Bewerber und veranlaßte die Regie, die Tabakquote lierabzusetzen. Die beiliegende Tabelle XI (siehe S. 1:6) soll dies veranschaulichen.

Gegenwärtig wird den Debitanten von den Bezirkshauptstädten ein Rabatt von 5) Proz. in dem Falle bewilligt. dab sie lediglich Tabaliverkauf treiben: andernfalls erhalten sie :3 Proz.: die anderen Dehitanten beziehen einen allgemeinen Rabatt von 5 Proz.

Im Jahre 1902 gab es 46227 Debitanten. Unter diesen befanden sich nur 227 oder 0.05 Proz. die lediglich Tabakverkauf trieben. während die übrigen ein anderes Handelsgewerbe damit verhamlen. Die meisten Debitanten sind Gastwirte.

Das Verhältnis der bestehenden Debite zur gesamten Bevöllierung Rumäniens (1902: 6081572 Seelen) berechnet, ergibt 1:131, d. h.

1) Creizenach a. a. O., S. 119. 
XI.

\begin{tabular}{|c|c|c|c|c|c|c|}
\hline \multirow[t]{2}{*}{ Jahre } & \multirow{2}{*}{$\begin{array}{c}\text { Verkanfte } \\
\text { Quantitäten } \\
\text { kg }\end{array}$} & \multirow{2}{*}{$\begin{array}{c}\text { Brutto- } \\
\text { Einnahmen } \\
\text { Lei }\end{array}$} & \multirow{2}{*}{$\begin{array}{c}\text { Gesamtbetrag } \\
\text { des Rabatts } \\
\text { Lei }\end{array}$} & \multicolumn{2}{|c|}{$\begin{array}{l}\text { Durchschuitts- } \\
\text { gewinn der } \\
\text { Debitanten } \\
\text { pro kg }\end{array}$} & \multirow{2}{*}{$\begin{array}{l}\text { Von d. Regie } \\
\text { bezahlter } \\
\text { Durch- } \\
\text { schnittsrabatt } \\
\text { pro Jahr } \\
\%\end{array}$} \\
\hline & & & & Lei & Bani & \\
\hline 1873 & 1308541 & 11916794 & 1337672 & 1 & 02 & 11,22 \\
\hline 1874 & ] 926722 & 16346945 & 2721848 & 1 & 41 & 16,65 \\
\hline 1879 & 1517756 & 13178075 & 1725777 & 1 & 14 & 13,10 \\
\hline 1884 & 3652295 & 27232578 & 2966767 & - & 85 & 10,90 \\
\hline 1889 & 3290729 & 31162185 & 2422905 & - & 74 & 7.77 \\
\hline 1893 & $3599 ! 25$ & 35608937 & 2404335 & - & 67 & 6,70 \\
\hline 1899 & 4052110 & 39867965 & 2392114 & - & 59 & 6,00 \\
\hline 1900 & 3746212 & 37043804 & 2050050 & -. & $5 \overline{5}$ & 5,, 54 \\
\hline 1901 & 3278761 & 37292807 & 2.289663 & - & 70 & 6,14 \\
\hline 1902 & 3871406 & 35303636 & 2214392 & - & 57 & 6,29 \\
\hline
\end{tabular}

auf 131 Einwohner kommt ein Debitlokal. Im gleichen Jahre stellt sich dieses Verhältnis in den anderen Monopolländern folgendermaßen:

$$
\begin{array}{ll}
\text { in Österreich 1: } 381 \\
\text { "Frankreich 1: } 831 \\
" \text { Italien } 1: 1209
\end{array}
$$

Diese verhältnismäßig große Zahl von Debitanten in Rumänien erklärt sich im Gegensatz zu den anderen Monopolländern aus der geringeren Bevölkerungsdichte des Landes, denn es entfallen auf 1 Quadratkilometer ${ }^{1}$ )

$$
\begin{aligned}
& \text { in Rumänien . . . . . . . . 40,3 } \\
& \text { "Österreich . . . . . . 71,2 } \\
& \text { "Frankreich . . . . . 72,6 Einwohner. } \\
& \text { "Italien . . . . . . . . 115,0 }
\end{aligned}
$$

Die grolie Zahl der Debitanten Rumäniens entspricht demnach den lokalen Verhältnissen, und dadurch gelang es auch der Regie, dlie Bedürfnisse der Levölkerung nach Tabakfabrikaten vollstïndig zu befriedigen und die Hauptursache der diesbezüglichen, während der Pachtperiode in Masien eingelanfenen Beschwerden zu beseitigen. Das Vorhandensein so vieler Debitanten hat allerdings zur Folge, daß der jährliche Nutzen derselhen viel geringer ist, als der der Debitanten in Frankreich. Österreich und Italien. Im Jahre 1!(02) betrug derselbe 41 Lei, in Österreich $287 \mathrm{Kr}$., in Italien 681 Lire und in Frankreich 794 Fres.

$$
\text { 1) v. Juraschek, a. a. O. }
$$


Daß in Rumänien der Nutzen der Debitanten aus (lem Tabakverkauf so klein ist, hat teilweise auch seinen Grund in dem seitens der Regieverwaltung gezahlten zu geringen Rabatt. Dieser betrug,

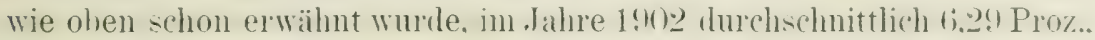
während sich im gleichen Jahre derjenige ler französischen Regie auf 8.99 Proz., der österreichischen auf 9,2:3 Proz. und der italienischen auf 8,31 Proz. bezifferte.

Wohl erzielen die Spezialdebitanten noch auferdem durch den Verkauf anderer monololisierter (regenstiunde einen hestimmten Rahatt. immerhin aber ist ihre Lage als eine gute nicht $\mathrm{zu}$ bezeichnen. Diese Tatsache beweist schon der L'mstand, daf die Terhälniszahl der Spezialdebitanten nur 0,05 Proz. beträgt.

Die Regie allerdings hat einen bedeutenden Vorteil insofern, als es ihr ermöglicht ist, den Verkauf ihrer Fabrikate, unter nur geringen Unkosten betreiben zu können.

\section{Die Verkaufstarife und der Konsum.}

Die Verkaufstarife, nach denen die Debitanten die Tabakfabrikate verkaufen sollen, werden jährlich von dem Verwaltungsrat der Regie aufgestellt und nach (ienehmigung des Finanzministeriums in (lem Staatsanzeiger (Monitorul oficial) und anderen Zeitungen bekannt regehen. Diese Bekanntmachung findet im Monat November des Buclgetjahres statt, in dem der Verschleißtarif in Kraft treten soll.

In Frankreich werden die Preise gesetzlich normiert und die Regieverwaltumg ist infolgerlessen bis zum Erscheinen eines neuen diesbezüglichen (iesetzes rerpflichtet. zu rliesen Preisen zu verkaufen. Diese Maßregel kann als nicht pralitisch genug angesehen werden, da Fälle eintreten können, in denen die Regieverwaltung fremule Tabake zu doppelten Preisen anzukaufen sich gezwungen sieht. In solchen Fällen kann die Regieverwaltung die Preise nicht erhöhen, aber sie wird, um die gleichen Resultate anderer Jahre zu erzielen, genötigt sein, das prozentuale Mischungsverhältnis der hesseren Tahakunalitäten hei der Herstellung der betreffenden Tabakfabrikate zu vermindern. Die Folge ist eine geringere Qualität der Fabrikate und die alsbald sich bemerkbar machende Unzufriedenheit des Publikums.

Um allen Bevölkerungsklassen gerecht zu werden, besteht die Aufgahe der Regie darin, die Preise derart ahzustufen. dab jeder Konsument hinsichtlich seiner finanziellen Leistungsfähigkeit, d. l. seines Einkommens, die nötige Berücksichtigung findet. 
Eine genügende Abstufung der Preise kann aber nicht stattfinden, wenn die Zahl der Fabrikatsorten zu klein ist. In dieser Beziehung kann. wie oben schon hervorgehoben wurde, der rumänischen Regieverwaltung der Vorwurf nicht ersprart werden, dab sie zu wenig Fabrikatsorten hesitzt und den grohen Vorzug der Tahaksteuer-Abstufung nach Qualitäten nicht genügend berürksichtigt. Des weiteren darf eine Regie die Preise des Verkaufstarifs nicht zu hoch stellen, weil dies riel zur Abnahme der Konsumtion beiträgt und noch den schädigenden EinHuß ausübt, daß nicht nur ordinäre und schwere Tabake. sondern schließlich auch statt des Tairalis andere Surrogate geraucht werden, wodurch die Gesundheit beeinträchtigt wird. Die Wichtigkeit dieses Prinzips blieh hei der Feststellung der Verkaufspreise während der Pachtperiode des rumänischen Tabahmonopols aulier Acht; die Preise waren zu jener Zeit im Verhältnis zur Qualität der Fabrikate entschieden $\mathrm{zu}$ hoch.

Bei dem Übergang des Tabakmonopols in Staatsregie behielt zwar die Verwaltung die früheren Verkanfspreise bei. aher der Raucher bekam dafür bessere Fabrikate. Diese sind allerdings im Laufe der Zeit nicht mehr dieselben geblieben, und es sind mannigfache Veränderungen der Qualitäten eingetreten, die sich jedoch mehr auf Zigarren- und Zigarettensorten als auf Rauch- und Schnupftabak beziehen. Neue Arten von Fabrikaten wurden eingeführt und andere abgeschafft: auch die Preise unterlagen verschiedenen Schwankungen, nur die für Rauch- und Schmupftabake blieben annähernd dieselhen.

Im Jahre 1900 fand eine hedeutende Erhöhung der Tahakfahrikatpreise statt, und zwar betrug die Preissteigerung bei Luxustabak 16,7 Proz., I. Qualität 25 Proz., II. Qualität 16,7 Proz., III. Qualität 20 Proz. und IV. Qualität 21 Proz., auch wurde zugleich noch eine extrafeine Tabakiqualität eingeführt. deren Preis auf so Lei pro Kilogramm festgesetzt wurde.

Dadurch bezweckte die Regieverwaltung die infolge der Krrisis von 1899 entstandenen Fehleinnahmen auszugleichen, jedoch beeinflubte diese Preiserhöhung die Konsumtion so stark, daß diese fast bis aúf die Hälfte des Jahreskonsums von 1899 sank.

Folgende Tabelle XII gibt darüber Aufschluß:

XII.

\begin{tabular}{c|r|c|c}
\hline Fabrikat & $\begin{array}{c}\text { Im Jahre 1900 } \\
\mathrm{kg}\end{array}$ & $\begin{array}{c}\text { Im Jahre 1901 } \\
\mathrm{kg}\end{array}$ & $\begin{array}{c}\% \\
\text { weniger }\end{array}$ \\
\hline Luxustabake & 6415 & 3498 & 45,47 \\
Tabak I. Qualität & 40522 & 24573 & 39,36 \\
" II. " " & 187885 & 118775 & 36,77 \\
" III. " & 1062793 & 779802 & 26,62 \\
" IV. " & 2150713 & 1952329 & 9,17
\end{tabular}


Die Regie ermäßigte infolgedessen die Preise im folgenden Jahre, mit anderen Worten: die normalen Preise der vergangenen Jahre gelangten wieder zu ihrer Geltung.

Gegenwärtig besteht folgender Preistarif (siehe Tal). XIII, S. 129).

XIII. Sorten.

\begin{tabular}{|c|c|c|c|c|c|c|c|}
\hline $\begin{array}{c}\text { Rauchtabak } \\
\text { pro kg }\end{array}$ & Lei| & $\begin{array}{l}\text { Zigaretten } \\
\text { pro } 1000\end{array}$ & Lei| & $\begin{array}{l}\text { Zigarren }{ }^{3} \text { ) } \\
\text { pro } 1000\end{array}$ & |Lei| & $\begin{array}{c}\text { Schnupftabak } \\
\text { pro } \mathrm{kg}\end{array}$ & |Lei \\
\hline $\begin{array}{l}\left.\text { Der feinste }{ }^{1}\right) \\
\text { I. Qualität } \\
\text { II. ", } \\
\text { III. ", } \\
\text { IV. " } \\
\text { Rural " . . } \\
\text { Scaferlati }{ }^{2} \text { ) } \\
\text { (superior) } \\
\text { Pfeifentabak }{ }^{2} \text { ) } \\
\text { Tumbeky }{ }^{2} \text {. }\end{array}$ & $\begin{array}{r}55 \\
40 \\
25 \\
15 \\
10 \\
5 \\
50 \\
40 \\
20\end{array}$ & $\begin{array}{l}\text { Carmen Sylva } \\
\text { Jassy } \\
\text { Spezialität } \\
\text { Minister } \\
\text { Ambre } \\
\text { Königliche } \\
\text { Intim-Club } \\
\text { Jaka } \\
\text { Reporter } \\
\text { Scaferlati } \\
\text { Prinzersin } \\
\text { Dame } \\
\text { Comerziale } \\
\text { Beamten } \\
\text { Militär } \\
\text { Sergeant } \\
\text { Dorobantz }\end{array}$ & $\begin{array}{l}150 \\
100 \\
80 \\
75 \\
60 \\
50 \\
30 \\
25 \\
15 \\
10\end{array}$ & $\begin{array}{l}\text { El Rio Sella } \\
\text { Regalitas } \\
\text { Integritas } \\
\text { Fleganta } \\
\text { Britanica } \\
\text { Farorita } \\
\text { Belvedere } \\
\text { Virginia } \\
\text { Trabucos } \\
\text { Veres } \\
\text { Indigene }\end{array}$ & $\left\{\begin{array}{l}300 \\
250 \\
200 \\
150 \\
\left\{\begin{array}{l}100 \\
100\end{array}\right.\end{array}\right.$ & $\begin{array}{l}\text { Ceam } \\
\text { I. Qualität } \\
\text { II. " } \\
\text { Rapé")" } \\
\text { Russischer }{ }^{2} \text { ) }\end{array}$ & $\begin{array}{r}40 \\
6 \\
3 \\
20 \\
8\end{array}$ \\
\hline
\end{tabular}

Diese Preise sind gegenüber denen des Tarifs der Pachtperiode um 22 Proz. niedriger.

Trotzdem der Verkaufstarif der rumänischen Regie sich im allgemeinen durch verhältnismäßig hohe Preise charakterisiert, ist der Konsum (siehe graphische Darstellung D.) beträchtlich gestiegen. Während im Jahre 187:3 nur $1308541 \mathrm{~kg}$ konsumiert wurden, gelangte im Jahre 1902 die dreifache Quantität, nämlich $3278761 \mathrm{~kg}$ zum Verbrauch; somit hatte der Berlarf an Tabak in 30 Jahren um 151 Proz. oder jährlich um 5 Proz. zugenommen. Bis 1884 war die Tabakkonsumtion in einem stetigen Steigen begriffen, um sodann bis 1890 wieder abzunehmen. Diese Abnahme machte sich am meisten

1) Bei der Bestellung kostet $1 \mathrm{~kg} 60$ Lei.

2) Alle diese Sorten sind eingeführt.

3) Neben den oben angeführten Zigarrensorten befinden sich im Verkauf fremde Zigarrensorten im Preis von 40 bani bis 3 Lei pro Stück. Ton bekannten Marken führen wir an:

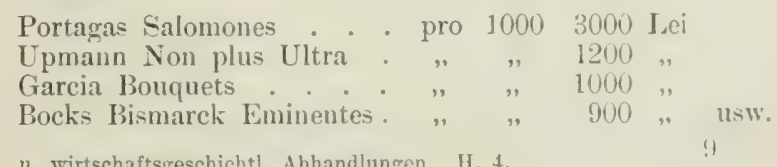

Yolkswirtschaftl, u, wirtschaftsgeschichtl, Abhandlungen. H, 4. 
in rlen Jahren 1887. 1889 und 1890 wegen der Erhöhung rler Tarifpreise und der Agrarkrisis der letzten zwei Jahre ${ }^{1}$ ) bemerkbar.

Diese Einschränkung des Konsums ließ, als die neue Last eine gewohntere wurde, allmählich nach und die Tabakkonsumtion stieg wieder bis zum Jahre 1899, wo sie das Maximum von $4037827 \mathrm{~kg}$ erreichte. Hier wiederholt sich die Erscheinung, daß eine Erhöhung der Verkaufstarife zunächst eine Verringerung des Tabakverbrauches zur Folge hat, welcher jedoch im Laufe einiger Jahre seinen früheren L'mfang wieder erreicht. "Allerdings“, sagt Mohl, ,lehrt die Erfahrung in Frankireich, dab auf jerle Erhöhung der Verkaufspreise des Regietahaks ein zeitlicher Rückschlag in dem Ahatz erfolgt, dab dieser Rückschlag infolge einer Preiserhöhung aber jederzeit von nur ganz kurzer Dauer ist, weil die Leute, welche sich eimmal an rlas Schmupten gewöhnt haben, davon nicht ablassen, die Raucher aber ihre Vorsätze, sich im Rauchen zu beschränken, in kurzer Zeit wieder vergessen, und daß schon in den nächsten Jahren die Bewegung des Verbrauchs zu einer Erweiterung bis zu dem Umfang, welchen derselbe vor der Preiserhöhung hatte, sich rasch wieder geltend macht $\left.{ }^{2}\right) . "$

Die Krisis von 1899 brachte für Rumänien zweifellos eine Verminclerung der 'Tabakkonsumtion aber nur für kurze Dauer mit sich, denn der Tabakverbrauch, welcher in Jahre 1901 auf $3278761 \mathrm{~kg}$ gesunken war, zeigte im Jahre 1902 bereits wieder steigende Tendenz und erreichte 1903 wieder das Maximum von $4036485 \mathrm{~kg}$.

Die Zunalme des Tabakverbrauches ist nicht oder doch nur in sanz geringen Mafe dem Anwachsen der Bevölkerung zuzuschreiben, denn dieses ging nur sehr langsam von statten, da in 30 Jahren nur eine Zunahme von 25,4 Proz. orler jährlich 0,84 Proz. zu verzeichnen war; mehr wird sie bedingt durch die allgemeine Verbreitung der Gewohmheit des Rauchens unter allen Schichten der Bevölkerung, wozu das jährliche Truppenliontingent zweifellos nicht weniw beiträgt. denn „La caserne est une école où l'on apprend à fumer.‘3).

Zur Vermehrung des Tabakverbrauches trägt auch der individuelle Verbrauch des Rauchers mit hei, welcher heute zur Befrierligung seines Tabakbedürfni--es eine gröbere Qnantität benötiont. als rlies früher der Fall war. Während im Jahre 1873 auf den Kopf der Bevölkerung nur 0,261 kg kam, ergibt sich aus der graphischen Darstellung D'

\footnotetext{
1) Popovicia. a. O., \&. 12.

2) $\mathrm{Mohl}$ a. a. O., S. 3i.

3) Beaulieu, S. 707 .
} 
eine steigende jährliche Durchschnittskonsumtion, welche im .Jahre 1902 $0,539 \mathrm{~kg}$ erreicht hat, mit einem Maximum von $0,650 \mathrm{~kg}$ in 1884 .

Selbstverständlich ist der Tabakkonsum in ganz Rumänien nicht gleichmäßig verteilt. Wie die Tafel A zeigt, ist die Tabakkonsumtion am stärksten im Bezirk Constanza, woselbst $1428 \mathrm{~kg}$ auf den Kopf der Gesamthevölkerung entfallen. Die Höhe des Verhrauches in diesem Bezirk findet ihre Erklärung sowohl in der großen Verschiedenheit seiner Einwohner, die sich aus Griechen, Tataren, Armeniern und Bulwaren rekitutieren. welche im allgemeinen leidenschaftliche Talakkonsumenten sind, als auch des weiteren in dem Umstand. daß in diesem Bezirk der größte Hafen Rumäniens Constanza (am Schwarzen Meer) gelegen und der Verkehr infolgedessen sehr stark ist. Als nächste Bezirke folgen Braila mit $0,982 \mathrm{~kg}$ und Covurlui mit $0,824 \mathrm{~kg}$ pro Koplf. welche ihre verhältnismäbig grofe Tabakionsumtion dem T'mstand verdanken, daf hier die zwei grö̈ften rumänischen Donau- Häfen Irraila und Galatzi liegcen, der Verkelır während der Schiffahrtszeit sehr bedeutend und auch die-Zahl der hier domizilierten Griechen und Armenier nicht gering ist. Am schwächsten ist die Tabakkonsumtion in den Gebirgsbezirken der kleinen und großen Walachei, woselbst sie den Verbrauch von 500 g pro Kopf nicht überschreitet.

Im allgemeinen ist die Tabakkonsumtion in Rumänien als zu kilein und infolgedessen der TabakgenuB als wenig eingehürgert zu bezeichnen, was aus einem Vergleich mit anderen Ländern hervorgeht. Nach den Berechnungen Mayrs ${ }^{1}$ ) betrug (der Konsum in der zweiten Hälfte der neunziger Jahre in den:

\begin{tabular}{|c|c|c|c|c|}
\hline Tierlerlanden & & & & 3, \\
\hline Vereinigten & Staaten & . & & 2,5 \\
\hline Belgien & . . . & . & & 2,31 \\
\hline eutschland & 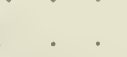 & & & 1. it \\
\hline jsterreich & & & & ,44 \\
\hline Bosnien und & Herze & govina & &, 35 \\
\hline panien & & 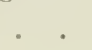 & & 1,01 \\
\hline Ungarn & & & & 1,23 \\
\hline Frankireich & & & & 178 \\
\hline chwerlen & & & & 92 \\
\hline Forwegen & v & & & 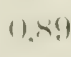 \\
\hline England & 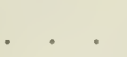 & & & 0,81 \\
\hline Rumänien & & 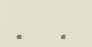 & & 0,72 \\
\hline
\end{tabular}

1) Art. Tabak und Tabakbesteueruug, Handw. usw. Bd. VII, 2. Aufl., S. 26. 


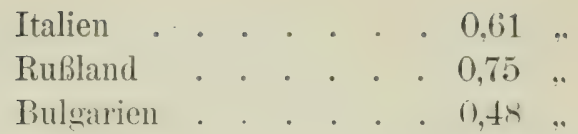

Die Gesamtkonsumtion der 4 Tabakhauptfabrikate - Rauchtabak, Zigaretten. Zigarren und Schmupftabak - beziffert sich für Rumänien folgendermaßen (Tafel XIV):

XIV.

\begin{tabular}{|c|c|c|c|c|c|c|c|c|}
\hline \multirow{2}{*}{ Jahre } & \multicolumn{2}{|c|}{ Rauchtabak } & \multicolumn{2}{|c|}{ Zigaretten } & \multicolumn{2}{|c|}{ Zigarren } & \multicolumn{2}{|c|}{ Schnupftabak } \\
\hline & Gewicht & Wert & Gewicht & Wert & Gewicht & Wert & Gewicht & Wert \\
\hline 1872 & $\begin{array}{l}0 / 0 \\
98,75\end{array}$ & 95,45 & 0.04 & 0,31 & 0.88 & 3,62 & $\begin{array}{l}0 \% \\
0,33\end{array}$ & 0,62 \\
\hline 1877 & 98,21 & 93,69 & 0,35 & 2,03 & 1,16 & 3,69 & 0,28 & $0, \overline{5} 9$ \\
\hline 1882 & 97,47 & 91,88 & 1,13 & 5,08 & 1,07 & 2,57 & 0,33 & 0,47 \\
\hline 1887 & 96,14 & 87,08 & 2.30 & 10,12 & 1,07 & 2,34 & 0,49 & 0,46 \\
\hline $189^{\circ}$ & 94,94 & 81,14 & 3,54 & 15,92 & 1,19 & 2,64 & 0,33 & 0,30 \\
\hline 1897 & 94,62 & 78,40 & 3,54 & 18,61 & 1,36 & $2,66^{\circ}$ & 0,48 & 0,33 \\
\hline 1902 & 93,62 & 75,84 & 4,99 & 21,56 & 1,03 & 2,29 & 0,36 & 0,31 \\
\hline
\end{tabular}

Aus der Tabelle XIV ergibt sich, daß der Rauchtabak sowohl dem Gewicht wie dem Wert nach den Hauptplatz eimnimmt, aber er verliert zu Gunsten der Zigarette immer mehr an Boden. Im Verlaufe von 30 . Jahren ist seine Konsumtion zwar in die Höhe gegangen aber viel langsamer als die anderen Sorten, und zwar nur mit 6,35 Proz. Gewicht und 4,55 Proz. Wert, während die der Zigaretten ein jährliches Steigen von 1061 Proz. (Gewicht) und 695 Proz. (Wert), die der Zigarren ein solches von 9,30 Proz. (Gewicht) und 94 Proz. (Wert) und die des Schnupftabaks ein Steigen von 7,20 Proz. (Gewicht) und 51,35 Proz. (Wert) aufweist. Des weiteren tritt in der Tabelle die riesige Vermehrung der Zigarettenkonsumtion hervor. welche mit Ausnahme des Jahres 1901 in einer ununterbrochenen Steigerung begriffen ist, während der Verbrauch der anderen Tabalifahrikate mehr oder minder großen Schwankungen ausgesetzt ist, wie dies aus der graphischen Darstellung E hervorgeht.

Diese so bedeutende Zunahme der Zigarettenkonsumtion ist der großen Beliebtheit dieses Fahrikates und rlen neu geschaffenen Zigarettensorten zuzuschreiben, welch letztere durch ihre Form und oft recht barocken Namen den Raucher interessieren. Es beweist dies aber auch, daß in dem Geschmack und der Gewohnheit des rauchenden rumänischen Publikums eine völlige Änderung eingetreten ist. 
Diese Erscheinung zeigt sich auch in Deutschland, Österreich und Ungarn, in welchen Ländern der Zigarettenverbrauch auf Kosten (les Rauch- und Schnupftabaks bedentend zugenommen hat ${ }^{1}$ ).

\section{Die Ausfuhr der Regiefabrikate.}

Aufer den für den inländischen Konsum hergestellten 'Tabakfabrikaten verkauft die rumänische Regie auch solche — nämlich geschnittenen Rauchtabak und Zigaretten besserer Qualitäten - nach deu Auslande, und zwar nach Dent-chlant. Deleien, Holland. Ö-terreich. Nordamerika, England, der Schweiz, der Türkei, Bulgarien, Frankreich und Rußland.

Allerdings verkauft die Regie die Fabrikate dem Ausland viel billiger als dem Inland, und zwar bewilligt sie ersterem einen Rabatt von 35-40 Proz. ${ }^{2}$ ) anf die im Inland geltenden Preise, während die Transportspesen dem Käufer zur Last fallen.

Trotzdem ist die Ausfuhr der rumänischen Tabakfabrikate sehr gering und besitzt keineswegs die verhältnismäßig große Bedeutung derjenigen Frankreichs, Österreichs oder Italiens. In der Tat betrug die Ausfuhr der französischen Regie 1 Proz. als Gewicht und 0,76 Proz. als Wert des Gesantverschleißes des Jahres 1902, die der österreichischen Regie 0,64 Proz. als Gewicht und 1,06 Proz. als Wert, die der italienischen Regie 2,33 Proz. als Gewicht und 0,96 Proz. als Wert aus dem Gesamtverschleiß des Jahres 1902, während die Ausfuhr der rumänischen Regie 0,71 Proz. als Gewicht und 0,002 als Wert des Gesamtverschleiß es desselben Jahres ausmachte. Deshalb verkauft auch die rumänische Regie die Tabakfabrikate dem Ausland zu solchen billigen Preisen, um eine Steigerung der Ausfuhr herbeizuführen. Ihıren löblichen Behiühungen stehen aber die hohen Zölle und die starke Konkurrenz anderer fremder Fabrikate entgegen; auch ist zu berïcksichtigen, daß die rumänischen Tabakfabrikate erst vor wenigen Jahren auf dem ausländischen Markt in

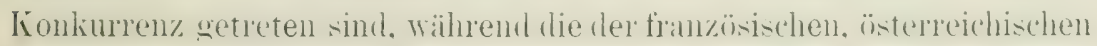
und italienischen Regie bereits seit langem bekannt sind und schon einen gewissen Grad ron Renommee besitzen. Auber den oben angefülnten Hindernissen haben die rumänischen Tabakfabrikate auf dem Weltmarkt auch noch mit anderen Faktoren zu kämpfen, so z. B. mit der unberechtigten ungünstigen Meinung seitens der Konsumenten be-

1) Siehe Kurt Apelt a. a. O., S. 153.

2) Ollanescu a. a. O., S. 397 . 
züglich der Güte der Fabrikate. Diese Meinung mochte wohl während der Pachtperiode ihre volle Berechtigung haben, umsomehr als die Pachtgesellschaft der Ausfuhr ihrer Fabrikate nicht das geringste Interesse entgegenlrachte und infolgedessen von 1872 bis 187 !) die Ansfuhrsumme an Tabak nur 198 Lei betrug, für die Neuzeit aber ist ein solches ungerechtfertigtes Mißtrauen nicht mehr am Platze.

Seit der Übernahme des Tabakmonopols durch den Staat richtete deshall, die Regieverwaltung ihre Aufmerksamkeit auch auf die Hel,ung der Ausfuhr der Tabakfabrikate. Diese begann mit einem Gesamtgewicht von $114 \mathrm{~kg}$ und Gesamterlös von 2857 Lei im Jahre 1880 und stieg ununterbrochen bis zum Jahre 1\%2, in welchen sie :34! ligg und 27470 Lei betrug. Also hat die Ausfuhr in diesen 23 Jahren um das 48fache an Gewicht und das 9fache an Wert zugenommen.

Yon einem bedeutenden Export rumänischer Tabalifal)rikate kann unter solchen Umständen natürlich bis jetzt noch nicht die Rerle sein, aber die erzielten Ergebnisse geben die Hoffnung eines stetigen wenn auch langsamen Steigens der Ausfuhr.

\section{Die finanziellen Ergebnisse.}

Die finanziellen Ergebnisse des Tabakmonopols, welche in allen Monopolländern den Kardinalpunkt dieses Besteuerungsșritems bilden. können nicht hesser hervorgehoben werden als durch die Würdigung der Gesamtausgahen und Bruttoeinnahmen, weil diese allein ein lilares Bild darüber zu geben imstande sind.

Es ist eine bekannte Tatsache, daß in jeder freien Industrie der Unternehmer danach strebt, die Ausgaben auf das geringste Ials zu beschränken. um dadurch billiger zu produzieren als seine Wettbewerber. Nur auf diese Weise kann er gegen die Konliurrenz kämpfen und sich halten. Unterläßt er dies aber, so geht sein Geschäft zu Grunde. Weil der rumänischen Tabakindustrie als Staatsmonopol, wie jeder anderen seitens eines States monopolisierten Industrie, dieses Streben fehlt, insoweit sie keinen Konkurrenten hat, könnte man annehmen, daß die Regieverwaltung auch nicht bestrebt sei, die Ausgaben zu vermindern und infolgedessen billiger zu prorluzieren. aus dem einfachen Grunde, daß sie gar liein direktes Interesse an dem fieleihen des Unternehmens habe. Das Gegenteil ist aber, der Fall, in dem Entwicklungsgang des rumänischen Tabakmonopols erkennt man das fortlanernde erfolgreiche Bemühen ler Regieverwaltung, die Ausgaben herabzusetzen. Die graphlisiche Dar- 
stellung D (siehe Anhang), welche auf Grund amtlichen Materials an statistischen Daten entworfen ist, veranschaulicht, wie die laufenden Ausgaben während 3 Jahrzehnte von 3906794 Lei im Jahre 1872 auf $\left.8426399^{1}\right)$ Lei gestiegen sind. Auffallend ist, daß die Ausgaben in der Pachtperiode höher sind und größere Schwankungen aufweisen als in der Staatsbetriebsperiode. In dem oben genannten Zeitraum gingen die Ausgaben langsam in die Höhe in engem Zusammenhang mit der Entwicklung des Betriebes. Nur im Jahre 1899 erreichten die Ausgaben ein Maximum von 10520472 Lei, welchse jedoch immerhin hinter dem Maximum ron 11936607 (1877/78) der Pachtperiode zurückbleibt. Abgesehen vom Jahre 1879, wo Ausgaben wie Einnahmen nur für 8 Monate angegeben sind, stiegen die Ausgahen jährlich in der Pachtperiode um :3t Proz., in der späteren (Staatsmonopol-) Periode jedoch nur um 4,87 Proz.

Dieser Unterschied wird ersichtlich aus der Angabe des Verhältnisses der Ausgaben zu den Bruttoeinnahmen, nämlich:

\begin{tabular}{cccc}
\multicolumn{3}{c}{ XV. } \\
Jahr & $\begin{array}{c}\text { Verhältnis } \\
\text { zu \% }\end{array}$ & Jahr & $\begin{array}{c}\text { Verhältnis } \\
\text { zı \% }\end{array}$ \\
1873 & 32,78 & 1889 & 31,38 \\
1874 & 50,86 & 1890 & 31,41 \\
1875 & 57,01 & 1891 & 29,21 \\
1876 & 56,55 & 1892 & 25,58 \\
1877 & 54,32 & 1893 & 28,29 \\
1878 & 59,59 & 1894 & $28,-$ \\
1880 & 39,47 & 1895 & 28,50 \\
1881 & 33,52 & 1896 & 28,83 \\
1882 & 34,25 & 1897 & 27,61 \\
1883 & 35,30 & 1898 & 26,27 \\
1884 & 36,45 & 1899 & 26,36 \\
1885 & 36,47 & 1900 & 28,16 \\
1886 & 32,16 & 1901 & 25,18 \\
1887 & 30,20 & 1902 & 23,87 \\
1888 & 29,87 & &
\end{tabular}

Die Höhe der Ausgaben in der Pachtperiode hat ihren Grund einerseits in den Schwierigkeiten, die die Pachtgesellschaft für die rollständige Durchführung des IIonopols hatte und andererseits in den großen Gehältern die sie, wie oben schon erwähnt, den Beamten — vor allem den höheren Beamten — zahlte. Bei dem Übergang des Inonopols in Staatsbetrieb) wurden schon im er'sten Jahre (1sis())

1) Diese Summe wurde in folgenden Posten ausgeführt:
a) Fabrikationskosten - 1341159,28 oder 15,92 Pro\%.
b) Tabakmaterial . . 4050927,08 , 47,95 "
c) Administrationskosten $608432,40, \quad 7,23$ ",
d) Sonstige Ausgaben - 2425881,15 " 28,90 ", 
20,12 Proz. an Ausgaben erspart. Die Fortschritte in der Verwendung des Rohmaterials und in der Organisation der Arbeit, sowie die Herabsetzung des Rabatts gestatten die Ausgaben immer mehr zu vermindern und infolgedessen billiger zu produzieren. Ein Vergleich in dieser Beziehung mit Frankreich. Österreich und Italien wirft ein günstiges Licht auf die rumänische Regieverwaltung, und zwar bildete der Prozentsatz der Ausgaben für das Jahr 1902:

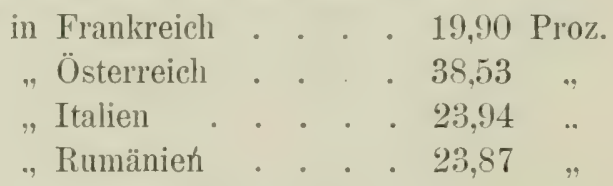

aus den Bruttoeinnahmen. Wenn demnach der Schluf, daß der Staat kein schlechter Unternehmer sei, für die erstgenannten drei Regien bezüglich der IIonopolverwaltung zutrifft, so gilt derselbe in gleicher Weise auch für die rumänische Regie.

Die Linie der Bruttoeinnahmen zeigt, wie aus der graphischen Darstellung D ersichtlich ist, ein fortwährendes Steigen derselben, Von 11916794 Lei im Jahre 1873 stiegen sie auf 21637681 Lei im Jahre 1878, es ist also ein jährliches Steigen von 10,2 Proz. in der Zeit der Pachtperiode zu verzeichnen. Dieses bedeutende Ansteigen ist der Einführung des Monopols und der großen Zahl von Fremden, die während des Unabhängigkeitskrieges von 1877-1878 nach Rumänien kamen, zuzuschreiben. Wenn wir aber von dem ersten Jahre des Monopols und dem Jahre 1877-1878 absehen, denn stellt sich nur ein jährliches Steigen von 2,3 Proz, in dieser Periode heraus.

In der Regieperiode stiegen die Bruttoeimnahmen von 20957053 Lei im Jahre 1880 anf 36470541 Lei im Jahre 1902.

Die stärkste Zunahme fällt in folgende Jahre:

1881 mit 2706676 Lei orler 12,92 Proz. gegen das Jahr 1880 $1892,2156297, \quad, \quad 6,57 \quad$ " $\quad$ " $\quad$ " 1891 $1899 \quad$ "2476661 " $, \quad 6,63 \quad, \quad, \quad, \quad$ " 1898 und die Mindereinnahmen beziffern sich in den Jahren:

1890 auf 161129 Lei oder 0,51 Proz. gegen das Jahr 1889

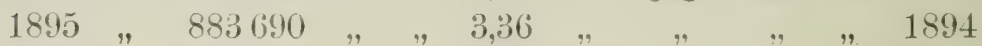

$1896 \quad$ " $325285 \quad, \quad, \quad 0,89 \quad, \quad, \quad, \quad, \quad, \quad, 1895$

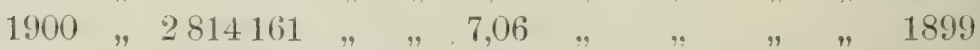

$1902,1989161 \quad, \quad, \quad 5,33 \quad, \quad . \quad, \quad, \quad, 1901$

Im ganzen betrug das jährliche Steigen der Bruttoeinnahmen 3,90 Proz. bis 1899 und 3,22 Proz. bis 1902 . 
Die Vorliebe der Konsumenten für das Zigarettenrauchen trug wesentlich zum Wachsen der Bruttoeimnahmen nit bei. wie aus folsender graphischen Darstellung (F) hervorgeht.

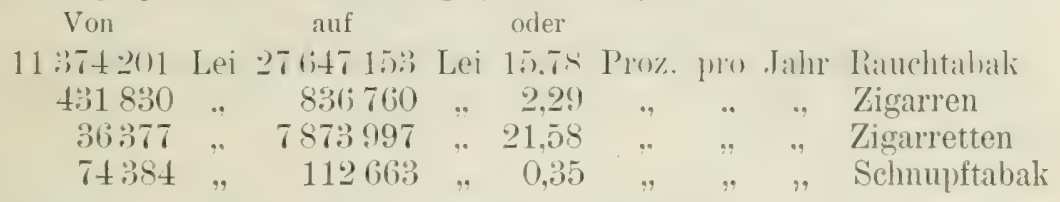

Im ganzen sind die Bruttoeinnahmen in 30 Jahren um das Dreifache gestiegen. Die Ursache dieser Zunahme liegt einerseits, wie schon gezeigt wurde, in der wachsenden Tabakkonsumtion und andererseits, als Folge der Vergrößerung des Nationalvermögens, in der Vorliebe des Publikums für bessere Qualitäten. In der Tat ist, während die Bruttoeinnahmen mit 3,90 Proz, jährlich gestiegen sind, für die konsumierte Tabakquantität ebenfalls ein jährliches Steigen von 2 Proz. zu verzeichnen.

Infolge der Zunahme der Bruttoerträge und der Verminderung der Ausgaben sind die Nettoemnahmen bedeutend gestiegen, wie die graphische Darstellung D es veranschaulicht. Schon im ersten Jahre

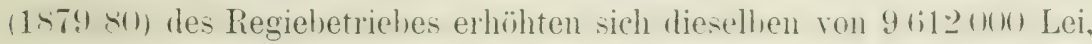

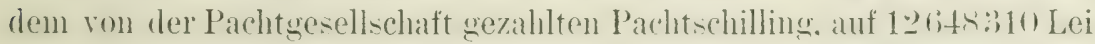
oder um 31,97 Proz. und erreichten, in den folgenden Jahren fortdauernd ansteigend, im Jahre 1899 das Maximum von 29347488 Lei; somit haben sich die Nettoeinnahmen in einem Zeitraum von 20 Jahren um das Dreiundeinviertelfache erhöht. Das jührliche Steigen hezifferte sich auf 4.38 Proz.

Die wirtschaftliche und finanzielie Krisis von 1899, die furchtbarste, die Rumänien seit 40 Jahren erlebt hat ${ }^{1}$ ), beeinflußte selbstverständlich die Nettoeinnahmen, die im Jahr 1900 un 9,30 Proz.

1) Eine gute Charakterisierung dieser Krisis ist in Handelsarchiv 1901, Br. II, S. 241 zu finden, der wir folgendes entnehmen: „Rumänien ist im Berichtsjahre von einer Mißernte heimgesucht worden, wie sie seit Menschengedenken nicht vorgekommen ist. Jedenfalls hat, wie festgestellt ist, in den letzten 40 Jahren keine Ernte soweit fehlgeschlagen. Der Grund war eine ganz außerordentliche Dürre. Fünf IIonate lang fiel so gut wie kein Regen, nachdem schon im Winter sehr wenig Schnee und Feuchtigkeit niedergegangen war. Die Ackerpflanzen waren dann trotzdem - infolge warmer Winde - während der Monate Februar, März und April emporgekeimt, dann sind sie aber tatsïchlich verdorrt. Der Boden war bei Umackerungsversuchen häufig geradezu ziegelhart, die spärlichen Halme wurden von den Leuten mit dem Händen ausgrerissen, von Anwendung der Sichel, der Sense oder gar der Sichneidemaschine konnte keine Rede sein. Die Bauern haben häufig nicht einmal die Saat hereingebracht". 
sanken und weiterhin bis 1902 ein jährliches Sinken von 2,81 Proz. zeigen. Trotzlem hielten sich die Nettoeinnahmen im allgemeinen auf ziemlicher Höhe, demn die im Jahre 1902 als Nettoeinnahme erreichte Summe von 26877237 Lei wurde nur von 4 vorhergehenden Jahren überschritten, abgesehen von dem außerordentlichen Jahre 1899.

Im ganzen wuchsen die Nettoeinnahmen in 30 Jahren mit 112 Proz. oder 3,73 Proz. jährlich.

Wenn der im Jahre 1872 abgeschlossene Vertrag der Monopolsverpachtung nicht abgeschafft worden wäre, würde er kaum in 1887 aufgehoben worden sein; in diesem Jahre hätte der Staat einen Nutzen von nur 11534400 Lei gehabt, während das in Regie betriebene MIonopol ihm für jenes Jahr ungefähr den doppelten Ertrag brachte, nämlich $213115: 9$ Lei. Seit 1879 bis 1887 hätte der Staat von der Pachtgesellschaft einen gesamten Nutzen von $\$(1) 70000$ Lei gehaht, die Staatsregie aber brachte in demselben Zeitraum 156830153 Lei Nettoeinnahmen, ein schönes Ergebnis, welches die Ansichten derjenigen, die den Staatshetriel, des Monopols verlangten und förderten, genügend rechtfertigt. Ziehen wir die jährlichen Nettoeinnahmen zusammen, so ergibt sich, daß das Tabakmonopol in 30 Jahren dem rumänischen Staat die Summe von 565505063 Lei als Reinertrag geliefert hat, also über ein Drittel der konsoliclierten Staatsschuld Rumäniens im Betrag von 1413339385 Lei im Jahı'e $\left.1902^{1}\right)$.

Bezieht man die Einnahmen auf die Bevölkerung, so ergibt sich, daß der Betrag von 2,36 Lei, welcher im Jahre 1873 pro Kopf der Berölkerung entfiel, im Jahre 1902 auf 5,57 Lei pro Kopf stieg, wie dies aus der graphischen Darstellung D ersichtlich ist, also verbraucht gegenwärtig der rumänische honsument mehr als die doppelte Quantität Tabalifabrikate. welcher lionsum selbstrerständlich sich nicht über Rumänien gleichmäfig verteilt, sondern, wie die Tafel B beweist, in dem einen Bezirk größer, im anderen kleiner ist.

Der Bezirk Ilfow mit der in ihm belegenen Hauptstadt Bukarest, nach welcher stets ein berlentender Berölkerungszuflub besteht, wirft (len höchsten Ertrag ab); es ist dahei aber zu berüchsichtigen, daß in Bukarest die reichsten Personen des Landes leben.

Ferner tragen bei:

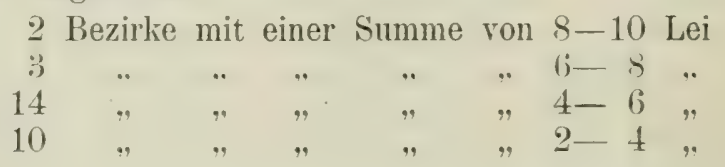

1) Frh. v. Brackel, Rumänieus Staats-Kredit, München 1902, S. 82. 
Diese 10 letzten Bezirke sind zum größten Teil Bergbezirke, wo im allgemeinen die Bevölkerung viel ärmer ist als auf dem platten Lande. Der Platz, den jeder Bezirk bezüglich der Abstufung in der Darstellung der Durchschnitserträge einnimmt. entspricht durchaus nicht dem, den er in der Abstufung der Konsumenten hat, denn jeder Bezirk hat anderen Geschmack, andere Gewohnheiten und ist reicher oder ärmer als ein anderer, infolgedessen seine Bewohner teuerere orler billigere Tabaksorten rauchen.

Im Vergleich mit den übrigen europäischen Ländern scheint der rumäni-che Tabakiaucher nicht so hoch durch die Tabakstener belastet zu sein, aber tatsächlich ist er es doch, denn er konsumiert viel weniger als der Raucher anderer Länder, in denen die Tabaksteuerbelastung schwächer ist, wie aus der folgenden Tabelle XVI hervorgeht, welche dem Handwörterbuch entnommen ist:

\section{XVI.}

¿weite Hälfte der neunziger Jahre.

\begin{tabular}{|c|c|c|c|c|c|c|}
\hline & & & & & le in Mark & $\mathrm{kg}$ \\
\hline Frankreich & & . & . &. & 6,87 & $1,0 \%$ \\
\hline England & . & . . & . . & . & 5,68 & 0,81 \\
\hline Italien & . & . . & . . & . & $3,8 \%$ & 0,61 \\
\hline Österreich . & . & . . & . . & . & 4,23 & 1,44 \\
\hline Spanien. & . & . . & . . & . & $4, \pi 6$ & 1,01 \\
\hline Rumänien . & & . . & . . & . & 3,60 & 0,72 \\
\hline Vereinigte & Sta & aten & . . & . & 3,86 & $2, \overline{3} 3$ \\
\hline Ungarn. & . . & . . & . . & . & 3,23 & 1,23 \\
\hline Serbien. & .. & . . & . . & . & 3,31 & \\
\hline Norwegen. & & .. & & . & 1,81 & 0,89 \\
\hline Bosnien un & & Herze: & egowin: & & 2,22 & 1,35 \\
\hline Bulgarien. & & .. & .. & . & 2,43 & 0,48 \\
\hline Deutschland & $d$ & . & . . & . & 1,18 & 1,64 \\
\hline Belgien . & . & . . & . . & . & 0,95 & 2,31 \\
\hline Schireden . & . & . . & . . & . & 0,93 & 0,92 \\
\hline Rußland & . & . . & . . & . & 0,78 & 0,70 \\
\hline Dänemark . & . & . . & . . & . & 0,66 &,-- \\
\hline Schreiz. & & . . & & & 0.49 & \\
\hline Niederlande & & . . & . . & . & 0,05 & 5,0 \\
\hline
\end{tabular}

Es ergibt sich auch aus der Tatsache, daß die Stener mehr als viermal höher ist als der Wert des hergestellten Produktes. Ein Kilo fabrizierten Tabaks kostete der Regie 1902 2,18 Lei und dieselbe verkaufte es den Konsumenten mit 9,12 Lei, sie erzielte also einen Nettogewinn von 6,94 Lei pro Kilogramm.

Die französische Regie hatte in demselben Jahr einen Nettogewinn von 8.73 Fres. pro Kilogramm, aher die Bevölkerung Frankreichs ist viel reicher als die Bevölkerung Rumäniens. Eine Erhühung der Tabalisteuer in Rumänien ist zurzeit, olne eine Beeintritchtigmng der Einnahmen herheizuführen, nicht mïglich. denn wir glaulen. dal. die 
Tabakstener in Rumänien den höchsten Grad der Elastizität erreicht hat. Die Einnahmen werden nicht stehen bleiben, sondern sie werden mehr und mehr steigen, weil sie Hand in Hand gehen mit der $\mathrm{Zu}$ nahme der Konsumtion und dem Reichtum Rumäniens, letzterer hervorgerufen durch fortschreitende wirtschaftliche und industrielle Entwicklung. Die bisher erzielten Tabalierträge sind zufrìedenstellend und ihre Bedeutung geht aus dem entsprechenden Vergleich mit den anderen Stevereinnahmequellen, und zwar am besten mit denen der anderen Staatsmonopole hervor.

Gegenwärtig bestehen in Rumänien außer dem Tabakmonopol noch die 5 folgenden: Salz-, Zündholz-. Spielkarten-, Pulver- und Zigarettenpapier-1Lonopol. Keines von diesen, selbst das Salzmonopol, welches sehr alt ist und schon seit 1860 von dem Staat betrieben wird, zeigt eine so große Entwicklung und Blüte wie das Tabakmonopol. Während die Salzmonopoleinkünfte in der Zeit von 1862 bis 1902 von 3,11 Mill. auf $7, \pm$ Mill. Lei oder um 138 Proz. (jährlich 3,37 Proz.), die Zündholzmonopoleinkünfte von 1881-1902 von 2,1 Mill. auf 2,9 Mill. Lei oder um 38 Proz. (jährlich 1,81 Proz.), die Spielkartenmonopoleinkïnfte von $1887-1902$ von 190050 auf 485710 Lei oder um 156 Proz. (jährlich 9,75 Proz.), die Schießpulvermonopoleinkünfte von $1889-1901$ von 601867 auf 496481 Lei oder um 77,50 Proz. (jährlich 1,35 Proz.) sinken, die Zigarettenpapiermonopoleinkünfte von 1900-1902 von 1,7 auf 3,9 Mill. um 129 Proz. (jährlich 43 Proz.) aber gestiegen sind, erhöhten sich die Tabakeinkünfte von 1872-1902 von 11,9 auf 35,3 Mill. Lei oder um 196 Proz.

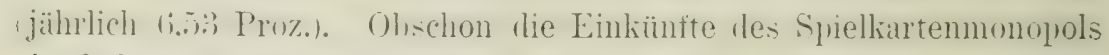
ein höheres jährliches Steigen zeigen als die Einkünfte des Tabakmonopols, fallen sie jedoch nicht schwer ins Gewicht. weil sie von keiner so großen Ausdehnung sind, wie die Tabakeinkünfte. Dem jährlichen Steigen der Einkünte aus dem Zigarettenpapiermonopol soll keine große Bedlentung beigelegt werden, weil die kurze Zeit seines Bestehens lieinen sicheren Schluf zu ziehen gestattet.

Alle diese 6 Staatsmonopole brachten dem Fiskus im Jahre 1901/02 einen Totalertrag von 50315000 Lei, welcher 23,26 Proz. des ganzen Budgets von 218, כ Mill. bildete.

Daran partizipierten:

das Tabakmonopol . . . mit 69,47 Proz.

.. Salzmonopol . . . . . . . $15,21 \quad$..

.. Zündholzmonopol . . . "

.. Spielkartenmonopol . . " ", 0,96 ".

. Pulvermonopol . . . . ., 0,97

.. Zigarettenpapiermonopol mit 7,67 .. 
Also alle Einkïnfte der anderen Monopole bleiben weit hinter denen des Tabakmonopols zurück. Diese Charakteristik zeigt das Tahakmonopol in seinem ganzen Entwicklungsgang. wie die sraphische Darstellung G es veranschaulicht. Ein Vergleich mit den anderen Steuerquellen fällt ebenfalls zugunsten des Tabakmonopols aus. Die direkten Steuern betrugen für das Jahr 1902 17,74 Proz. des Budgets, also nur 1,59 Proz. mehr als die Tabakmonopoleinkünfte. Selbst die indirekten Steuern, welche 16,52 Proz. des Budgets ausmachen, sind nur um 2,39 Proz. überstiegen, da dieselben bloß 14,13 Proz. ausmachen. C̈berhaupt decken die Tabakmonopoleinkünfte ein Sechstel aller Staatsausgaben.

Alle diese Ergebnisse zeigen zur Genüge, daß die Tabakmonopoleinkünfte eine wichtige Stellung in dem rumänischen Budget einnehmen und daß sich für Rumänien das Tabakmonopol als eine ebenso zuverlässige, wie konstant reichliche Stenerquelle bewährt hat.

Dies allein, abgesehen von der bedeutenden Einwirkung des Tahakmonopols auf die Tabakikultur, würde genügen, die Einführung des Tahakmonopols dessen größten Gegnern gegenüber zu rechtfertigen. 


\section{Schluß.}

Rückblickend auf unsere Betrachtungen über das rumänische Tabakmonopol und dessen Organisation sehen wir, daß das Tabakmonopol sich auch in Rumänien als die beste Besteuerungsart des Tahals erwiesen und infolgerlessen der Volkswirtschaft Rumäniens im allgemeinen auch die Vorteile gebracht hat, die von den Theoretikern vorausgesehen wurden.

Zunächst hat sich das Tabakmonopol dem Tabakbau nicht ungünstig erwiesen, wie dies im allgemeinen von den Gegnern des Monopols behauptet wird. Im Gegenteil nahm unter der Herrschaft des Monopols die Ausilehnung der Talsakanhautläche mehr und mehr zu, und durch das Bestreben der Regieverwaltung wurde eine wohltätige Wirkung auf die Verbesserung der Tabaksorten ausgeübt.

Obschon die Tabakptlanzer für ihre Tabakernte nicht so hohe Preise erhalten, wie z. B. in Frankreich und Italien, befinden sie sich trotz alledem in einer besseren Lage als bei freier Konkurrenz. Sie laufen nicht die Gefahr der Ausbeutung durch Zwischenhändler oder bedeutender Preisschwanliungen. weil sie im Staat einen regelmäfigen und sicheren Abnehmer besitzen, der ihnen ohne Schikanen schon im Voraus bestimmte Preise zahlt. Außerdem wird jede Ausbeutung seitens der Landwucherer vermieden, denn die Tabakbauer können von der Regieverwaltung Geldrorschüsse beliommen. Die Belehrung durch die Regieagenten, die Errichtung von Trockenanstalten u. a. m. sind auherdem noch Vorteile, die der rumänische Tabalibuter hei freier Konkurrenz weder gehabt hat noch haben würde.

Eine Gewährung höherer Einlösungspreise für das Erntematerial würde die einzige noch bestehende Schattenseite in dieser Beziehung beseitigen. Freilich wird die Regieverwaltung eine Änderung hierin sobald nicht eintreten lassen.

Die Tabakindustrie wurde keineswegs geschädigt, denn eine solche im engeren Sinne des Wortes bestand nicht. Demgemäß ist der Einwanł der Gegner des Monopols, daß es die Tabakindustrie zerstöre, für Rumänien nicht gültig. Im (iegenteil. das Tabakmonopol hat die Tabakindustrie ins Leben gerufen, so daß man behaupten kann: eine eigentliche Tabalindustrie besteht in Rumänien erst seit und durch Einführung des Tahakmonopols. Bei freier Konkurrenz wäre die Tabaliindustrie noch lange Zeit auf der früheren primitiven Stufe geblieben, wïrle sich eventnell heute noch dort befinden, sorlaf viele Millionen, die jetzt im Lande bleiben, jährlich über die Grenze gehen würden. 
„Industrieen“ - sagt mit Recht Metzler - „lassen sich jedoch nicht aus der Erde stampfen. Ein kapitalarmes Land wie Rumänien, dessen Bevölkerung an der Scholle klebt $[\ldots \ldots \ldots \ldots \ldots$. $)]$ konnte aus der Privatinitiative allein heraus niemals zu einer schnellen Entwirkelung industrieller Tätigkeit gelangen. Hier mulite der Staat fördernd eingreifen. Zwar waren Ansïtze einer nationalen Industrie hereits vorhanden. So blühten die staatlich monopolisierten Tabak-, Salz- und Zümlholzindustrieen und führten der Statskinse reiche Erträge zu“").

Unter der neuen Form des Großbetriebs nimmt the Tabakindustrie immer mehr zu. Sie gestattet nicht nur den inländischen Bedarf zu decken, sondern auch für den Export zu erzeugen, eine nennenswerte Erscheinung, die bei freier Konkurrenz nicht stattgefunden hat. Die Konsumenten erhalten gute, gleichmäfige und reine Tabakfabrikate, denn „le monopole gouvernemental est le seul procédé pour aroir des produits convenahles hrgiéni(yues. non soplhistiqués.."). Die hleine Auswahl der Tabalfalmikate ersheint hier als eine Schattenseite. die tler Grundlage des Monopols gemäß eine rasche Beseitigung erfordert.

In Bezug auf die Arbeitsverhältnisse haben wir gesehen, daff die Arbeiter sich in einer zufriedenstellenden Lage befinden, die sie bei freier Konkurrenz nicht hätten, wie die Lage ihrer Genossen aus der Privatindustrie es beweist. Für sie sorgt die Regie in sittlicher, wirtschaftlicher und sanitärer Weise. Dadurch wird die wichtigste

1) Wir haben folgende Worte bei Seite gelassen: „.. . und mit einer schwer ausrottbaren Arbeitsunlust und Trügheit zu kämpfeu hat", weil sie uns als übertrieben erscheinen.

Zunächst widerspricht der Verfasser sich später selbst, indem er sagt: „Für die landwirtschaftliche Betätigung hat daher die Berölkerung noch genügenden Spielraum. Dazu kommt, daß der Rumäne von Hause aus Ackerbauer ist und wenig Liebe für die Fabriktätigkeit hegt". (a. a. O. S. 53). Außerdem halten wir dafür, daß eine Landberölkerung, die während der Periode der Landarbeit mindestens 15-16 Stunden täglich tüchtig arbeitet, keineswegs den Vorwurf einer schwer ausrottbaren Arbeitsuulust und Trägheit verdient. Die Tatsache, daß die rumänische Landbevölkerung im Winter im allgemeinen sehr wenig tätig ist, darf nicht verallgemeinert werden. Die Ursache dieser Untätigkeit liegt nicht in der Natur des Bauern, sondern mehr in seiner Unwissenheit, denn der Bildun@sdrang unter denselben ist leider ein sehr geringer. Der staat hat bis jetzt soviel wie nichts für die rumänischen Bauern getan, deren Arbeit Rumänien zum größten Teil alles verdankt. Wenn der rumänische Bauer aber gut geleitet ist, dann gibt er den Bauern anderer Länder nichts nach, die sich als tüchtigr rühmen.

2) Rumänien, seine Handelspolitik und sein Handel 1890-1900, Altenburg 1902, S. 8.

3) Leroy-Beaulieu, Paul, Traité de la science des finances, IV. Autl. Paris 1888, Bd. I, p. 701 . 
und dringlichste Forderung der Arbeiterklasse verwirklicht, daß die Arbeitsdauer eine humane und die Arbeitsart keine die Gesundheit oder das Leben gefährdende sei ${ }^{1}$ ).

Daneben erfreuen sich die Tabakarbeiter eines genügenden Lohns und der Sicherheit gegen Arbeitsstockung.

Auch der schwerwiegendste Vorteil des Monopols, nämlich größte Sicherheit und Höhe der Eimnahmen. hat in dem rumänischen Tabakmonopol seine Verwirlichung gefunden. inden es jührlich der Statskasse große Beiträge einbringt und dem Staate durch andere Tabaksteuern schwer zu erlangende Einnahmen zusichert.

Ferner ist noch zu berïcksichtigen der Gewimn an Vermehrung inländischer Kultur und Fabrikation. worlurch ebenfalls weniger Geld in das Ausland geführt wird. Wohl sind diese finanziellen Resultate nicht so glänzend, wie die beim französischen oder österreichischen Monopol, mit denen sie aber nicht verglichen werden dürfen; denn diese Länder besitzen iu dieser Hinsicht reiche Erfahrungen. Immerhin sind die rom Monopol erzielten Resultate für Rumänien ron größter Bedeutung.

An der Hand dieser Ergebnisse kann die gegenwärtige Besteuerungsart des Tabaks in Rumänien als eine sehr hefrierligende Lösung der Tabalisteuerfrage angeschen werien. Deshalh unterliegt es keinem Zweifel. dal. das Tabakmonopol, welches sich nicht nur als eine herleutende Staatseinnahmequelle. sondern auch als eine Quelle von Benefizien für die inländische Kultur und Industrie erwiesen hat. sich auch ferner bewähren und seine Organisation, die sich im allgemeinen durch Vollständigkeit auszeichnet, zweckmälig weiter entwickeln wird.

In den Hänrlen einer umsichtigen und tüchtigen Staatsverwaltung. die schon durch den Geist der Sparsamkeit, Ordnung und des Fortschritts sich charakterisiert hat, wird clas Tabakmonopnol dem Staate noch größere Einnahmen einbringen, deren er seiner politischen und volkswirtschaftlichen Entwicklung wegen nur zu nötig bedarf.

Der Entwicklungsgang und die Ergebnisse des Tabakmonopols in Rumänien beweisen, daß es sehr an seinem Platz und den Ländern zu empfehlen ist, in denen die Kultur und Industrie auf einer niedrigen Entwicklungsstufe stehen.

1) Schönberg, a. a. O. Bd. II, S. 93. 


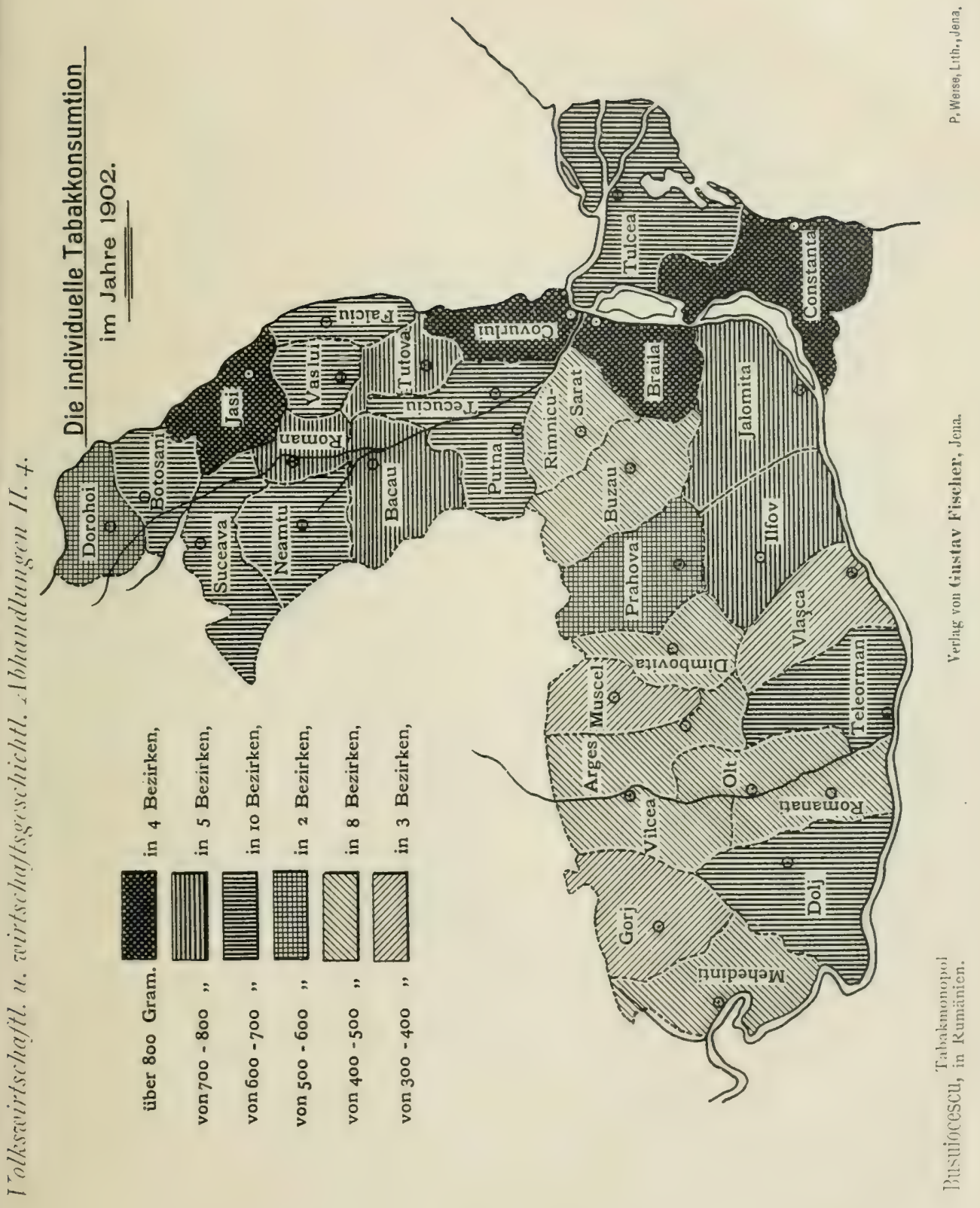





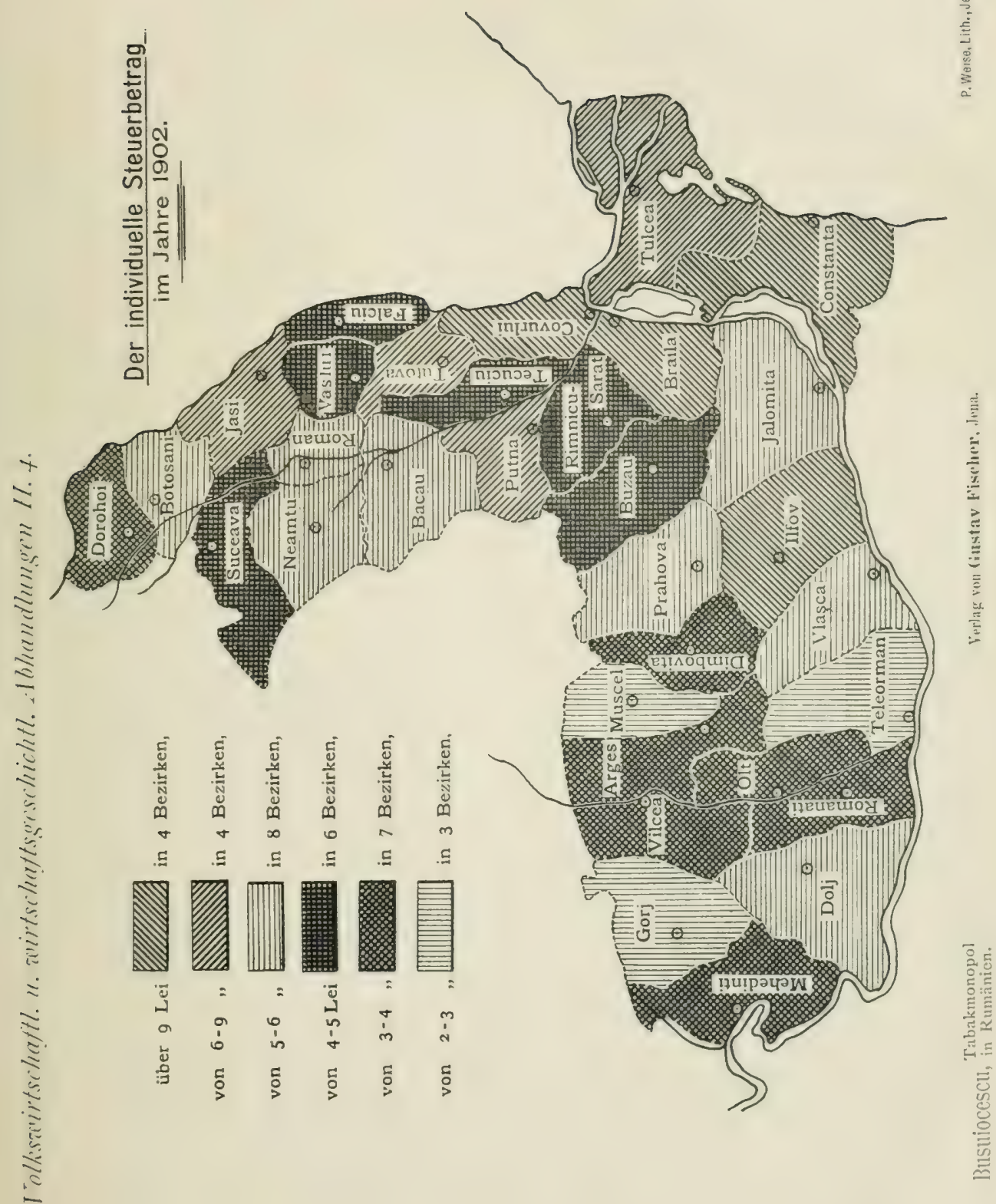



Graphische Darstellung A.

-Die Gesammiproduktion,---die mit Tabak bebauete Boden fläche,

-.-.-die durchschnittliche Produtition auf Ha.von 1873-1902.
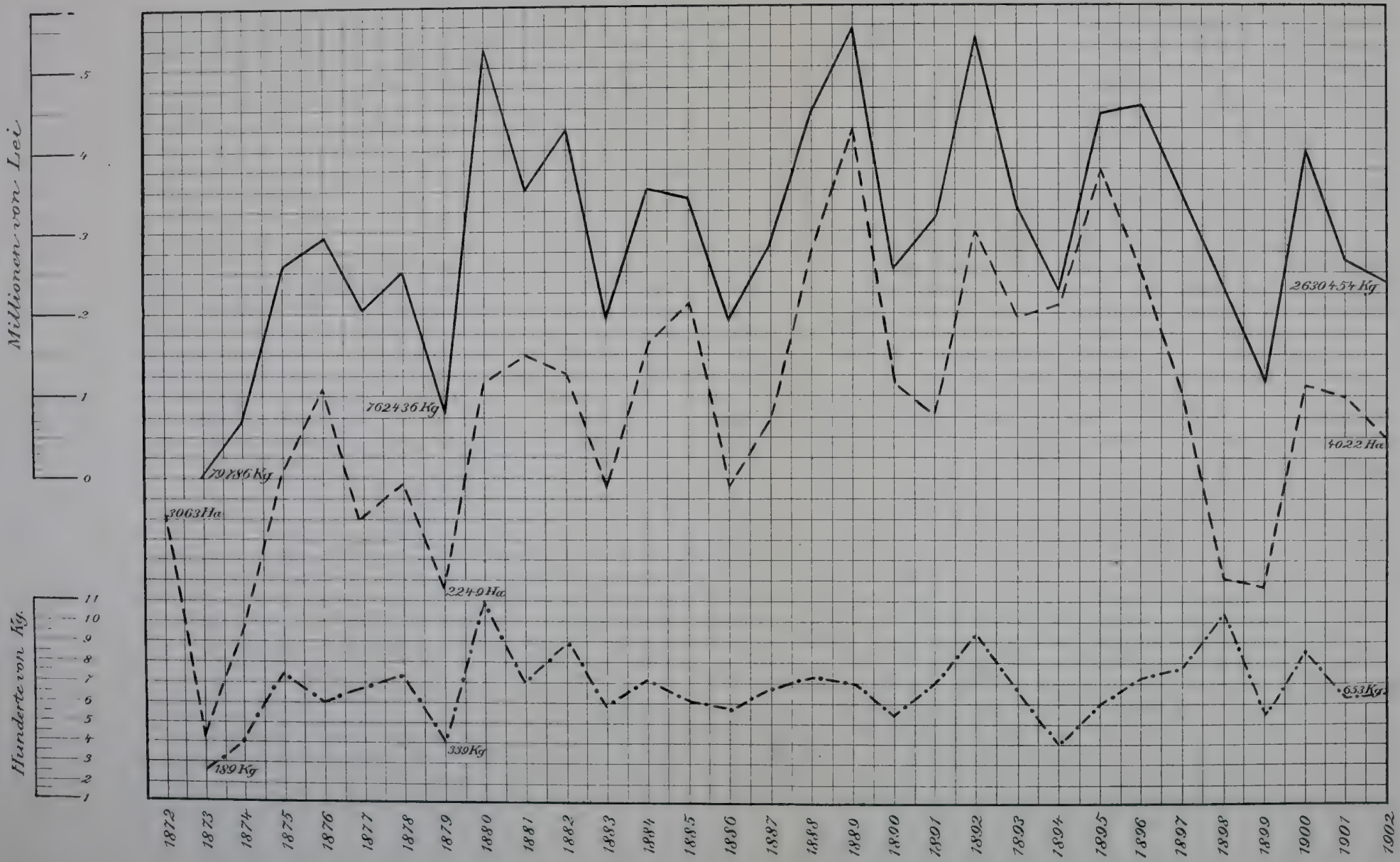



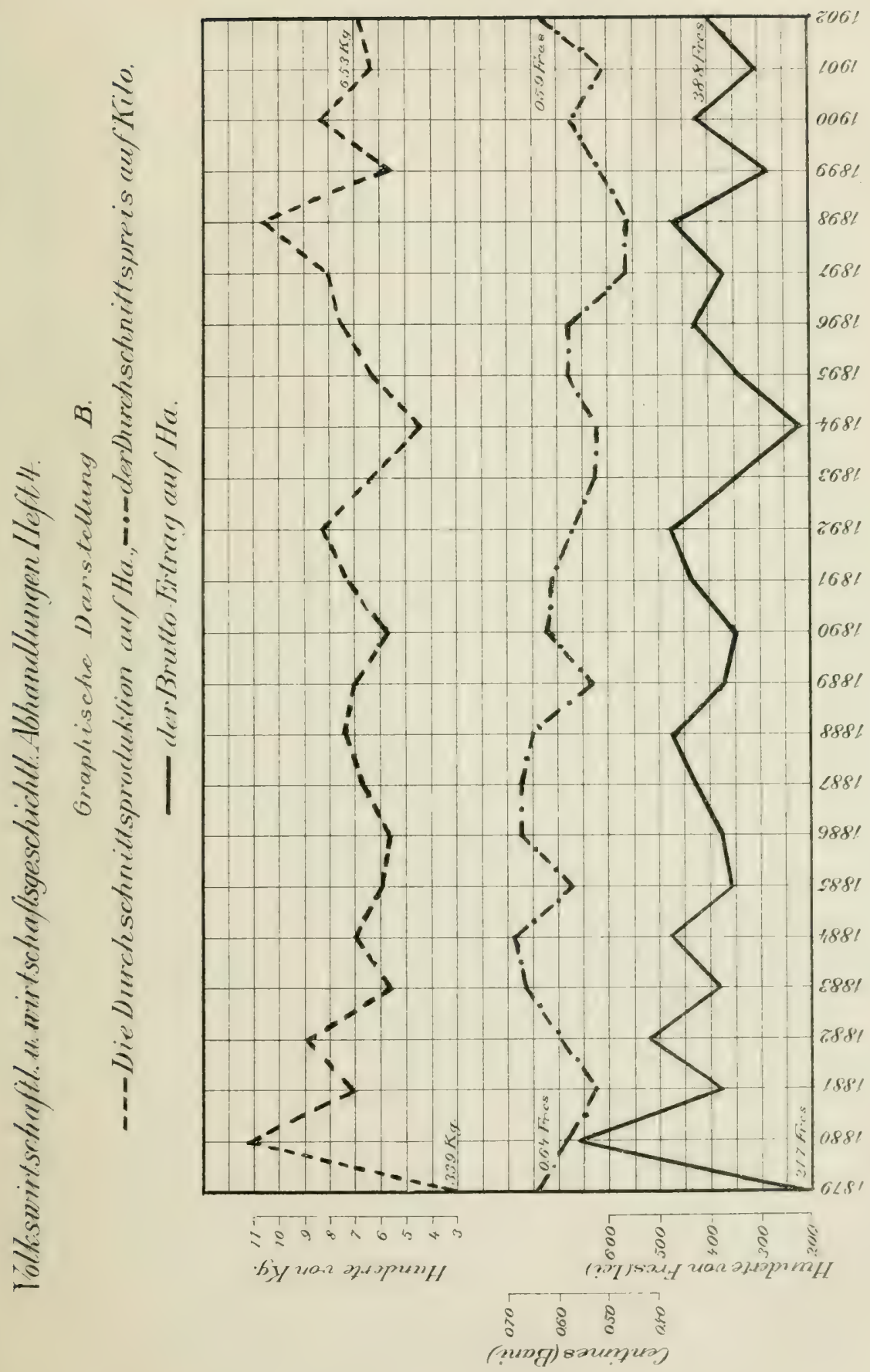





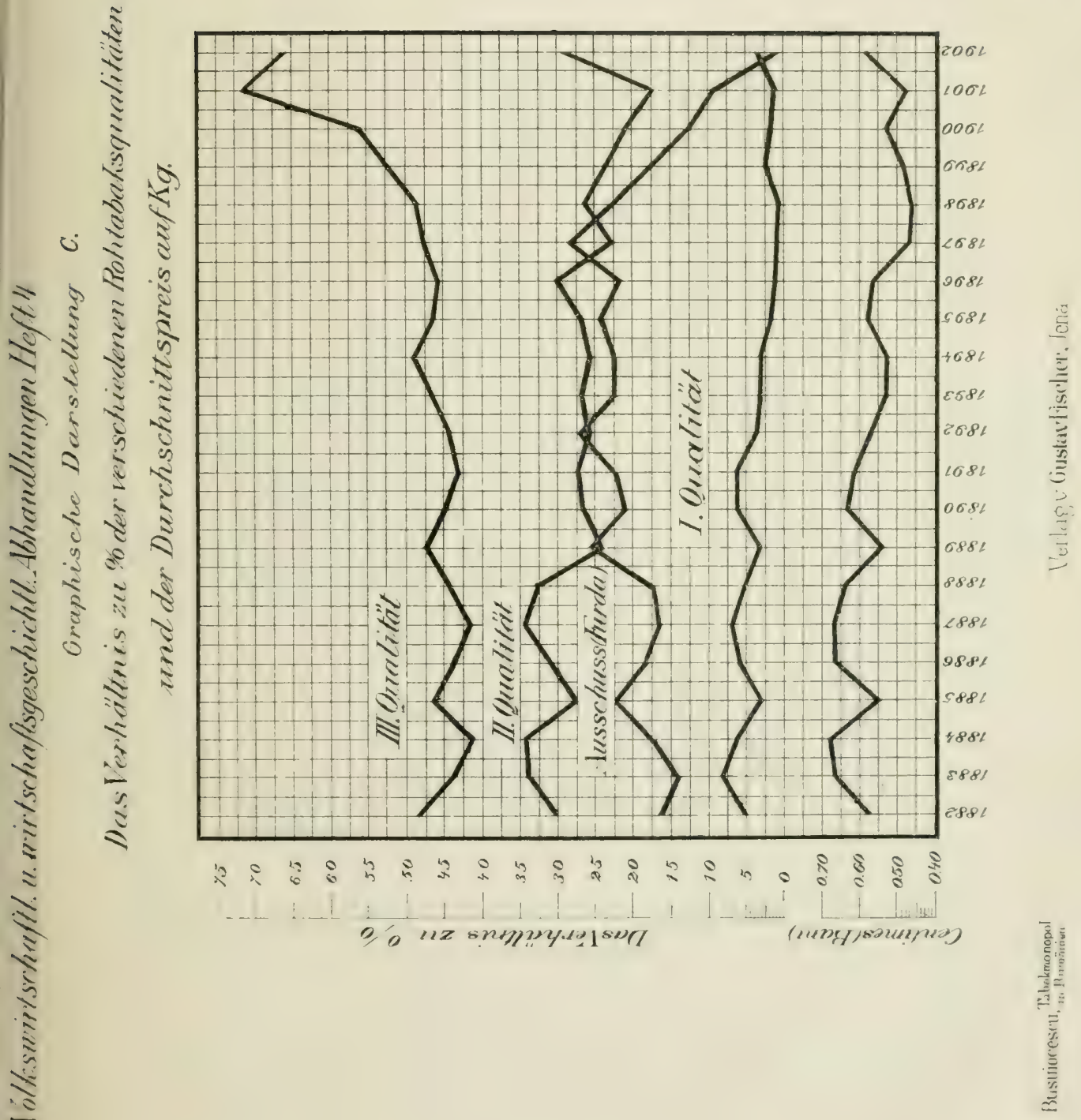



Iolkswirtschafth. un wirtschaftsgeschichth. Abhandlengen Heft4.

$$
\text { Graphische Darstellung D }
$$

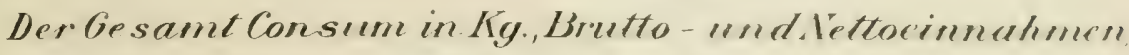
und Ausgaben in Lei.
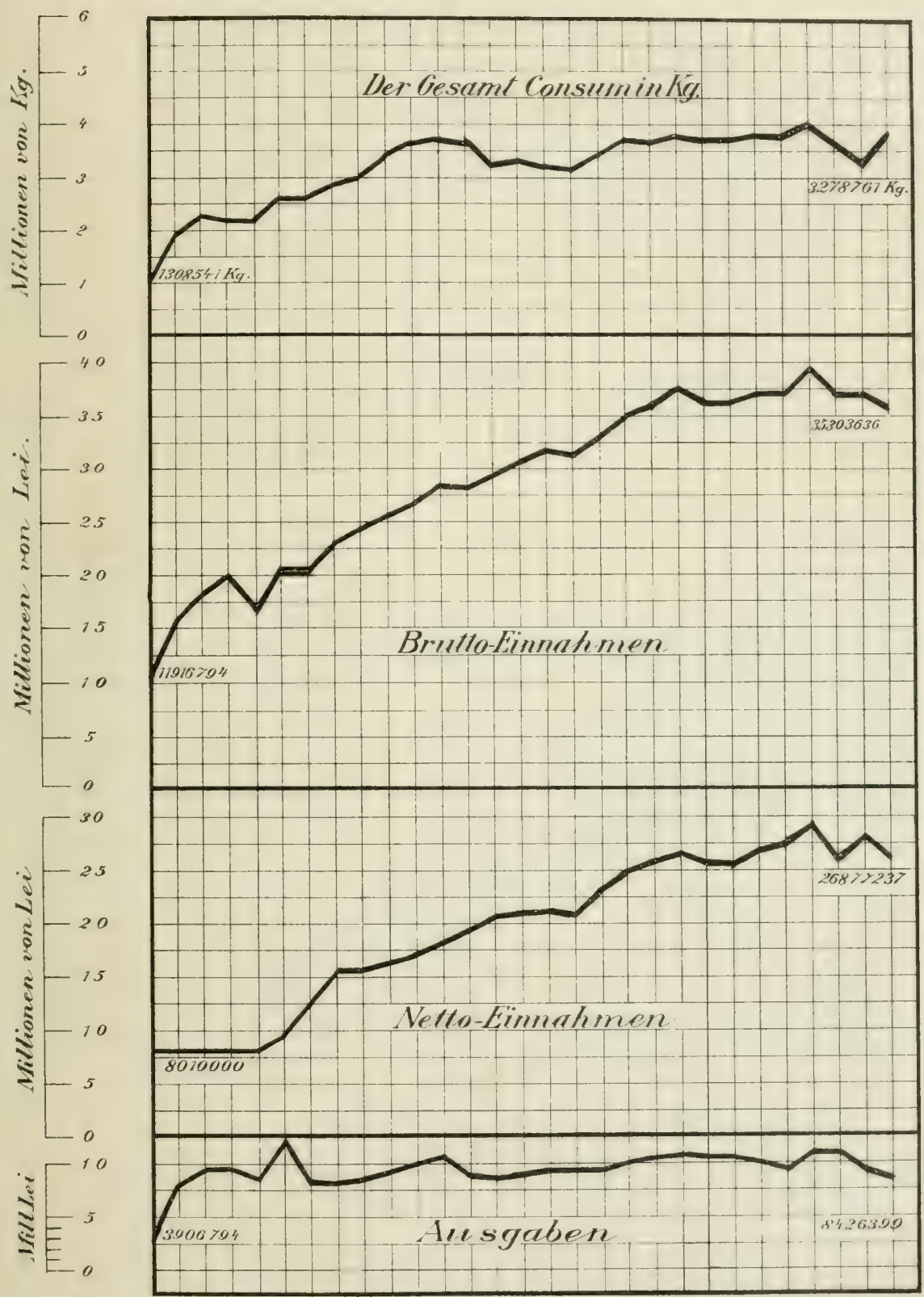

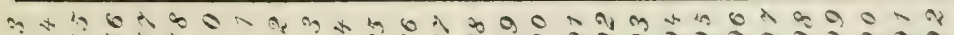

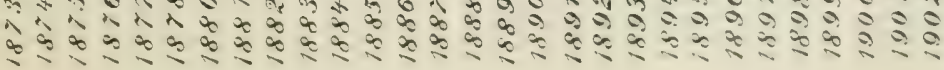





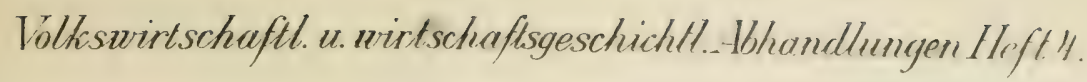

Graphische Dar:tellung $D^{\prime}$

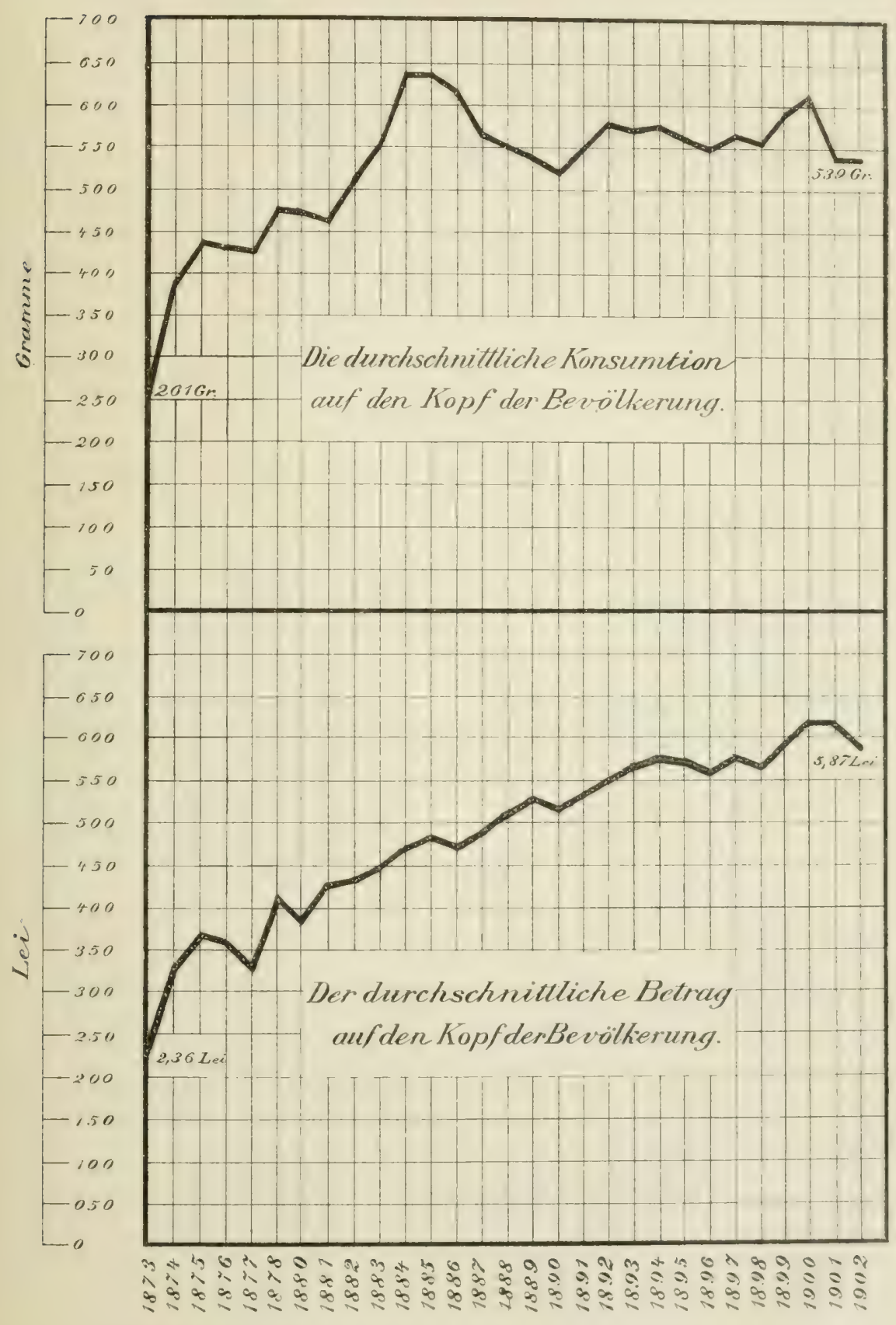



Volkswirtschafth unirtschaftsgeschichth-Abhandhungen Heft 4.

Graphische Darstellung $E$

Die fabricienten Tabaks quantitälen verkauft nach Sorten

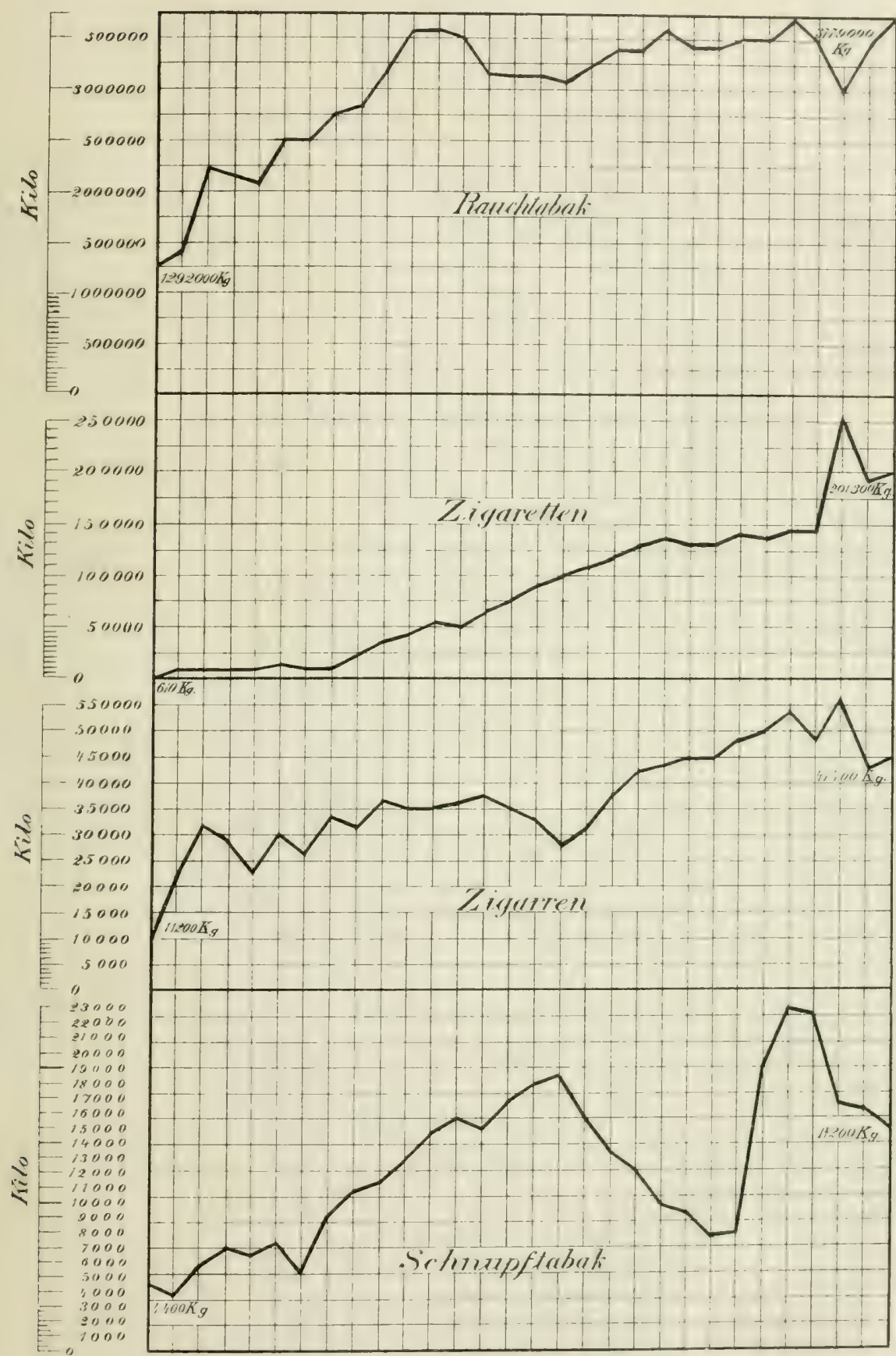

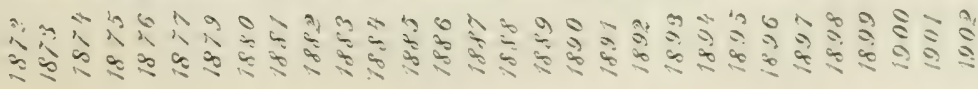





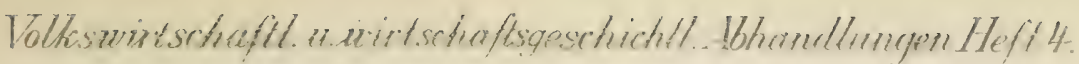

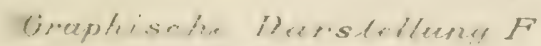

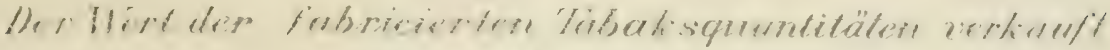
suech. Sirortess.

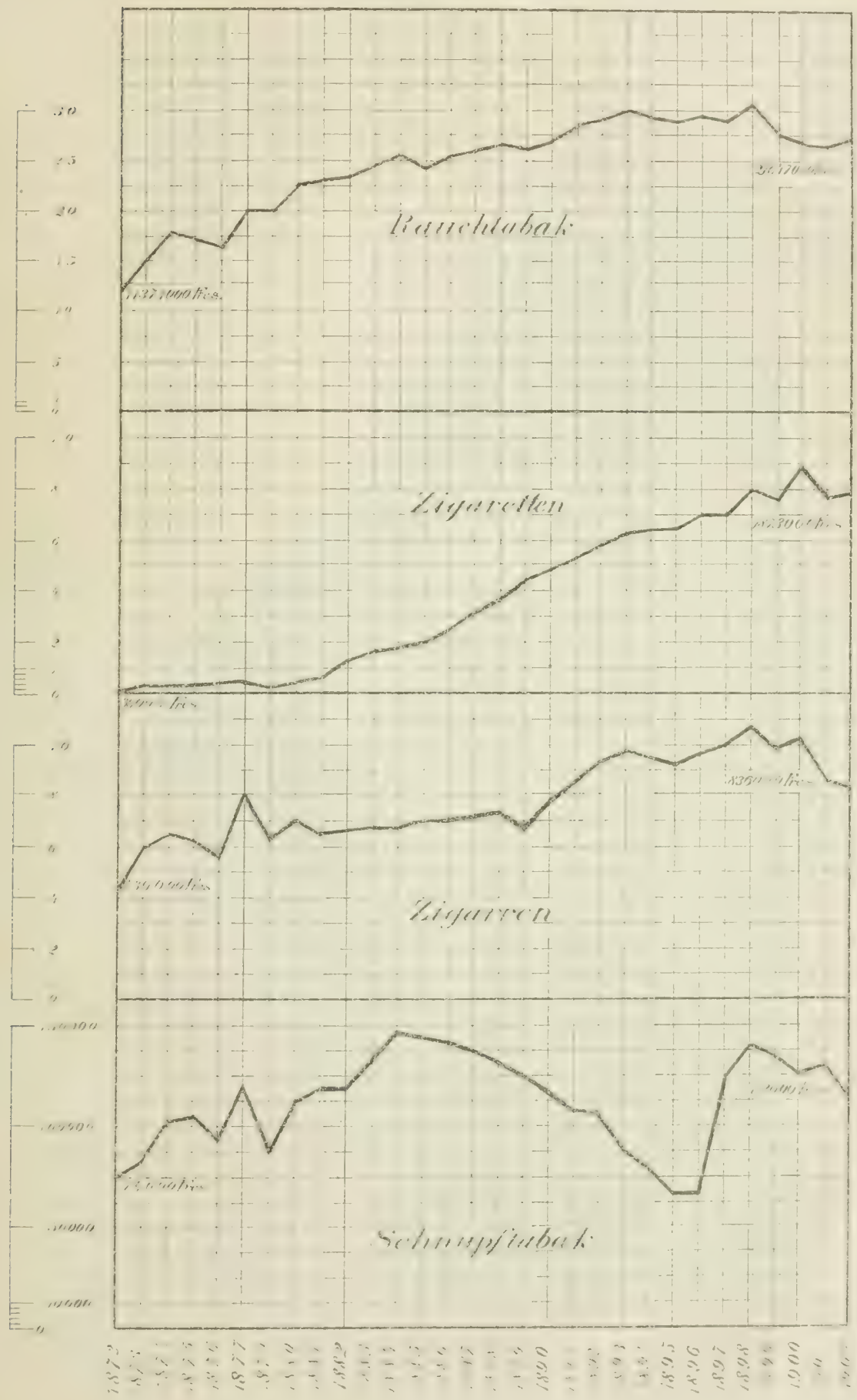



Volkswirtschaftl. u. wirtschaftsseschichth. Abhandhungon H. 4 .

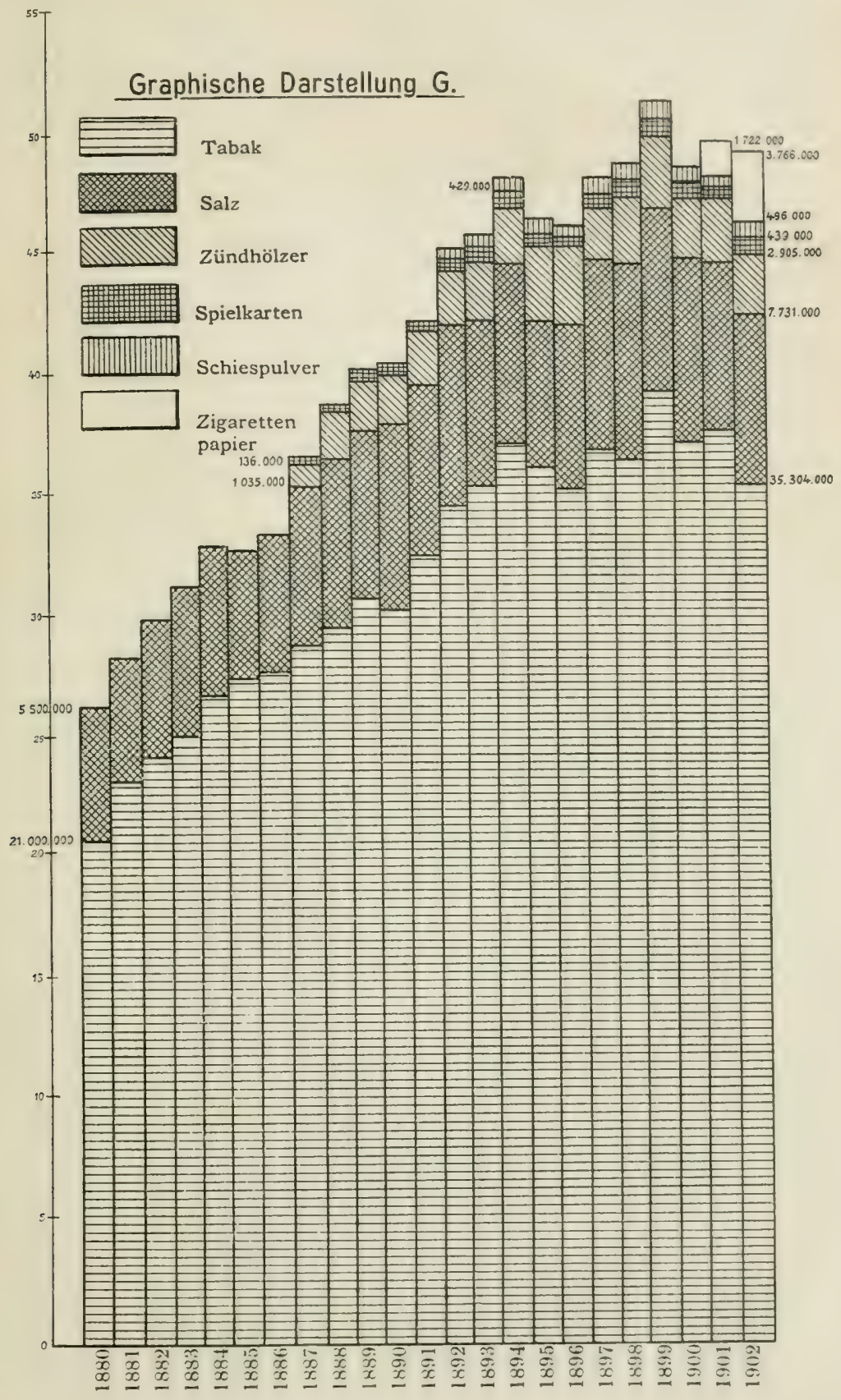

Busuiocescu, Tabakmonopol 

Volkswirtschaftliche und wirtschaftsgeschichtliche Hbhandlungen. Herausgegeben von Dr. Wilhelm Stieda, o. ö. Folge. 1905.

Heft I: Sternberg, Wilhelm, Dr. jur. et phil., Das Verkehrsgewerbe Leipzigs. 1905. Preis: 2 Mark 50 Pf.

Heft 2: Rost, Dr. Bernhard, Ueber das Wesen und die Ursachen unserer heutigen Wirtschaftskrisis. 190ri. Preis: 1 Mark.

Heft 3: Hartmeyer, Hans, Der Weinhandel im Gebiete der Hanse im Mittelalter. 1905̄. Preis: 2 Mark 50 Pf.

Das Wirtschaftsjahr 1903. Jahreserericte iber den Wirtschattse Das (Wirtschaltsjabr 1903. und Arbeitsmarkt. Für Vollssirte und Geschäftsmänner, Arbeitgeber- und Arbeiterorganisationen. Von Richard Calwer. Erster Teil: Handel und Wandel in Dentschland. 1904. Preis: brosch. 8 Mark, geb. 9 Mark.

\section{Deutschland auf den Fochstrassen des Weltwirt- schaftsuerkebrs. Von A. Dix. 1900. Preis: 4 Mark 50 Pf.}

Grosse Vermögen. Ihre Entstethung und ihre Bedeutung., Band I: Die dungen. 1902 Preis: 3 Karger - Rothschild - Krupp. Mit 11 AbbilHamburg. Mit 6 Abbildungen. 1904. Preis: 3 Mark, geb. 4 Mark.

Vor kurzem begann zu erscheinen:

Chünen-Archiv, Organ für exakte Wirtschaftsforsdung, herausgegeben von Professor Dr. Richard Ehrenberg in Rostock.

Mit dem Thünen-Archiv ist ein Organ ins Leben gerufen worden, welches dazu bestimmt ist, die Wirtschaftswissenschaften weiterzubilden durch genane Ermittelung und Vergleichung von Erfahrungen der Praxis. Das Thünen-Archiv nimmt zunächst vorzugsweise das Studium soleher Probleme in Angriff, welche für Gegenwart und nächste Zukunft bedeutsam sind. Es erscheint in zwanglosen Heften, deren Umfang sich je nach dem vorhandenen Stoff richten wird. Dieselben werden in Bänden im Umfange von etwa 50 Druckbogen vereinigt, die 20 Mark kosten werden. Bisher erschien Heft $1-3$.

\section{Die deutsche Montanindustrie auf dem Wege zum}

Crust. Von W. Jutzi, leitender Handelserealkteur der Könimischen Zeitung.

Das deutsche Reich und der Weltmarkt. Von Dr. Julins an der Universität Breslau. 1901. Preis: 2 Mark.

nationalökonomie der technischen Betriebskraft.

Erstes Buch. Grundlegung. Von Dr. Gottfried Zoepfl, Handelsattaché des auswärtigen Amtes. 1903: Preis: 4 Mark.

Inhalt: Die technische Betriebskraft in technischer und ökonomischer Beziehung. Die technische Betriebskraft in statistischer und sozialer Beziehung.

Conrads Jahrbiicher, Bd. XXV, Heft 2 vom 2. Februar 1903:

Der Verfasser hat sich die sicherlich höchst dankenswerte Aufgabe gestellt, der nationalölkonomischen Wissenschaft ein neues Arbeitsfeld zuzuweisen: Die eingehende Betrachtung der technischen Betriebskraft in ihrem Einfluss auf das gesamte Wirtschaftsleben. Dankenswert ist das Unternehmen schon deshalb, weil ein gut Stück Wagemut dazu gehört, sich auf das schwankende Gebjet technisch-ökonomischer Fragen zu begeben, ein Gebiet, auf dem kaum zwei Fachleute gleicher Meinung sind. 


\section{Volkswirtschaftliche und wirt- schaftssgeschichtliche Abhandlungen.}

Herausgegeben

von

\section{Wilhelm Stieda,}

๑. 0̈. Professor der Nationalökonomie in Leipzig.

Neue Folge. Viertes Heft.

Das Tabakmonopol in Rumänien.

Von

Dr. Demeter Busuiocescu.

Mit 2 Karten und 8 graph, Darstellungen.

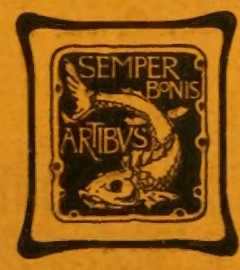

Verlag von Gustav Fischer in Jena. 1905.

Druck von Anton Kämpfe, Jena. 


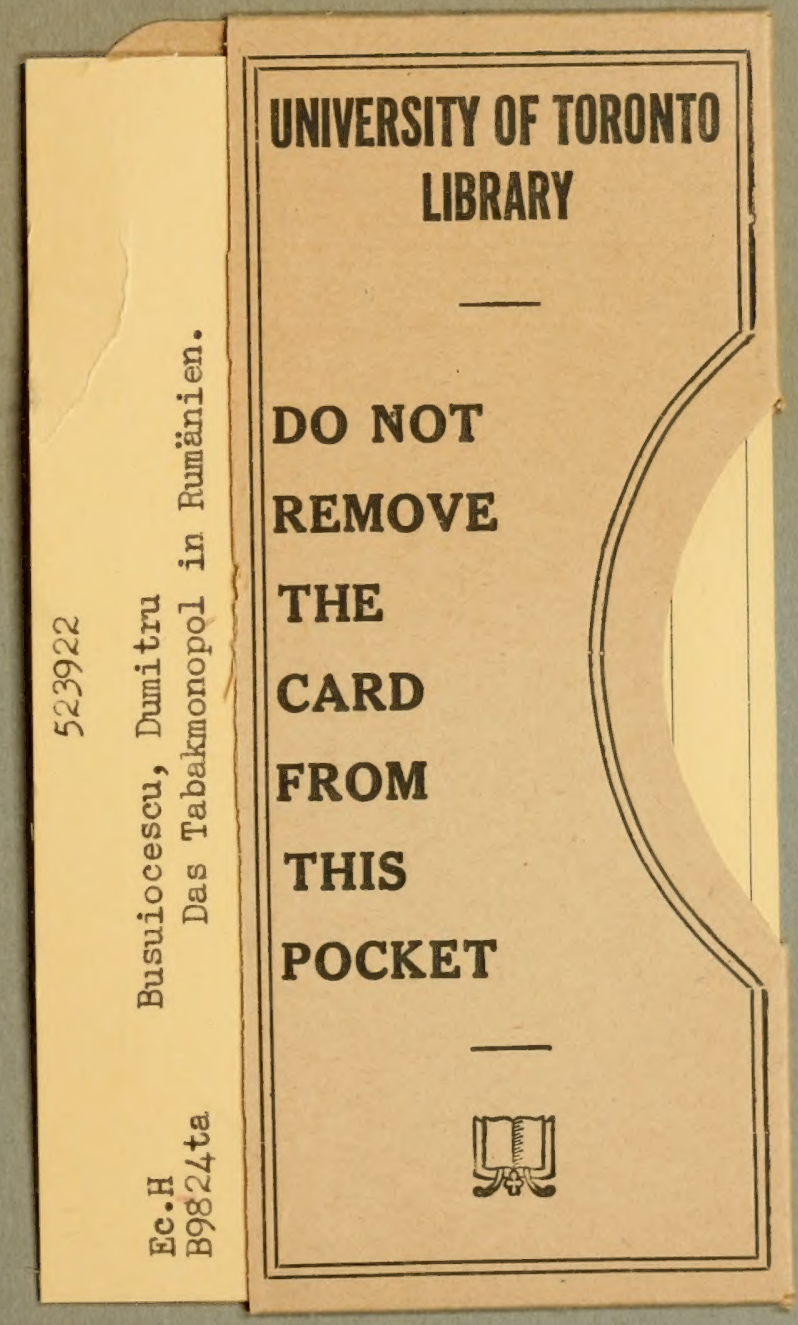




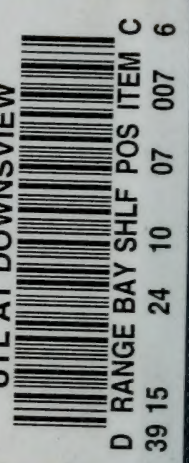

